Available from the National Technical Information Service, U.S. Department of Commerce, Springfield, Viriginia 22161

$\begin{array}{cc}\text { Price: Printed copy } & \text { A08 } \\ \text { Microfiche } & \text { AOO1 }\end{array}$

Codes are used for pricing all publications. The code is determined by the number of pages in the publication. Information pertaining to the pricing codes can be found in current issues of the following publications, which are generally available in most libraries: Energy Research Abstracts (ERA), Government Reports Announcements and Index (GRA and I), Scientific and Technical Abstract Reports (STAR); publication, NTIS-PR-360 available from NTIS at the above address. 


\section{Carbon Dioxide and Climate: Summaries of Research in FY 1990}




\section{TABLE OF CONTENTS}

FOREWORD

PREFACE

vii

INTRODUCTION

ix

GLOBAL CARBON RESEARCH

1

CLIMATE RESEARCH

CHAMMP Initiative

40

VEGETATION RESEARCH

49

RESOURCE ANALYSIS

65

INFORMATION AND INTEGRATION

71

OCEANS RESEARCH

73

QUANTITATIVE LINKS

ARM Initiative

98

APPENDIX A: ADDRESSES OF PRINCIPAL INVESTIGATORS

SUBJECT INDEX

PRINCIPAL-INVESTIGATOR INDEX 


\section{FOREWORD}

Scientific and public interest in greenhouse gases, climate warming, and global change virtually exploded in 1988. The Department's focused research on atmospheric $\mathrm{CO}_{2}$ contributed sound and timely scientific information to the many questions produced by the groundswell of interest and concern. Research projects summarized in this document provided the data base that made timely responses possible, and the contributions from participating scientists are genuinely appreciated.

In the past year, the core $\mathrm{CO}_{2}$ research has continued to improve the scientific knowledge needed to project future atmospheric $\mathrm{CO}_{2}$ concentrations, to estimate climate sensitivity, and to assess the responses of vegetation to rising concentrations of $\mathrm{CO}_{2}$ and to climate change. The Carbon Dioxide Research Program's goal is to develop sound scientific information for policy formulation and governmental action in response to changes of atmospheric $\mathrm{CO}_{2}$.

The recent heightened concern about global warming from an enhanced greenhouse effect has prompted the Department of Energy to accelerate the research necessary to improve predictions of climate change. The emphasis is on the timing and magnitude of climate change as well as on the regional characteristics of this change. One initiative, the Atmospheric-Radiation Measurement (ARM) program, was developed to supply an improved predictive capability, particularly for the cloudclimate feedback. A second initiative, the Computer Hardware, Advanced Mathematics, and Model Physics (CHAMMP) program, is designed to provide rapid improvement of the models used to predict climate change. These initiatives are the DOE's principal contributions to the U.S. Global Change Research Program, which is coordinated by the Committee of Earth and Environmental Sciences (CEES) of the Office of Science and Technology Policy.

This Program Summary describes projects funded by the Carbon Dioxide Research Program during FY 1990 and gives a brief overview of objectives, organization, and accomplishments.

Ari Patrinos, Acting Director

Atmospheric and Climate Research Division

Office of Health and Environmental Research 


\section{PREFACE}

This document describes the activities and products of the Cari on Dioxide Research (CDR) Program during Fiscal Year (FY) 1990. The report is organized in four main sections.

SECTION

\section{DESCRIPTION}

Introduction

Research Areas and Project Descriptions

Appendixes

Indexes and objectives the program

- Shows the level of effort area project
- Describes overall $\mathrm{CO}_{2}$ issues

- Ties $\mathrm{CO}_{2}$ issues to the rescarch approach, program goals,

- Relates each specific research area to the overall goals of

- Describe the scientific questions in each research

- Provide descriptions of individual research projects

- List the expected product for each project

- Show the research approach or methodology used in each

- Provide results to date when applicable

- Provide locator information on subjects, principal investigators, and research institutions for the overall report

- Provide indexes of keywords, principal investigators, anó research institutions for easy reference

Questions concerning the Carbon Dioxide Research Program or specific projects may be addressed to the Atmospheric and Climate Research Division, U.S. Department of Energy, ER-76, Washington, DC, 20585. The Program's telephone number is (301) 353-3281. 


\section{INTRODUCTION}

The Atmospheric and Climate Research, Division of the Office of Health and Environmental Research, Office of Energy Research (Figure 1) supports a Carbon Dioxide Research Program to determine the scientific linkage between the rise of greenhouse gases in the atmosphere, especially carbon dioxide, and climate and vegetation change. One facet is the Core $\mathrm{CO}_{2}$ Program (Figure 2), a pioneering program that DOE established more than 10 years ago to understand and predict the ways that $\mathrm{CO}_{2}$ from energy could affect atmospheric $\mathrm{CO}_{2}$ concentration, global climate, and the earth's iiosphere.

\section{CORE $\mathrm{CO}_{2}$ PROGRAM}

Global carbon cycle. Understanding global carbon dynamics to be able to predict future atmospheric $\mathrm{CO}_{2}$ concentration is the main objective. This effort involves research on sources, sinks, and biogeochemical processes that control the atmospheric $\mathrm{CO}_{2}$ concentration, including measurements of carbon and physical processes in oceans related to climate. Data acquisition and modeling $\mathrm{CO}_{2}$ exchanges of atmosphere, ocean, and terrestrial ecosystems have been emphasized.

Climate detection and models of climate change. This research involves the climatic interdependence of atmosphere, ocean, biosphere, and cryosphere. The objective is to understand the climate system to determine if global climate is indeed changing. A key element is the diagnostic intercomparison of climate models for evaluating the role of clouds and the regional/interannual climate sensitivity to greenhouse gases; tested climate models are then used to determine climate sensitivity to changing concentrations of greenhouse gases.

Vegetation research. This work is designed to determine the direct effects of $\mathrm{CO}_{2}$ and different climate conditions on plants. Experimental and modeling studies involve plant physiology (including photosynthesis, transpiration, and respir- ation) and field-scale effects on vegetation. Basic processes for sequestering carbon on land are evaluated. The opportunity for enhancing $\mathrm{CO}_{2}$ fixation with advances in biotechnology is a candidate research topic.

Resource analysis. The general concept is to examine ways that climate and vegetation change might impact health and resource sectors, such as hydrology, ecosystems, agriculture, shorelines, and fisheries. One study employs historical climate variation along with the contemporary rise of $\mathrm{CO}_{2}$ as forcings to determine the sensitivity to regional climate change of agriculture, water resources, forestry, transportation, etc.

Global research on atmospheric $\mathrm{CO}_{2}$ and climate produce vast quantities of data that require systematic management and information exchange. The objective of Information and Integration is to provide mechanisms through which scientific intormation can be obtained, evaluated, subjected to quality-control procedures, safely stored, and redistributed. This function is carried out by the Carbon Dioxide Information Analysis Center, Oak Ridge, Tennessee, which fosters exchange of data among scientists and other users.

\section{EXPANDED PROGRAM}

A second facet of carbon dioxide research is the Expanded Program, which is composed of several initiatives that wer. adopted by the Committee on Earth and Environmental Sciences (CEES) as part of the U.S. Global Change Research Program.

Suantitative Links. The objective of this initiative is to quantify the expected change in climate that may result from an increase in atmospheric concentrations of $\mathrm{CO}_{2}$ and other greenhouse gases. This effort includes a broad range of research on the linkages between changes in atmospheric composition and temperature. 


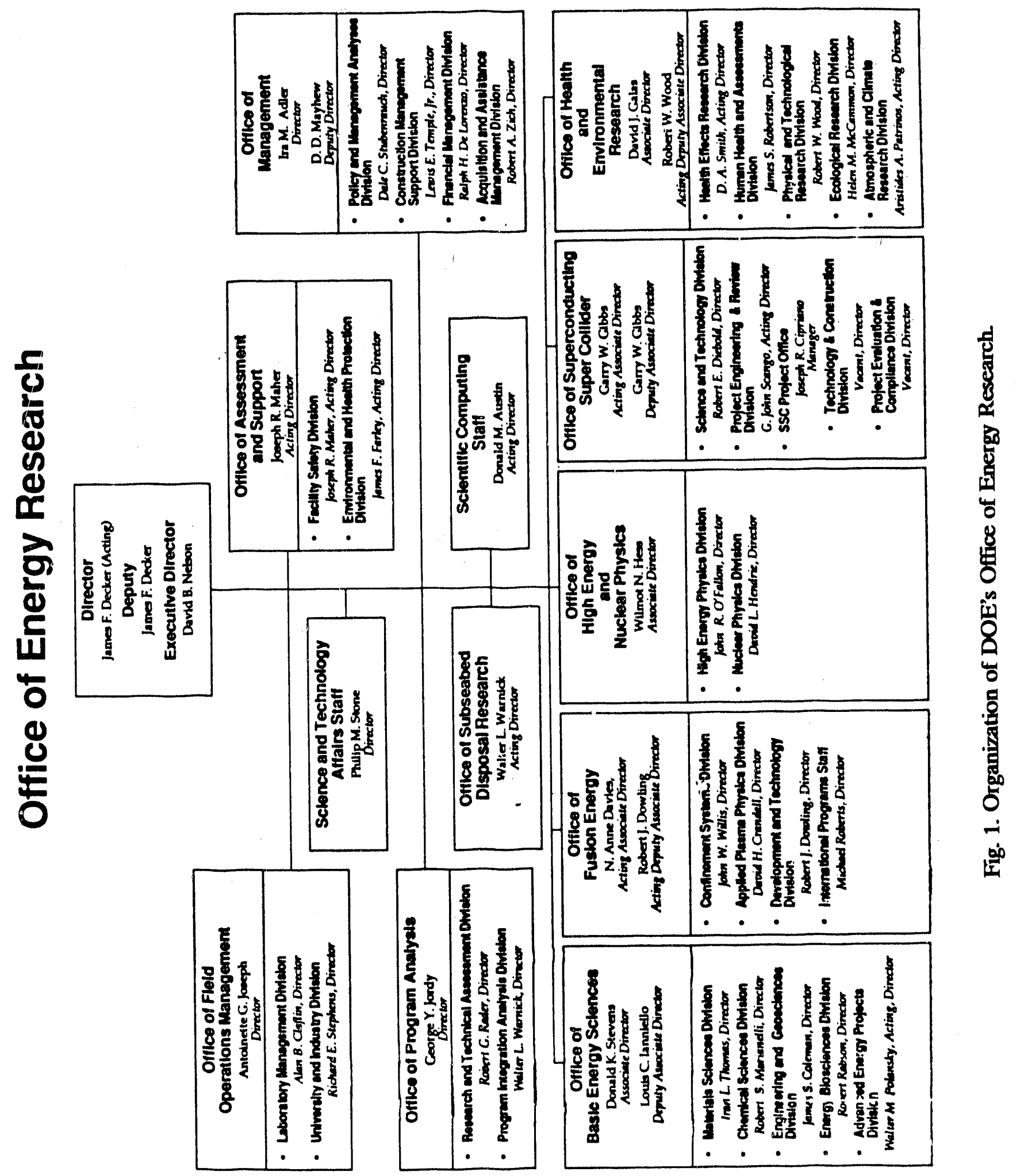




\section{CARBON DIOXIDE RESEARCH}

Core Program

Carbon Cycle

Climate Diagnostics

Vegetative Effects

Resource Analysis

Information and Integration

\section{Expanded Program}

\author{
Oceans \\ CHAMMP \\ Quantitative Links/ARM \\ Education \\ NIGEC
}

Fig. 2. Breakdown of the Carbon Dioxide Research Program Showing the Core-Program and the Newly Instituted Expanded-Program Components.

An important element of the quantitative-link research is the Atmospheric-Radiation Measurement (ARM) program, which examines climate feedbacks and energy fluxes of the coupled landatmosphere-ocean system. The objective is to quantitatively describe the radiation balance from the surface to the top of the atmosphere and to determine the atmospheric characteristics responsible for this balance. A related objective is to use ARM measurements to inderstand cloud formation and its proper representation in climate models. The ARM data will provide the testbed for the process models representing the cloud-climate feedbacks in the present general circulation models (GCMs) as well as in future models designed to predict climate change with a regional-scale resolution.

Another new initiative in carbon dioxide research is the Computer Hardware, Advanced Mathematics, and Model Physics (CHAMMP) program. CHAMMP's objective is to accelerate and improve prediction of the future response of global and regional climates to the increasing atmospheric concentrations of carbon dioxide and other greenhouse gases. This task will require advanced climate models that are capable of much-longer and more-detailed simulations and that incorporate significant improvements in their representation of the physics and chemistry of the climate system. Developing an advanced climate model (ACM) with such capabilities will require the use of computers capable of increasing throughput by a factor of at least 10,000 , mathematical formulations and software that use the extensive parallelism of the emerging generations of computers, and improved algorithms that have been more thoroughly verified using more-comprehensive sets of field observations.

The expanded program includes an Ocean Research Initiative, the initial objectives of which are to conduct a global survey of carbon dioxide in the ocean and to improve the oceancirculation models used for climate research. This research involves laboratory and field measurements as well as modeling studies to understand oceanic mixing and transport processes, carbon cycling, and the storage and the exchange of heat and carbon between the ocean and the atmosphere. In related research, ACRD is developing advanced low-power sensors for measuring physical, optical, and chemical properties of the ocean to provide sea-truth for satellite observations and data from remote regions for verification of ocean models.

Strong Congressional interest dictated the creation of the National Institute for Global Environmental Change (NIGEC). The Institute is composed of a national center at the University 
of California ai Davis and four regional centers situated at Harvard University, Tulane University, Indiana University, and the University of California system. NIGEC supports both the research goals of the Carbon Dioxide Research Program as well as analyses of strategies for the DOE Office of Policy, Planning, and Analysis. Among the NIGEC tasks are the development of an early-warning system for energy-related environmental risks and public-education programs on global rhange. The four centers vill focus on the regional characteristics of global environmental ch inge.

Distribution of Research Because of the diverse types of research needed to meet the objectives of the research program, a wi.je range and large number of research institutions and agencies are participating. DOE is supporting leading scientists in universities, the national laboratories, private industry, and government agencies. The distribution of research funds to types of re- search institutions by fiscal year and for the overall program is presented in Figure 3.

Level of Effort Research sponsored by the CDR Program has increased steadily since its beginning in FY 1978 when $\$ 1,479,000$ was made available for program development and research. By FY 1990 , the budget reached $\$ 49,435,000$. The distribution of research funds to research areas by fiscal year and for the overall program is presented in Figure 4.

Organization of the Program Summary Descriptions are provided for all projects funded by DOE under annual contracts in FY 1990. Each description contains the project's title, 3-year funding history (in thousands of dollars), the contract period over which the current funding applies, the name(s) of the principal investigator(s), the institution(s) conducting the projects, and the project's objectives, products,

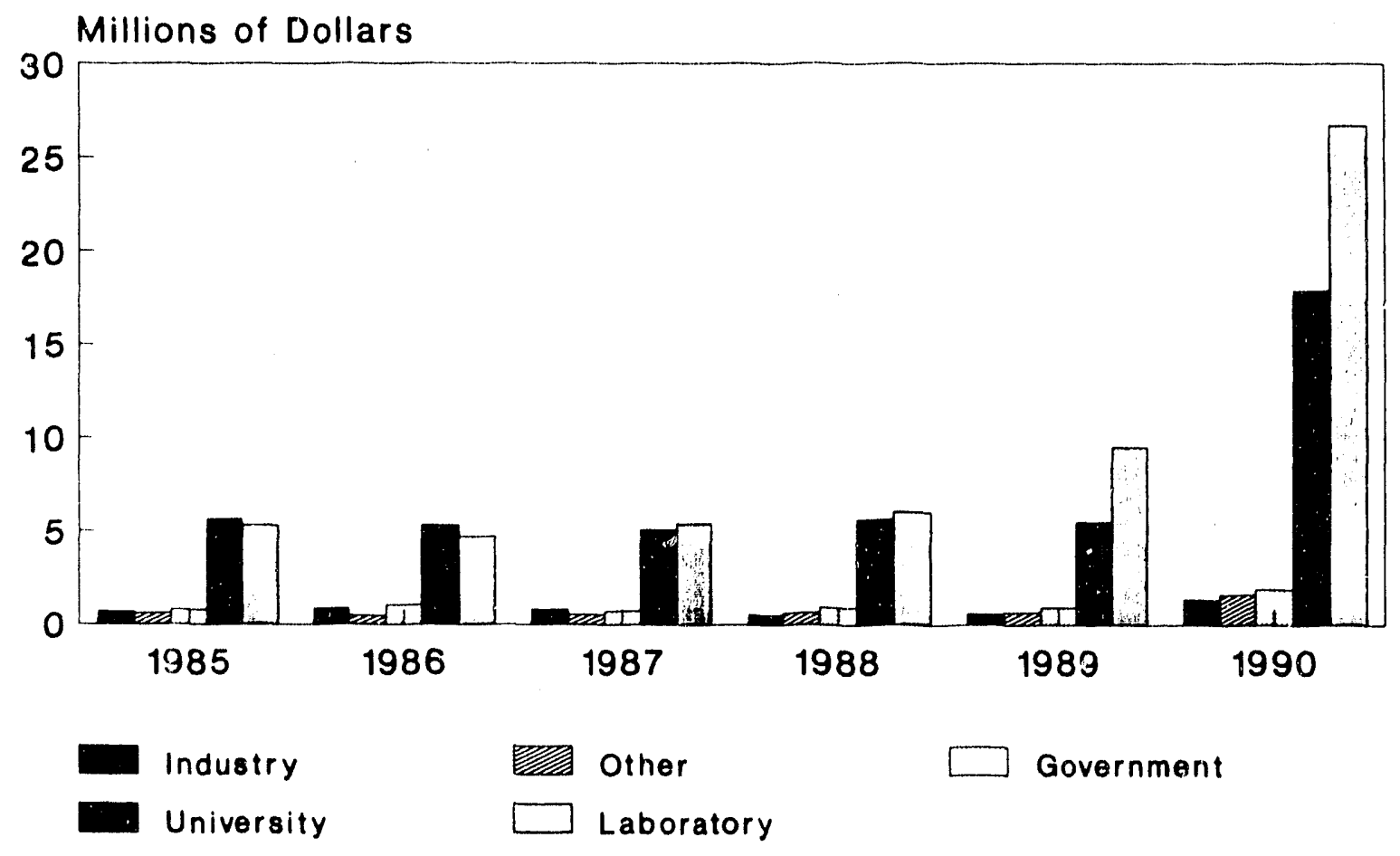

Fig. 3. Carbon Dioxide Budget History by Type of Institution. 


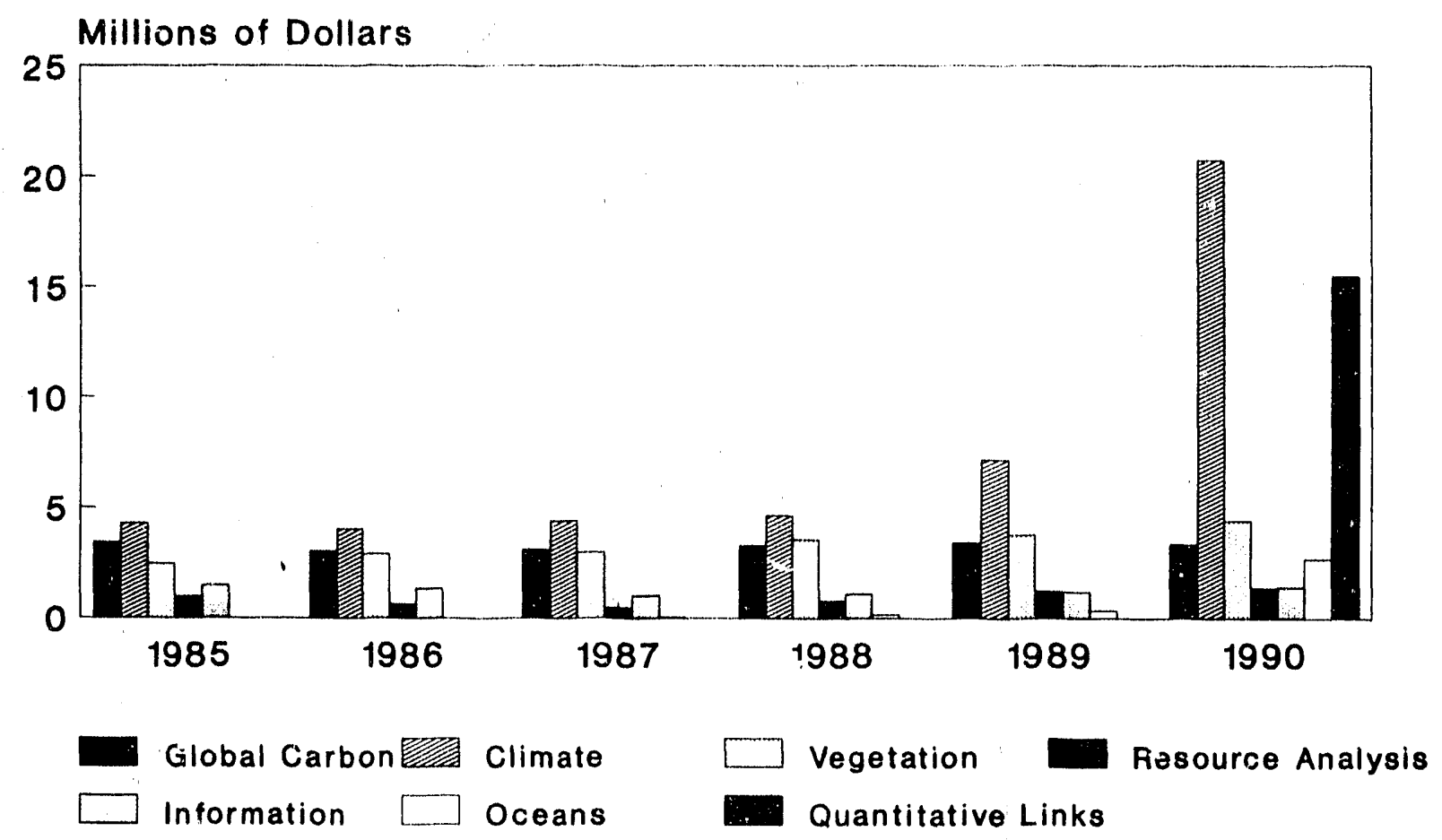

Fig. 4. Carbon Dioxide Budget History by Research Category.

approach, and results to date (for most projects older than one year).

Project descriptions are categorized within the report according to program arear: global carbon, climate research, vegetation research, resource analysis, information and integration, oceans research, and quantitative lin's. Within these categories, the descriptions are grouped by program initiative and then alphabetically by principal investigator. Each program area is preceded by a brief text that defines the program area, states its goals and objectives, lists principal research questions, and identifies program and/or principal scientists.

Indexes and Keywords This document has been indexed to aid the reader in locating research topics, participants, and research institutions in the text and the project descriptions. Comprehensive subject, principal investigator, and institution indexes are provided at the end of the text for this purpose. The comprehensive subject index includes keywords from the Introduction and chapter texts in addition to those from the project descriptions. 


\section{GLOBAL CARBON RESEARCH}

Global carbon research provides the scientific underpinnings for predicting future concentrations of $\mathrm{CO}_{2}$ in the atmosphere. The research addresses natural systems that govern the abundance of $\mathrm{CO}_{2}$ in the atmosphere, including the role of oceans and terrestrial ecosystems in determining exchanges of $\mathrm{CO}_{2}$ with the atmosphere. In addition, carbon-cycle research compiles information about technology, economics, geology, and other factors required for estimating emissions of $\mathrm{CO}_{2}$ and other radiatively important gases (RIGs).

Significant progress has occurred during the past decade. Major studies have (1) measured the current and historical release of $\mathrm{CO}_{2}$ from fossilfuel use; (2) examined the effects of existing and possible future technologies on global $\mathrm{CO}_{2}$ emissions; (3) estimated the uncertainty surrounding future global fossil-fuel $\mathrm{CO}_{2}$ emissions; (4) examined the components of the ocean carbon cycle and carbon reservoirs; and (5) estimated fluxes between the terrestrial biosphere and the atmosphere and integrated components of the carbon cycle into global models.

Despite a decade of progress, major uncertainties remain about what happens to the $\mathrm{CO}_{2}$ produced by the burning of fossil fuels. This inability to balance the global carbon budget affects the accuracy of future atmospheric $\mathrm{CO}_{2}$ predictions. Moreover, the uncertainties seriously limit the nation's ability to quantify the effectiveness of possible actions that could modify the natural carbon cycle (i.e., reforestation or enhanced carbon fixation in terrestrial and marine ecosystems) and possibly slow the rise of atmiospheric $\mathrm{CO}_{2}$.

Research Objectives The current program is designed to take the next step beyond the State-
of-the-Art inventory of our current knowledge about the carbon cycle. It aims to increase our knowledge and understanding of the carbon cycle so we can predict change of atmospheric $\mathrm{CO}_{2}$ from energy emissions. Specific objectives are (1) to understand processes of the carbon cycle, (2) to document energy emissions of $\mathrm{CO}_{2}$, (3) to evaluate source-sink mechanisms for atmospheric $\mathrm{CO}_{2}$, and (4) to develop reliable models for projecting atmospheric concentrations of $\mathrm{CO}_{2}$.

Research Questions In the Carbon Cycle area:

- What additional knowledge of carbon-cycle processes is needeci to accurately estirnate the contribution of fossil-fuel burning to the level of $\mathrm{CO}_{2}$ in the atmosphere?

- What are the significant sources or sinks for carbon that must be considered?

In the Energy area:

- What scientific, technological, economic, and geologic data are needed for estimating emissions of $\mathrm{CO}_{2}$ and other RIGs from energy activities?

- How can the scientific information be used to consider decisions about emissions trading?

\section{Program Manager}

Roger C. Dahlman

Carbon Dioxide Research Program

U.S. Department of Energy, ER-76

Washington, DC 20585

(301) $353-4951$ 


\section{EXCHANGES OF CARBON BETWEEN THE ATMOSPHERE AND TERRESTRIAL ECOSYSTEMS AS A RESULT OF LAND-USE CHANGE}

\author{
BROWN, SANDRA
}

UNIVERSITY OF ILLINOIS

$\begin{array}{lr}\text { FY 1990 } & 99 \\ \text { FY 1989 } & 0 \\ \text { FY 1988 } & 0\end{array}$

$09 / 15 / 90-09 / 14 / 91$

Objective: This research is part of an integrated project to examine terrestrial sources and sinks for atmospheric $\mathrm{CO}_{2}$. The work has six aspects: (1) documentation of the rates at which the areas of forests have contracted and expanded over the past 150 years; (2) determination of the biomass of forests, including changes in the standing stock of carbon from indigenous degradation; (3) determination of the changes in soil carbon that result from changes in land use; (4) spatial integration of the data on land use, biomass, and soils with a geographic information system; (5) calculation of the net flux of carbon, including model-sensitivity analysis; and (6) comparison of the calculated net flux with observed geographic variations in atmospheric concentrations of $\mathrm{CO}_{2}$. The present component focuses on Items (2) and (3). The specific objectives are (1) to determine geographically referenced biomass estimates of different tropical forest types (wet to dry, undisturbed, logged, and secondary) with emphasis on forests of south and southeast Asia; (2) to summarize and integrate data on net primary productivity (NPP) of tropical forests and to incorporate them into a geographically referenced data base; and (3) to explore whether the information contained in the spatial and temporal variations in the NDVI (normalized-difference vegetation index) data base can be used to describe variations in biomass within tropical forested landscapes.

Product: (1) A method for converting different types of structural data for forests (inventory of trees by species, diameter, and height from known-size plots; stand and stock tables from large-scale forest inventories; stand tables only; and total commercial volumes of forests) into biomass estimates for all the tropical region; more-accurate and -precise biomass estimates for tropical forests in south and southeast Asia, geographically referenced; preliminary models for predicting forest biomass for areas where no inlormation is available with a geographical information system (GIS); and a revised estimate of the biomass of tropical forests for all tropical countries based on the commercial volumes reported in FAO publications and new expansion factors.

(2) A method for converting different types of forest data into estimates of net primary productivity (NPP) and a geographically referenced data base of NPPs of tropical forests in south and southeast Asia.

Approach: Components of the method for estimating biomass of forests have already been established under prior support and include the development of biomass regression equations and application to detailed forest-plot data for calculating expansion factors (total biomass to commercial biomass). This method has been applied to stand tables produced during forest inventories, and the resulting biomass estimated has been compared to the commercial biomass obtained from corresponding stock tables. A comparison of the resulting expansion factors with those determined from previous work established that this method is valid. All possible data sources useful for estimating biomass will be gathered from the literature and subjected to the methods described above. A method will also be developed to use forest-inventory data that only include trees with diameters greater than $30 \mathrm{~cm}$ and to apply it to a more extensive inventory data set. All resulting biomass values will be geographically referenced and entered into the GIS. Although the data base described above is vast, areas will still exist for which no data are available. To fill these gaps, relationships will be developed between biomass and climate type, soils, slope, elevation, etc.

Results to Date: (1) Two papers on biomass estimation methodology have been published: 
Brown, Gillespie, and Lugo, "Biomass Estimation Methods for Tropical Forests with Applications to Forest Inventory Data," Forest Science 35, 881-902, 1989; and Gillespie, Brown, and Lugo, "Tropical Forest Biomass Estinnation from Truncated Stand Tables," Forest Fcology and Management, in press.

(2) A paper on biomass estimates for the forests of tropical Asia has been accepted for publication: Brown, Gillespie, and Lugo, "Biomass of Tropical Forests of South and Southeast Asia," Canadian Journal of Forest,y Research. The major results in this paper demonstrate that biomass for the forests of this region are relatively low mostly because of illicit human disturbance. Analysis of two national forest inventories of Peninsular Malaysia (done in 1972 and 1982) showed that, whereas the area declined by $18 \%$ during the 10 year period, biomass declined by $28 \%$. Subsequent digitizing and analysis of the forest maps for these two inventories showed that the greatest declines in biomass per unit area occurred in those forests with the greatest increase in the perimeter to area ratio. That is, the more fragmented the forest becomes over time the greater the amount of biomass degradation that occurs in the residual forests.

(3) A geographically referenced data base of biomass estimates (mean and $99 \%$ confidence interval) for forests of tropical America has been compiled. The data base covers parts of 10 countries: Bolivia, Brazil, Ecuador, Guatemala, Guyana, Nicaragua, Panama, Peru, Surinam, and Venezuela, cncompassing an area of about 6.7 million ha. The aboveground biomass estimates ranged from $10 \mathrm{Mg} / \mathrm{h}$ to $>850 \mathrm{Mg} /$ ha in moist life zones and from $<10 \mathrm{Mg} / \mathrm{ha}$ to $550 \mathrm{Mg} / \mathrm{ha}$ in the wet life zones. The low estimates were from forests that were identified in the inventories as being disturbed. As with tropical Asian forests, many of the forest areas in tropical Amer a are also degraded, resulting in reduced biomass.

\section{ENERGY END-USE PATT'ERNS AND ENERGY TECHNOLOGIES IN MAJOR $\mathrm{CO}_{2}$ EMISSION COUNTRIES}

\author{
CHENG, H. C., AND STEINBERG, M. \\ BROOKHAVEN NATIONAI \\ LABORATORY
}

$$
\begin{array}{lc}
\text { FY } 1990 & 258 \\
\text { FY } 1989 & 200 \\
\text { FY } 1988 & 200 \\
10 / 01 / 89-09 / 30 / 90
\end{array}
$$

Objective: To obtain a better understanding of energy end-use patterns and energy technologies in major $\mathrm{CO}_{2}$-producing countries; to shed light on energy efficiencies in these countries; and, thus, to estimate the potential fossil-fuel savings and associated global $\mathrm{CO}_{2}$ emission reductions through using improved energy technologies.

Product: A report that documents the characterization and related data of energy use and tecinnologies by end-use sector and fuel type for a group of important $\mathrm{CO}_{2}$-emission countries and that summarizes the comparisons of energy efficiency among these countries.

Approach: One task is to develop a data base on energy uses and technologies in major $\mathrm{CO}_{2}$ producing countries. The main emphasis will be on the identification and characterization of the present energy technologies used in these countries. Three benchmark years to be studied are 1975, 1980, and 1885. Requisite energy information on these countries will be collected through detailed research and study of a wide variety of information sources. These sources include, but are not limited to, the United Nations, the World Bank, the International Energy Agency, and the Energy Information Administration at DOE. The energy uses and technologies will be presented for three end-use sectors (i.e., residential and commercial, transportation, and industrial and electricity generation). With this information, the potential fossilfuel savings and associated global $\mathrm{CO}_{2}$-emission reductions i asulting from improved energy 
technologies can then be made. This task will be performed closely with the energy-emission study of Battelle Pacific Northwest Laboratories. Another task is to devise a systematic approach of coal refining to use coal without generating $\mathrm{CO}_{2}$ emissions.

Results to Date: (1) Data on energy-use patterns and energy efficiencies for major $\mathrm{CO}_{2}$-emitting countries in 1975, 1980, anc 1985 have been developed. These data include electricity generation and use. The energy consumptions are disaggregated into sectors by end use and fuel type. (2) A systematic process design including energy and material balances has been made for coprocessing fossil fuels and biomass to produce methanol, hydrogen, and carbon black. The process can result in negative $\mathrm{CO}_{2}$ emissions from the use of fossil fuel. The data are suitable for such uses as estimation of future total energy demand, forecasting, and study of conservation and fuel substitution.

\section{ENERGY AND FUTURE CARBON DIOXIDE EMISSIONS}

\section{EDMONDS, JAMES A.}

\section{PACIFIC NORTHWEST LABORATORY}

$\begin{array}{cc}\text { FY } 1990 & 378 \\ \text { FY } 1989 & 300 \\ \text { FY } 1988 & 300 \\ & \\ 19 / 01 / 89-09 / 30 / 90\end{array}$

Objective: To develop the scientific basis to make and bound projections of future energyrelated emissions to the atmosphere of carbon dioxide and other radiatively important gases, to support the Department of Energy in its participation in the Intergovernmental Panel on Climate Change (IPCC), and to support the Department of Energy in its participation in the Committee on Earth Sciences (CES).

Product: Model Development: The theoretical structure for a revised energy-economic model of $\mathrm{CO}_{2}$ and other radiative precursor emissions and the initial model computer code.
Data Base Development: A global, disaggregated, energy-production-and-use data base for the years 1975,1980 , and 1983 that is consistent with the revised long-term, global energyeconomic model.

U.S./Japan Energy/GNP Comparison: An analysis of the observed differences in aggregate energy intensity between the U.S. and Japan.

Energy and Methane: Examination of the relationship between energy production and use and the release of methane to the atmosphere.

IPCC Support: Support for the U.S. DOE in its participation in the Irtergovernmental Panel on Climate Change, Response Strategies Working Group, Energy and Industry Subgroup (IPCC/RSWG/EIS).

Approach: Model Development: The EdmondsReilly model will be revised to improve the representation of energy supply and the interaction of energy and GNP.

Data Base Development: A global, disaggregated, energy-production-and-use data base will be developed for the years 1975, 1980, and 1983 , consistent with the revised long-term, global energy-economic model.

U.S.JJapan Energy/GNP Comparison: Comparable data will be developed for the U.S. and Japan and a common set of measurements will be used to compare energy use and efficiency in the residential, commercial, industrial, and transportation sectors.

Energy and Methane: Methane emissions from four energy related activities will be analyzed, and methane emission rates will be developed for each of these activities. Emission coefficients will then be combined with rates of energy production to develop estimates of annual energy related methane emissions.

IPCC Support: Quantitative support will be provided for DOE participation in the IPCC; IPCC/RSWG/EIS meetings will be attended. 
CES: DOE will be represented on the CES Task Group on Human Interactions and Global Change.

Results to Date: Model Development: The Edmonds-Reilly model was revised to improve the representation of energy supply and the interaction of energy and GNP. This secondgeneration model of greenhouse-gas emissions is an integrated model of human activities and related greenhouse-gas emissions. Work was completed in the development of preliminary design and initial module construction. Collaboration with two institutions, the Energy Research Institute of the Soviet Union and the Energy Research Institute of the Peoples' Republic of China, was initiated. Design of behavioral elements of nonmarket economies was begun with visiting scholars Igor Bashmakov and Zhou Dadi.

Data Base Development: A global, disaggregated, energy-production-and-use data base for the years 1975,1980 , and 1983 that is consistent with the revised long-term, global energyeconomic model was completed. Two data bases were developed: Primary and Internally Consistent. The Primary energy data base refers to a data base that is traceable to primary source material. Because no international group collects data for all countries that include end-use energy detail, primary data sources are, in general, not consistent with one another. The Internally consistent data base resolves inconsistencies between alternative primary data sources but is not necessarily traceable to specific primary data sources. An internally consistent data base is necessary to benchmark the second-generation model. This work was coordinated with Brookhaven National Laboratory and Oak Ridge National Laboratory, and it completes work begun on the development of this data base in FY 1987.

U.S.JJapan Energy/GNP Comparison: Comparable data were developed for the U.S. and Japan, and a common set of measurements was used to compare energy use and efficiency in the residential, commercial, industrial, and transportation sectors. This study took into consideration cultural, geographic, and other differences between these two cruntries that help to explain differences in energy intensity.

Energy and Methane: The examination of the relationship between energy production and use and the release of methane to the atmosphere has been completed. Methane emissions from four energy-related activities were analyzed: (1) natural gas production and transport; (2) deepmined coal; (3) energy combustion, including traditional biomass fuel use; and (4) landfills. Methane emission rates were developed for each of these activities, and emission coefficients were then combined with rates of energy production to develop estimates of annual energy-related methane emissions. This closure finishes work begun in FY 1988.

IPCC: Support was given to the U.S. DOE in its participation in the IPCC. This support consisted of analysis of the U.S. and international energy and economic systems.

CES: DOE was represented on the CES Task Group on Human Interactions and Global Change.

\section{CARBON CYCLE STUDIES}

FARRELL, MICHAEL P.

OAK RIDGE NATIONAL LABORATORY

$\begin{array}{lr}\text { FY } 1990 & 1242 \\ \text { FY 1989 } & 1529 \\ \text { FY } 1988 & 205\end{array}$

$10 / 01 / 89-(09 / 30 / 90$

Task 1. Changes in Atmospheric $\mathrm{CO}_{2}$ and TotalCarbon-Cycle Analysis (A. W. King and W. R. Emanucl)

Objective: To clarify the relationships between fossil-fuel emissions and atmospheric $\mathrm{CO}_{2}$ concentration that control further $\mathrm{CO}_{2}$ increases as fossil-fuel use continues. 
Product: Models of the global carbon cycle and under!ying data (including descriptions of carbon dynamics in the terrestrial and oceanic reservoirs) and analyses to clarify potential responses of atmospheric $\mathrm{CO}_{2}$ to further fossil-fuel use.

Approach: Observational studies of the phenomena controlling $\mathrm{CO}_{2}$ concentration are often impractical because of the time scales involved (decade; to centuries), the vast extent and spatial heterogeneity of earth systems, and the small perturbations to natural levels that fossilfuel releases cause in very large reservoirs, such as the oceans. Furthermore, many mechanistically important variables cannot be measured directly. Mathematical models are an important means of contending with these limitations of direct studies. They also provide a means of synthesizing the diverse data assembled to address the $\mathrm{CO}_{2}$ issue and of interpreting those data in terms of changes in atmospheric $\mathrm{CO}_{2}$ levels.

To estimate changes in atmospheric $\mathrm{CO}_{2}$ concentration that are caused by different amounts of fossil-fuel use, we must, at a minimum, consider the influences of the oceans, land plants, and dead organic matter and its decomposers in soil. These parts of the global carbon cycle certainly affect $\mathrm{CO}_{2}$ levels over decades and centuries. This task takes a total-carbon-cycle approach and integrates data, concepts, and models from atmospheric, terrestrial, and oceanic projects.

The Carbon Dioxide Information Center will produce annual updates of emissions estimates. The emissions data set will be based largely on data compiled by the United Nations Statistics Office. These data do not include details of energy end-uses that allow analysis of the relationships between $\mathrm{CO}_{2}$ emissions and socioeconomic factors. With energy data increasingly available and available in increasing accuracy and detail, we will reexamine the accuracy of the data and differences between data sets. We will also analyze the energy end-uses most related to $\mathrm{CO}_{2}$ emissions to describe where $\mathrm{CO}_{2}$ emissions are concentrated within the global economy.
Results to Date: $\mathrm{CO}_{2}$ projections are most useful if alternative scenarios are analyzed with the same model or if they are at least referenced to solutions of a widely analyzed model. A firstphase reference model was completed during FY 1990. The model describes carbon turnnver in the atmosphere and world oceans in a manner similar to that used by Oeschger and coworkers in their box-diffusion model. Changes in terrestrial carbon pools are incorporated into this initial model only as a net flux into the atmosphere.

We continually analyze a wide range of model formulations. We reported comparisons of the responses of eight models to estimates of historical carbon transfers caused by land-use change at a major conference in March 1990. As part of our model-comparison strategy, we use Monte Carlo simulation to analyze the influences of errors or uncertainties in model parameters on solution variance and to estimate errors in $\mathrm{CO}_{2}$ projections.

The characteristics of model solutions depend on the nature of the fossil-fuel and land-use forcing functions. An analysis of ocean-model properties in terms of responses to reduced fossil-fuel emissions indicates that atmospheric $\mathrm{CO}_{2}$ may continue to rise even if fossil-fuel emissions are decreased to $50 \%$ of current levels.

Carbon releases because of land-use change are now caused primarily by tropical-forest clearing. In recent decades, the amount of carbon released from tropical areas has increased sharply. During FY 1990, we refined estimates of landuse changes and associated changes in carbon storage in tropical Asia and South America.

We also participated in assessments of global environmental change. During FY 1990 we contributed to the U.S. National Energy Strategy and to plans for the U.S. Global Change Research Program.

Task II. Natural and Forced Carbon Turnover in Terrestrial Erosystems (W. M. Post and V. H. Dale) 
Objective: To develop a realistic model of carbon turnover in terrestrial ecosystems as it affects responses to fossil-fuel emissions that treats the dependence of processes on environmental conditions and perturbations by such human activities as land use.

Product: Terrestrial carbon-cycle models and their underlying data sets to be incorporated into the total global carbon cycle models described in Task I with land-use summaries provided for specific regions of interest.

Approach: Two classes of models must be merged to realistically describe terrestrial carbon dynamics because, even though the slow circuit of carbon through vegetation and dead organic matter is responsible for significant carbon storage, environmental conditions are also influenced by carbon circuits that respond much more quickly, such as photosynthesis, respiration, translocation, and transpiration in plants and the turnover of microbial decomposers in actively decomposing organic-matter pools.

We cannot simply integrate models that describe the rapid processes of $\mathrm{CO}_{2}$ diffusion, photosynthesis, fluid transport, respiration, and transpiration in cells and leaves to estimate productivity of whole plants and ecosystems. The nature of the spatial averaging implied in the selection of parameters and processes to be included is difficult because of nonlinearities. For example, photosynthesis models assume uniform biochemical concentrations over an entire plant, a condition rarely found outside the laboratory. Furthermore, computational error accumulates when small deviations are multiplied by scaling factors or accumulated over long time periods.

Important carbon-storage responses to changing environmental conditions will be clarified by exercising a number of models, initially without concern as to how they might be organized for global-scale applications. Based on this experience, two modules that address carbon dynamics with two sets of characteristic response tirnes will be formulated. A rapid-dynamics module will describe $\mathrm{CO}_{2}$ exchanges, photosynthesis, water loss, and energy balance for a prototype leaf or photosynthetic unit. And a slow-dynamics module will represent ecosystem carbon storage as a compartmental system of living and dead components and the fluxes between them.

Ideally, plant growth in the slow module should be determined by the rapid module. It is this coupling that is difficult in practice. For numerous reasons, some of which were outlined above, typical models of the rapid dynamics usually yield an overestimate of plant productivity. Concepts handled by vegetation dynamics or ecosystem models have to be invoked to reconcile the differences between potential and actual responses.

Human activities affect a large fraction of the world's terrestrial ecosystems. These disturbances, which range from total management, harvest, and land-use change to subtle pollutant impacts, cannot be ignored in any analysis of changes in atmospheric $\mathrm{CO}_{2}$. Carbon releases because of land-use change are now caused primarily by large-scale tropical-forest clearing. The tropics cover more than $30 \%$ of the earth's land surface, and about $42 \%$ of the tropics is forest. Work will concentrate on estimating land-use changes and associated changes in carbon storage in tropical Asia and South America.

Results to Date: During FY 1990, we completed the design and initial testing of both slow and fast components of a refined model of terrestrial carbon cycling. We expect the slow component of the model to remain unchanged but expect substantial refinement of the descriptions of environmental conditons and their effects on carbon uptake and release in the fast component.

Research to estimate the effect of land-use changes in tropical Asia relies on excellent historical information. These data are being compiled, documented, and transferred to ecological modelers who integrate it to produce a better estimate of the contribution of land-use changes to atmospheric $\mathrm{CO}_{2}$. 
Task III. Extended Testing of the Importance of Oceanic Processes in Controlling Atmospheric $\mathrm{CO}_{2}$ (T.-H. Peng)

Objective: To improve the representation of oceanic carbon cycling in models and to interpret new oceanic data in terms of changing atmospheric $\mathrm{CO}_{2}$ concentration.

Product: Refinements to oceanic carbon-cycle models and analyses of ocean data in terms of the influence of the oceans on atmospheric $\mathrm{CO}_{2}$ responses to fossil-fuel emissions.

Approach: Mathematical models of carbon turnover in the oceans are continually refined to incorporate more-realistic descriptions, to take advantage of new data, and to use insights gained in the development of oceanic circulation models. We will use these models to clarify the control of the oceans over atmospheric $\mathrm{CO}_{2}$ concentration. In addition to the fossil-fuel era, we will investigate climate-induced changes in oceanic carbon turnover indicated by our paleooceans model, emphasizing the formation and demise of North Atlantic Deep Water, a major force in ocean circulation.

Recent analyses of surface-water $\mathrm{CO}_{2}$ measurements estimate oceanic-carbon uptake on a regional basis. The consistency of these estimates with results based on tracers, including natural and weapons-testing ${ }^{14} \mathrm{C}$, tritium, and radon, needs further clarification. To understand the global-scale implications of regional estimates requires improved modeling of the linkages between major ocean basins.

The Global Ocean Flux Study (GOFS) will yield new data on the role of marine organisms in oceanic element cycling. We will evaluate the implications of GOFS data as they become available. An immediate objective will be to determine the biological processes that must, at a minimum, be explicitly considered in the analysis of changes in atmospheric $\mathrm{CO}_{2}$ levels and to incorporate a representation of these processes into our reference models. This activity will provide an avenue for bringing results from DOE's oceans program into the development of total-carbon-cycle models.

Results to Date: We have developed a preliminary model that includes lateral transport within the major oceans. The model is based on the distribution of weapons-testing ${ }^{14} \mathrm{C}$ measured by the GEOSECS program. Independent flow and mixing patterns describe carbon dynamics in the Atlantic, Pacific, and Indian oceans. But the appropriate linkage of these components is critical, especially with respect to the role of Antarctic circumpolar waters. Although the Antarctic waters are the most important linkage, other connections are important, including the Indonesian archipelago and Aguihas current flows at the southern tip of Africa.

\section{SIMULATIONS OF THE CARBON CYCLE IN THE OCEANS}

FASHAM, MICHAEL J. R.

\section{INSTITUTE OF OCEANOGRAPHIC SCIENCES}

$$
\begin{array}{lr}
\text { FY } 1990 & 102 \\
\text { FY } 1989 & 0 \\
\text { FY } 1988 & 0
\end{array}
$$

$$
08 / 15 / 90-08 / 14 / 91
$$

Objective: Developing a 3-D model of the ocean carbon cycle requires three related components of research. The goal is to develop a prognostic model of the ocean carbon cycle that can be used to predict future increases of atmospheric $\mathrm{CO}_{2}$ from human activities. Objectives of the Institute of Oceanographic Sciences component are (1) to develop 3-D models of the ocean carbon cycle and to test a carbon/nitrogen mixed-layer ecosystem model against data sets for the North Atlantic; (2) to analyze carbon/nitrogen ecosystem components for a 3-D North Atlantic simulation; and (3) to embed equations of the North Atlantic ecosystem model into the 3-D ocean GCM and to extend the ecosystem model to deeper ocean layers. 
Product: A fully documented description of an euphotic-zone ecosystem model describing the nitrogen and carbon cycles, including estimates of parameter values.

Approach: This research aims to predict the role of biological populations in the uptake and recycling of $\mathrm{CO}_{2}$ in the upper ocean with simple, coupled, carbon and nitrogen ecosystem models. Models of gradually increasing complexity will be tested with integrated mixed-layer or 1-D models of the physical processes and the results will be compared with suitable data sets. The resulting models and their associated parameter sets will then be embedded in various 3-D physical models developed at Princeton University for the prediction of basin-scale and global effects. The ultimate aim is to develop a model that is geographically robust in the sense that a single model and parameter set coupled with geographically varying physical forcing will reproduce the observed variability in biological production and $\mathrm{CO}_{2}$ uptake.

Results to Date: A seven-compartment nitrogenbased ecosystem model of the oceanic euphotic zone was validated against data from Bermuda Station S. This model and its associated parameter set were then embedded in the Princeton 3-D seasonal GCM of the North Atlantic, and the results were compared with seasonal data obtained from both ships and the CZCS satellite. The results were very encouraging and showed first-order agreement between modelled and observed primary production, phytoplankton biomass, and nitrate concentrations. However, in some areas, the agreement was unsatisfactory, mainly because the GCM over- or underestimated the vertical flux of nitrate into the euphotic zone. Similar problems have been experienced in using the GCM to predict surface heat flux and were corrected by using a higher horizontal spatial resolution.

Considerable progress has been achieved in developing a seven-compartment, coupled nitrogen and carbon ecosystem model. An integrated mixed-layer version of this model complete with water carbonate chemistry and air-sea flux of $\mathrm{CO}_{2}$ is operational and has been tested against data from the 1989 JGOFS North Atlantic Spring Bloom Experiment. It is intended to run this model in the North Atlantic GCM in late 1990.

\section{EXCHANGES OF CARBON BETWEEN THE ATMOSPHERE AND TERRESTRIAL ECOSYSTEMS AS A RESULT OF LAND-USE CHANGE}

\author{
FUNG, I. Y.-S \\ GODDARD INSTITUTE FOR SPACE \\ STUDIES
}

$\begin{array}{lr}\text { FY 1990 } & 101 \\ \text { FY 1989 } & (\text { ) } \\ \text { FY } 1988 & 0\end{array}$

$09 / 15 / 90-09 / 14 / 91$

Objective: This research is part of an integrated project to examine terrestrial sources and sinks for atmospheric $\mathrm{CO}_{2}$. The work has six aspects: (1) documentation of the rates at which the areas of forests have contracted and expanded over the past 150 years; (2) determination of the biomass of forests, including changes in the standing stock of carbon from indigenous degradation; (3) determination of the changes in soil carbon that result from changes in land use; (4) spatial integration of the data on land use, biomass, and soils with a geographic information system; (5) calculation of the net flux of carbon, including model-sensitivity analysis; and (6) comparison of the calculated net flux with observed geographic wriations in atmospheric concentrations of $\mathrm{CO}_{2}$. The present component focuses on Item 6 , and the specific objective is to analyze global patterns of atmospheric $\mathrm{CO}_{2}$ circulation based on carbon exchange between terrestrial ecosystems and the atmosphere from deforestation and other changes in land use.

Product: Analysis of net llux of carbon to the atmosphere as a result of land-use changes, especially in the tropics, based on satellite data and estimates of atmosphere-biosphere $\mathrm{CO}_{2}$ 
exchange consistent with observed concentrations and gradients of atmospheric $\mathrm{CO}_{2}$.

Approach: Biomass will be estimated with the normalized difference vegetation index (NDVI). Information contained in NDVI variations (spatial and temporal) will be examined to describe the variations of biomass within an ecosystem. This investigation, if successful for south and southeast Asia, will provide a starting point for the inventory and monitoring of ecosystem biomass on a global basis.

The GISS 3-D atmospheric transport model will be used to simulate atmospheric $\mathrm{CO}_{2}$ response to refine estimates of $\mathrm{CO}_{2}$ fluxes from land-use modification. The modeled concentrations and gradients will be compared with those observed.

The data for south and southeast Asia acquired by Duke University will be evaluated. The evaluation will be based on three analyses: (1) checking the data for internal consistency and attempting to calculate the annual net flux of carbon with them; (2) comparing the carbon flux calculated with this data with the flux calculated previously by different methods; and (3) defining the sample size appropriate for detailed analyses with a Monte Carlo approach.

Results to Date: $\mathrm{CO}_{2}$ release from land-use modification and fossil-fuel burning were combined with $\mathrm{CO}_{2}$ exchanges with the ocean in a global 3-D general circulation model (GCM) to test the consistency of $\mathrm{CO}_{2}$ budget source/sink hypotheses. The GCM calculation showed that if all the fossil fuel $\mathrm{CO}_{2}$ remained airborne, a pole-to-pole concentration difference of $4.4 \mathrm{ppm}$ would result, much larger than the $3.0 \mathrm{ppm}$ found in the observations. Tropical deforestation, though important in the global budget, is not an important contributor to the polar difference of atmospheric $\mathrm{CO}_{2}$. The 3-D simulations thus argue that the sink for fossil fuel $\mathrm{CO}_{2}$ must be larger in the northern hemisphere than in the southern hemisphere.

The synthesis of $\mathrm{CO}_{2}$ measurements in the oceans showed that the oceans north of $15^{\circ} \mathrm{N}$ are a weak sink for fossil-fuel $\mathrm{CO}_{2} \quad(-0.6$
GtC/year). Error analysis of the data and sensitivity analysis with the GCM ruled out the possibility of the ocean's being the sole sink for fossil fuel $\mathrm{CO}_{2}$. To match the budget and the north-south gradient, a land sink must have predominated in middle latitudes of the northern hemisphere from 1980 to 1987 . Current oceanic data suggest that the land sink is larger than the ocean sink. The mechanisms for $\mathrm{CO}_{2}$ uptake on land are unknown, as is the time of evolution of the sink itself.

The magnitude of the missing land sink is intimately linked not only to the strength of the oceanic sink but also to the release from landuse modification. Improved estimates of the tropical land-use source would be crucial for unravelling carbon dynamics in middle latitudes.

\section{EXCHANGES OF CARBON BETWEEN THE ATMOSPHERE AND TERRESTRIAL ECOSYSTEMS AS A RESULT OF I.AND-USE CHANGES}

HALL, CHARLES A. S.

\section{STATE UNIVERSITY OF NEW YORK, SYRACUSE}

$\begin{array}{lr}\text { FY } 1990 & 75 \\ \text { FY } 1989 & 0 \\ \text { FY } 1988 & 0\end{array}$

$09 / 15 / 90-09 / 14 / 91$

Objective: This research is part of an integrated project to examine terrestrial sources and sinks for atmospheric $\mathrm{CO}_{2}$. The work has six aspects: (1) documentation of the rates at which the areas of forests have contracted and expanded over the past 150 years; (2) determination of the biomass of forests, including changes in the standing stock of carbon from indigenous deg. radation; (3) determination of the changes in soil carbon that result from changes in land use; (4) spatial integration of the data on land use, biomass, and soils with a geographic information system; (5) calculation of the net flux of carbon, including model-sensitivity analysis; and (6) 
comparison of the calculated net flux with observed geographic variations in atmospheric concentrations of $\mathrm{CO}_{2}$. The present component focuses on Items 2 and 5 ; the specific objective is to analyze the importance of shifting cultivation in estimates of ca.bon released from land-use change.

Product: Updated assessments of the exchange of carbon between tropical landscapes and the atmosphere, including more-sophisticated analyses of the importance of uncertainties in the data base for shifting cultivation.

Approach: The first step is to assess the extent to which forests cut by shifting cultivation grow back to their original biomass vs the degree to which they are converted to permanent agricul. ture, lower-biomass secondary forest, or something else. Each land-use calegory (i.e., permanent cultivation or secondary forest) will be characterized by different inventories of carbon, which sometimes change over time. Carbon release will be estimated by examining the pattern of land-use change after the forest enters the shifting cultivation. If a virgin forest (the land category containing the most biomass) is converted to pasture (the land category with the least biomass), the result will be a relatively large net loss of carbon from the area in the form of $\mathrm{CO}_{2}$. But most conversions are of a lesser magnitude. We will use FAO/UNEP (1981) data on forest types and rates of land-use change as baseline information. Simulations of land-use change will be carried out with the computer model GLOBC 8 . The consequences of various assumptions about land-use change in terms of carbon flux over time will be determined by changing (1) the areas in given land categories and (2) the rates of change between one category and the other in the input files of the FAO/UNEP 1981 data. We will also test the hypothesis that quantitative aspects of shifting cultivation can be ignored entirely in estimating $\mathrm{CO}_{2}$ release from selected tropical countries.

Results to Date: The inclusion of the effects of shifting cultivation has been found to increase our estimate of carbon released because of landuse change in tropical countries by about $30 \%$ compared to neglecting the consideration of these areas. However, were one to consider these areas as "completely deforested," the converse occurs. The results for individual countries varied considerably based on the use of different literature sources for model runs. The most general pattern of inaccuracy is that newer literature sources suggest that fallow land area is decreasing not increasing. Hence, a larger part of new, permanent agriculture is being derived from shifting-cultivation fallow rather than from virgin forest. For some countries, this situation produces a smaller estimate of carbon released, and for some countries, a larger estimate. The results reconfirmed the basic validity of our previously published range of estimates of carbon release from tropical land-use change, and they greatly increased our confidence in those numbers.

\section{EXCHANGES OF CARBON BETWEEN THE ATMOSPHERE AND TERRESTRIAL ECOSYSTEMS AS A RESULT OF LAND-USE CHANGE}

HOUGHTON, R. A.

WOODS HOLE RESEARCH CENTER

$\begin{array}{cc}\text { FY 1990 } & 222 \\ \text { FY 1989 } & 0 \\ \text { FY 1988 } & 0\end{array}$

$09 / 15 / 90-09 / 14 / 91$

Objective: This research is part of an integrated project to examine terrestrial sources and sinks for atmospheric $\mathrm{CO}_{2}$. The work has six aspects: (1) documentation of the rates at which the areas of forests have contracted and expanded during the past 150 years; (2) determination of the biomass of forests, including changes in thr: standing stock of carbon from indigenous deg. radation; (3) determination of the changes in soil carbon that result from changes in land use; (4) spatial integration of the data on land use, biomass, and soils with a geographic information system; (5) calculation of the net flux of carbon, including model-sensitivity analysis; and (6) 
comparison of the calculated net flux with observed geographic variations in atmospheric concentrations of $\mathrm{CO}_{2}$. The present compunent focuses on Item 5 , and the specific objective is to improve the accuracy of the estimated flux of carbon to the atmosphere produced by global land-use change.

Product: Improved estimates, based on georeferenced data, of the long-term (1880 to 1985) and current (around 1990) flux of carbon to the atmosphere from changes in the area of forests, agricultural land, and other land uses in tropical Asia and Latin America. One estimate of flux will be gengraphically distributed over a grid of $0.5^{\circ}$ latitude by $0.5^{\circ}$ longitude. The estimate will include an analysis of the errors and a consideration of the factors contributing most to the uncertainty in estimates of flux.

Approach: The flux of carbon between terrestrial ecosystems and the atmosphere will be calculated with models based on rates of landuse change and on the carbon stocks of the ecosystems disiurbed. Unlike previous analyses, the data here will be georeferenced so that the estimates of carbon stocks will be specific to the disturbed ecosystems instead of means for the entire region.

Results to Date: Data obtained by other investigators have made it clear that the density (biomass per hectare) of tropical Asian forests has decreased with time. This decrease means that previous estimates of carbon flux, based only on changes in forest area, have underestimated the release of carbon from tropical deforestation. Including degradation of forests in the analyses increased the estimated flux by $100 \%$ over that calculated with low estimates of biomass density. Widespread, recent reductions in biomass of tropical Asian forests also help explain the discrepancy between estimates of biomass, which vary by almost a factor of two and which have been responsible for most of the range in flux estimates.

\section{A STUDY OF THE ABUNDANCE AND ${ }^{13} \mathrm{C} /{ }^{12} \mathrm{C}$ RATIO OF ATMOSPIIF CARBON DIOXIDE AND OCEANIC CARBON IN RELATION TO THE GLOBAL CARBON CYCLE}

\author{
KEELING, CHARLES D.
SCRIPPS INSTITUTION OF OCEANOGRAPHY

\author{
FY $1990 \quad 250$ \\ FY 19890 \\ FY $1988 \quad 0$
}

$02 / 15 / 90-02 / 14 / 91$

Objective: To continue high-precision and accuracy measurements of atmospheric $\mathrm{CO}_{2}$ at the Mauna Loa Observatory and to expand measurements of ${ }^{13} \mathrm{C} /{ }^{12} \mathrm{C}$ isotopic ratios of $\mathrm{CO}_{2}$ for distinguishing the biological and oceanic carbon processes undergoing change.

Product: A data base for calibrating atmospheric $\mathrm{CO}_{2}$ circulation models, and for evaluating sources and sinks of exchange with oceans and the terrestrial biosphere.

Approach: High-precision $\mathrm{CO}_{2}$ and isotopic measurements will be carried out at background air-pollution-monitoring stations of the Central Pacific region (e.g., Mauna Loa, Hawaii). Atmospheric $\mathrm{CO}_{2}$ data will be collected at additional sites to create a data base for validating 3-D models of atmospheric and oceanic transport of carbon. These models are used to predict atmospheric $\mathrm{CO}_{2}$ in relation to changing processes and properties of the global carbon cycle. 


\section{EXCHANGES OF CARBON BETWEEN THE ATMOSPHERE AND TERRESTRIAL ECOSYSTEMS AS A RESULT OF LAND-USE CHANGE}

\author{
MOORE, B., III, and SKOLE, D. L. \\ UNIVERSITY OF NEW HAMPSHIRE
}

$\begin{array}{cc}\text { FY 1990 } & 144 \\ \text { FY 1989 } & 0 \\ \text { FY 1988 } & 0\end{array}$

$09 / 15 / 90-09 / 14 / 91$

Objective: This research is part of an integrated project to examine terrestrial sources and sinks for atmospheric $\mathrm{CO}_{2}$. The work has six aspects: (1) documentation of the rates at which the areas of forests have contracted and expanded over the past 150 years; (2) determination of the biomass of forests, including changes in the standing stock of carbon from indigenous degradation; (3) cetermination of the changes in soil carbon that result from changes in land use: (4) spatial integration of the data on land use, biomass, and soils with a geographic information system; (5) calculation of the net flux of carbon, including model-sensitivity analysis; and (6) comparison of the calculated net flux with observed geographic variations in atmospheric concentrations of $\mathrm{CO}_{2}$. The present component focuses on Item 4, and the specific objective is use of remote sensing and sateilite images to improve the accuracy of the estimates of the net flux of carbon between terrestrial ecosystems and the atmosphere because of deforestation and other land-use changes.

Product: Data on land-use patterns in south and southeast Asia and an estimate of the scale of resolution and intensity of effort required to obtain data on land-use change and biomass in other regions of the globe.

Approach: Statistics, remotely sensed data, ecologica! iiterature, etc. on the tropics and specifically on south and southeast Asia will be tabulated to identify and quantify land-use changes associated with deforestation.
Results to Date: This research has resulted in the development of a GIS of historical land use data for Asia. In addition, a compilation of a suite of geographically referenced global data sets on such factors as soil type and vegetation type have been completed. Geographically de:tailed land-use and environmental data sets have: been integrated in a GIS-based data management system to form the framework for a geographically referenced terrestrial carbon model. A further application of the GIS framework is the land-cover-change-detection models. Preliminary results indicate that the distribution and time-variant dispersion of land-cover conversion is difficult to predict from data on physical features of the environment, soil type, vegetation characteristics, and other geographically varying biophysical parameters. An improved method is being developed that couples empirical data from census literature and remote sensing.

\section{EXCHANGES OF CARBON BETWEEN THE ATMOSPHERE AND TERRESTRIAL ECOSYSTEMS AS A RESULT OF LAND-USE CHANGE}

RICHARDS, JOHN F. DUKE UNIVERSITY

$\begin{array}{lc}\text { FY } 1990 & 98 \\ \text { FY } 1989 & 0 \\ \text { FY } 1988 & 0\end{array}$

$09 / 15 / 90-09 / 14 / 91$

Objective: This research is part of an integrated project to examine terrestrial sources and sinks for atmospheric $\mathrm{CO}_{2}$. The work has six aspects: (1) documentation of the rates at which the areas of forests have contracted and expanded over the past 150 years; (2) determination of the biomass of forests, including changes in the standing stock of carbon from indigenous degradation; (3) determination of the changes in soil carbon that result from changes in land use; (4) spatial integration of the data on land use, biomass, and soils with a geographic information system; (5) caliculation of the net flux of carbon, 
including model-sensitivity analysis; and (6) comparison of the calculated net flux with observed geographic variations in atmospheric concentrations of $\mathrm{CO}_{2}$. The present component focuses on items 1 and 4, and the specific objective is to narrow the range of estimates and to improve the accuracy of current estimates of $\mathrm{CO}_{2}$ release from land in south and southeast Asia. From these data we are trying to estimate long-term reductions in standing stock of biomass to calculate carbon release from the region.

Product: Time-series data on carbon balance for land components (vegetation and soil) in relation to agriculture and increased population in south and southeast Asia and an estimate of the scale of resolution and intensity of effort required to obtain comparable data for the remaining regions of the world.

Approach: We have compiled comprehensive land-use data for the period from 1880 to 1980 along with estimated values for changes in biomass converted to carbon. Our reconstruction covers a contiguous area of 1.7 million $\mathrm{km}^{2}$ in Northern India, Bangladesh, and Burma. The data are compiled first by subcountries, and finally by the entire study region. The data are estimated for four dates: 1880, 1920, 1950, and 1980. The total land-use area is divided into eight categories of use: net cultivated area, settled and built-up, forest/woodland, interrupted woods (less than 30\% canopy), grass/shrub complexes, barren/sparsely vegetated, wetlands, and surface water. Net cultivated area is further subdivided into temporary and permanent crops. For each date, estimates for area in each category rely on numerous statistical and narrative sources.

Area figures for land use at each level will be converted into estimates of carbon in standing stock of vegetation. These estimates will be based upon a large regional ecological and botanical literature measuring biomass for various types of vegetation. Degradation of vegetation within classes of land use will also be systematically adjusted for based upon increasing human and livestock populations in the region.
Results to Date: For the study region $\left(4.5 \times 10^{6}\right.$ $\mathrm{km}^{2}$ or $3.4 \%$ of the world land area), carbon release has been estimated as follows: 1880 to $1920,5.1 \times 10^{15} \mathrm{~g} ; 1920$ to $1950,5.0 \mathrm{Pg} ; 1950$ to $1980,7.4 \mathrm{Pg}$; total 1880 to $1980,18.4 \mathrm{Pg}$. During the century, the human population increased by $281 \%$, and that of livestock by $134 \%$. Net cultivated area increased by $110 \%$, and area in grass/shrub complexes grew $44 \%$. Forest/woodland area dropped by $36 \%$; that of wetlands declined $34 \%$. Increased carbon content in cultivated land was offset by extremely large releases concentrated in forest/woodland and wet lands. These categories had included more than $90 \%$ of the 1880 carbon stock, and accounted for an even higher proportion of the total release. The total carbon release estimate generated by the method described ahove was $55 \%$ higher than that calculated on the assumption that degradation caused no reductions or carbon stock within categories over the century. This result demonstrates that accurate estimation of the carbon release caused by land use change requires attention not only to changes in the area of each land-use category but also to degradation-induced shanges in the mean biomass per unit area. The latter concern is particularly important for forest/woodland and wetland vegetation.

The paper "Historical Analysis of Changes in Land Use and Carbon Stock of Vegetation in South and Southeast Asia" has been accepted for publication by the Canadian Journal of Forest Research. This paper describes our methodology and presents data on land use and carbon stock of live vegetation for a contiguous area of $1.7 \times 10^{6} \mathrm{~km}^{2}$ in northern India, Bangladesh, and Burma. 


\section{SIMULA'TIONS OF THE CARBON CYCLE IN THE OCEANS}

SARMIENTO, JORGE L.

PRINCETON UNIVERSITY

$\begin{array}{cr}\text { FY } 1990 & 263 \\ \text { FY } 1989 & 0 \\ \text { FY } 1988 & 0\end{array}$

$08 / 15 / 90-08 / 14 / 91$

Objective: To develop a prognostic model of the ocean carbon cycle that can be used to predict future increases of atmospheric $\mathrm{CO}_{2}$ from human activities. Objectives of the Princeton (Sarmiento) component are to develop 3-D models of the ocean carbon cycle and perform the fixcd atmospheric $\mathrm{CO}_{2}$ simulation with nonseasonal and seasonal ocean circulation; to predict background total carbon fields and use a seasonal 3-D North Atlantic ecosystem model to do carbon and nitrogen simulations; and to perform simulations with the global carbon cycle ecosystem model and estimate the uptake of anthropogenic $\mathrm{CO}_{2}$ by the oceans.

Product: Three-dimensional ocean-model simulations of the uptake of anthropogenic $\mathrm{CO}_{2}$, including possible feedback effects from changes in the ocean carbon cycle.

Approach: Our strategy involves two parallel approaches. The first assumes that the preanthropogenic ocean carbon cycle continues to operate without being affected directly by anthropogenic perturbations. This "steady state" approach enables us to treat the anthropogenic $\mathrm{CO}_{2}$ as a passive tracer. The only information needed, other than the appropriate thermodynamic constants, is the pre-anthropogenic surface total carbon and alkalinity concentrations. Siegenthaler is helping us in dealing with the chemistry and boundary conditions for these experiments as well as by collaborating in the analysis of the results. The second approach assumes that the oceanic carbon cycle will respond dynamically to the climatic effects of anthropogenic greenhouse gases. M. Fasham has primary responsibility for developing the ecosystem rnodels required for this approach and for carrying out seasonal simulations of the $\mathrm{CO}_{2}$ uptake; we have primary responsibility for placing these ecosystem models into our ocean circulation models.

Results to Date: (1) A journal article has been written that describes a set of $\mathrm{CO}_{2}$-uptake simulations that have been performed with a nonseasonal world ucean general circulation model. The results give an average fossil- $\mathrm{CO}_{2}$ uptake of $1.9 \mathrm{GtC} /$ year for the past decade. The sensitivity to a doubling of the gas exchange rate is of the order of $10 \%$. The Southern Hemisphere oceanic uptake is $\sim 60 \%$ of the total. This result is inconsistent with atmospheric transport estimates carried out by other grouns, which suggest that the Southern Hemisphere ocean uptake must be negligible and that the entire $1.9 \mathrm{GtC} /$ year must be taken up in the Northern Hemisphere ocean. This situation has consequences for atmospheric $\Delta^{13} \mathrm{C}$ and for preanthropogenic interhemispheric $\mathrm{CO}_{2}$ transport that are supported by various measurements made by Keeling's group at the Scripps Institution of Oceanography. (2) A seasonal world ocean general circulation model has been developed by Toggweiler at GFDL that will be used to study the effect of seasonality on $\mathrm{CO}_{2}$ uptake. (3) The recent suggestion of using iron fertilization as a way of enhancing oceanic uptake of $\mathrm{CO}_{2}$ is being investigated with the simple HILDA model in collaboration with Joరs and Siegenthaler and with our world ocean general circulation model. (4) Najjar has completed a Ph.D. thesis describing a world ocean model of phosphate regeneration in the water column that will serve as a basis for a total carbon and alkalinity model. The salient result of this work is the major importance of dissolved organic matter in explaining the observed nutrient distributions. (5) A large number of studies have been completed to test various ecosystem models of nitrogen production in the surface ocean in an ocean general circulation model of the Atlantic. Three manuscripts describing this work are in various stages of completion. Development of a carbon version of this model has been initiated 
by Fasham, and plans are under way for testing the carbon model in the Atlantic circulation model.

\section{SIMULATIONS OF THE CARBON CYCLE IN THE OCEANS}

$$
\text { SIEGENTHALER, U. }
$$

\section{UNIVERSITY OF BERN}

$\begin{array}{lr}\text { FY } 1990 & 52 \\ \text { FY } 1989 & 0 \\ \text { FY } 1988 & 0\end{array}$

$08 / 15 / 90-08 / 14 / 91$

Objective: To study the oceanic uptake of anthropogenic $\mathrm{CO}_{2}$ by means of a 3-D model and simple box models of the global carbon cycle.

Product: Model simulations of the oceanic uptake of $\mathrm{CO}_{2}$ for different emission scenarios; development of a simple model that will be calibrated with natural tracers and the 3-D model to permit fast, economical simulations for arbitrary $\mathrm{CO}_{2}$-emissions.

Approach: The 3-D model runs will be carried out at Princeton, where the necessary expertise and infrastructure exist. The University of Bern will collaborate in planning and interpreting these model experiments. A 1.5-D diffusionadvection model (HILDA) has been developed that horizontally resolves high and middle/low latitudes. The question is to what degree a simple model can simultaneously simulate distributions of several oceanic properties governed by different processes and different time scales. The oceanic uptake of anthropogenic $\mathrm{CO}_{2}$ and its dependerice on physical factors will be studied by means of the various models.

Results to Date: A journal article describing the 3-D simulations of the oceanic $\mathrm{CO}_{2}$ uptake has been written and submitted for publication. The mode of calculation chosen was to prescribe, from atmospheric observations and ice-core analyses, the atmospheric $\mathrm{CO}_{2}$ concentration history since pre-industrial time (1750) and to calculate the flux into the ocean. The rate of emissions into the atmosphere was obtained as the annual ...cumulation in the atmosphere plus the ocean. For the decade 1980 to 1989, an average oceanic uptake of $1.9 \mathrm{GtC} / y e a r$ was obtained. This value, added to the atmospheric increase, totals $5.1 \mathrm{GtC} / y e a r$, which compares with $7.0 \mathrm{GtC} /$ year of total estimated emissions. The imbalance, which confirms results based on simpler models, indicates that parts of the land biota are probably sequestering carbon, perhaps in response to increased atmospheric $\mathrm{CO}_{2}$ levels.

The transport parameters of box-type models must be calibrated with tracer observations. In HILDA, we found that to reproduce the oceanic distributions of both natural and bomb-produced ${ }^{14} \mathrm{C}$, a depth-dependent vertical eddy diffusivity with high values in the top layers must be assumed. With the 3-D-model velocity fields, we showed that this reflects the fact that the winddriven plus thermohaline circulation is more vigorous near the surface than in the deep ocean. With the calibrated HILDA model, calculations similar to those conducted with the 3-D model were carried out. The average oceanic $\mathrm{CO}_{2}$ uptake between 1980 and 1989 was found to be $2.2 \mathrm{GtC} /$ year, slightly higher than the 3-D model result. A journal article cescribing these results is being prepared for publication. 


\section{CLIMATE RESEARCH}

Climate defines the physical environment to which man and the biosphere respond. The principal components of the climate are the atmosphere, the oceans, the cryosphere, and the land surface. As $\mathrm{CO}_{2}$ increases in the atmosphere, the climate will respond (e.g., if the atmospheric energy balance were modified, temperature might be expected to increase, and the physical and chemical characteristics of the ocean would also be expected to change). The many complex interactions within the climate system would further modify the response. For example, changes in cloudiness may either enhance or reduce a greenhouse warming. This process is called cloud feedback. Another example is that the oceans can store large quantities of heat, possibly delaying evidence of the greenhouse effect. The general circulation models (called GCMs) are presently incapable of reaistically treating the clouds or oceans. Model improvement, data collection, and analysis will be required before the ocean-delay and cloudfeedback uncertainties can be resolved.

Specific information is required to analyze changes that may impact man and the biosphere as the climate responds to increased concentrations of greenhouse gases. The primary information needs are:

- the rate of the regional climate change and

- the distribution and magnitude of the regional climate change on a monthly basis.

Current climate models cannot adequately provide the rate, distribution, and magnitude of regional climate change. To provide the needed information, it is necessary to understand why the models respond as they do and to develop them further.
Research Objectives 'his component of the research effort seeks to develop and improve our capabilities to estimate the range of global and regional climate change resulting from increasing $\mathrm{CO}_{2}$. Research interests include, but is rot limited to, the rate and magnitude of changes in such climate parameters as temperature, precipitation, frequency of extreme events, and changes in the variability of these quantities.

A second objective is to detect evidence of the climate response to the past and continuing increase in atmospheric $\mathrm{CO}_{2}$. This objective addresses the question: Does the observed climate record reflect the changes that would be expected (as estimated from the climate model projections) given the past and continued increases in atmospheric $\mathrm{CO}_{2}$ ?

The third objective is to provide the information needed for resource analysis. This information includes direction, rate, and magnitude of regional changes in temperature, precipitation, soil moisture, and extreme events. It would be used in the analysis of food, fiber, and other resources.

Rescarch Questions During the next five years of climate research, answers to the following questions will be developed:

- What are the physical and methodological (model-formulation) causes for the differences among models and between models and the observed climate?

- Can GCMs, independently or in combination with other techniques, estimate regional, $\mathrm{CO}_{2}$-induced climate change? This effort will specify what information can be 
delivered (as requested by the other program areas) and when such estimates can be provided.

- How rapidly can the climate change?

- To what extent will the ocean delay the climate change?

- Can a climate response to the greenhouse gases, particularly $\mathrm{CO}_{2}$, be observed? If not, can it be estimated as to when the signal might be expected to rise above the natural climate variability?

- What are the information requirements for resource analysis?

\section{Computer Hardware, Advanced Mathematics, and Model Physics (CHAMMP)}

Evaluating the importance of the future response of regional climates to the increasing atmospheric concentration of greenhouse gases will require advanced climate models capable of much longer ard more numerous simulations, finer resolution, and significant improvements in their representation of the physics and chemistry of the climate system. Developing an advanced climate model (ACM) with such capabilities will require computers capable of increasing throughput by 'a factor of at least $10^{4}$, mathematical formulations and software that utiliz' the extensive parallelism of the emerging, generations of computers, and improved algorithms that have bcen more thoroughly verified with more-comprehensive sets of field observations than are currently available.
The CHAMMP initiative will develop an ACM employing the hardware and software capabilities offered by emerging computer architectures to address the challenging physics of understanding the climate system. The objectives of CHAMMP are phased over ten years. In the near term ( 2 to 3 years), improved performance of existing climate system models will be achieved by taking advantage of emerging parallel computing architectures. In the intermediate term ( 3 to 6 years), an initial scaleable version of the climatesystem model components for the ACM will be designed and developed; they will be capable of achieving in excess of 100-gigaflop performance. And in the extended term (6 to 10 years), the initial versions of the ACM components will be improved and assessed, an optimized ACM will be assembled, and detailed research calculations will be initiated that will be faster by a factor of $10^{4}$ or more than present speeds achieved on the Cray-2.

The CHAMMP initiative is designed to bring study of the climate system to the forefront of scientific problems, taking advantage of the developing computational capabilities under way as part of the DARPA TeraO $\mu$ initiative and the Federal High Performance Computing Program. Collaboration and coordination with these initiatives will be an integral part of the CHAMMP initiative.

\section{Program Managers}

Michael R. Riches \& Ari Patrinos Carbon Dioxide Research Program U.S. Department of Energy, ER-76 Washington, DC 20585

(301) 353-3264 


\section{SUPPORT FOR ACTIVITIES OF THE POLAR RESEARCH BOARD, NAS}

\author{
ABBOTT, SHERBORNE
}

\section{NATIONAL ACADEMY OF SCIENCES}

$\begin{array}{lr}\text { FY 1990 } & 35 \\ \text { FY 1989 } & 0 \\ \text { FY 1988 } & 0\end{array}$

$03 / 01 / 90-02 / 28 / 91$

Objective: To advise on U.S. and international policies and research of the Arctic and Antarctic, to represent the U.S. within the Scientific Committee on Antarctic Research (SCAR), and to develop plans for a strategy for the conduct of polar research during the decades ahead.

Product: (1) Advice to federal agencies in the development and implementation of national initiatives in global processes and coordination with the ICSU global change prograrı. (2) Liaison between the Academy's National Committee for the International Geosphere-Biosphere Program and other federal agencies, ensuring that poiar research on climatic and other global environmental processes receives attention as the program evolves. (3) Integration of polar processes and the program into global initiatives under consideration by other NRC activities in the oceans, earth, and atmospheric sciences. (4) Selection of the PRB Chairman by the Scientific Committee on Antarctic Research (SCAR) to head a new SCAR Group of Specialists to develop a research plan for an Antarctic component of the IGBP and in 1990 to develop an implementation plan in support of this SCAR effort. (5) The development of a national bipolar research plan initially focusing on global change issues. (6) The contribution of the Board to efforts to develop an Arctic Environmental Data System, an effort to improve the availability and accessability of data and information on the Arctic and all science disciplines relevant to understanding Arctic processes and their possible contributions to global change.
Approach: The Board is a multidisciplinary body with representation from marine and terrestrial biology, earth sciences, engineering, medicine, physical sciences, and social sciences. Members are drawn from academic institutions, industry, and national laboratories. In addition, the Board always has one member representing Canadian research activities. Federal agencies, such as the Department of Energy, with programs in the Arctic or the Antarctic have liaison representation on the Board and brief the Board on these activities periodically at its meetings. Advice, guidelines, and recomniendations on polar research will result from interactions during the semiannual mectings of the Board and the meetings of its subgroups and from special studies organized by the Board to respond to particular problems or to develop long-range plans and priorities.

\section{COMMITTEE ON GLOBAL CHANGE AND CES WORKING GROUP ON GLOBAL CHANGE}

ANDERSON, PATRICIA A.

\section{NATIONAL RESEARCH COUNCIL}

$\begin{array}{cr}\text { FY 1990 } & 172 \\ \text { FY 1989 } & 0 \\ \text { FY 1988 } & 0\end{array}$

$05 / 15 / 90-05 / 14 / 91$

Objective: To provide partial support to the NRC Committee on Global Change so that effects from energy research and development are accurately reflected in global studies of Earth-system processes.

Product: Advice to federal agencies on scientific plans for U.S. participation in the International Geosphere-Biosphere Program (IGBP) in relation to the U.S. research program on global change, coordination of plans for U.S. participation with plans developed for the IGBP in the international commurity, and a fostering of involvement of the U.S. scientific community in Earth-systems science. 
Approach: The committee will develop scientific plans for a national research program that will contribute to the international plans for the IGBP. The plan will provide guidance on appropriate priorities and possibilities for time phasing of activities. To achieve this task, the committee will establish seven working groups of eight to ten scientists each. The committee will integrate the separate plans submitted by these teams and produce a single report for the second meeting of the Scientific Advisory Council for the IGBP in the summer of 1990 . Th 2 committee will also use a "consultative group" to promote continued interaction and cocrdination of the activities related to global change throughout the many relevant units of the NRC. Finally, the committee will continue to fulfill its responsibilities to pay international dues to support the planning efforts for the IGBP within the International Council of Scientific Unions.

In addition, the committee will assume printing costs for global-change research documents prepared by the Committee on Earth Sciences of the Office of Science and Technology Policy and printed by the Joint Oceanographic Institution, Inc., through a contract with the NSF.

\section{CLIMATE SYSTEM RESEARCH - STUDIES OF GLOBAL AND REGIONAL INSTRUMENT DATA}

BRADLEY, RAYMOND S.

\section{UNIVERSITY OF MASSACHUSETTS}

$$
\begin{array}{cc}
\text { FY } 1990 & 199 \\
\text { FY } 1989 & 170 \\
\text { FY } 1988 & 0 \\
\multicolumn{2}{l}{12 / 01 / 89-11 / 30 / 90}
\end{array}
$$

Objective: (1) To extend the DOE long-term surface climate da:a set for regional analysis. (2) To analyze the data for cri.. al regions with special climate characteristics likely to change under $\mathrm{CO}_{2}$-induced climate change. (3) To assess spacial and temporal coherence of hydrological variability. (4) To compare the regional data to climate-modeling results.

Product: An updated global set of station and 5 $x 10$ gridded temperature data providing morereliable data coverage through 1990 and improved and updated precipitation coverage.

Approach: A primary scientific need is to detect regional climate change and to relate the changes documented in the observations to those expected for a $\mathrm{CO}_{2}$-induced climate change. The basic climate data set (prepared under past and continuing grants at the University of East Anglia) will be improved by assessing the quality of additional temperature and precipitation measurements from the USSR. These data have been obtained under the USA/USSR bilateral agreement and now require examination and incorporation into the data set. The Soviet data set is important because the USSR is large and thus the data may significantly influence Northern Heinispherir averages (e.g., surface air temperatures). The significance of the additional data will be evaluated. The USSR data will also be used to test for regional urban warming. This is not a duplication of the East Anglia effort because they are concentrating on the European urban warming.

Because the marine air temperature is important to establishing a true global data set, the PI will continue to develop techniques to correct the data for known problems. This effort again requires close coordination with the East Anglia group, which is examining the differences between the two existing raw data sets (the NOAA data and the U.K. Meteorological Office data) so that one of the two marine data sets can be used to form an improved global temperature data set.

Models and paleoclimate analyses suggest that high-latitude and high-altitude environments and arid and semiarid marginal zones will be sensitive to climate change. To establish the climate in these regions as a basis for assessing change and to test climate models, the researchers will develop special regional data bases. These data will include sea ice, surface and low-level at- 
mospheric temperatures, and precipitation. The research will attempt to evaluate the evidence for climate change in these regions.

Climate models predict changes in precipitation (a global increase with regional increases and decreases) and increased temperatures. Any changes in the amount and type (rain or snow) combined with temperature changes can result in changes in stream flow and other hydrological variables. The existing data sets will be evaluated and compiled for assessing changes and for testing climate models. This effort will be difficult because of human influence on the hydrological system (e.g., dams and other diversions). However, without such data and an assessment of the data's utility, testing the reliability of climate models and documenting change in the climate variables most important to agriculture will be difficult.

The data set will be analyzed for patterns of regional and hemispheric climatic change for comparison with GCM projections of greenhouse gas-induced climatic change. This research will be closely coordinated with other Division research projects.

Results to Date: An expanded precipitation data set for global land areas has been prepared with more than 4800 station records, many of which extend into the 19th century. A reassessment of precipitation changes over global land areas confirms that precipitation over the continents decreased from the late 19th to the early 20 th century by 4 to $5 \%$; an increase of $\sim 5 \%$ occurred around 1945 to 1955 , leading to the highest precipitation amounts in the mid-seventies. Since then, precipitation over the continents has declined by 3 to $4 \%$.

Model precipitation changes projected for (equilibrium) $2 \times \mathrm{CO}_{2}$ conditions at high latitudes are highly variable and are not supported by empirical relationships between precipitation and temperature. Empirical estimates of arctic precipitation changes with modcl-generated temperature changes are lower (8 to 20\%) and more spatially coherent than model-generated estimates.
Analysis of high-altitude (generally mountain observatory) temperature records from different regions of the world reveals trends and changes similar to those in regional records from adjacent lower-elevation (generally urban) stations.

An assessment of solar variability as a major factor influencing global mean temperatures since the mid-19th century has been completed and indicates little support for this argument.

\section{RESEARCH PROJECT ON $\mathrm{CO}_{2}$-INDUCED CLIMATE CHANGE}

CESS, ROBER'T' D., and HAMEED, S.

STATE UNIVERSITY OF NEW YORK, STONY BROOK

$$
\begin{array}{cc}
\text { FY } 1990 & 372 \\
\text { FY } 1989 & 513 \\
\text { FY } 1988 & 331 \\
& \\
03 / 01 / 90-02 / 28 / 91
\end{array}
$$

Objective: To intercompare GCMs, documenting physical processes responsible for agreement and disagreement, and to statistically analyze the U.S.A. and Chinese regional temperature data set for relationships between large-scale and regional climate.

Product: An understanding of the GCMs' abilities to represent large-scale climate and of the relationships between large-scale climate and regional climate.

Approach: GCMs will be compared model-tomodel and model-to-data. An experimental protocol will be applied to the model-to-model comparison with a $\pm 2^{\circ} \mathrm{C}$ sea-surface temperature change as the forcing mechanism. The approach will assist in diagnosing cloud feedback and cloud forcing and the interactions of ice/snow albedo feedback and clouds in GCMs as a probable cause for GCM disagreements. Some 18 GCMs from throughout the world are involved, including models from the U.S.A., 
France, Canada, West Germany, Japan, Australia, China, U.K., and the U.S.S.R.

Another aspect of the research is devoted to understanding the natural variability in climatic parameters, the variability that may be affected and superposed upon by the predicted gradually increasing impact of atmospheric carbon dioxide. Analysis will be made of subseasonal, annual, and interannual variations in air temperature, precipitation, and sunshine durations in station observations, and these data will be compared with their simulations in GCMs. The purpose is dual: to quantitatively ascertain the deficiencies of the models so that these may be repaired by the modelers and to demonstrate their regime of success so that useful applications of the presently available models may be made. Climatic data developed by the National Climatic Data Center in the United Siates and the Institute of Geography of the Chinese Academy of Sciences will be used in this project.

The two tasks will be brought together to guide the estimation of regional climate change.

Results to Date: Work has progressed concerning both model-to-model and model-to-data GCM intercomparisons. The various modeling groups are now supplying the perpetual April $\pm 2^{\circ} \mathrm{C}$. sea-surface temperature perturbation simulations. The goal here is to appraise snowalbedo feedback. The simulations that have so far been performed show that this feedback in turn induces a secondary infrared feedback whose sign is model dependent. In addition, four models (CSU, ECMWF, GFDL, and OSU/LLNL) have been compared to seasonal cloud-radiative forcing data. Both such intercomparisons are being extended to other modeling groups and will be the subject of discussion at the GCM Intercomparison Workshop to be held Dec. 3-4, 1990, at Brookhaven National Laboratory.

Diagnostic studies of the OSU coupled oceanatmosphere GCMs have been carried out. They explain a large part of interannual climate variability in terms of the frequency response of the atmosphere-ocean system to the annual solar forcing. The frequency spectrum of atmospheric pressure is found to be discrete, indicative of a weakly nonlinear system and unlike a chaotic system.

Analysis of historical climatic data from China has led to a new hypothesis on the fall of the Ming dynasty and its replacement by Qing. We have found evidence closely linking the peasant uprisings of 1628-1644 that led to the fall of the Ming to the ongoing drought of that period.

\section{GLOBAL CHANGE INSTITUTE ON EARTH SYSTEM MODELING}

\author{
EDDY, JOHN A.
}

\section{UNIVERSITY CORPORATION FOR ATMOSPHERIC RESEARCH}

$$
\begin{array}{lr}
\text { FY 1990 } & 55 \\
\text { FY 1989 } & 0 \\
\text { FY 1988 } & 0
\end{array}
$$

$$
09 / 30 / 90-09 / 29 / 91
$$

Objective: To strengthen the intellectual foundation and to advance the development of Earth-system modeling within the IGBP and the U.S. Global Change Research Program.

Product: A volume that includes the edited review lectures and summaries of the conclusions of each discussion group of the 1990 Institute.

Approach: The 1990 Institute will be held July 16-27, 1990, in Snowmass, Colorado. This is the third in a planned series of three Institutes. The 1990 Institute will be directed by Bert Bolin, University of Stockholm, and Francis Bretherton, University of Wisconsin. The three discussion themes on Earth-System Modeling will be (1) Identifying Critical Gaps in the System "Wiring Diagram"; (2) Development of Simplified Working Models; and (3) Nodel Validation. Following the successful pattern of the past two years, the 1990 Institute will bring together leading scientists who in different disciplines now work to build models of the coupled Earth system. They 
will live and work together for two weeks in an informal, working environment. Through a series of initial, tutorial lectures and subsequent working group sessions, the attempt will be made to identify weak links in Earth-system modeling, to seek ways of addressing them, and to forge vorking, interdisciplinary associations.

\section{PROGRAM FOR CLIMATE MODEL DIAGNOSIS AND INTERCOMPARISON}

\section{GATES, W. LAWRENCE \\ LAWRENCE LIVERMORE NATIONAL LABORATORY \\ $10 / 01 / 89-09 / 30 / 90$}

Objective: To better understand (and eventually to reduce) differences among climate-model estimates of regional $\mathrm{CO}_{2}$-induced climate changes through a program of systematic model diagnosis and intercomparison.

Product: A systematic basis for the improvement of GCMs through the provision of a coordinated and centralized program in model diagnosis that will permit the study of a number of model attributes, including variables of particular interest to those conducting studies of the possible impacts of climate changes.

Approach: One of the first major questions to be addressed by the PCMDI is the issue of model resolution. Models used for climate studies have generally been run at resolutions dictated by available computer memory and time; we have undoubtedly been paying a price for the limited resolution in our studies of regional climate change. The Eurnnean Centre for Medium Range Weather Ire asts (ECMWF) operitional model is recognized as the best in the world in weather forecasting and lends itself well to resolution studies. It can be : un at T-21, T-42, T-63, T-106, and T-213 (spanning $6^{\circ}$ to $0.5^{\circ}$

latitude grids). Parallel with the resolution study, a preliminary diagnostics package will be implemented with the ECMWF model to estimate the structure and distribution of systematic errors and their relationship to the model's parameterized physical processes. Particular attention will be given to the diagnosis of the models' surface heat and hydrologic balance, their cloudradiative forcing, and their portrayal of lowfrequency variability. A data bank for systematic model verification and a comprehensive model inventory will also be developed.

Results to Date: In cooperation with the European Centre for Medium Range Weather Forecasts, the ECMWF global atmospheric model was made operational on the NERSC Cray- 2 at Livermore following extensive revision of the input-output and memory-management routines. The validated model has been used in a set of several 60 - to 90 -day perpetual season simulations to calculate the model's cloud-radiative forcing for comparison with satellite (ERBE) flux measurements and with other models. When used in sensitivity experiments with a prescribed change of sea-surface temperature, the model displays a negative cloud-radiative feedback. We have also begun a set of integrations with the ECMWF model to show the effects of horizontal resolution on the simulated climate. Using four resolutions that span the range of approximately 100 to $500 \mathrm{~km}$, we are developing diagnostic packages for the analysis of the global heat, momentum, and moisture balances.

As part of an international intercomparison of global atmospheric models in cooperation with the World Climate Research Programme, we have made preparations to assist participating groups in the conduct and diagnosis of comparative climate model simulations under standard conditions with observed monthly averaged sea-surface temperature and sea-ice distributions as boundary conditions. 


\section{A RESEARCH PROGRAM ON NATURAL AND ANTHROPOGENIC CLIMATE CHANGE}

GUTOWSKI, WILLIAM J.

\author{
ATMOSPHERIC AND ENVIRONMENTAL \\ RESEARCH, INC.
}

\author{
FY 1990408 \\ FY 1989394 \\ FY $1988 \quad 273$
}

$03 / 01 / 90-02 / 28 / 91$

Objective: To compare climate data and climate model results to improve the understanding of local/regional climate changes in relationship to large-scale climate, in particular the desertification problem. The work is divided into three tasks: (1) to assist in understanding GCMs, (2) to analyze climate data and to evaluate the climate model statistics against the observed climate, and (3) to assist in the scientific coordination of the USA-DOE/PRC-CAS joint research project on $\mathrm{CO}_{2}$-induced climate change.

Product: Possible cause/effect physical mechanisms between local/regional climate and largescale climate.

Approach: (1) Task 1 has three subtasks. Spectral to Grid-Point Comparison. This work will attempt to isolate the causes for the differences between the spectral and grid-point numerical formulations. The hypothesis is that the moisture field and the moisture fluxes are different between the two formulations. If one numerical technique is superior to another, these results will provide the basis for expanded experiments on more-detailed GCMs. Regional Study. From the above, the effect of resolution on regional results will be examined. The objective is to assess the ability to use GCM results as the boundary conditions for a mesoscale model to further improve the representation of regional climate. This ability may depend on the resolıtion of the GCM and on the numerical formulation of the GCM and the mesoscale model.
Energy Budget. The effort will analyze the atmospheric energy-budget components associated with atmospheric moisture and clouds. This includes the horizontal and vertical latent and sensible heat fluxes, thermal and solar radiation, and heat storage. The results will be combined with the previous surface-energy-budget analysis to assist in identifying the physical processes that cause the model differences.

(2) Task 2 will begin the statistical analysis with data that includes paleoclimate data for 6000 years BP. A major area of interest is that the U.S. climate is essentially monsoon free and the Chinese climate is dominated by the monsoon. This difference is important for model validation because the timing of the monsoon, which is known to within a few days in the historical record, can be used as a climate parameter to test the models. The same statistical analyses conducted on the data will be conducted on the model results, and the observed climate will be compared to the model climates. (More than one GCM will be used.)

Research will continue on the physical causes of arid/semiarid climate in the U.S. and China and how the areas defined as arid/semiarid regions may change with the increase of atmospheric $\mathrm{CO}_{2}$.

(3) Under Task 3, coordination will be provided for the USA-DOE/PRC-CAS joint research project on $\mathrm{CO}_{2}$-induced climate change.

Results to Date: (1) The spectral/gridpoint comparison has revealed substantial circulation differences between the two models. The gridpoint model produces a more vigorous hydrological cycle with more-frequent precipitation and greater cloud cover. Diabatic heating tends to amplify differences. A report, W. J. Gutowski, M. J. Iacono, X.-Z. Liang, and W.-C. Wang, Simulating Climate with Two Different Numerical Schemes, TR049, DOE/ER-0459T (1990), was published on the subject.

NCAR MM4 mesoscale model simulations driven by CCM 1 output have been performed to study arid/semiarid regions of China. The results 
are currently being analyzed. As an alternative means for evaluating regional climate variability, tropical, $\mathrm{CO}_{2}$-doubling changes from $\mathrm{GCMs}$ have been fed into a hurricane model to determine changes in local severe-rainfall characteristics. Using these changes in a hydrological basin model, we find that global warming could negate most of the benefits of existing water-management practice established in the South Florida basin. A report, W. J. Gutowski, G. F. McMahon, P. Kirshen, and S. Schluchter, 1990: "Projecting Climate Change to Small Basins: Potential Impact of Global Warming on Flooding in South Florida," has been submitted to $J$. Geophys. Res.

(2) We have developed a technique for comparing daily variability in a GCM gridbox with collocated observations. Applications to NCAR CCM1 simulations show a strong seasonal cycle in the model/observations differences. An article, D. P. Portman, W.-C. Wang, and T. R. Karl, "1990: A Comparison of General Circulation Model and Observed Regional Climates: Daily and Seasonal Variability," has been submitted to J. Climate.

A study of urban warming in China from 1954 to 1983 with data from the DOE/PRC agreement has shown urban warming increasing from the mid-sixties onward, but decreasing during the previous 10 years. An article, W.-C. Wang, Z.-M. Zeng, and T. R. Karl, "Urban Heat Islands in China," has been submitted to Geophys. Res. Lett.

A comparison of climate changes in China between 6000 years $\mathrm{BP}$ and the present with simulated $\mathrm{CO}_{2}$-doubling changes shows many similar characteristics, lending insight into the possible regional effects of global warming in China. An article, U. Zhang and W.-C. Wang, "The Surface Temperature in China During Mid-Holocene," Acta Geographica Sinica, is currently in press.

(3) Dr. W.-C. Wand (subcontractor, SUNY/Albany), as USA-DOE/PRC-CAS chief scientist, has continued the coordination of the joint project, which included organizing with $\mathrm{M}$.
Riches the April 1990 project science meeting in Livermore, California, and the 1990 international climate conference in Beijing.

\section{RADIATIVE, CHEMICAL, AND DYNAMICAL FEEDBACK PROCESSES \\ INFLUENCING $\mathrm{CO}_{2}$ AND TRACE GASES' CLIMATE EFFECTS}

GUTOWSKI, WILLIAM J.

\section{ATMOSPHERIC AND ENVIRONMENTAL RESEARCH, INC.}

$\begin{array}{ll}\text { FY 1990 } & 207 \\ \text { FY 1989 } & 199 \\ \text { FY 1988 } & 255\end{array}$

$09 / 01 / 90-08 / 31 / 91$

Objective: To develop and improve the radiative-transfer codes for climate studies and to incorporate trace gases radiative effects into the NCAR GCM.

Product: Advanced radiative codes with particular focus on the water-vapor continuum and a radiative-transfer code for the NCAR GCM that includes additional trace gases.

Approach: Radiative-transfer models will be developed/improved with a focus on the watervapor continuum in the context of the ICRCCM. Surface radiation measurements before, during, and after a dust event in China together with the ERBE satellite data will be used to test the quantitative connection between the dust event and aerosol-induced changes and regional meteorological responses. This approach draws theory, parameterizations, laboratory data, field data, regional radiation perturbation, and regional response together, a key requirement for improved detection and prediction of $\mathrm{CO}_{2}$ induced climate change.

How the other trace gases may modify the initial radiative heating/cooling profile in the atmosphere from that of $\mathrm{CO}_{2}$ alone will be studied. Such differences may lead to significantly dif- 
fererit climate feedbacks (e.g., clouds). The combined effects in a GCM experiment will assist in uncierstanding and defining the predicted climate response. This understanding may suggest detection strateries as well as improve the predictive capabilities of the GCMs. To assist in the analysis of the GCM experiment and to examine meridional heat transport feedback mechanism, the development and application of the seasonal energy balance model will continue. Adding a stratospheric photochemical model will expand the research to include the effect of stratospheric temperature changes on surface temperature.

Results to Date: We have computed effects of the water-vapor continuum on detailed line-byline radiative heating calculations using the Air Force Geophysics Laboratory's FASCODE model. For a midlatitude summer profile, significant effects occur near the tropopause and in the lower half of the troposphere. Comparison with similar continuum computations performed by the Goddard Laboratory for Atmospheres shows differences large enough (as much as $-20 \%$ ) to indicate the importance of using a proper continuum model. We have also provided a set of trace-gas radiation-flux calculations to the ICRCCM program.

We have implemented the radiative effects of trace gases $\left(\mathrm{CH}_{4}, \mathrm{~N}_{2} \mathrm{O}\right.$, and $\left.\mathrm{CFCs}\right)$ into the NC.AR CCM1 longwave-radiation scheme. Computations comparing current climate simulations with and without the trace gases show, thus far, a substantially warmer climate (by $\sim 4^{\circ} \mathrm{C}$ ) in the simulation including trace gases, indicating that these gases play an important role in maintaining global temperature in the current climate. An article on this subject, W.-C. Wang, G.-Y. Shi, and J. T. Kiehl, "Incorporation of the Thermal Radiative Effect of $\mathrm{CH}_{4}, \mathrm{~N}_{2} \mathrm{O}, \mathrm{CF}_{2} \mathrm{Cl}_{2}$, and $\mathrm{CFCl}_{3}$ into the National Center for Atmospheric Research Community Climate Model," J. Geophys. Res., is currently in press.

We have used our 2-D seasonal radiative dynamic model to investigate tropical cloudiness feedbacks. Interactions between cloud amount and drizzle formation and between sea surface temperature and deep convective clouds together reduce global warming by $\mathrm{CO}_{2}$ doubling by $23 \%$, indicating a need for further study of these feedbacks in GCMs. A paper, G. M. Molnar and W.-C. Wang, "Interactions Between I ow-Latitude Marine Clouds and Their Climatic Implications," Extended Abstracts, 1990 Conference on Cloud Physics, AMS, J61-J63 (1990), has been prepared.

\section{DATA PREPARATION AND ANALYSIS FOR ANNEX III, USA/PRC COOPERATION IN THE FIELD OF ATMOSPHERIC TRACE GASES}

KARL, THOMAS R.

NATIONAL CLIMATIC DATA CENTER

$\begin{array}{lr}\text { FY 1990 } & 209 \\ \text { FY 1989 } & 0 \\ \text { FY 1988 } & 0\end{array}$

$03 / 15 / 90-03 / 14 / 91$

Objective: To develop comprehensive regional climate reference data sets and to quantify and understand regional climate change in the United States and China by using both observations and GCM calculations (model control climates).

Product: A regional climite data set that can be used as a primary reference for understanding climate change and testing GCMs.

Approach: Information for the contiguous United States and Alaska on such surface quantities as precipitation, moisture, temperature, and snow cover as well as information on clouds, temperature, moisture, pressure, and wind above the surface will be collected, keypunched, quality checked, and merged with existing data bases.

Climate statistics will be derived from the regional climate reference data sets and analyzed in context with GCM equilibrium and perturbed experiments. 
The Climatological Prediction by Model Statistics (CPMS) will be developed to test the model results against the observations. After developing and testing the CPMS, the changes in the CPMS as $\mathrm{CO}_{2}$ is increased in the model will be examined. If successful, the technique will provide a method for estimating regional climate change from the GCM results, a major advance.

Model fields will be compared to observations, including the diurnal temperature range, upperatmospheric variables (e.g., temperature and pressure height), and multidimensional analysis of surface- and upper-air variables.

Concomitant changes in snow depth and temperature will be studied to determine if there is any long-term evidence for early spring snowmelt.

An attempt will be made to quantify any urban heat islands in China, a key element in determining the cause of global warming. The U.S. urban heat island is often used to estimate urban effects on the global data set. The scientific basis for this practice is not established. This research will be one of several world-wide efforts to document differences in urban heat island effects.

Results to Date: Several comprehensive data bases for stations in the U.S. have been assembled and updated through 1987. These include a historical cloud-cover and sunshine data base that has been assembled for the $1890 \mathrm{~s}$ through 1987. A paper describing the changes in the relationship between these two parameters during the past century has been accepted for publication. Monthly water vapor and daily temperature and precipitation data sets for the same period have been completed with documentation in preparation. Monthly sea-levelpressure, monthly station-pressure, and daily snow-depth data bases are nearing completion. In addition, an update scheme is being planned so that each of the above-mentioned reference data bases will contain the most current and complete data available.

A method has been developed that relates the gridded output statistics from GCMs to observed local climate reports. This method, called Climatological Projection by Model Statistics, is described in a paper that has been aceepted for publication.

\section{CLIMATOLOGICAL AEROLOGICAL (UPPER AIR) REFERENCE DATA SET (CARDS)}

\author{
KARL, THOMAS R. \\ NATIONAL CLIMATIC DATA CFNTER
}

$\begin{array}{lr}\text { FY 1990 } & 225 \\ \text { FY } 1989 & 0 \\ \text { FY 1988 } & 0\end{array}$

$(07 /(01 / 90)-06 / 30) / 91$

Objective: To build a Climatological Acrological (Upper Air) Reference Data Set (CARDS) from the radiosonde data archives.

Product: A key data set for climate research requiring atmospheric profiles of temperature, winds, and humidity.

Approach: The data consist of temperature, pressure, wind velocity, and humidity profiles of the atmosphere. Such data have been measured from twice-daily balloon launches at some $7(0)$ to 800 sites around the globe for about 50 years. However, the data are subject to many biases, including the effects of solar radiation on the temperature and humidity sensors. Early data are of ten uncertain and require extensive correction. The research team will build, quality control, and analyze the CARDS: A global data set of daily upper-air and concomitant surface synoptic observations will be produced from various collections of upper-air and collocated surface observations. The most extensive data set possible will be collected. A suite of algorithms will be developed to correct for random crrors and outliers because these data sets have not been quality controlled in a systematic manner. The analytical procedures will include a range of methods from statistical to physical (impossible temperatures, pressures, etc.). Suspect stations 
have been noted by the U.S. and European weather centers. This list will assist the task. The homogeneity of the data from the upper-air network will be assessed, and corrections for biases will be implemented where appropriate. The station histories will provide the information necessary to correct for known biases for sensor and methodology changes and differences over time and between stations (national procedures). These data will be analyzed with basic climatechange-analysis schemes to help ensure against undetected errors and biases, and complete documentation will be provided. A modest operational program will be instituted to ensure the integrity of future data, and these data sets will be made readily available through the Carbon Dioxide Information and Analysis Center.

NATIONAL INSTITUTE FOR GLOBAL ENVIROIIMENTAL CHANGE (NIGEC) INITIAL MANAGEMENT PLAN

KNOX, JOSEPH

\section{UNIVERSITY OF CALIFORNIA, DAVIS}

$$
\begin{array}{cc}
\text { FY 1990 } & 5916 \\
\text { FY 1989 } & 0 \\
\text { FY } 1988 & 0
\end{array}
$$

$$
\text { 07/15/90-07/14/91 }
$$

Objective: To plan jointly with the DOE and to conduct through Regional Centers a balanced research program supportive of the Department's essential mission related to global environmental change.

\section{Product:}

- Improved scientific understanding of the mechanisms of global environmental and climate change.

- The reduction of key scientific uncertainties surrounding environmental and climate change.
- Improved assessments of the potential impacts of regional environmental and climatic conditions projected for the next century.

- Development of innovative experimental or observational programs to enhance our understanding of regional-scale or ecosystem-scale processes contributing to global change.

- Development of policy and decision-making tools that are more appropriate for the global environmental and climate change issue than those currently in use.

- Education and training opportunities to increase the flow of talented young researchers into global-environmental-change research areas.

- Focused contributions to the education of the public and development of new curricular materials for educational purposes at all levels.

Approach: The management of the Institute will work in close cooperation with the DOE to facilitate the development of centers of research in global environmental change. Four regional centers will be established in four distinctive geographic areas of the United States: in the West at the University of California, in the South at Tulane University, in the Midwest at Indiana University, and in the Northeast at Harvard University. The University of California, Davis, is responsible for the leadership, administration, and operation of the NIGEC. The four regional centers are encouraged to focus the resources of their own institutions and of other outstanding institutions in their geographic area on global-change scientific areas emphasizing energy-related risks and climatic impacts. 


\section{THE MULTIDIMENSIONAL ASPECTS OF RECENT CLIMATE CHANGE IN NORTH AMERICA}

\author{
KUKLA, GEORGE \\ LAMONT-DOHERTY GEOLOGICAL \\ OBSERVATORY
}

\author{
FY 1990185 \\ FY 1989183 \\ FY 1988174 \\ $08 / 15 / 90-08 / 14 / 91$
}

Objective: To analyze time-related changes in the properties and the frequency of individual air masses over North America and to determine the degree to which the observed climate changes agree with the predictions of climate models.

Product: A regional data base for first detection of $\mathrm{CO}_{2}$-induced climate change. The information will be used for model validation.

Approach: Daily climate data sets from the 91 stations for North America (Canada and the United States) will be combined with upper-air data sets. Temperature, precipitation, cloudiness, and derived information (such as air-mass type and diurnal range of temperature) will be developed. Changes in regional climate will be assessed with principal-component analysis and canonical correlation, and possible causal relationships will be posed. For example, the relationships among temperature, cloudiness, and air-mass type will be examined. The data set and the derived information will be compared to GCM results. (Initially the OSU and the NCAR GCMs will be used.) Research questions like "How has the temperature change taken place relative to other variables, such as clouds and air mass (in time and space), and how do these changes compare with the GCM results?" will be investigated.

Results to Date: Both average monthly as well as daily data on atmospheric pressure, temperature, precipitation, clouds, humidity, winds, etc. are being analyze $t$, ality controlled, reduced, and made available to other interested scientists.

Although a gradual warming during the past 40 years was noticed in the western and northwestern parts of North America, the eastern half of the continent shows gradual cooling accompanied by increasing precipitation and decreased diurnal temperature range. The bulk of the observed changes can be explained by the changing frequency of air masses caused by the natural $\left(\mathrm{CO}_{2}\right.$ unrelated) variability of atmospheric circulation. However, the air masses with comparable characteristics and similar humidity warmed in the past four decades at some stations, indicating a possible $\mathrm{CO}_{2}$ link. We have also compared surface-air and sea-surface-temperature trends in the remaining continents and oceans of the Northern Hemisphere and noticed that the recent pronounced cooling of the North Atlantic shows similarities to the projections of the NCAR transient model run in which the $\mathrm{CO}_{2}$ is gradually increasing by $1 \%$ annually for 30 years. The North Atlantic cooling zone dissipates in the model with further increase of the $\mathrm{CO}_{2}$ concentrations. Both the model output and the observed temperature trends display a very high short-term spatial and temporal variability that precludes drawing definite conclusions on the cause-and-effect links between the two data sets.

The most notable feature of the temperature change in North America, namely the gradual increase of the nighttime temperatures and the decreased frequency and intensity of cold temperature extremes is accompanied by little change in daily maxima. Similar features agree with the expected impact of $\mathrm{CO}_{2}$ and were also found in the Soviet Union. We are currently completing a paper on these results in cooperation with a Soviet scientist. 
CARBON DIOXIDE EFFECTS RESEARCH

MaCCRACKEN, MICHAEL C.

\section{LAWRENCE LIVERMORE NATIONAL LABORATORY}

$$
\begin{array}{lr}
\text { FY } 1990 & 1085 \\
\text { FY } 1989 & 970 \\
\text { FY } 1988 & 978
\end{array}
$$

$10 / 01 / 89-09 / 30 / 90$

Task I. Climate Modeling and Data Analysis (K. E. Taylor)

Objective: To improve our understanding of climate models so that, when these models are used to make projections of future climate change, the reliability of the projections can also be evaluated. More specifically, (1) to establish the relative roles of the processes that contribute to the latitudinal and seasonal sensitivity of climate models to increasing $\mathrm{CO}_{2}$ concentrations, (2) to examine the processes controlling the rate of change of climate, (3) to use a 2-D climate model and other simplified models to assist in analyzing and interpreting results from 3-D models (GCMs), and (4) to update and to improve the 2-D climate model to treat interactions between climate and atmospheric chemistry.

Product: An updated and improved model that will be an efficient tool for model diagnosis and study of climate change. By establishing the relative roles of the processes that lead to climate-model sensitivity, the importance of uncertainties and limitations in representations of these processes can be assessed, and models improved. In cooperation with D. Wuebbles's project, a better understanding of the importance of feedbacks between atmospheric chemistry and climate change will be obtained.

Approach: To explore all components of the relationship between $\mathrm{CO}_{2}$ and trace gases on the one hand and climate on the other, the complexity of climate models must be balanced against available computational capabilities. Here, equations for the zonally averaged component of climate will be formulated and directly solved. The resulting 2-D climate model will retain many of the essential characteristics of the climate system and can be used as an important tool for understanding the climate itself as well as the results obtained by $3-\mathrm{D}$ climate models.

The weather systems that are explicitly simulated in 3-D models are accounted for by eddy parameterizations in 2-D models (or can be prescribed). The consequent reduction in "climatic noise" along with the greatly reduced computational costs of 2-D simulations make it possible to carry out runs in which individual processes can be examined in detail. Because computational costs preclude such studies with 3-D climate models, the 2-D model is rerognized as an essential tool within the climate model hierarchy. It will be used to address a number of important questions concerning the hisiorical climate record and future climate change. A study is planned, for example, to determine how the pattern of climatic response to a stratospheric injection of volcanic aerosols depends on the latitude and season of the volcanic eruption. Another planned application is to use the 2-D model to explore the limitations of the GCM experiments undertaken as part of Task II of this project. In particular, the climate-model response to a doubling of atmospheric $\mathrm{CO}_{2}$ concentration will be compared to its response to a prescribed increase in sea surface temperature.

Results to Date: A technical report has been prepared describing the 2-D climate model treatment of surface processes. Extensive analyses were completed to assess the model's ability to simulate seasonal changes in cloud forcing and surface temperature. Because the model can only represent averages over all longitudes, it is difficult to reproduce realistically the observed cloud fraction and relative humidity profiles. Further refinements of the pertinent parameterizations are currently under way.

A manuscript describing a GCM-based estimate of the upper-limit to sea-ice albedo feedback was accepted for publication in Climatic Change. We 
are also completing a manuscript concerned with dissecting cloud-radiation feedbacks in climate models with an application to a GCM. These two articles are concerned with processes that are generally not well simulated in climate models and therefore account for much of the uncertainty of climate-warming estimates.

Task II. Model Intercomparison

(G. Potter)

Objective: To develop a basis and strategy for intercomparing climate $m$ - tels so that the causes of different results from different models can be determined. Comparison of climate models' $\mathrm{CO}_{2}$ sensitivities will be used to investigate the differences that can arise between models and the mechanisms that contribute to the differences.

Product: An understanding of the causes of differences in results from different models, providing a basis for model improvement.

Approach: The causes of the range of results that can occur in climate models will be analyzed in terms of the differences inherent in model structure and the effects caused by different parameterizations of the oceanic meridional transport and heat capacity. The OSU GCM will be used to develop a strategy for model intercomparison with sea-surface-temperature perturbations as a surrogate for increasing $\mathrm{CO}_{2}$.

Results to Date: See the Results to Date section for the project entitled "Program for Climate Model Diagnosis and Intercomparison," which covers the intercomparison of models' simulation of cloud-radiative forcing.

Task III. Program Management

(M. C. MacCracken)

Objective: To prepare technical reports and presentations on the climate effects of increasing $\mathrm{CO}_{2}$ and the extent to which such changes have started to occur and to assist in providing technical oversight of the climate research area and in integrating the research program.
Product: A focal point for research undertaken by federal and international climate programs relevant to the $\mathrm{CO}_{2}$-climate issue; technical coordination of DOE contract research; specific studies on timely $\mathrm{CO}_{2}-$ climate issues (e.g., small studies of immediate interest, such as an analysis of patterns of climatic change); and statisticalanalysis support for activities, such as overviews of model/data comparisons.

Approach: These activities will provide a source of intellectual stimulation and focus for DOE participation in the $\mathrm{CO}_{2}$-climate issue and will help assure coordination of the research activities conducted by climate research groups sponsored by DOE.

Results to Date: Two major reports were prepared: a special DOE multilaboratory report Energy and Climate Change in support of the DOE National Energy Strategy and Prospects for Future Climate, describing the benefits from both the modeling and empirical approaches to climate, under the auspices of the US/USSR bilateral on the environment. Contributions were also made to the international report of the Intergovernmental Panel on Climate Change. In addition, the early development of the CHAMMP program was carried out.

\section{FIELD, LAB, AND MOI)ELING STUDIES OF WATER INFILTRATION AND \\ RUNOFF IN SUBFREEZING SNOW ON REGIONAL SCALES TO ESTIMATE FUTURE GREENHOUSE-INDIJCED CHANGES IN SEA LEVEL}

MEIER, M. F., and ILLANGASEKARE, T. H.

\section{INSTITUTE OF ARCTIC AND ALPINE RESEARCH}

$\begin{array}{lr}\text { FY 1990 } & 202 \\ \text { FY 1989 } & 0 \\ \text { FY } 1988 & 0\end{array}$

$09 / 15 / 90-09 / 14 / 91$ 
Objective: To forecast future sea-level change caused by greenhouse-induced changes in runoff from polar glaciers and ice caps.

Product: A model to predict the development of impermeable firn (and consequent runoff and discharge to the ocean) in response to predicted future climate change.

Approach: The processes of infiltration and refreezing, which lead to the formation of impermeable firn layers, will be observed in the field and reprociuced in the laboratory to confirm and further quantify understanding. A regional-scale numerical model that can simulate these processes will be developed and calibrated, based on measured parameters; it will be driven by boundary conditions determined by climate. This model will be applied to predict the development of impermeable firn (and consequent runoff and discharge to the ocean) in response to predicted future clinate change.

Results to Date: Our field program at Mer de Glace Agassiz, Arctic Canada, was completed with the comparison of stratigraphy before and after the July 1988 melt season and the retrieval of hourly temperature records for 1988 to 1989 from an array of 64 thermistors placed in the snow. Pits dug and analyzed at 9 sites up to $18 \mathrm{~km}$ distant revealed stratigraphy on a regional scale. Measured changes in the density and temperature structure are being used to calculate the total, horizontally averaged, vertical meltwater flux during the July 1988 melt season and for use in validating models of runoff.

A fully 2-D model that treats water flow in subfreezing snow and allows complex spatial variations in material properties to be included was developed. It reproduces wetting-front propagation in a realistic way for layered, heterogeneous snow and calculates the corresponding distributions of water content and temperature. It has been used to determine which of the controlling parameters are most influential in governing the pattern of water flow, and to simulate the process of densification and the development of impermeable ice. A regionalscale; extended model is being developed that will be based on cells of moderate size vertically (1 to $2 \mathrm{~m}$ ) and large size laterally $(1 \mathrm{~km})$.

\section{THE ROLE OF CLOUDS IN $\mathrm{CO}_{2}$-INDUCED CLIMATE CHANGE}

\author{
RANDALL, DAVID A. \\ COLORADO STATE UNIVERSITY
}

$\begin{array}{lr}\text { FY } 1990 & 169 \\ \text { FY } 1989 & 109 \\ \text { FY } 1988 & 0\end{array}$

$09 / 15 / 90-09 / 14 / 91$

Objective: To develop a quantitative understanding of surface radiative forcings as related to clouds and cloud-climate feedbacks on climate change and to develop an advanced ocean/atmospheric GCM.

Product: An understanding of the surface radiative forcings relative to clouds from the various GCMs, the models' comparisons with the available observations, and their possible methodological shortcomings; an improved GCM with fully coupled ocean and atmosphere.

Approach: The research will focus on the radiative role of clouds in current climate and in a climate modified by increased atmospheric concentrations of $\mathrm{CO}_{2}$. The research will address the roles clouds play in the different GCMs and will provide for improved physical parameterization of clouds in the GCMs. Fourteen GCMs will be compared in terms of surface fluxes (sensible, latent heat, infrared and solar); precipitable water content; and precipitation and evaporation. These comparisons will be carried out in cooperation with the GCM intercomparison led by LLNL and State University of New York at Stony Brook.

Differing cloudiness parameterizations will be studied in a simple coupled ocean/atmosphere model as atmospheric $\mathrm{CO}_{2}$ concentrations change. This work will provide a simple educational tool to guide and assist in understanding 
the effects of these modifications on the cloudiness schemes when used in the GCMs. The simple model will run on desktop computers, while the GCMs require tens to hundreds of hours on supercomputers.

The observational research programs, GCM development, and intercomparison research will be integrated by the use of cloud data from satellite, aircraft, and balloons to quantify cloud forcing and feedback processes as observed.

An ocean GCM will be added to the existing CSU atmospheric GCM in a stepwise fashion. The mechanics are simple; however, coupled GCMs magnify the imperfect models being brought together. Understanding the physical and methodological problems and then making appropriate, physically based corrections is difficult. The primary concern will be the effect on clouds. For example, simple changes in ocean albedo can have dramatic impact on model cloudiness, requiring modification of the cloud parameterizations.

The Q-flux version of the ocean model will be developed, and the CSU GCM will be coupled with an ocean GCM.

Results to Date: The most significant accomplishment of the first year of this project is our study of the $\mathrm{CO}_{2}$ forcing using the CSU GCM, the first model to have been used for such a calculation. We called the longwave radiation routine twice, to determine the radiative fluxes and heating rates for both $2 \times \mathrm{CO}_{2}$ and $1 \times \mathrm{CO}_{2}$. In the analysis of our results, we have concentrated on the effects of clouds on the $\mathrm{CO}_{2}$ forcing. The results show that the clouds increase the $\mathrm{CO}_{2}$ forcing of the troposphere in high latitudes, where the clouds are found at low levels. On the other hand, clouds reduce the $\mathrm{CO}_{2}$ warming of the troposphere in the tropics and in the middle latitudes of the summer hemisphere, where high clouds block the upwelling longwave radiation. Clouds tend to reduce the $\mathrm{CO}_{2}$-induced warming in the tropical and summer-hemisphere troposphere and to increase it in both the middle and the high-latitude troposphere.
We have also finished construction of the Q-flux ocean model, including a simple sea-ice parameterization. The ocean model is currently being tested by driving it with the history tapes produced by the atmosphere model.

\section{ATMOSPHERIC METHANE: RESEARCH PROGRAM FOR A STUDY IN CHINA}

\author{
RASMUSSEN, R. A. \\ FY $1990 \quad 297$ \\ FY 1989302 \\ FY 1988272 \\ $02 / 01 / 90-01 / 31 / 91$
}

OREGON GRADUATE CENTER

Objective: To measure the magnitude of the methane source from rice paddy fields and biogas generators, including seasonal cycles.

Product: New information on the magnitude of rice paddies and biogas generators as sources of methane and on the seasonal characteristics of these sources so the time series documenting the increase in atmospheric methane can be understood better.

Approach: OGC will cooperate with the PRC to measure methane releases to the atmosphere from rice paddy fields, nonagricultural soils, and biogas generators. Standard techniques developed by OGC will be used. The measurements will be made so that seasonal characteristics of the releases can be determined. This data will be used in analysis and modeling programs to understand the time-series record of atmospheric methane.

Results to Date: Chinese rice fields we have studied so far emit methane at an average rate of about 60 milligrams $/$ meter $^{2} \mathrm{hr}^{-1}$ during the growing season. This emission rate is 4 to 10 times higher than that from rice fields in the United States and Europe. Methane emissions have a pronounced seasonal variation with the highest emissions during the middle of the 
growing season and with lesser emissions at the beginning and end of the growing seasons. Methane emissions increase dramatically with increasing soil temperature. These results suggest that Chinese rice fields and similar rice fields are a large source of methane in the atmosphere.

Additional experiments showed that biogas generators (some $10,000,000$ ) are not a significant source of methane to the atmosphere. Indeed, they contribute less than 1 teragram per year. Rice fields release $\mathrm{CO}, \mathrm{CHCl}_{3}$, and $\mathrm{CO}_{2}$ at observable rates. Neither rice ficlds nor biogas generators contribute significantly to local and regional pollution. Some chlorocarbons $\left(\mathrm{CH}_{3} \mathrm{CCl}_{3}, \mathrm{CF}_{3} \mathrm{Cl}_{2}\right.$, and $\left.\mathrm{CCl}_{4}\right)$ are taken up by the rice paddies.

These findings were reported in two publications: M. A. K. Khalil, R. A. Rasmussen, M.-X. Wang, and L. Ren, "Emissions of Trace Gases from Chinese Rice Fields and Biogas Generators: $\mathrm{CH}_{4}, \mathrm{~N}_{2} \mathrm{O}, \mathrm{CO}, \mathrm{CO}_{2}$, Chlorocarbons, and Hydrocarbons," Chemoshere 20, 207. 226 (1990); and M. A. K. Khalil, R. A. Rasmussen, M.-X. Wang, and L. Ren, "Sources of Methane in China: Rice Fields, Biogas Pits, Cattle, Urhan Areas and Wetlands," Proceedings of the Air and Waste Management Association (Paper No. 90-139.5, 83rd Annual Meeting, Pittsburgh, Pennsylvania, June 24-29, 1990).

\section{PARTIAL SUPPORT OF VOLCANIC SIGNAL IN GLOBAL CHANGE}

\author{
ROBOCK, ALAN \\ UNIVERSITY OF MARYLAND
}

$\begin{array}{lr}\text { FY } 1990 & 50 \\ \text { FY } 1989 & 0 \\ \text { FY } 1988 & 0\end{array}$

$06 / 15 / 90-06 / 14 / 91$

Objective: To develop an improved volcanic index for climate analysis and to analyze the observed climate record (surface temperature) for evidence of volcanic-induced cooling, including comparison with GCM calculations.

Product: An improved volcanic index for climate studies.

Approach: The research is divided into: volcanic index development, comparison of the index to the climate observations, and GCM calculations and comparison to the data. (1) A wide range of volcanic indices have been developed, including the well known Lamb Dust Veil Index (DVI), which is primarily an annual, hemispheric average index, which makes it difficult to determine regional and seasonal effects or to use the index to drive a GCM. A new index will be developed that will be based on such time and spatial information as solar radiation data, atmospheric turbidity data, and ice-core chemical analyses. In addition, existing volcanic indices will be examined to establish a time series for use with climate models (ideally, an estimate of atmospheric aerosol concentrations). (2) The surface temperature record of the past 150 years will be analyzed and compared to the newly developed volcanic index. The resultant information is expected to provide a clearer understanding of the relationship between natural variability of the climate cause/effect mechanisms, such as volcanic activity, and will contribute to the DOE effort to quantitatively link $\mathrm{CO}_{2}$ and other tracegas increases to climate change by reducing unexplained noise. (3) The GCM analysis will be conducted to further assess cause and effect. The analysis will be initiated as appropriate as the study progresses.

\section{PARTIAL SUPPORT OF RESEARCH ON GREENHOUSE-GAS-INDUCED CLIMATE CHANGE}

\author{
SCHLESINGER, MICHAEL E. \\ UNIVERSITY OF ILLINOIS
}

$\begin{array}{cc}\text { FY 1990 } & 140 \\ \text { FY 1989 } & 0 \\ \text { FY 1988 } & 0\end{array}$

$(06 / 15 / 90-06 / 14 / 91$ 
Objective: (1) To analyze the feedbacks in the $\mathrm{CO}_{2}$-induced warmings simulated by the twolevel model and the new multilevel model, (2) to analyze the causes of the $\mathrm{CO}_{2}$-induced drying in the Northern Hemisphere continents in the summer as simulated by the models, (3) to analyze the $\mathrm{CO}_{2}$-induced changes in the diurnal cycle simulated by the multilevel model, and (4) to analyze the cloud optical feedbacks on $\mathrm{CO}_{2}$ induced climate change.

Product: An increased understanding of the GCM feedbacks, leading to an improved model of known capability.

Approach: The research will include two areas: understanding the equilibrium and transient climate change and explicating the cloud optical feedback.

To determine why the $\mathrm{CO}_{2}$-induced warming in the model increases as the temperature of the control $\left(1 \times \mathrm{CO}_{2}\right)$ decreases and whether the increase results from ice-albedo feedback, cloudcover feedback, or a combination of these and other feedbacks, the range of model feedbacks will be quantitatively determined as part of the overall DOE program of model diagnostics. A previously developed radiative-transfer-model will be used.

To study what model mechanism is responsible for the summer midcontinentai drying indicated by this GCM, the soil water balance in the model will be quantitatively analyzed. This approach will lay the basis for improvements in the soil water modeling subcomponent of the GCM.

To develop a basis for the detection of climate change, the model's diurnal cycle of temperature will be compared between the $1 \times \mathrm{CO}_{2}$ and the $2 \times \mathrm{CO}_{2}$ experiments. Observations, analyzed by T. Karl in other DOE research, suggest that the diurnal range of temperature should decrease. The daily maximum is dominated by solar heating, so $\mathrm{CO}_{2}$ warming should have little impact; on the other hand, the nighttime low may show a large impact of $\mathrm{CO}_{2}$-warming (i.e., if the nighttime low gets warmer, the range decreases).
Testing the model for this possible phenomenon provides a possible piece of a specific $\mathrm{CO}_{2}$ fingerprint.

A transient model run will be conducted to provide a basis for the comparison with the observation over the past 100 years. To carry out this experiment, the new ocean GCM must be verified by comparing the observed ocean tracer data (e.g., the penetration of bomb tritium) with the model estimates of the tracer distribution. Subsequently, the coupled model will be run with $1 \times \mathrm{CO}_{2}, 2 \times \mathrm{CO}_{2}$, and in a transient mode with slowly increasing greenhouse gases. The results will be intercompared as well as compared to the observed record of climate, and multiple variables will be examined.

Recent GCM research has shown that model sensitivity can change by a factor of two when cloud optical properties are changed or calculated rather than prescribed. Research will continue to develop more physically based parameterizations, include a new boundary-layer parameterization, for incorporation in the GCM.

Multitasked versions of the GCM will be developed as part of the overall approach.

Results to Date: We have revised our atmospheric general circulation/mixed-layer ocean (AGC/MLO) model and used it to simulate the present $\left(1 \times \mathrm{CO}_{2}\right)$ and $2 \times \mathrm{CO}_{2}$ climates. The $1 \mathrm{x}$ $\mathrm{CO}_{2}$ results from the revised model are in better agreement with observations than those of the antecedent model, and the global-mean $\mathrm{CO}_{2}$-induced warming correspondingly increased from $2.8^{\circ} \mathrm{C}$ to $4.2^{\circ} \mathrm{C}$. The earlier $1 \times \mathrm{CO}_{2}$ and $2 \times \mathrm{CO}_{2}$ results have been provided to 71 individual researchers and research groups. In a collaborative effort, we helped develop a method to estimate the greenhouse-gas-induced change in local climate, either at a point or averaged over an area smaller than that of a GCM grid square. The method uses the statistical relationships between the observed large-scale free-air climate and the local surface climate, together with the simulated large-scale free-air climate, to obtain an estimate of the local surface climate. 
A new, simple model has been developed to represent our earlier coupled atmosphere/ocean GCM simulations of the transient response of the climate system to a doubling of $\mathrm{CO}_{2}$. This simple model has been used to project the response of the coupled GCM and to estimate the characteristic response time of the climate system to a $\mathrm{CO}_{2}$ doubling to be between 40 and 60 years. A simulation of the penetration into the ocean of tritium, CFC-11, and CFC-12 has been made with the coupled atmosphere/ocean GCM. The penetration depth of the $\mathrm{CO}_{2}$-induced heating is bracketed by the smaller penetration depth of tritium and the larger penetration depths of CFC-11 and CFC- 12 .

A parameterization of clouds and their radiative interactions has been developed for our multilayer atmospheric GCM model. In this parameterization, cloud water is a prognostic variable; the fractional cloud amount is predicted semiprognostically; stratiform and cumuloform clouds can coexist in a vertical column; clouds can exist either as liquid water, ice, or mixed liquid water and ice; and the radiative properties of clouds depend on their predicted liquid water and ice amounts. Tests of this parameterization show that it is capable of successfully simulating many observed features of cloud cover, the vertically integrated cloud water, precipitation, and the components, of the earth's radiation budget at the top of the atmosphere.

\section{ENHANCED RESEARCH PROGRAM ON THE LONG-RANGE CLIMATIC EFFECTS OF INCREASING ATMOSPHERIC CARBON DIOXIDE}

WASHINGTON, W. M., and MEEHL, G.

NATIONAL CENTER FOR ATMOSPHERIC RESEARCH

$\begin{array}{cc}\text { FY 1990 } & 409 \\ \text { FY 1989 } & 0 \\ \text { FY 1988 } & 0\end{array}$

$06 / 01 / 90-05 / 31 / 91$
Objective: To couple the advanced atmospheric CCMO and the advanced $1^{\circ} \times 1^{\circ}$ dynamical ocean GCM and to perform a series of sensitivity experiments with the coupled and uncoupled models, including transient $\mathrm{CO}_{2}$ experiments.

Product: An advanced GCM capable of regional climate calculations.

Approach: A control run ( $\left.1 \times \mathrm{CO}_{2}\right)$, an instantaneous $2 \times \mathrm{CO}_{2}$ experiment, and a transient experiment will be performed with the new atmosnheric GCM. These experiments will benchmark the new version of the model against the previous results and provide a basis for analyzing the experiments conducted with the advanced dynamical ocean (i.e., understand the differences and assess the improvements).

The two advanced models will then be coupled. The dynamical ocean model is a $1^{\circ} \times 1^{\circ}$ version of the Semtner-Chervin $1 / 2^{\circ} \times 1 / 2^{\circ}$ ocean model with 20 vertical levels. The $1^{\circ} \times 1^{\circ}$ version of the Semtner-Chervin to be used in this research does not explicitly resolve the mesoscale eddies as does the parent model, but research has shown that observed ocean features sufficient for climate experiments, can be simulated without such an explicit calculation. The research with the coupled model will test this hypothesis.

The coupling scheme is synchronous rather than the often used asynchronous coupling. Asynchronous coupling does not allow for the time evolution of the interaction between the ocean and atmosphere. In the NCAR scheme, the atmospheric model provides wind stress, precipitation minus evaporation, and the sum of the surface energy balance to the ocean. The ocean model provides the atmosphere, surface temperature, and sea-ice information. The coupled experiment will be started from separate runs of the new models, each forced with the appropriate observed climate conditions (e.g., the observed sea surface temperature for the spinup of the atmospheric model). This procedure will allow separate diagnosis of any model problems before coupling. 
The result will be the first coupled GCM experiments with an ocean model sufficient to simulate primary ocean climatological features.

Results to Date: To determine how the regional aspects of our model simulation change with time, we have extended our experiments for more than 50 years. Examination of 5-year seasonal means has shown that the regional patterns have a large amount of natural variability, roughly the same as is found in the observations by T. Karl (NOAA). This variability will make a regional greenhouse-gas-caused signal more difficult to identify as a function of time than originally believed.

We are continuing to study the effects of increased $\mathrm{CO}_{2}$ on the El Nino-Southern Oscillation (ENSO) as internally generated by the model. Early indications are that ENSO continues to function with increased $\mathrm{CO}_{2}$, but the warmer mean tropical sea-surface temperatures (SSTs) mean that ENSO events are more intense because of the nonlinear relationship between SST and evaporation. Extratropical teleconnections are also altered because of the change of mean basic-state climate with the increase of $\mathrm{CO}_{2}$.

We have already made progress on a new, multitasked version of the climate model. This version contains improved physical processes in the atmosphere, $1^{\circ}$ horizontal resolution, and 20 layers in the ocean. Incorporation of the Arctic Ocean was difficult, but we have overcome the associated problems. We are presently adding to the ocean model a new, simple sea-ice model with dynamics (from G. M. Flato and W. D. Hibler, III). The latter will be an improvement over the simple thermodynamic sea-ice model.

We are continuing to participate in modeling intercomparison studies, including those of the IPCC and the DOE.

\section{MODEL-VALIDATION RESEARCH: COM- PARISON OF SIMULATED AND, OBSERVED CLIMATE PATTERNS FOR THE PAST 18,000 YEARS}

\author{
WEBB, THOMPSON, III \\ BROWN UNIVERSITY
}

$$
\begin{array}{lr}
\text { FY } 1990 & 419 \\
\text { FY } 1989 & 420 \\
\text { FY } 1988 & 409 \\
& \\
02 / 01 / 90)-01 / 31 / 91
\end{array}
$$

Objective: To attempt to validate the NCAR GCM against paleoclimate data.

Product: A GCM validated against the paleoclimate data record.

Approach: The project will (1) use GCMs to simulate a series of climatic changes from the past, (2) provide assembled paleoclimatic data from large areas of the tropics and the Northern Hemisphere mid-to-high latitudes for the comparison of model simulations and observations, (3) develop methods and procedures for improving the comparability of the observed and simulated data, and (4) compare the model results with the paleoclimatic data. The COHMAP book will be completed.

Results to Date: During the past year, we worked with researchers at NCAR to correct a model error affecting rates of snowmelt in CCM1 (the current version of the NCAR GCM) and then completed a simulation for $6000 \mathrm{BP}$ with the corrected version of the model. The simulation exactly parallels a $6000 \mathrm{BP}$ simulation produced by the climate model of the U.K. Meteorological Office. A comparison of the two simulations is in progress, and both simulations are being compared to paleoclimatic data for $6000 \mathrm{BP}$. The $6000 \mathrm{BP}$ simulations for both CCM0 and CCM1 are also being compared to evaluate how improvements to the model, such as including a full seasonal cycle, affected its ability to simulate a climate with a significantly different pattern of seasonal radiation. 
We participated in a major workshop meeting that included Soviet Quaternary scientists, and we began developing plans to include more Soviet data in the comparison of paleoclimatic data with model simulations of past climates. We updated the set of pollen data from eastern North America and produced a new set of temperature and precipitation estimates. These values showed temporal and spatial patterns of similarities and differences with the model results. Maps of lake-level data were used to check the estimates derived from the pollen data, and estimates were derived from lacustrine ostracodes in the northern Midwest to show how changes in water chemistry fit with the estimates of past climate changes there. In the Indian cuzan, eolian sediments provided a record of monsoon variability that was compared to model simulations.

\section{INTERNATIONAL CONFERENCE ON THE ROLE OF THE POLAR REGIONS IN GLOBAL CHANGE}

WELLER, GUNTER

\section{UNIVERSITY OF ALASKA}

$\begin{array}{lr}\text { FY 1990 } & 10 \\ \text { FY 1989 } & 0 \\ \text { FY 1988 } & 0\end{array}$

$03 / 01 / 90-02 / 28 / 91$

Objective: To bring together experts from a wide variety of scientific disciplines of relevance to the polar regions and global change, to address the role of the polar regions in global change, to summarize what we know about the role of the polar regions in global change, and to identify where gaps in our knowledge still exist.

Product: A synthesis of knowledge about the part polar regions play in global change and an identification of the topics that still need additional research.

Approach: An International Conference on the Role of the Polar Regions in Global Change will take place on the campus of the University of Alaska in Fairbanks on June 11-15, 1990. The organizer of the conference is the Geophysical Institute of the University of Alaska Fairbanks under the auspices of the Arctic Research Consortium of the United States.

The program will consist of two simultaneous sessions on six interdisciplinary topics for three half days, followed by a third day of working group sessions that will address what is not known and what the next steps are.

\section{DETECTION OF $\mathrm{CO}_{2}$-INDUCED CLIMATE CHANGE}

WIGLEY, T. M. L., and JONES, P. D.

\section{UNIVERSITY OF EAST ANGLIA}

$\begin{array}{ll}\text { FY 1990 } & 111 \\ \text { FY 1989 } & 121 \\ \text { FY 1988 } & 113\end{array}$

$12 / 01 / 89-11 / 30 / 90$

Objective: To assemble and analyze instrumental climate data and to develop simple climate models as a basis for detecting greenhouse gas-induced climatic change, and for validation of GCMs.

Product: A high quality, spatially extensive data base, which is required to define the "noise" of natural climatic variability (resulting from such factors as changes in ocean circulation, volcanic activity, and solar irradiance) and its spatial characteristics so that the signal of the greenhouse effect can be detected.

Approach: Available land and marine data bases will be updated and expanded, and differences between different data sets wi"! be reconciled where possible. The data will be analyzed to determine the potential effects on climate of greenhouse-gas concentration changes and other factors. Analyses will be guided by simple energy-balance climate models. These analyses will be oriented towards obtaining early evidence of 
greenhouse-gas-induced climatic change that would lead to confirmation, rejection, or modification of model projections and towards the statistical validation of GCM control runs.

Results to Date: Uncertainties in our global land-based temperature data set have been reduced through studies of possible urbanization influences in western U.S.S.R., eastern Australia, and eastern China. Rural/urban comparisons show little urban influence in our gridded data in these regions. Together with earlier results from the United States, these findings imply an urban bias of less than $0.05^{\circ} \mathrm{C}$ in the $0.5^{\circ} \mathrm{C}$ warming during the past 100 years. Detection studies have concentrated on multivariate pattern-correlation techniques using the observed patterns of tem. perature change. Any greenhouse signal should become more evident in the observed data as time goes by, but this is not the case if conventional test statistics such as Barnett and Schlesinger's $C_{t}$ are used. A new method to highlight regions with larger signal-to-noise ratios has been developed, giving encouraging results. Transient-response studies have concentrated on solar forcing and natural variability. From Foukal and Lean's constructions back to 1874, the maximum range of global-mean temperature variation caused by sunspot effects is only $0.03^{\circ} \mathrm{C}$. The spectrum of passive, internally generated, natural variability has been extended, and a frequency-dependent effective heat capacity has been defined for the oceans. The latter may be up to 50 times the heat capacity of the mixed layer.

\section{TRACE-GAS INTERACTIONS IN THE GLOBAL ATMOSPHERE}

WUEBBLES, DONALD J.

\section{LAWRENCE LIVERMORE NATIONAL LABORATORY}

$\begin{array}{ll}\text { FY } 1990 & 346 \\ \text { FY } 1989 & 250 \\ \text { FY } 1988 & 275\end{array}$

$10 / 01 / 89-09 / 30 / 90$
Objective: To understand the effects that increasing atmospheric concentrations of $\mathrm{CO}_{2}$ and other trace gases may be having on global atmospheric chemistry and climate; to understand the interactions among climate, chemical, and radiative processes; and to establish clear relationships between theoretical models and the measurements of atmospheric constituents being made in the troposphere and stratosphere.

Product: A beiter understanding of the processes relating to global atmospheric chemistry and climate; insights into the determination and evaluation of the mechanisms and processes reflecting the influence that trace gases may be having on the global environment; and an understanding of what measurements are required to further develop and validate global atmospheric models to study climate and chemical interactions.

Approach: These studies will (1) develop information on past trends and the potential for future trends of the various trace species, an effort being coordinated with studies of tracespecies histories and economic analyses being done at PNL; (2) examine budgets of relevant trace gases to better establish which uncertainties require consideration in our development of scenarios of future emissions; (3) extend existing capabilities for modeling global atmospheric chemical, radiative, and physical processes; (4) perform model sensitivity analyses to better define the mechanisms, key parameters, and overall uncertainties of potential trace-gas influences on the atmosphere; and (5) establish a clearer relationship between theoretical models and the measurements of atmospheric constituents being made in the troposphere and stratosphere with the purpose of defining and reducing existing uncertainties in the determination of trace-gas effects.

To accomplish this evaluation, LLNL is extending present modeling capabilities and developing new models to allow courdinated treatment of chemical and climatic effects. The I,LNL 1-D atmospheric-chemistry transport models have been reference models for past assessments. The LLNL 2-D model of tropospheric and strato- 
spheric chemical, radiative, and dynamical processes is rapidly becoming the new standard for such assessments. Results of atmospheric chemistry perturbation studies with the 2-D model can be used to determine radiative perturbations, the climatic significance of which can be evaluated with climate models. Efforts are also under way to develop a $1-\mathrm{D}$ radiative-convective chemistry model and to couple our 2-D chemistry and climatic models for use in interactive simulations.

Results to Date: A major emphasis this year was the preparation of national and international assessment reports relating to global change lead-author responsibilities in the following major reports: for DOE, Energy and Climate Change; for UNEP-WMO, Scientific Assessment of Stratospheric Ozone: 1989; for UNEP-WMO, the Alternative Fluorocarbon Environmental Acceptability Study; the special U.S.-U.S.S.R. report, Prospects for Future Climate; and the Intergovernmental Panel on Climate Change report, Scientific Assessment of Climate Change. Special atmospheric-model calculations and theoretical analyses were underta? the development of a concept for weighting the relative effects of different atmospheric gases for their effect on climate, referred to as the Global Warming Potential concept. Results from the LLNL models played an important role in the recent reevaluation of the Montreal Protocol to limit the production and emissions of chlorofluorocarbons.

The continued development and application of chemical-radiative-transport and specialized atmospheric-radiative-transfer models to study global change was also emphasized. Published studies include analyses of solar influences and the effect of trace-gas emissions on recent trends in ozone and temperature. The Primer on Greenhouse Gases has been updated and rewritten and will be published as a book.

\section{CHAMMP Initiative}

\section{CHAMMP DETAILEE ASSIGNMENT}

BADER, DAVID C.

\section{PACIFIC NORTHWEST LABORATORY}

$\begin{array}{lr}\text { FY } 1990 & 65 \\ \text { FY } 1989 & 0 \\ \text { FY } 1988 & 0\end{array}$

$$
\text { 07/01/90-09/30/90 }
$$

Objective: To provide the full-time assignment of an atmospheric scientist familiar with largescale computer modeling for a 1- to 2-year period to help coordinate the early development of the Computer Hardware, Advanced Mathematics, and Model Physics (CHAMMP) research initiative.

Product: A well coordinated CHAMMP Program.

Approach: The coordinator will provide technical input to the Carbon Dioxide Research Program staff, review program plans and proposals and make recommendations regarding their disposal, aid in coordinating project-planning and research activities among CHAMMP investigators, and perform any other duties assigned consistent with the detailee responsibilities and limitations established by DOE. 
TARBON DIOXIDE RESEARCH (CLIMATE MODELING)

\author{
CHEN, TSING-CHANG, \\ GUSTAFSON, JOHN, \\ and
}

TAKLE, EUGENE

\section{AMES LABORATORY}

$\begin{array}{lr}\text { FY } 1990 & 125 \\ \text { FY } 1989 & 0 \\ \text { FY } 1988 & 0\end{array}$

$06 / 01 / 90-09 / 30 / 90$

Objective: To adapt a well-developed global climate model and a fine-resolution mesoscale to execute on a massively parallel machine for regional climate research.

Product: A high-resolution mesoscale regional model driven by the output of a global model in such a way that the regional implications of global climate change are realized.

Approach: Seasonal means for summer and winter will be computed for cyclone frequency, thunderstorm frequency, low-level circulation and low-level jet, water-vapor transport (divergent and rotational component), precipitation, and $500-\mathrm{mb}$ height. These seasonal means will be analyzed with EOF analysis to establish the temporal and spatial relationships over the United States. The length of record varies for the elements from 5 decades to 12 years.

A similar analysis will be performed on mesoscale model calculations. The NCAR GCM will simulate 20 years with fixed sea surface temperatures. A second, limited-area mesoscale model will be run with the daily fields from the NCAR GCM as the initial conditions.

Both models will be adapted to run on massively parallel processing machines. The result will be the restructured code for parallel processing and the demonstration of the technique of using a GCM as a driver for a mesoscale model.

\section{PARALLEL PROCESSING FOR ADVANCED PARALLEL CHEMISTRY (APACHE) CLIMATE MODELS}

\author{
CLINE, RAYMOND E., JR.
}

\section{SANDIA NATIONAL LABORATORIES}

$\begin{array}{cc}\text { FY } 1990 & 400 \\ \text { FY } 1989 & 0 \\ \text { FY } 1988 & 0 \\ & \\ 04 / 01 / 90-09 / 30 / 90\end{array}$

Objective: To develop parallel processing techniques for the next-generation advanced climate model (ACM).

Product: Radiation-transport and atmosphericchemistry submodels of the ACM.

Approach: (1) Flexible software will be developed based upon a distributed-memory, distributed-instruction model. Programs developed for such a model can also be implemented on shared-memory multiprocessors. At least two major coding revisions will occur as programming languages and tools evolve. The near-term development will make use of existing portable systems and language extensions. The long-term development will exploit high-level object-oriented language approaches and descriptive languages that can produce machine-dependent code from a common source.

Our experience with the Linda parallel language extensions suggest that they should be considered as a viable solution for use as a nearterm portable-programming environment. The Linda system has been shown to be effective for programming shared-memory multiprocessors, network-distributed computing, and distributedmemory parallel processors. One of the initial goals of this work will be to compare programs developed with the Linda system with functionally identical code developed with the Oak Ridge PICL system, the Argonne monitors and macros approach, and Strand software systems. 
(2) Parallel implementations of these models would be greatly enhanced if the solution method required locally available information. The solution of chemical equations falls into this category, which may limit the applicability of spectral methods. It may also be necessary to solve different model units, (i.e., oceans, biosphere, etc.) with greatly different discretizations. The coupling of these model units may be accomplished more readily though the use of a tinite-element formulation on the problem.

Experience suggests that the solution of flow fields can be efficiently performed on parallel machines. The treatment of radiation transport as a columnar process, as is done in current chemical models, may prohibit the use of adaptive gridding lechniques for the optimization of the solution of the finite-element equations. The same optimization benefits can be achieved for finite-clement methods by using a fixed grid and adapting the order of the approximating polynomial, referred to as the adaptive p-method. The p-method can be viewed as a localized spectral method. We will investigate the application of the adaptive finite-element p-method, as well as local mesh refinement for both the finite-difference and finite-element methods, to climate modelling.

(3) All of the relevant physical processes of a chemistry-radiation climate model can be represented by a common computational structure by imposing a 3-D mesh on the atmosphere. Chemical processes are then solved internal to each mesh element, while radiation and flow calculations require information exchange between elements. Radiation transport is currently treated as a 1-D problem with information passing down a column of mesh elements. The 3-D mesh imposed on the atmosphere contains a "short dimension," because we expect that fewer mesh points will occur in the altitude dimension than in either the longitude or latitude dimension, permitting the mesh to be mapped onto a 2-D array of computational elements. Because the chemistry and flow fields can be calculated with a 3-D array of processing elements, the choice for the best mapping of this problem onto a parallel platform will depend on the relaiive computational and communications performances of the two possibilit $\times s$.

Understanding these computational structure questions is vital to producing an efficient parallel chemistry climate model and is a major focus of the initial period of this project.

\section{CLIMATE-SYSTEM MODELING ON MASSIVELY PARALLEL COMPUTERS I: GLOBAL OCEAN-CIRCULATION MODEL}

DANNEVIK, WILLIAM P.

\section{LAWRENCE LIVERMORE NATIONAL LABORATORY}

$\begin{array}{lr}\text { FY 1990 } & 150 \\ \text { FY } 1989 & 0 \\ \text { FY 1988 } & 0\end{array}$

$01 / 01 / 90-(09 / 30 / 90$

Objective: To determine the degree to which advanced climate-modeling efforts may benefit from current trends in the field of massively parallel supercomputing.

Product: The transfer of a highly vectorized ocean GCM running on a multiprocessor Cray computer to a massively parallel computer (MPC) and the coupling of it with an atmospheric model.

Approach: An existing global, high-resolution, primitive-equation ocean circulation model will be ported onto the LL.NL MPC; the model of Semtner and Chervin, presently designed for vectorization on longitude and limited parallelization on latitude, has been identified for this purpose.

The sensitivity of alternative data-management strategies and physics-package-algorithm selection in such a model will be evaluated with respect to issues of communications latency tolerance, load balancing, and cache/local/global memory allocation on the MPC. 
Model design elements will be optimized with regard to parallel scaling properties for the case in which the number of available processor elements becomes very large, and the developed strategies will be assessed for transfer to coupled atmosphere-ocean climate-design efforts.

\section{PARALLEL ATMOSPHERIC CLIMATE MODEL}

FOSTER, I. T.

ARGONNE NATIONAL LABORATORY

$\begin{array}{cc}\text { FY 1990 } & 200 \\ \text { FY 1989 } & 0 \\ \text { FY 1988 } & 0\end{array}$

\section{$04 / 01 / 90-09 / 30 / 90$}

Objective: To provide the technological advances in numerical methods and parallel processing required to support the modeling of the atmospheric component of the climate system on advanced-computing architectures (i.e., massively parallel computers).

Product: An advanced climate model with a capability that is significantly greater than that of current models.

Approach: An interdisciplinary team will be established at each of three national research institutions, Argonne National Laboratory, Oak Ridge National Laboratory, and the National Center for Atmospheric Research. Research will be conducted each year in advanced numerical methods, model development, and parallel software tools. New methods, large-scale testbeds, and parallel software tools will be developed in three distinct but closely integrated subprojects.

The first will develop and evaluate both parallel algorithms for existing numerical methods and new methods and algorithms suitable for largescale parallel climate models. Prototype implementations of methods and algorithms applied to the shallow-water equations on the sphere will be used to study accuracy, efficiency, and suitability for massively parallel execution.

The second will investigate an existing climate model (NCAR Community Climate Model, CCM2) with the intention of developing a usable parallel implementation for distributed-memory MIMD computers. Parallel algorithms and promising new methods developed in the first subproject, as well as techniques for including new model physics, will be incorporated into the parallelized CCM2 for further evaluation.

The third will design and develop parallel software techniques and tools to support algorithm development. These tools are intended to sup. port the archiving of expertise developed in the project and the performance evaluation and characterization of large-scale parallel codes.

\section{CRAY COMPITER}

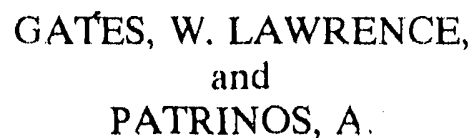

\section{LAWRENCE LIVERMORE NATIONAL} LABORATORY

$\begin{array}{cc}\text { FY } 1990 & 3100 \\ \text { FY } 1989 & 0 \\ \text { FY } 1988 & 0\end{array}$

$$
02 / 01 / 90-(09 / 30 / 90
$$

Objective: To use the eight-processor Cray-2 and its successor Cray-3 to provide enhanced supercomputing to the climate-modeling community.

Product: Accelerated GCM improvement leading to the ability to predict regional climate change.

Approach: The National Energy Research Supercomputer Center (NERSC) at Lawrence Livermore National Laboratory is acquiring an eight-processor Cray-2 computer in March 1990 that will be placed in service on or about April 1,1990 . This computer will initially have 64 or more million words of memory. It will be enhanced in the summer of 1990 to have 128 
million words. At that time it will be the most capable Class VI/VII supercomputer available to the Department or, in fact, to the U.S. Government. It is expected that the Carbon Dioxide Research Program will receive a total additional 3,000 computer resource units, the equivalent of about 3,000 Cray-1 hours, in its base and "Grand Challenge" allocation from this enhancement of resources at NERSC. The supplemental resources to the climate-modeling projects from this project will be 12,000 CRUs.

\section{CHAMMP INITIATIVE ORGANIZATION}

MacCRACKEN, MICHAEL C.

\section{LAWRENCE LIVERMORE NATIONAL LABORATORY}

$\begin{array}{cc}\text { FY } 1990 & 180 \\ \text { FY } 1989 & 0 \\ \text { FY } 1988 & 0\end{array}$

04/01/90-09/30/90

Objective: To organize the CHAMMP initiative to develop a new generation of climate models able to provide convincing estimates of the timedependent regional changes in climate that may result from increasing atmospheric concentrations of carbon dioxide and other greenhouse gases.

Product: (1) A report outlining the intent and implementation plan for the CHAMMP project suitable for review by the scientific community and (2) coordination with other agency initiatives.

Approach: The CHAMMP scientific program will build on a three-part strategy involving use of advanced computer-hardware architectures, development and application of advanced mathematical approaches to representing the physics on massively parallel machines and analyzing and presenting the data, and use of improved representations of physical and chemical processes.
The organization of this initiative must involve a widely based collaborative effort feeding into a focused, mission-oriented objective. This organizational effort will require outreach to and beyond the climate-modeling community and to and beyond the few groups involved in climate modeling. Organizing this effort will require a core scientific-management team that works through contact with and encouragement of other groups, workshops, and prototype studies.

Three phases are envisioned. During the initial phase (about 2 years), the community of researchers will be assembled and involved in prototype studies that will allow both the study of the challenges to be faced and the production of versions of existing models that perform well in the massively parallel environment. During this phase, design criteria for the ACM will be developed.

During the model-development phase (about 4 years), an initial version of the ACM will actually be constructed and tested on machines capable of increasing throughput by $10^{2}$ to $10^{3}$. This task will require the close coordination of the efforts of many groups.

And during the model-implementation phase (about 4 years), the initial version of the ACM will be extended in its physics, it will be transferred to even-faster machines, its performance will be further optimized, and useful model simulations will be conducted.

Throughout, close cooperation among a wide set of participants will be needed. This, in addition to setting project objectives, will be the central task of the CHAMMP management activity. Workshops and communications will be essential. 


\section{LOOSELY COUPLED DISTRIBUTED MODEIING OF CLIMATE CHANGE}

\author{
PEIERLS, R. F., and MICHAEL, P. A. \\ BROOKHAVEN NATIONAL \\ LABORATORY
}

\author{
FY 1990200 \\ FY 19890 \\ FY 19880
}

$04 / 01 / 90-09 / 30 / 90$

Objective: To develop methods of running coupled submodels of advanced climate models simultaneously on separate processors.

Product: Techniques that will allow the power of physically separated computers to be harnessed for a single model computation, which should alleviate some of the serious software problems inherent in building large, complex climate models.

Approach: The approach explores the hypothesis that the modeling of climate systems can be decomposed to treat different processes coupled only loosely in time. Such decomposing means that ihe exchange of information between processes need not be strictly constrained in phase. Such asynchronous coupling allows exploration of alternate computing approaches.

Three computing environments will be explored: shared-memory multiprocessor systems (e.g., IBM3090/x00 and Cray X/MP); heterogeneous computers linked by a local area rietwork; and geographically separate, network-connected supercomputers.

Tests will be performed with two kinds of prototype models. Highly parameterized models of the atmosphere, ocean, sea ice, chemical constituents, ecosystems, etc. will be run in a coupled mode to test constraints resulting from the intrinsic time structures of the various subsystems and from the interaction of n.ultiple subsystems. Detailed, regional atmospheric and oceanbasin models will define data-transfer re- quirements. Final testing will use full-scale atmospheric and oceanic circulation models.

The evaluation will compare traditional climate variables, such as the seasonal and latitudinal dependence of temperature as well as various fluxes, to expose differences in any compensating errors.

MASSIVELY PARALLEL ADAPTIVE ACM

TREASE, HAROLD

LOS ALAMOS NATIONAL LABORATORY

$\begin{array}{lr}\text { FY 1990 } & 360 \\ \text { FY 1989 } & 0 \\ \text { FY 1988 } & 0\end{array}$

$04 / 01 / 90-09 / 30 / 90$

Objective: To improve the current state of the art in global climate modeling through the creative use of massively parallel computing hardware and algorithms along with improvement in the underlying numerical models.

Product: A new basis for the atmosphericdynamics component of the advanced climate mociel (ACM) of the CHAMMP Program.

Approach: Los Alamos National Laboratory's current 3-D code will provide a framework for the new $\mathrm{ACM}$, allowing the rapid development of prototypic new model-physics algorithms within the context of an existing code and freeing us from having to worry about programming details, such as data management, $\mathrm{I} / \mathrm{O}$, and the user interface.

An adaptive-mesh technique called the FreeLagrange Method will be used as the basis for the new GCM. This method gives the freedom to dynamically add (or remove) mesh resolution to capture such flow features as fronts, vortices, and shear layers. The Lagrangian nature of our current implementation will be modified to account for the boundary-layer behavior of the 
atmosphere relative to global circulation patterns.

Currently massive parallel hardware will be used as a platform upon which to build the parallel algorithms.

Each piece of model physics will be implemented such that the algorithms take advantage of the parallel nature of the machine on which they are run.

The development effort will start with the display techniques created for viewing the current 3-D data.

\section{PARALLEL ATMOSPHERIC CLIMATE MODEL}

WARD, ROBERT C.

OAK RIDGE NATIONAL LABORATORY

$\begin{array}{cc}\text { FY 1990 } & 800 \\ \text { FY 1989 } & 0 \\ \text { FY 1988 } & 0\end{array}$

$04 / 01 / 90-09 / 30 / 90$

Objective: To provide a usable parallel implementation of an existing model for use by modelers, to investigate the coupling of the parallel atmospheric model with other components of a climate-simulation system, to produce algorithm libraries and software tools to aid in the development of parallel climate models, and to sponsor workshops for sharing information among the climate-modeling community.

Product: The advances in numerical methods and parallel processing techniques required to support the modeling of the atmospheric component of the climate system on advanced computing architectures (i.e., massively parallel computers).
Approach: Work will begin on parallel implementations of three existing methods in prototypes for MIMD and SIMD machines. Both MIMD and SIMD parallel computers will be examined in this project to maintain generality for the coupling of the atmospheric model with other components of the global climate system. The aim of this work will be to evaluate the suitability of these methods for large-scale parallel execution. The prototypes will apply the spectral method, finite-difference method, and a composite-mesh-finite-difference method to the nonlinear shallow-water equations on the sphere.

A portable parallel version of the NCAR Community Climate Model, CCM2, will be developed. This code will be designed to run on distributed-memory, MIMD computers, such as Intel iPSC/860, BBN Butterfly, and NCube machines. Only the Intel computer will be our initial computational engine. The initial work will be to modify the existing CCM2 to run on medium-grained parallel processors to isolate sequential bottlenecks and other deficiencies in the existing algorithms and to quantify load imbalances caused by model physics.

The development of a portable version of the Cray code will be completed with profiling tools to identify computationally intensive components; a workshop will be held to discuss approaches to parallelization and to devise an initial strategy; then the recommendations of the workshop will be implemented in an incremental fashion with both FORTRAN and higher-level languages. Both versions will use PICL and other software tools for portability and performance evaluation and characterization.

Regular workshops will be held to integrate components developed at different institutions into the parallelized CCM2. Parallel-algorithm development and enhanced physics can be smoothly incorporated within the same incremental framework. 
To be able to address the computational problems associated with advanced model physics, the existing CCM2 will be ex ${ }_{1}$ nded by coupling it with a vegetation model. The computational load of the coupled system will be measured.

The biosphere-atmosphere coupling will use the existing BATS interface to CCM2. The description of the interaction between the atmospheric and terrestrial systems will be restricted to exchange fluxes.

Activity in performance-monitoring tools will focus on improvement to data-reduction and -collection techniques and on improved graphic tools for presenting decompositions and performance data.

- Existing tools will be extended and validated for data reduction and collection on a parallel computer with about 100 nodes.

- Existing graphic tools will be extended for visualizing the decompositions employed in the initial parallel version of CCM2 and the parallel-algorithm prototypes.

A workshop will be held at Argonne National Laboratory on "Parallel Programming: Tools and Concepts for Advanced Climate Models." Two further topics for workshops are numerical methods and model physics.

\section{SCIENTTFIC DEVELOPMENT OF THE ADVANCED PARALLEL CHEMISTRY (APACHE) CLIMATE MODEL}

WUEBBLES, DONALD J.

\section{LAWRENCE LIVERMORE NATIONAL LABORATORY}

$\begin{array}{cc}\text { FY 1990 } & 290 \\ \text { FY 1989 } & 0 \\ \text { FY 1988 } & 0\end{array}$

$04 / 01 / 90-09 / 30 / 90$

Objective: To lead the development of detailed simulation components of the chemical, radiative, and transport processes occurring in the global atmosphere during the development of the advanced climate model (ACM) under the CHAMMP Program.

Product: A highly advanced capability for the investigation of energy and environmental issues.

Approach: The optimal treatment of the chemical and physical processes to be included in the model will be determined to ensure a highquality, but computationally efficient, product. The scientific components of the chemical, radiative, and transport submodels will be designed and developed. And the necessary studies to evaluate and validate the resulting submodels will be performed. 


\section{VEGETATION RESEARCH}

The thrust of this research is to provide information about the effects of $\mathrm{CO}_{2}$ and climate on vegetation. The research strategy is to determine primary effects for representative plant systems and to explore ways of extrapolating the basicprocess information to other plant systems. Other important requirements are to acquire new experimental data and to develop and validate models for vegetation effects from altered $\mathrm{CO}_{2}$ and climate conditions. Once developed and tested, the models would be applied to different types of vegetation (e.g., forests and rangelands) and at larger geographic scales.

Emphasis is placed on changes to plant physiology and to system-level properties, such as productivity, yield, structure and function, and plant-animal-microbe relationships. Effects of $\mathrm{CO}_{2}$ and climate change on plant and systemlevel hydrologic conditions will also be considered.

Primary products will be experimental data and process models of plant response to variable $\mathrm{CO}_{2}$ and climate conditions. As a general requirement, the research products represent plant- and system-level effects of $\mathrm{CO}_{2}$ and climate change.

Research Objectives The first objective is to improve our capability of predicting effects on vegetation from more $\mathrm{CO}_{2}$ and different climate conditions. The second is to search for existing evidence of biological response to the atmospheric- $\mathrm{CO}_{2}$ and climate changes of the past few centuries. Intuitively, the historical $25 \%$ increase in $\mathrm{CO}_{2}$ should $\mathrm{b} c$ registered in changes of plant growth rate. And the third is to determine experimentally the role of plants in fixing atmospheric $\mathrm{CO}_{2}$ as a sink mechanism in the global carbon balance.

Research Questions Examples of questions to be addressed are:

- How much do plant growth, productivity, and carbon content change in relation to increases in $\mathrm{CO}_{2}$ and associated climate changes? At the fundamental system level, what are the interactive effects of simultaneous changes of these and other variables on photosynthesis and transpiration?

- How will functional and structural properties of plants and ecosystems change with different $\mathrm{CO}_{2}$ and climate regimes?

- What historical or paleo records would be useful for detecting changes of plant and ecosystem response to variable $\mathrm{CO}_{2}$ and climate?

\section{Piogram Manager}

Roger C. Dahlman

Carbon Dioxide Research Program

U.S. Department of Energy, ER-76

Washington, DC 20585

(301) 353-4951 


\section{SIMULATION MODELING OF CROP RESPONSE TO $\mathrm{CO}_{2}$ ENRICHMENT}

ACOCK, BASIL

SYSTEMS RESEARCH LABORATORY

$\begin{array}{ll}\text { FY } 1990 & 100 \\ \text { FY 1989 } & 100 \\ \text { FY } 1988 & 100\end{array}$

09/01/90-08/31/91

Objective: To define a "generic" modular structure for models of plant growth and then to develop and test modules needed as components of modular crop models; to perform sensitivity/uncertainty analysis of the soybean crop model GLYCIM; and to make yield predictions of response to $\mathrm{CO}_{2}$ for large areas with a scaledup version of GLYCIM.

Product: A validated, mechanistically based plant growth simulation model that can treat $\mathrm{CO}_{2}$-dependent physiological processes in the framework of the whole plant and the associated environmental factors affecting growth.

Approach: The "generic" approach will incorporate essential $\mathrm{CO}_{2}$ dependent processes and interactions as well as physiology and growth processes that are common to many plant species. Modular concepts will be employed in this phase, and ways will be explored to aggregate plant processes to represent generic functions with analytical approaches described for large-area forecasts.

The 2-D soil model SOILSIM will be used to treat movement of water and solutes in both the unsaturated (rooted) and saturated portions of the soil.

SOILSIM will be incorporated into GLYCIM and will be validated with data sets collected from all over the United States under the sponsorship of the American Soybean Association. The coupled model will be used to make large- area predictions to test the proposed methodology. That methodology involves using the model to predict yields for sites representative of the area as determined by the National Agricultural Statistics Service, weighting and aggregating the yields over the area, and comparing the prediction with reported yields.

Results to Date: SRL scientists represented DOE and USDA on the Intergovernmental Panel on Climate Change and contributed to several workshops and reports on climate change.

During the year, the supercomputer at the Florida State University Computing Center was changed from a Cyber 205, through several models of ETA-10, to a Cray. When the situation stabilized, uncertainty analysis with PRISM resumed, and we found that the soybean crop model GLYCIM is more sensitive to waterholding capacity than to any other soil characteristic in the soil model RHIZOS.

SOILSIM, a 2-D soil-process model was amended to stop solute entering and leaving the soil surface with rain and evaporation. The algorithm to solve the matrix equations was improved to reduce the run time. A new root-growth model was written to better interface SOILSIM with crop models. Data sets for validating SOILSIM were collected.

Soybeans were grown in a greenhouse at a controlled temperature. Seeds were sown every two weeks though the growing season, and the times of floral initiation and anthesis were observed. The results confirmed that the rates of development appear to differ in increasing and decreasing photoperiods. 


\section{ASSESSMENT OF CROP RESPONSE TO INCREASED ATMOSPHERIC CARBON DIOXIDE: RISING $\mathrm{CO}_{2}$ EFFECTS ON RICE}

\author{
ALLEN, L. H. \\ PLANT STRESS AND PROTECTION \\ RESEARCH UNIT
}

$\begin{array}{lr}\text { FY } 1990 & 260 \\ \text { FY } 1989 & 250 \\ \text { FY } 1988 & 250 \\ & \\ 09 / 01 / 90-08 / 31 / 91\end{array}$

Objective: (1) To determine the direct effects of $\mathrm{CO}_{2}$, and the interactive effects of temperature, water management, and nutrition on rice photosynthesis, growth, water use, and yield and (2) to develop and/or adapt process-level crop model(s) for prediction of rice growth and yield responses to elevated $\mathrm{CO}_{2}$ and to environmental and germplasm variables.

Product: Primary information on physiology, growth, and yield of rice in relation to increasing atmospheric $\mathrm{CO}_{2}$; a plant-simulation model for another $\mathrm{C} 3$ grain, winter wheat; and data on how interactions of $\mathrm{CO}_{2}$ enrichment, variable temperature, and nutrient and water stress affect rice growth and productivity in a higher $\mathrm{CO}_{2}$ world with different climate regimes.

Approach: The Plant Stress and Protection Research Unit is conducting a 6-year study on the effects of increased atmospheric carbon dioxide on physiology, growth, and yield of rice at both optimal and stress levels of temperature, water, and nutrients. The initial experiment will derive response functions to $\mathrm{CO}_{2}$ concentration under conditions of nonlimiting water and nutrients and near-optimum temperatures. These results will be used to determine coefficients for specific rate equations to modify and adapt an existing plant simulation model. This experiment is aimed primarily at determining process rates for the PNET module of the simulation model.
Simultaneously, the structure and equations of an existing plant-simulation model will be adjusted according to plant properties of rice. This modification will be an initial test of the concept of adapting existing modules rather than developing new ones to simulate responses of new and different plants to $\mathrm{CO}_{2}$ and climate changes. Subsequent experiments will investigate temperature interactions with $\mathrm{CO}_{2}$ enrichment, interactive effects of $\mathrm{CO}_{2}$ and nitrogen fertilization, and interactive effects of $\mathrm{CO}_{2}$ and water-management practice. An independent model-validation experiment is also planned.

Results to Date: An indica (tropical) type of rice (Oryza sativa, L., cultivar IR-30) was grown under paddy-culture conditions in six sunlit, controlled-environment chambers from July to November 1989. In five of the chambers, $\mathrm{CO}_{2}$ concentration was maintained at $6,00 \mathrm{ppm}$. In these five chambers, temperature treatments of $25 / 18 / 21^{\circ} \mathrm{C}, 28 / 21 / 25^{\circ} \mathrm{C}, 31 / 24 / 28^{\circ} \mathrm{C}, 34 / 27 / 31^{\circ} \mathrm{C}$, and $37 / 30 / 34^{\circ} \mathrm{C}$ (daytime-air, nighttime-air, and constant-paddy-water temperatures) were maintained. In the sixth chamber, a control treatment of $330 \mathrm{ppm} \mathrm{CO}_{2}$ was maintained at $28 / 21 / 25^{\circ} \mathrm{C}$.

In this experiment, $\mathrm{CO}_{2}$ enrichment from 330 to $660 \mathrm{ppm}$ resulted in a $37 \%$ increase in final grain yield at the $28 / 21 / 25^{\circ} \mathrm{C}$ temperature treatment. This yield increase with $\mathrm{CO}_{2}$ enrichment was produced by increases in both the number of panicles per plant and filled grains per panicle. Indeed, the optimum temperature for grain yield was near the $28 / 21 / 25^{\circ} \mathrm{C}$ treatment. With increasing temperature, grain yields declined from 10.4 metric tons per hectare at the $28 / 21 / 25^{\circ} \mathrm{C}$ treatment to only 1.0 metric tons per hectare at the $37 / 30 / 34^{\circ} \mathrm{C}$ treatment. Although the number of panicles per plant increased with increasing temperature, the number of filled grains per panicle declined sharply. Thus, the decreased number of filled grains per panicle was the yield component primarily responsible for the decreased grain yield with increasing temperature.

These results indicate that global increases in $\mathrm{CO}_{2}$ should have an overall beneficial effect on 
rice production. However, this experiment and previous experiments at this location indicate that rice grain yields may be reduced (at least for the cultivar IR-30) by as much as $10 \%$ for each $1^{\circ} \mathrm{C}$ rise in temperature.

Research on $\mathrm{CO}_{2}$ interactions with nitrogen fertilization are under way. The only results available at this time show that transpirational water use is reduced by high levels of $\mathrm{CO}_{2}$ and increased by high levels of nitrogen fertilization.

\section{INTEGRATION OF EXPERIMENTAL AND MODELING APPROACHES TO STUDY COMPETITIVE INTER- ACTIONS AMONG PLANTS UNDER ELEVATED $\mathrm{CO}_{2}$}

\author{
BAZZAZ, F. A. \\ HARVARD UNIVERSITY \\ FY 1990183 \\ FY 1989229 \\ FY 1988213 \\ $11 / 01 / 89-10 / 31 / 90$
}

Objective: To obtain data for predicting effects of $\mathrm{CO}_{2}$ and physical influences (e.g., light and moisture) on plant communities based on knowledge of component species and their growth, productivity response, and resource use.

Product: Data on growth and physiology of individuals and mixtures of species will be produced at several levels of $\mathrm{CO}_{2}$. Responses of individuals and mixtures will be parameterized and data will be used in models describing $\mathrm{CO}_{2}$ effect on plant competition in relation to $\mathrm{CO}_{2}$ and other environmental variables.

Approach: Experiments will be carried out with mixtures of species representing annual communities and native grasslands. Experimental studies will test the hypothesis that $\mathrm{CO}_{2}$ affects competitive outcome primarily through its influence on utilization of other resources. With $\mathrm{CO}_{2}$-controlled growth chambers, the designs will examine relative responses at three $\mathrm{CO}_{2}$ levels; two light intensities; and variable water, nutrient, and temperature conditions. Companion data on physiology will provide insight on causes of differential responses to $\mathrm{CO}_{2}$.

The resulting data will be used in a plant-competition model to simulate $\mathrm{CO}_{2}$ effects on community growth and comfosition change. The initial phase of the rescarch will develop a data base for annuals for which a mechanistic model of interspecific competition will be formulated. Because the model represents general physiological features, it can be tested with other assemblages of species and/or communities (e.g., the general model structure will serve as a basis for application to mixtures of perennial plants subjected to different levels of $\mathrm{CO}_{2}$ and different physical environments).

Specific data for modeling community response to $\mathrm{CO}_{2}$, temperature, and light will also be obtained. Specifically, experiments will characterize the physiological properties of individual leaves throughout the canopy and the life cycle of co-occurring plant species. Growth and resource deployment will be examined as well as $\mathrm{CO}_{2}$ and light conditions associated with photosynthesis.

\section{EFFECTS OF ENRICHED $\mathrm{CO}_{2}$, WATER, AND NUTRIENT STRESS ON SWEET POTATOES: TOWARDS THE DEVELOPMENT OF A UNIVERSAL CROP SIMULATION MODEL}

BISWAS, P. K.

TUSKEGEE INSTITUTE

$\begin{array}{lr}\text { FY } 1990 & 170 \\ \text { FY } 1989 & 150 \\ \text { FY } 1988 & 150 \\ & \\ 09 / 15 / 90-09 / 14 / 91\end{array}$


Objective: To determine how growth, yield, physiology, rhizosphere biochemistry, and soil microbial activity of field-grown sweet potatoes are affected by interaction of water stress with $\mathrm{CO}_{2}$ enrichment; interaction of nutrients (nitrogen, phosphorous, and potassium) with $\mathrm{CO}_{2}$ enrichment; and interaction of potassium only with $\mathrm{CO}_{2}$ enrichment.

Product: New data on the physiology and growth of sweet potatoes and on the interactive efiects of $\mathrm{CO}_{2}$, water, and nutrient stress.

Approach: The field experiments will be carried out with open-topped chambers that have been well calibrated for this type of research. The experimental design will examine physiology and growth differences as a function of different $\mathrm{CO}_{2}$ concentrations. The experiments will produce data on physiological, photosynthetic, and biochemical characteristics of sweet potato in relation to variations in $\mathrm{CO}_{2}$ concentration in combination with different water and nutrient treatments. The growth, morphological, physiological, and rhizosphere biochemistry responses will be examined at the different treatments. The research will focus on an apparent potassium deficiency that is often observed when plants are grown at elevated $\mathrm{CO}_{2}$.

Results to Date: Midday canopy photosynthesis and transpiration data collected in 1989 showed that canopy photosynthesis was $40 \%$ higher in FACE plots than in control plots in June. This difference decreased to about $20 \%$ in July and August, because of a decrease in the size difference between the two canopies. Canopy transpiration did not differ.

In 1989, midday leaf photosynthesis was 20 to $40 \%$ higher in FACE plots than in control plots. Leaf transpiration was slightly lower in FACE plots than in control plots. Thus, the lower water use per leaf area in FACE plots was offset by the larger plant size, leading to no difference in canopy transpiration.
In 1990, the FACE and control plots were split into well-watered and water-stressed half plots. In each half plot we measured: (1) canopy and leaf photosynthesis and transpiration, (2) canopy leaf area, (3) plant water potential, (4) soil respiration, (5) soil microbial activity, and (6) soil nutrient status. This information will be used as validation data for $\mathrm{COTCO} 2$, a cotton growth model that incorporates $\mathrm{CO}_{2}$ effects.

\section{PHOTOSYNTHETIC ACCLIMATION TO ELEVATED CARBON DIOXIDE: BASIS FOR VARIABILITY AMONG PLANTS}

\author{
CURE, JENNIFER D. \\ DUKE UNIVERSITY \\ FY $1990 \quad 146$ \\ FY 1989139 \\ FY 1988161 \\ $09 / 01 / 90-08 / 31 / 91$
}

Objective: (1) To examine the rate or extent of acclimation of photosynthesis $\left(\mathrm{P}_{\mathrm{s}}\right)$ (shift in the A: $\mathrm{C}_{\mathrm{i}}$ curve) upon extended exposure to elevated $\mathrm{CO}_{2}$ and in the presence of internal and external constraints on growth. (2) To describe biochemically the time course of acclimation in terms of changes in RuBisCo activity, activation state, and concentration; coricentrations of RuBP, total protein, and chlorophyll; starch and soluble sugar accumulation and export rates; and SPS activity per unit area. And (3) to survey leaf tissues, significant changes in leaf structure, and changes in cell properties among the various photosynthetic tissues of the leaf.

Product: Experimental data of the effects of $\mathrm{CO}_{2}$ enrichment on causes and variability in $\mathrm{P}_{8}$ acclimation response to $\mathrm{CO}_{2}$; data and insights on the time course of changes in gas-exchange patterns simultaneous with changes in carbon allocation and RuBisCo activity. 
Approach: Experiments will test the hypothesis that, upon exposure to high- $\mathrm{CO}_{2}$ environments, plants of low genetic growth potential will rapidly lose $\mathrm{P}_{8}$ capacity even in optimal growing conditions, whereas plants with high growth potential will maintain $\mathrm{P}_{\mathrm{s}}$ capacity to the extent that growth is not limited by one or more external factors. Limiting external conditions will take the form of low-light and low-temperature treatments. The proportional contribution of leaf morphological adaptations to the overall acclimation process will be evaluated, and the impact of altered mesophyll structure on $\mathrm{P}_{8}$ capacity will also be examined.

Results to Date: In the second year of this project, experiments were carried out in which kudzu plants were introduced to elevated $\mathrm{CO}_{2}$ at several light levels beginning at 27 days. Biomass data indicated "normal" 34 to $43 \%$ increases after 4 weeks at high $\mathrm{CO}_{2}$ in high to low light, respectively, accompanied by 13 to $37 \%$ increases in leaf area. The leaf area ratio (LAR) increased with time for all treatments, but especially for the high-light treatments. LAR for the high-light plants was less than that for the low-light plants. Also, within light treatments, LAR for high- $\mathrm{CO}_{2}$ plants was less than LAR for controls. Other partitioning variables likewise varied predictably with treatment. Stem-weight ratio doubled (at the expense of roots and leaves) for this climbing vine over the experimental period.

Levels of protein per gram of leaf dry weight increased in the high-light treatments, but no $\mathrm{CO}_{2}$ effect occurred within light levels. RuBisCo activity (per gram) showed little or no light response. However, within light treatments there was a strong trend for decreases in both initial and total activity per gram of RuBisCo at high $\mathrm{CO}_{2}$. When adjusted for specific leaf weight, however, these latter differences resulted in no $\mathrm{CO}_{2}$ effects on photosynthesis.

The photosynthesis measurements with the steady state "closed" system were so low that problems of $\mathrm{RuBis} C \mathrm{C}$ deactivation were unavoid- able at very low and very high $\mathrm{CO}_{2}$ levels. A new approach to the problem of acclimation was required. By using an "open" system with a small leaf cuvette and total system volume, precise $\mathrm{CO}_{2}$-exchange data may be rapidly obtained. Stumatal equilibration at each level of light and $\mathrm{CO}_{2}$ can be bypassed, and problems of $\mathrm{RuBis} \mathrm{Co}$ deactivation can be eliminated. Such a system can also provide an estimate of assimilatory charge, or assimilatory power (post-illumination $\mathrm{CO}_{2}$ uptake), which in turn will yield insights into the mechanisms of acclimation. Construction of this system is now nearly complete.

\section{A FIELD STUDY OF THE EFFECTS OF ELEVATED AMBIENT $\mathrm{CO}_{2} \mathrm{ON}$ ECOSYSTEM PROCESSES IN CHESAPEAKE BAY WETLANDS}

\author{
DRAKE, BERT G. \\ SMITHSONIAN INSTITUTION \\ FY 1990209 \\ FY 1989206 \\ FY 1988208 \\ $09 / 20 / 90-09 / 19 / 91$
}

Objective: To determine whether elevated ambient $\mathrm{CO}_{2}$ concentration as well as higher temperatures will increase photosynthesis and net ecosystem production; alter species composition; alter relative partitioning of biomass between above-ground and below-ground structures; change carbon and nitrogen concentrations in plant tissue; alter decomposition rates; and change the water balance in plants and plant communities of a mesohaline salt marsh on Chesapeake Bay.

Product: Mechanistic biophysical information on the response of a wetland plant community when continuously exposed to elevated $\mathrm{CO}_{2}$ and a data base for modeling the effects of $\mathrm{CO}_{2}$ enrichment on ecosystem processes. 
Approach: Three community-types will be investigated over a long term at a salt-marsh research site where elevated $\mathrm{CO}_{2}$ ievel will be controlled by small, replicated open-topped chambers. Several year-long data sets have been obtained, and the experiment will continue to investigate photosynthesis, respiration, net productivity, compositional change, carbon storage, and nutrient cycling of an ecosystem treated to variable $\mathrm{CO}_{2}$ and different temperature and water conditions. A data base will be obtained for modeling effects of $\mathrm{CO}_{2}$ enrichment on ecosystem processes.

Results to Date: Chambers have been placed on the marsh from April until late November to create test atmospheres of present ambient $\mathrm{CO}_{2}$ and twice ambient. This study is now the longestrunning experiment in which plants have been exposed continuously to elevated $\mathrm{CO}_{2}$. Elevated $\mathrm{CO}_{2}$ caused increased growth (mainly of roots and rhizomes), increased photosynthesis in leaves and canopies, reduced respiration of green tissues, and reduced nitrogen content of C3 plants. The most significant finding is that exposure to twice the present $\mathrm{CO}_{2}$ concentration doubled carbon accumulation.

While many of these results confirm greenhouse and controlled-environment studies, several effects were not anticipated. These included sustained high photosynthetic responses of the C3 species for at least 4 years, decreased respiration, and large stimulation of ecosystem carbon assimilation. The most striking feature of the results compiled in this study is the importance of photosynthesis in determining the impact of $\mathrm{CO}_{2}$ on the ecosystem, which suggests that environmental factors that regulate photosyn. thesis may be expected to determine how ecosystems respond to rising atmospheric $\mathrm{CO}_{2}$.

\section{FREE-AIR CARBON DIOXIDE FIELD ENRICHMENT (FACE) FACILITY DEVELOPMENT}

\author{
HENDREY, GEORGE
}

\author{
BROOKHAVEN NATIONAL \\ LABORATORY
}

$\begin{array}{lr}\text { FY } 1990 & 1095 \\ \text { FY } 1989 & 830 \\ \text { FY } 1988 & 808\end{array}$

$10 / 01 / 89-09 / 30 / 90$

Objective: To develop and test a free-air gasdelivery system for enriching a field crop to specified levels of $\mathrm{CO}_{2}$; to characterize physical and biological conditions of the Maricopa, Arizona, field site prior to field experiments with cotton at specified levels of $\mathrm{CO}_{2}$; and to obtain physiology, growth, and yield data for validating a plant simulation model, COTCO2.

Product: An experimental facility for maintaining specified levels of $\mathrm{CO}_{2}$ in the canopy of a cotton crop throughout a growing season and a field data set on plant response to $\mathrm{CO}_{2}$ enrichment.

Approach: Realistic field data on the effects of increasing ambient $\mathrm{CO}_{2}$ concentrations on the flux of carbon between the biosphere and atmosphere will be obtained from a $\mathrm{CO}_{2}$-enrichment experiment in an agricultural field. Concentrations of $\mathrm{CO}_{2}$ will be controlled in a freeair setting by regulating the mass flow of pure $\mathrm{CO}_{2}$ into a 22 -m-diam dispersion system. The $\mathrm{CO}_{2}$ will be prediluted by mixing with ambient air prior to release through 32 independently valved vertical vent pipes (VVP). Opening of the VVPs is controlled by wind direction. The mass of $\mathrm{CO}_{2}$ released is proportional to wind velocity, but is also adjusted by feedback regulation based on 1-sec measurements of $\mathrm{CO}_{2}$ in the center of the array.

FACE $\mathrm{CO}_{2}$ delivery/control systems will be constructed and used in joint research with 
USDA to produce validation data for evaluating $\mathrm{CO}_{2}$ effects with native and agricultural species/ vegetation. The 1990 field experiment will produce biological data on physiology, growth, and plant-environment interactions for ambientand elevated- $\mathrm{CO}_{2}$ treatments and for irrigated and water-stressed conditions.

Results to Date: During this year, full-scale biological experimentation began with four FACE arrays in a cotton field at Maricopa, Arizona. A split-plot design was established to evaluate the interaction of $\mathrm{CO}_{2}$ and water on cotton. The FACE system continues to maintain $\mathrm{CO}_{2}$ concentrations to within $\pm 10 \%$ of the 550 -ppm setpoint more than $90 \%$ of the time, based on 1-min average concentrations. This degree of control applies to an area of 110 to $350 \mathrm{~m}^{2}$ in the center of each FACE plot. Analyses conducted on 1989 operating data show that the FACE system is less expensive to operate per unit of experimental plot than various other chamber-exposure systems. Three-dimensional engineering models of gas dispersion within and downwind of the FACE system made use of an advanced, multiport, selectable-sequencing sampler (MPS2) developed at BNL and installed in the engineering array at Maricopa. Physical processes were also studied with a full-scale FACE segment operated at BNL to obtain data for the models. Model predictions of gas dispersion are verified by independent field data.
ELEVATED $\mathrm{CO}_{2}$ : MODEIING COTTON RESPONSE INTERACTIONS WITH TEMPERATURE ON PHOTOSYNTHESIS, INSECT POPULATION DYNAMICS AND TEMPERATURE INTERACTIONS, AND LONG-TERM EFFECTS ON TREES

KIMBALL, B., and MAUNEY, J.

\section{WATER CONSERVATION LABORATORY and WESTERN COTTON RESEARCH LABORATORY}
FY 1990
140
FY 1989
176
FY 1988
191

\section{$09 / 01 / 90-08 / 31 / 91$}

Objective: (1) To assemble data for use in modifying a plant-growth simulation model that incorporates $\mathrm{CO}_{2}$ and other climate-variable effects into physiological processes affecting plant growth; (2) to determine the effects of elevated $\mathrm{CO}_{2}$ on the growth and physiology of trees (Citrus aurantium, L.); (3) to determine the effects of environmental factors, particularly $\mathrm{CO}_{2}$ and elevated temperature, on "feedback inhibition" of photosynthesis, and on the rates of development and growth of plant organs; (4) to determine the effects of temperature on growth, development time, and survival of beet armyworm and pink bollworm reared on plants grown at elevated $\mathrm{CO}_{2}$ and to determine if these insects are affected by the $\mathrm{CO}_{2}$-altered tissue of plants; and (5) to develop a database of virtually all the available data about the effects of $\mathrm{CO}_{2}$ on important plant processes.

Product: Primary information on the physiology, growth, and yield of plants, trees, and annual species in relation to increasing atmospheric $\mathrm{CO}_{2}$, validation data sets for testing the model COTCO2, and data about the interactive effects of $\mathrm{CO}_{2}$ and temperature on "feedback inhibition" of photosynthesis and about the enhancement of growth at higher temperature. 
Approach: A comprehensive database of the quantitative information available in the literature about the effects of carbon dioxide on several important plant processes or parameters will be assembled. The processes or parameters include yield, biomass, leaf stomatal conductance, leaf transpiration, harvest index, shortand long-term carbon-exchange rates, short- and long-term net assimilation rates, root-to-shoot ratio, and $\mathrm{C} / \mathrm{N}$ ratio. Classification variables, such as species, crop type, photosynthetic type, and carbon dioxide exposure method, will be included as well as experimental condition variables, such as carbon dioxide concentration, light intensity level, temperature, humidity, irrigation level, salinity, nutrient level, and air pollutants. The database will be implemented on a desktop computer with a popular program so that it will be easily transported to other computers.

The open-topped $\mathrm{CO}_{2}$-enrichment chamber technique will be used with ambient and 650-ppm levels of $\mathrm{CO}_{2}$, and plant physiology and growth will be determined for different temperature conditions. An experiment with citrus will examine $\mathrm{CO}_{2}$ effects on leaf area, biomass, yield, foliage temperatures, net photosynthesis, stomatal conductance, photosynthetic response to $\mathrm{CO}_{2}$, leaf carbohydrate content, and stomatal response at variable soil-moisture content.

Insect studies with cotton will be done inside mesh enclosures under field conditions, where $\mathrm{CO}_{2}$ concentration is controlled by open-topped chambers. Beet armyworm larvae will be fed cotton plants that have been grown at elevated carbon dioxide in a greenhouse. The beet armyworms themselves will be in incubators in the laboratory where their survival, development, and growth can be closely observed. The experiment will be conducted at various temperatures so that the interactive effects between carbon dioxide and temperature can also be observed.

Results to Date: Substantial progress was made in developing a new cotton growth model, COTCO2, which should be capable of predicting the effects of the increasing atmospheric $\mathrm{CO}_{2}$ concentration and any associated climate change on cotton growth and water use. The mechanistic model is modular, and it features an hourly (variable) time step, thereby allowing diurnal patterns of photosynthesis, translocation, evapotranspiration, growth, and other physiological processes to be simulated. Complementary fieli validation data fer the model were obtained in the large cooperative free-air $\mathrm{CO}_{2}$ enrichment (FACE) experiment at Maricopa.

With open-topped chambers, a 300-ppm increase in $\mathrm{CO}_{2}$ concentration above ambient was found to substantially increase the growth of orange trecs, amounting to a $94 \%$ increase in the crosssectional area of the trunks at a height of $45 \mathrm{~cm}$ after 2 years of enrichment.

An additional experiment was conducted with screened-top chambers to determine the effect of high- $\mathrm{CO}_{2}$-grown host cotton on the growth and development of pink bollworms. The data from this experiment are being analyzed.

Extraction of data from the literature about the effects of $\mathrm{CO}_{2}$ on plant processes and entering it into a computerized data base has continued.

\section{RANGELAND-PLANT RESPONSE TO ELEVATED $\mathrm{CO}_{2}$}

\author{
KIRKHAM, M. B., and OWENSBY, C.
}

\section{KANSAS STATE UNIVERSITY}

$$
\begin{array}{lc}
\text { FY } 1990 & 371 \\
\text { FY } 1989 & 250 \\
\text { FY } 1988 & 100 \\
06 / 01 / 90-08 / 14 / 91
\end{array}
$$

Objective: To identify the response of plants and grazing animals (sheep) on a native grassland in central Kansas to different soil-moisture conditions and atmospheric $\mathrm{CO}_{2}$ concentrations. Specific objectives are to determine the effect of 
elevated concentrations of $\mathrm{CO}_{2}$ on photosynthetic rate, water use, growth, and carbon balance of the plant component of a grassland ecosystem; the effect of $\mathrm{CO}_{2}$ on diet quality of ruminants; and (3) the interaction of variable $\mathrm{CO}_{2}$ concentrations and nutrient amendments.

Product: Data on the physiology and growth of representative plant species of the grassland, including changes in forage quality.

Approach: The experiments will be carried out with field chambers that have been well calibrated for this type of research. The experimental design will examine physiology and growth differences of native grassland vegetation as a function of different $\mathrm{CO}_{2}$ concentrations.

Sixteen round, plastic, closed-topped chambers (1.52 $\mathrm{m}$ in diameter) will be placed over plots of grassland. Half of the chambers will receive the ambient level of $\mathrm{CO}_{2}$ (about $360 \mathrm{~mL} / \mathrm{L}$ ), and half of the chambers will receive two times the ambient concentration (about $720 \mathrm{~mL} / \mathrm{L}$ ). Measurements of photosynthesis, transpiration, leaf temperature, stomatal resistance, plant-water potential, and plant height will be taken periodically. Carbon balance of the vegetation component will be estimated from net $\mathrm{CO}_{2}$ exchange data for both ambient and elevated levels of $\mathrm{CO}_{2}$.

Six round, plastic, open-topped chambers $(4.5 \mathrm{~m}$ in diameter) will be placed over plots of grassland, and $\mathrm{CO}_{2}$ will be injected. Three chambers will be kept at the ambient level of $\mathrm{CO}_{2}$, and three chambers will be maintained at the ambient level $+350 \mathrm{ppm} \mathrm{CO}_{2}$. Every two weeks throughout the growing season, esophageally fistulated sheep will graze in the chambers to determine how the level of $\mathrm{CO}_{2}$ affects diet quality. Biomass accumulation and species composition will also be determined.

Treatments will be set up to determine effects of $\mathrm{CO}_{2}$ enrichment on plant requirements for nitrogen. Effects on the $\mathrm{C}: \mathrm{N}$ ratio in plant leaves and the implication for forage quality will be determined.

Results to Date: During the 1989 season, soilwater content was greater with the elevated level of $\mathrm{CO}_{2}$ than with the ambient level. Under the high- and low-water treatments, soil-water content was $1.3 \%$ and $1.7 \%$ greater, respectively, in the plots with double the ambient $\mathrm{CO}_{2}$. Under both the high- and low-water treatments, transpiration of big bluestem (Andropogon gerardii, Vitman, the main species at the experimental site) grown with the elevated level of $\mathrm{CO}_{2}$ was less than that of big bluestem grown with the ambient level of $\mathrm{CO}_{2}$. Also, for both watering regimes, stomatal resistance of big bluestem grown with the doubled $\mathrm{CO}_{2}$ was greater than that of big bluestem grown with the ambient $\mathrm{CO}_{2}$. This result was expected, because stomata close when the level of $\mathrm{CO}_{2}$ is raised. Apparently, soil moisture was greater in treatments with increased $\mathrm{CO}_{2}$ because the plants on these plots had a higher stomatal resistance and transpired less water than the plants at ambient $\mathrm{CO}_{2}$. Carbon-dioxide concentration did not affect the rate of photosynthesis of big bluestem.

During the 1989 season, total biomass (determined biweekly) was generally higher in the $\mathrm{CO}_{2}$-enriched chambers than in chambers at the ambient level of $\mathrm{CO}_{2}$ or on outside, unchambered plots. A chamber effect occurred with total biomass accumulation. Chambered plots at the ambient level of $\mathrm{CO}_{2}$ had a greater biomass than unchambered plots. Big bluestem had a greater biomass accumulation in $\mathrm{CO}_{2}$-enriched chambers than in chambers at ambient $\mathrm{CO}_{2}$ or on outside plots. Tip angle of leaves in enriched chambers was lower than that of leaves at the ambient ungrazed plots. Apparently, plants grown under enriched $\mathrm{CO}_{2}$ or with grazing produced a less upright canopy than those grown at the ambient level of $\mathrm{CO}_{2}$ or without grazing. Sheep have adapted well to grazing inside the chambers. Acid detergent fiber, acid detergent indigestible nitrogen, in vitro dry matter digestibility, and nitrogen content of masticated 
samples from the sheep are now being determined.

\section{HERBIVORE RESPONSES TO PLANTS GROWN IN ENRICHED $\mathrm{CO}_{2}$ ATMOSPHERE}

\author{
LINCOLN, DAVID E. \\ UNIVERSITY OF SOUTH CAROLINA
}

\begin{tabular}{|c|c|}
\hline FY $: 990$ & 78 \\
\hline FY 1989 & 51 \\
\hline FY 1988 & 46 \\
\hline
\end{tabular}

Objective: To determine (1) the biochemical basis for the altered nutritional value of leaves resulting from elevated $\mathrm{CO}_{2},(2)$ the demographic and consumptive responses of an herbivore to $\mathrm{CO}_{2}$ regimes, (3) whether plants with the $\mathrm{C}_{4}$ photosynthetic pathway will also have altered relationships with herbivores, (4) if the impact of defoliation is lessened under enriched $\mathrm{CO}_{2}$ conditions, and (5) if specialist feseding herbivores respond to host-plant $\mathrm{CO}_{2}$ enrichment in the same manner as generalist feeders.

Product: Experimental data on insect feeding rates as affected by plant tissue produced at different $\mathrm{CO}_{2}$ levels.

Approach: W/hile plants are exposed continuously to $\mathrm{CO}_{2}$, insects will be allowed to feed on live plant material, and feeding rates will be determined on plants growing at different levels of $\mathrm{CO}_{2}$. Effects of $\mathrm{CO}_{2}$ on plant nutrition and biochemical properties will be determined simultaneously, and feeding rates will be correlated with the changed plant properties. Five experiments will be carried out at the Duke University Phytotron: (1) Mechanisms for the $\mathrm{CO}_{2}$-induced increase in feeding by individual herbivores will be studied with Artemisia plants and Melanoplus grasshoppers. (2) The influence of $\mathrm{CO}_{2}$-induced changes in plants will be measured with growth, development, reproduction, and population size of grasshoppers; grasshoppers will be used in feeding trials with Bromus, an annual grass of western ranges. (3) Herbivore response to $\mathrm{CO}_{2}$ induced changes of plants with $\mathrm{C}_{3}$ and $\mathrm{C}_{4}$ photosynthetic pathways will be tested with Bromus tectorum, a $\mathrm{C}_{3}$ annual, and with Eleusine indico, $\mathrm{a} \mathrm{C}_{4}$ grass. (4) Response of a specialist herbivore (the cabbage butterfly) to $\mathrm{CO}_{2}$-induced changes in its host plant will be tested with two species of mustards, a crop type and a widespread weed; the $\mathrm{CO}_{2}$ effect on glucosinolate, the cueing biochemical for insect attack on the plant, will be examined. (5) The effect of herbivory on defoliation will be examined in different $\mathrm{CO}_{2}$ environments.

\section{ELEVATED CARBON DIOXIDE EFFECTS} ON WOODY-PLANT SOIL SYSTEMS

\author{
NORBY, R. J., LUXMOORE, R. J., and \\ O'NEILL, E. G.
}

OAK RIDGE NATIONAL LABORATORY

$$
\begin{array}{rr}
\text { FY } 1990 & 544 \\
\text { FY } 1989 & 265 \\
\text { FY 1988 } & 256 \\
& \\
10 / 01 / 89-09 / 30 / 90
\end{array}
$$

Objective: To determine whether temperate forest trees increase in growth and carbon storage as the concentration of carbon dioxide in the atmosphere increases, to investigate mechanisms of nutrient cycling in relation to treegrowth change as influenced by atmospheric $\mathrm{CO}_{2}$ concentration, to compare simulated tree-ring chronologies with field data on forest response to $\mathrm{CO}_{2}$ increases, and to develop methods for scaling up soil-plant models in space and time.

Product: Data on effects of $\mathrm{CO}_{2}$ on tree growth under field conditions; a data base on growth and physiological responses; and new methods of tree-ring analysis that will extend the capabilities for detecting historical environmental changes 
on forests and that will provide a definitive framework for assessing studies of $\mathrm{CO}_{2}$ and climate impacts.

Approach: Leaf litter from white oak seedlings will be analyzed for components of litter quality after two growth cycles in elevated $\mathrm{CO}_{2}$. An experiment will be conducted on the effect of $\mathrm{CO}_{2}$ enrichment on the uptake of ${ }^{32} \mathrm{P}$ by mycorrhizal tulip poplar. Techniques of mathematical growth analysis and nutrient analysis of plant tissue will be used to determine the interactive eftects of nutrient supply and $\mathrm{CO}_{2}$ enrichment on tulip poplar seedlings.

Ni.le open-topped field chambers will be added to the existing Controlled Exposure Facility at ORNL. The field chambers will be tested for temperature, light, and $\mathrm{CO}_{2}$ gradients, and the computerized $\mathrm{CO}_{2}$-dispensing systen will be tesiad for maintenance of appr ipriate $\mathrm{CO}_{2}$ concentrations.

White oak and tulip poplar seedlings will be planted in the field chambers. The chambers will be maintained at ambient $\mathrm{CO}_{2}$, ambient +150 pprn, or ambient $+300 \mathrm{ppm}$, with three replicate chambers for each treatment level. The treatments will be maintained during daylight hours for four growing seasons. Aboveground growth, leaf production, and mycorrhizal infection of roots will be characterized. Physiological measurements will include analysis of photosynthetic characteristics, instantaneous and seasonal water-use efficiency, water relations during drought periods, and key metabolites in harvested material.

Leaf litter collected in the fall will be analyzed for lignin, cellulose, carbohydrates, phenolic compounds, and inorganic nutrients. The data will be used in empirical relationships that predict the decomposability of the litter and total nutrient return. Litter and fine-root decomposition will be measured directly with fine-mesh litter bags placed in the chambers after the second growing season. Microbial populations associated with litter will be quantified. Internal
$\mathrm{N}$ cycling will be followed with a budget approach and with the use of ${ }^{15} \mathrm{~N}$. In the second year, ${ }^{15} \mathrm{~N}$-enriched organic matter will be added to the system, and the release of $\mathrm{N}$ to soil solution and appearance in the plant will be monitored.

A forest succession model (FORET) will be reformulated into a backcasting mode to predict (backwards in time) tree-wood-growth increments for two sites with established tree-ring chronologies. Physiological responses to $\mathrm{CO}_{2}$ enrichment will be integrated into annual growth increments with the Unified Transport Model. The potential annual increments will be modified by FORET to predict realized annual increment and will be compared with actual tree-ring chronologies.

Methods for applying models to larger space and time scales will be based on a hierarchical structure and will incorporate efficient stochastic procedures for representing parameter heterogeneity. Model outputs will be defined statistically so that confidence intervals for comparison ietween alternative modeling scenarios can be actermined.

Results to Date: Aboveground biomass (assessed as diameter squared times height) of white oaks in the second field season remained larger in elevated $\mathrm{CO}_{2}$, but the relative growth rates of plants in ambient $\mathrm{CO}_{2}$ have now surpassed those of $\mathrm{CO}_{2}$-enriched plants. Analysis of yellow poplar harvested in 1990 indicated that dry weight of the main stem increased with increasing $\mathrm{CO}_{2}$ but that $\mathrm{CO}_{2}$ had no significant effect on branch biomass stem density, or leaf area. Specific leaf weight increased, and foliar nitrogen concentration decreased with increasing $\mathrm{CO}_{2}$, suggesting a sink limitation and the possibility of a negative feedback. Nevertheless, photosynthesis and transpiration efficiency remain higher in elevated $\mathrm{CO}_{2}$, although the relative enhancement is decreasing with time.

Leaf litter collected from the yellow poplars in fall 1989 were placed in litter bags in a forest. 
The growth $\mathrm{CO}_{2}$ concentrations have had no effect on the early stages of decomposition.

Physiologically based simulations of forest response to 260-, 340-, and 600-ppm $\mathrm{CO}_{2}$ were conducted with the Unified Transport Model, and a $12 \%$ increase in stem-wood production was predicted for each rise in $\mathrm{CO}_{2}$. The initial simulations with a forest-succession model showed that the physiological responses were masked after a few decad is by the heterogeneity of ingrowth and mortality algorithms.

\section{RESPONSE OF TUNDRA ECOSYSTEMS TO ELEVATED ATMOSPHERIC CARBON DIOXIDE}

OECHEL, WALTER C.

SAN DIEGO STATE UNIVERSITY

$\begin{array}{ll}\text { FY 1990 } & 295 \\ \text { FY 1989 } & 244 \\ \text { FY 1988 } & 135\end{array}$

$09 / 15 / 90-09 / 14 / 91$

Objective: To determine current patterns of $\mathrm{CO}_{2}$ flux from tussock and wet coastal tundras along environmental gradients on the north slope of Alaska at sites representing a range of vegetation types and environmental conditions, to evaluate recent patterns of peat accumulation in tussock and wet coastal tundras, and to determine the methane content of permafrost and the current rates of methane release as a function of vegetation and environment.

Product: (1) Definitive statement of what is known and unknown about tundra response to varying $\mathrm{CO}_{2}$ and climate conditions and (2) measurements of $\mathrm{CO}_{2}$ and $\mathrm{CH}_{4}$ exchange across tundra ecosystems.

Approach: The research will evaluate current rates of $\mathrm{CO}_{2}$ and $\mathrm{CH}_{4}$ flux along a latitudinal gradient from the foothills of the Brooks Range to the coast of the Arctic Ocean. Measurements will be made along the transect formed by the Haul Road and at other sites where permafrosttemperature research has been done on the north slope. Peat-profile dating will be performed at the same sites as the $\mathrm{CO}_{2} / \mathrm{CH}_{4}$ flux measurements to compare past and current rates of carbon accumulation or loss.

Field research will be carried out with small popon chambers to measure $\mathrm{CO}_{2}$ and $\mathrm{CH}_{4}$ fluxes with different ecosystems across the North Slope of Alaska. Simultaneously, environmental parameters (air temperature, radiation, relative humidity, soil moisture, and temperature) will be determined during the short-term gas-exchange experiments. In addition, continuous monitoring of the physical environment will be done at the three sites. Ecosystem data (leaf area, aboveground biomass, carbon content of thaw layer, and depth to permafrost) will be determined simultaneously with the flux measurements. Initial interpretations will relate the $\mathrm{CO}_{2}$ and $\mathrm{CH}_{4}$ fluxes to environmental and biotic properties of the systems under observation.

Results to Date: Until very recently, tussock tundra and wet tundra have been assumed to be currently accumulating carbon and, therefore, to be a net sink for atmospheric $\mathrm{CO}_{2}$. Our research over the past few years has shown that tussocktundra vegetation near Toolik Lake, Alaska, is losing carbon to the atmosphere, possibly in response to recent climatic and environmental conditions. Given the very large pools of soil carbon in northern ecosystems ( $390 \mathrm{GT})$, the release of a sizeable portion of the stored soil carbon to the atmosphere would potentially have a significant impact on atmospheric $\mathrm{CO}_{2}$.

Our research this year was designed to determine the net carbon balance of tundra ecosystems along latitudinal and moisture gradients on the north slope of Alaska and to evaluate whether current carbon flux patterns are an early inuication of the effects of climatic or environmel.al change. Preliminary inspection of this year's data, the first year of extensive sam- 
pling, indicates that a large majority of tundra sites examined between the foothills of the Brooks Range and the Arctic Ocean are losing carbon. Rates of loss from tussock tundra may be of the order of 0.1 to $0.3 \mathrm{GT}$ per year. Losses are also occurring in the moist coastal tundra. Only the wettest, coolest locations showed net carbon accumulation in 1990.

If ibere has been a recent change from carbon sequestering to carbon loss, it may have been in response to surface drying following recent temperature increases as reported by Lachenbruch and Marshall (1986) and may further indicate an important potential positive feedback on atmospheric $\mathrm{CO}_{2}$ and climate change.

\section{THE DEVELOPMENT OF A GENERIC ECOSYSTEM MODEL FOR ASSESSING THE EFFECTS OF ELEVATED $\mathrm{CO}_{2} \mathrm{ON}$ ECOSYSTEMS}

\author{
REYNOLDS, J.
}

\section{SAN DIEGO STATE UNIVERSITY}

$\begin{array}{ll}\text { FY 1990 } & 424 \\ \text { FY 1989 } & 350 \\ \text { FY 1988 } & 253\end{array}$

$09 / 01 / 90-08 / 31 / 91$

Objective: (1) To predict primary, secondary, and tertiary effects of elevated $\mathrm{CO}_{2}$ and climate change on individual plants; (2) to develop the capability of simulating plant growth at conditions beyond those used to calibrate the model; (3) to incorporate individual and aggregated plant response into an ecosystem framework to predict primary effects of global change (i.e., different physical conditions); (4) to validate system-level response with various ecosystem field studies of elevated $\mathrm{CO}_{2}$ and different climate conditions; and (5) to use a validated ecosystem model to test hypotheses and make predictions about ecosystem response to global change.

Product: A suite of plant and ecosystem models for analyzing the combined effects of $\mathrm{CO}_{2}$ and changing climate conditions.

Approach: A suite of linked models will be developed, tested, and used to predict plant and ecosystem response to rising $\mathrm{CO}_{2}$, warmer temperature, and more or less moisture or light.

A leaf model will simulate primary effects at the leaf level, including photosynthesis, respiration, stomatal conductance, the processes controlling $\mathrm{CO}_{2}$ diffusion, and biochemical fixation. A supply-demand structure will be formulated, and feedbacks in photosynthesis involving acclimation and carbon and nitrogen allocation patterns will be incorporated. Effects of light, temperature, water stress, and leaf age will also be incorporated into the leaf model.

A canopy model will integrate leaf-ler el processes, characterize the microenvironm at of the plant canopy, and produce calculations of gas exchange and response to variable light and temperature nvironment. The model will simulate daily time-course of plant photosynthesis and transpiration and will describe the aggregate behavior of a population of leaves with known properties The efiects of altered photosynthesis and morphology caused by elevated $\mathrm{CO}_{2}$ will be incorporated.

A whole-plant model will combine canopy and partitioning models into an overall carbon and nitrogen balance for predicting root, stem, leaf, and reproductive growth. The objective is to understand and simulate growth of whole plants in response to $\mathrm{CO}_{2}$, temperature, light, nitrogen, and water as well as other variables. The model will consider resource availability (e.g., photosynthate, nitrogen, and water) and determine potential for growth of organs; this approach also require 3 knowledge of allocation and biomass partitioning. Patterns of resource availability and allocation determine actual growth; by consid- 
ering supply-demand relationships, actual growth will be estimated relative to potential.

Modeling the plant community or population response will be an intermediate step that links the plant to the ecosystem. The community model will examine ways in which species interaction might change as resources (e.g., $\mathrm{CO}_{2}$ ) or other environmental variables (e.g., temperature) are modified. The objective is to develop a mechanistic plant-community model for examining multispecies response to $\mathrm{CO}_{2}$ subsidy and to nitrogen, water, and temperature stress. Properties proposed for modeling studies include interspecific competition, nearest-neighbor effects, and resource abundance.

Modeling ecosystem response requires the integration of results from whole-plant and community models coupled with ecosystem processes, such as nutrient cycling, water dynamics, microbial activity, and herbivory. Objectives are to develop linkages among modules and nierarchical relationships for representing interactions. This phase of the research will devote considerable attention to the scaling problem; that is, how to represent processes at the hectare and larger scale when the bulk of knowledge comes from detailed physiology and small-plot studies.

\section{INTEGRATION OF EXPERIMENTAL AND MODELING APPROACHES IN THE UNMANAGED-ECOSYSTEM RESEARCH PLAN}

$$
\text { STRAIN, BOYD R. }
$$

\section{DUKE UNIVERSITY}

FY $1990 \quad 391$

FY 1989350

FY $1988 \quad 353$

$09 / 15 / 90-09 / 14 / 91$
Objective: To examine the direct physiological effects of $\mathrm{CO}_{2}$ on plants with emphasis on the long-term effects on the physiology, growth, and ecosystem interactions of lobloily pine.

Product: Data on physiology of whole, intact plants and data for modeling and predicting changes of plant physiology and growth as functions of different future $\mathrm{CO}_{2}$ and climate conditions, including new experimental information on physiological and ecological controls of whole-plant and whole-system functions.

Approach: Under field conditions, the research will examine physiological controls on plant response to $\mathrm{CO}_{2}$ with special attention to feedback effects of the plant source-sink carbon balance on $\mathrm{CO}_{2}$-assimilation rate.

A 2-year partial-factorial-design experiment will be conducted with seedlings and saplings to determine if limited nitrogen and phosphorous affects loblolly pine's response to increased $\mathrm{CO}_{2}$. Gas exchange (in terms of the $A$ vs $C_{1}$ curve), whole plant carbon balance, chlorophyll fluorescence, leaf tissues composition (for $\mathrm{CHO}$, proteins, and nutrients), and $\mathrm{RuBisCo}$ activity will be determined as a function of $\mathrm{CO}_{2}$ treatment.

These studies will be continued for an additional 3 years to achieve "long-term" data on plant response to increased concentrations of atmospheric $\mathrm{CO}_{2}$. Measurements will continue with plants that have been "conditioned" by high $\mathrm{CO}_{2}$, which will allow a realistic and in-depth examination of the degree and mechanisms of how plants photosynthetically acclimate to $\mathrm{CO}_{2}$. Moreover, plants will be grown in the ground to avoid stresses from root confinement.

In addition to the field research, existing information about carbon fixation and allocation in plants will be assembled. This information will be used in evaluating ecosystem productivity and stability in relation to $\mathrm{CO}_{2}$ and climate variables, including nutrient availability and cycling, and in 
an assessment of properties of the ecosystem likely to be affected by $\mathrm{CO}_{2}$-altered growth (e.g., plant-animal and plant-microbial interactions and water fluxes). This information will be used in reexamining the Farquhar equation and to formulate generic models (e.g., PRECO and SERECO) of whole-plant and whole-system response to $\mathrm{CO}_{2}$ and climate.

Results to Date: Interactions of root restriction and long-term $\mathrm{CO}_{2}$ enrichment on growth, photosynthesis, carbohydrate partitioning, and activities of enzymes related to sucrose metabolism were studied in cotton (Gossypium hirsutum, L.). Increased biomass caused by $\mathrm{CO}_{2}$ enrichment was more pronounced in the plants grown without root restriction. Night respiration rate $(\mathrm{Rn})$ of leaves of plants grown without root restriction was greater under $\mathrm{CO}_{2}$ enrichment, but growth and maintenance respiration were similar in both $\mathrm{CO}_{2}$ treatments when root growth was restricted. When differences were observed in $\mathrm{Rn}$, they were clearly dependent on plant source-sink balance. A large growth response to $\mathrm{CO}_{2}$ in cotton was always associated with high sink strength and high Rn.

Plants exposed to elevated $\mathrm{CO}_{2}$ for a long period decreased in net photosynthesis (Pn), increased in leaf starch, and decreased in sucrose phosphate synthase (SPS) activity. Plants growing in elevated $\mathrm{CO}_{2}$ treatment with root restriction had additional decreases in $\mathrm{Pn}$ and SPS activity. Sucrose accumulation decreased and was attributed to elevated activity of acid invertase. This research gives further credence to the hypothesis that photosynthetic decline in response to long-term $\mathrm{CO}_{2}$ enrichment is a regulatory feedback process associated with source-sink balance. 


\section{RESOURCE ANALYSIS}

Changes in climate and vegetation caused by increasing atmospheric $\mathrm{CO}_{2}$ may have significant consequences for human health and welfare. Many important resources, such as agriculture, forests, fisheries, hunian populations, and water resources, could be affected by the interactive effects of changing $\mathrm{CO}_{2}$ and climate. Some of these resources will be affected primarily by climate, while for others the direct effect of $\mathrm{CO}_{2}$ may be significant. Additionally, coastal resources may be sensitive to rising sea level and related factors, such as changes in tidal regimes. Effects on resources like these could have important implications for industrial productivity, land use, and energy use.

Research Objectives The objectives of Resource Analysis are (1) to provide integrated quantitative analyses of the effects of $\mathrm{CO}_{2}$-climate change on key resources on a regional basis, (2) to develop useful responses to possible problerss, and (3) to develop mechanisms to take advantage of possible benefits introduced by $\mathrm{CO}_{2}$-climate change. The effects of both $\mathrm{CO}_{2}$ and climate will be considered, and important interresource connections will be accounted for.

Research Questions To fulfill these objectives, the following types of questions must be answered:
- What are the most important resource areas and resource issues for analysis?

- What are the most important interresource connections?

- What are the best definitions of regions to be used in these analyses?

- What analytical approach is best to develop solutions?

- How satisfactory is our understanding of the response of resources both to $\mathrm{CO}_{2}$ climate change and to other important factors, such as technology, government actions, or economic trends?

- What additional analysis methodologies need to be developed?

- How much of the required data base is available, and what additional data need to be developed for the analyses?

\section{Program Manager}

Michael R. Riches

Carbon Dioxide Research Program

U.S. Department of Energy, ER-76

Washington, DC 20585

(301) 353-3264 


\section{CARBON DIOXIDE INFORMATION AND ANALYSIS RESEARCH PROGRAM: RESOURCE ANALYSIS}

\section{CUSHMAN, ROBERT}

\section{OAK RIDGE NATIONAL LABORATORY}

$\begin{array}{ll}\text { FY 1990 } & 281 \\ \text { FY 1989 } & 450 \\ \text { FY } 1988 & 367\end{array}$

$10 / 01 / 89-09 / 30 / 90$

Objective: To plan, monitor, and produce data sets needed for analyses to allow anticipation of the consequences of changing $\mathrm{CO}_{2}$ and climate on natural and societal resources.

Product: (1) Evaluations of the current issues concerning the responses of natural and societal resources to changing $\mathrm{CO}_{2}$ and climate, including responses to climate-induced rising sea level; (2) assembly of data bases useful for analyses of the responses of resources to changing $\mathrm{CO}_{2}$ and climate.

Approach: Current issues concerning the responses of resources to changing $\mathrm{CO}_{2}$ and climate will be analyzed based on critical reviews of the literature. Methods for the analysis of the response of resources to changing $\mathrm{CO}_{2}$ and climate will be investigated, including the definition of regions for use in regional resource analyses and the application of climate-model output in resource analyses. A global coastalhazards data base will be further developed to identify those coastal areas that are especially susceptible to erosion and inundation, based on geology, geomorphology, terrain, tidal range, wave heights, trends in relative sea level, and other variables. Other data bases will be developed as needed for specific resource analyses. Geographic information systems will be applied to the analyses of this subtask, where appropriate.
Results to Date: Agricultural, water resources, and base data for a midwest region, under existing conditions, were mapped with a geographic information system (GIS). The results were published in the Environmental Atlas of the Jowa-Kansas-Missouri-Nebraska Climate-Change Study Region (ORNL/CDIAC-33) as part of a study being conducted in collaboration with Pacific Northwest Laboratory, Resources for the Future, and Sigma Xi. The project evaluates the regional response of the agriculture, water resources, forestry, and energy sectors to a possible climatic change. Results of simulations of the effects of a recurrence of the dry climate of the 1930s on regional agriculture, with and without an increase in atmospheric carbon dioxide concentrations, were displayed with the GIS to show spatial patterns to the response.

In association with the Global Coastal Hazards Data Base project (V. M. Gornitz, LamontDoherty Geological Observatory), data on geology, geomorphology, elevation, tidal range, wave heights, erosion/accretion trends, and relative-sea-level trends were input to and analyzed with the GIS. Areas especially vulnerable to rising sea level were identified for the U.S. East Coast. Additional data on the frequency and intensity of coastal storms were also input to the GIS.

\section{RESOURCE ANALYSIS RESEARCH}

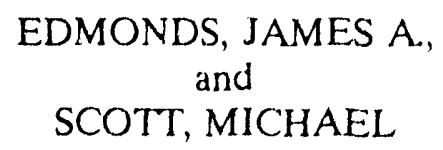

\section{PACIFIC NORTHWEST LABORATORY}

$$
\begin{array}{cc}
\text { FY 1990) } & 846 \\
\text { FY 1989 } & 700 \\
\text { FY 1988 } & 0 \\
10 / 01 / 89-(19 / 30 / 90
\end{array}
$$

Objective: To develop the scientific information base and analytic toois needed to describe the 
nature or kind, timing, magnitude, and uncertainty associated with the consequences of increasing atmospheric $\mathrm{CO}_{2}$ and climate change on human and natural systems, including describing direct and indirect effects (e.g., waterresources interactions with the energy system) at the regional level and how regional-system changes and responses interact within and between regions.

Product: Program Coordination: Coordination of (1) proposals requested, received, and evaluated for the Resources Analysis Research Project (previously called Precursor to a Methodology Project) and (2) the Regional Analysis and Knowledge Transfer areas to ensure that efforts at all program levels are focused on an appropriate region for analysis and on the goals of the overall project and the Resources Analysis Area.

Regional Analysis: Development of a research plan; design and development of a baseline description of the resources and interactions within the region for today's climate and resources; analysis of the impact of a historical analog climate with today's resources and of a future climate scenario with resources that can be expected to prevail early in the 21 st century; and structuring of the model code to be used in the analysis.

Knowledge Transfer: Selection of a region for analysis; identification of the most-important research issues to be addressed by the Resources Analysis Research Project; the transfer of knowledge needed by the project from outside the DOE/CDRP Resources Analysis Research Project to the project and other potential beneficiaries; and securing peer review of the knowledge gained in the project.

Approach: Program Coordination: PNL will coordinate research efforts among Resources Analysis Research Project participants and ensure the integrity, continuity, and focus of efforts at all institutions toward the goals of the project and the Resources Analysis Area. A relatively simple region of study with a geo- graphically coherent climate will be used, centering on the four states of Missouri, lowa, Nebras$\mathrm{ka}$, and Kansas (MINK).

Regional Analysis: A quantitative analysis of the current relationship between the regional resource base and the economic and social viability of the region will be conducted, providing a baseline description of the Region of Study and accounting for external influences, such as world agricultural markets and technological change, that operate on regional natural-resource systems and their relationships to human systems. The methodology used in this analysis will link physical plant-productivity models for both agriculture and forestry, water-resources-delivery models, expert systems describing firm-level economic responses, and input-output models of regional economies. Resources for the Future was instrumental in preparing this product, and input was also provided by ORNL.

Knowledge Transfer: Knowledge transfer will proceed through the conduct and participation in workshops and meetings and the publication of papers and reports. Sigma $\mathrm{Xi}$ is helping prepare this product.

Results to Date: During the 1930s, the analog climate had several effects on the MINK region's key natural resources and economy. The actual weather associated with analog climate was found to be complex. Although our computer crop models have limitations, simulations showed that, if farmers did not react to climate change, the 1930s analog climate with today's technology would reduce average dryland-corn yiclds by approximately $25 \%$ across the MINK region, with comparable impacts on soybeans and sorghum. Winter wheat and irrigated corn yiclds suffered far less damage. $\mathrm{CO}_{2}$ fertilization and simple, low cosst adaptations by farmers, such as shifting planting dates and cultivars, each would gain back about half the yield lost. Analog climate resulted in reduced simulated forest yields and some forest dicback in central and northern Missouri. Only salvage logging was a cost-efiective response in this already marginal 
timber-producing area. Limited ground- and surface-water resources of the region are already being stressed by withdrawals and in-stream needs. Increased irrigation and reduced supply would exacerbate this situation. Regional irrigation energy demand would increase. Regional economic impact depends on the livestock industry. Future technologies and model uncertainty are being investigated, and a regional and international conference are planned.

GLOBAL_CLIMATE AND ACIDDEPOSITION ASSESSMENTS

EDMONDS, JAMES A.

\section{PACIFIC NORTHWEST LABORATORY}

$\begin{array}{lr}\text { FY 1990 } & 50 \\ \text { FY } 1989 & 0 \\ \text { FY } 1988 & 0\end{array}$

$09 / 15 / 90-09 / 30 / 90$

Objective: To support the U.S. Department of Energy (DOE) in its development of a National Energy Strategy (NES).

Product: Research, reports, and presentations to DOE in support of the development of the NES chapter on energy and climate change.

Approach: PNL will conduct research with stateof-the-art energy models, prepare analyses of energy- and economic-cost results, make presentations to DOE, and generally support the development of the NES chapter on energy and climate change.

\section{DEVELOPMENT OF A GLOBAL COASTAL-HAZARD DATA BASE}

GORNITZ, VIVIEN M.

\section{LAMONT-DOHERTY GEGLOGICAL OBSERVATORY}

$\begin{array}{ll}\text { FY 1990 } & 25 \\ \text { FY 1989 } & 50 \\ \text { FY 1988 } & 35\end{array}$

$12 / 01 / 88-09 / 30 / 90$

Objective: To develop a single data base that incorporates all of the information needed to consistently predict on a global basis which coastal segments are at greatest risk from a rise in sea levels.

Product: A global coastal-hazards data base for coastal managers and engineers at national and international levels.

Approach: A coastal data base will be compiled that contains relevant topographic, geologic, geomorphologic, erosional, and subsidence information. These data will be integrated into a geographic information system (GIS), and highrisk shorelines (areas characterized by low coastal relief, an erodible substrate like sand or unconsolidated sediment, present and past eviderice of subsidence, extensive shoreline retreat, and/or high wave or tide energies) will be identified.

Information on seven variables relating to the coastal zone [elevation (relief), bedrock geology, geomorphology (coastal landforms), vertical movements (relative-sea-level changes), horizontal shoreline movements (erosion or accretion), tidal ranges, and wave heights] will be compiled and entered into the ORNL ARC/INFO GIS. The ARC/INFO GIS is an integrated software package that includes a number of associated modules that can relate numerical data with spatial data and can display statistical information in the form of maps. 
Results to Date: Data compilation for the U.S. has been completed for the seven variables, and the effort is currently being extended to Canada and Mexico. Classification schemes for coastal geology and geomorphology have been especially adapted for this project. Statistical summaries of the coastal variables have been prepared. Mean differences in these coastal properties between the east and west coasts of the U.S. can be largely attributed to fundamental differences in plate-tectonic settings. Mean elevations, even at the relatively coarse spatial resolution of $0.25^{\circ}$ latitude-longitude, vary sufficiently to distinguish among geomorphologic/geologic environments.

Data entry into the ARC/INFO GIS has been completed for the U.S. East Coast for all seven variables, and for the U.S. Gulf Coast for several variables. Each variable, consisting of either numerical or nominal data, is assigned a rank from 1 to 5 , based on assessment of the relative risk factor. These risk factors have been combined into an overall coastal-vulnerability index (CVI). Experimentation with various forms of CVI and weighting factors are in progress. For the purposes of demonstration, CVI is taken as the square root of the geometric mean of the risk factors.

Results for the East Coast indicate a region of relatively high vulnerability. For example, $61 \%$ of the land near the shoreline lies at an average elevation of $5 \mathrm{~m}$ or less, about three-quarters of coastal materials consists of unconsolidated sediments, and dominant landforms include estuaries ( $42 \%$ by length), barrier coasts (18\%), and lagoons (15\%), with rocky, embayed coasts $(12 \%)$ concentrated in New England. Furthermore, $89 \%$ of the region is subsiding at rates exceeding $2 \mathrm{~mm} / \mathrm{year}$, or 1.5 to 2 times the global eustatic range of 1 to $2 \mathrm{~mm} /$ year. A quarter of the coast is eroding at rates greater than $1 \mathrm{~m} /$ year, while around two-thirds experiences shoreline displacements within $\pm 1 \mathrm{~m} /$ year.

High risk areas along the East Coast, have been identified along parts of Cape Cod, Long Island and the New Jersey barrier beaches, the North Carolina Outer Banks, the southern Delmarva Peninsula, Georgia-South Carolina, and Cape Canaveral.

Finally, a questionnaire has been mailed internationally to about 412 government marine and coastal management agencies, research institutes, and university departments requesting additional information on coastal conditions in individual countries.

\section{POSTDOCTORAL RESEARCH PROGRAM FOR GLOBAL CHANGE}

\author{
WOHLPART, A. \\ OAK RIDGE ASSOCIATED \\ UNIVERSITIES
}

$\begin{array}{lr}\text { FY 1990 } & 74 \\ \text { FY } 1989 & 0 \\ \text { FY } 1988 & 0\end{array}$

$08 / 01 / 90)-(99 / 30 / 91$

Objective: To increase the involvement of scien" tists and engineers in areas supportive of the government's mission in all aspects of globalchange research.

Product: An expansion of the pool of professionals with experience necessary for future global-change research efforts.

Approach: The program will support recent doctoral-degree recipients to conduct research on projects related to global change. The program will provide a flow of scientists and engineers into DOE and other laboratories to support current and long-range research needs through continued postgraduate education. Appointments of up to 2 years in length will be tenable at labratories having resear in programs supportive of global-change projects. Participants 
will collaborate on a full-time basis with out. standing professionals working on governmentsupported or related projects, have access to onsite resources and facilities, and become familiar with the government global-change research initiative. 


\section{INFORMATION AND INTEGRATION}

Knowledge is of little use if the persons needing it are not aware of it or cannot obtain it. In a program like the CDRP, which must explore scientific issues that are often both comprehensive and complex, the need for effective communication among scientists, policy makers, and the interested public is vital.

Research Objectives The information and integration component of the CDRP provides mechanisms through which scientific information can be obtained, evaluated, and subjected to quality-control procedures; the exchange of data can be promoted and facilitated; and high-quality analyses of complex data can be performed to synthesize information used in eval suren en vironmental issues. Specific objective: ..... de preparing numerous scientific and infort, 'ational reports, sponsoring scientific conferences, and providing scientists access to current scientific material and data on $\mathrm{CO}_{2}$ through the Carbon Dioxide Information Analysis Center.

\section{Program Manager \\ Thomas J. Gross \\ Carbon Dioxide Research Program \\ U.S. Department of Energy, ER-76 \\ Washington, DC 20585 \\ (301) 353-3316}

\section{SUPPORT 'THE NUMERICAL DATA ADVISORY BOARD}

CARTER, G. C.

NATIONAL ACADEMY OF SCIENCES

$\begin{array}{ll}\text { FY } 1990 & 3 \\ \text { FY } 1989 & 0 \\ \text { FY 1988 } & 5\end{array}$

$09 / 28 / 90-09 / 27 / 91$

Objective: To improve the quality, reliability, accessibility, dissemination, informed use, and management of scientific data to meet the present and future needs of the scientific and technical communities.
Product: Enhanced quality and management of numerical data.

Approach: The Numerical Data Advisory Board (NDAB) is a standing board of the National Research Council. It provides a unique national mechanism to bring together experts from the private sector, academia, and national laboratories, chosen by highly selective procedures of the NRC to address scientific and technical-management and data-flow issues. NDAB also provides the nation's formal mechanism to interact with CODATA, the Committee on Data for Science and Technology in the International Council of Scientific Unions. 


\section{CARBON DIOXIDE INFORMATION ANALYSIS CENTER}

\author{
KANCIRUK, PAUL, and CUSHMAN, \\ ROBERT
}

\section{OAK RIDGE NATIONAL LABORATORY}

$$
\begin{array}{cc}
\text { FY } 1990 & 1323 \\
\text { FY } 1989 & 1130 \\
\text { FY } 1988 & 1055 \\
& \\
10 / 01 / 89-09 / 30 / 90
\end{array}
$$

Objective: To acquire or compile, quality assure, document, archive, and distribute $\mathrm{CO}_{2}$-related information in support of DOE's Carbon Dioxide Research Program (CDRP).

Product: A fully integrated information analysis center to support CDRP's research program and to provide $\mathrm{CO}_{2}$-related infurmation to the research and policy-making communities.

Approach: The Carbon Dioxide Information Analysis Center will identify users' needs by working closely with the research community, the Carbon Dioxide Research Program, and policy makers by attending workshops, reviewing the literature, and maintaining personal contacts. Data, models, and other products and services will be evaluated as to usefulness and acquired if available or compiled at CDIAC if not alreaay in a usable form. These products will undergo extensive quality assurance and complete documentation in full coordination with the original supplier of the information. They will then be made available to the research and policymaking communities. CDIAC will work with other data centers and individual researchers to promote the compilation and exchange of data. CDIAC's activities and approaches will evolve with changing research needs and technology, and furure emphasis will be placed on using new technologies of communication (e.g., electronic bulletin boards), new media for archiving and distribution (e.g., CD ROMs), and new data products (e.g., geographic information systems and fully registered and projected cartographic data packages). These new approaches to information management will complement the suite of CDIAC tools.

CDIAC's research activities will reflect any new programmatic directions of CDRP. CDIAC's activities will include information support for the evaluation of complex environmental issues associated with elevated levels of atmospheric $\mathrm{CO}_{2}$, including the technical-management aspects of the national $\mathrm{CO}_{2}$ program.

Results to Date: CDIAC has provided technical support for CDRP and the general research and policy-making communities by serving as CDRP's information-gathering and -distribution center. Autivities included obtaining and evaluating data and technical literature; producing numeric data packages (NDPs) and computer model packages (CMPs); distributing $\mathrm{CO}_{2}$-related reports; and producing the Research Project of the Month and the newsletter "CDIAC" Communications. In aciuition, CDIAC produced TRENDS '90, the first in a series of annual reports that summarizes data related to global change in the areas of climate and of emissions and atmospheric concentrations of trace gases. Five issues of the Research Project of the Month, a special edition of CDLAC Communications (the twelfth in that series) devoted to data and global change, and an updated version of Glossary: Carbon Dioxide and Climate were produced.

Through the third quarter of the FY 1990, CDIAC provided 163 copies of NDPs and CMPs to researchers in 13 countries, bringing the total since FY 1985 to 2778 copies of data sets and models. CDIAC has filled 4814 requests for information through the third quarter of FY 1990 , bringing our total to 18,680 requests from users in 80 countries since FY 1985. 


\section{OCEANS RESEARCH}

The ocean has a large but poorly known capacity to absorb heat from the atmosphere and to sequester it in slowly ventilated subsurface waters. By storing heat, the ocean provides thermal inertia to the climate system, limiting its sensitivity to increased atmospheric levels of greenhouse gases.

Atmospheric $\mathrm{CO}_{2}$ is absorbed by the surface layer of the ocean and fixed into particles and dissolved matter by biological processes. Mixing and advection of dissolved matter (and to a lesser degree sinking particles) remove carbon from the well-mixed surface reservoir for periods ranging from days to millennia and thereby affect the rate of $\mathrm{CO}_{2}$ accumulation in the atmosphere.

The ocean circulation in a warmer climate could be systematically different than the circulation is today. Paleoceanographic evidence indicates that reorganization of ocean circulation has occurred since the last glaciation. However, most observations and models of the ocean continue to focus on the present state to understand how the ocean operates now.

The ocean is an important component of four major feedback processes in the climate system. (1) With atmospheric-water-vapor feedback, a warmer troposphere will contain more moisture, leading to greater radiative forcing than would occur from increased atmospheric $\mathrm{CO}_{2}$ alone. (2) Because of sea-ice-albedo feedback, less sea ice in a warmer climate would reduce reflection of solar radiation and produce warmer surface temperatures in high latitudes. (3) In the case of cloud feedback, a warmer atmosphere may contain more clouds or clouds with different radiative-transfer characteristics than Earth's present cloud cover. (4) In regard to oceanic heat transfer and stcrage, a warmer ocean with reduced thermohaline circulation may absorb a different amount of heat from the climate system than the ocean does at present.

It is generally agreed that the first two feedback processes are positive (i.e., they amplify greenhouse warming). The strength of these feedbacks in a future climate system is not known with much confidence largely because of limited knowledge about (1) how sea surface temperatures will change with increased radiative forcing and (2) the factors controlling the area and volume of annual sea ice. Uncertainty about the last two feedbacks extends even to their signs. Here again, limited understanding of the ocean, specifically cloud forcing in ice-covered regions and the coupling between the surface and deep layers, is largely responsible for the incertitude. These deficiencies and the lack of an acceptable way to predict future oceanic conditions on interdecadal to centennial time scales drive the CDRP to expand its ocean-research program.

Research Objectives The program's objectives are to estimate the future climate change resulting from emissions of carbon dioxide from energy use and to estimate the future emissions of carbon dioxide from energy sources and its concentration in the atmosphere.

To meet its objectives, CDRP will support the acquisition of large sets of ocean data with other agencies through and in global-observation programs. These data are essential for continued improvement and validation of models of the ocean-atmosphere system and the carbon cycle. The programs that may supply these data are the World Ocean Circulation Experiment (WOCE) and the Global Ocean Flux Study (GOFS). The primary data-acquisition effort will be to support the global survey of ocean $\mathrm{CO}_{2}$ in conjunction with the WOCE Hydrographic: Program. 


\section{Program Manager}

Michael Riches

Carbon Dioxide Research Program

U.S. Department of Energy, ER-76

Washington, $\Gamma \mathrm{C} 20585$

(30i) $353-3264$

\section{EFFECTS OF BREAKING WAVES AND WHITECAPS ON $\mathrm{CO}_{2}$ EXCHANGE}

\author{
ASCHER, W. E. \\ BATTELLE MARINE SCIEINCES \\ LABORATORY
}

$$
\begin{array}{cr}
\text { FY 1990 } & 356 \\
\text { FY 1989 } & 150 \\
\text { FY 1988 } & 0
\end{array}
$$

\section{$03 / 01 / 90-09 / 30 / 90$}

Objective: To develop a method for prediction of air/sea gas-transport coefficients from passivo microwave radiometric measurements of oceanic whitecap coverage.

Product: An empirical parameterization of air/water gas-transport coefficients in terms of fractional whitecap coverage and molecular diffusivity developed from laboratory experiments; and a test of the empirical parameteriza. tion with oceanic measurements of whitecap coverage and air/sea gas transport coefficients.

Approach: The main goal is to be able to predict air/sea gas-transport coefficients, $k_{L}$, rom remotely sensed fractional-area whitecap coverage, $\mathrm{W}$. Because it may be possible to determine $\mathrm{W}$ from sitellite measurements of the micrnwave apparent brightness temperature of the sea surface, correlation of $k_{l}$ wil: $W$ may allow prediction of $\mathrm{k}_{\mathrm{L}}$ with the spatial coverage sary for cáliculáting gioval $\mathrm{CO}_{2}$ flures. $\mathrm{As}_{\mathrm{s}}$ an initial step in developing this remote-sensingbased method of determining $k_{L}$, we are investigating the conditions under which the fractional-area bubble-plume coverage, $F_{c}$, of simulated breaking waves may be used as a predictor of $k_{L}$ and the effect of bubble plumes caused by breaking waves on transport rates. A model relat._. $g k_{L}$ to $F_{c}$ will be $t$ 'sted with the Battelle PNL/MSL Whitecap Simuistion Tank (WST). By partitioning $k_{L}$ in terms of transport rate caused by breaking-wave processes, $\mathrm{k}_{\mathrm{w}}$, and a transport rate caus $i$ by non-breaking wave processes, $\mathbf{k}_{\mathbf{v}}$, the model predicts that $k_{L}$ is linearly correlated with $\mathrm{F}_{\mathrm{c}}$. The WST allows reproducible generation of simulated breaking waves with known water volume and breaking frequency with a computer-controlled tipping bucket. Therefore, $k_{L}$ may be easily determined as a function of $F_{c}$. Study of different gases $\mathrm{CO}_{2}, \mathrm{O}_{2}, \mathrm{DMS}, \mathrm{SF}_{6}$, and $\mathrm{He}$ ) with varying aquecus phase solubilities and molecular diffusivities will allow parameterization of the bubble-plume-governed gas-transport process in terms of these variables.

In collaboration with Dr. R. Wanninkhof of Lamon:-Doherty Geological Observatory and Prof. E. Monahan of the University of Connecticut, the laboratory-derived parameterization of $k_{L}$ in terms r.f $F_{c}$ will be tested with : ceanic measurements of $k_{L}$ and $W$. Oceanic gas-flux measurements will be performed with the dualtracer method, and concurrent measurements of W will be made with a viden technique. This field experiment will be performed in the Atlantic Ocean. 
Results to Date: With oxygen as a tracer gas, the initial laboratory results have shown $k_{L}$ to be linearly correlated with $F_{c}$ over the range $F_{c}=$ 0 to $0.21 \%$ for both gas invasion and evasion. Furthermore, the oxygen results show that very small bubble-plume coverages can cause large increases in $k_{L}$ (e.g., $k_{L}$ increased by a factor oi 4 for $F_{c}$ increasing from $C$ to $0.21 \%$ ). This result suggests that it will be possible io relate oceanic $\mathrm{k}_{\mathrm{L}}$ values to fractional-area whitecap coverages $F_{c}$ for the ocean. Interestingly, the oxygen data show no differences between invasion and evasion rates for a given value of $F_{c}$, suggesting that bubble dissolution (caused by the overpressure produced by the Kelvin effect in small bubbles) is not an important mechanism for transport of gases into water.

\section{$\mathrm{CO}_{2}$ MEASUREMENTS ALONG THE SOCE P-16 AND -19 SECTIONS IN THE SOUTH PACIFIC OCEAN: A JOINT LDGO/WHOI PROGRAM}

\author{
BREWER, PETER G. \\ WOODS HOIE OCEANOGRAPHIC \\ INSTITUTION
}

$\begin{array}{lr}\text { FY } 1990 & 150 \\ \text { FY } 1989 & 0 \\ \text { FY } 1988 & 0\end{array}$

$06 / 01 / 90-05 / 31 / 91$

Objective: To contribute accurate data on the carbon chemistry of seawater to a global or anic data base for numeric modeling.

Product: Tabulated carbon-chemistry properties of South Pacific Ocean seawater and an evaluation of the compatibility of total- $\mathrm{CO}_{2}$ and alkalinity measurements made by different methods.

Approach: Three carbon-chemistry properties will be measured in seawater from the South Pacific Occañ along the WOCE P-16 añ P-19
Lines. Measurements of total $\mathrm{CO}_{2}$ and partiai pressure of $\mathrm{CO}_{2}$ from at least one-thire of the 440 sampling stations will yield a profile of carbon chemistry with depth in the Soush Pacific. At least two samples of the surface mixed layer will be analyzed at every station. Total $\mathrm{CO}_{2}$ will be determined with a coulometer aboard ship, and alkalinity analyses will be performed ashore as companion measurements for radiocarbon measurement by accelerator mass-spectrometer at Woods Hole Oceanographic Institution. A number of samples will be analyzed for total $\mathrm{CO}_{2}$ by both the coulometric and manometric methods to resolve disagreement between the methods and to evaluate the compatibility of coulometric and manometric total- $\mathrm{CO}_{2}$ data. $\mathrm{CO}_{2}$ partial pressure will be determined aboard ship with an equilibrator/gas-chromatograph system. Seawater samples will be stored for onshore alkalinity determinations by potentiometric acid titration. If possible, the $\mathrm{CO}_{2}$-chemistry data sets will be produced in a gridded format for numerical modeling. Because virtually no carbon measurements exist for either the surface or deep water of the South Pacific Ocean, the total $\mathrm{CO}_{2}, \mathrm{CO}_{2}$ partial pressure, and alkalinity measurements to be made during this project will fill an important data gap.

\section{DEVELOPMENT OF OCEANIC DEEP- CONVECTION MODELS FOR CLIMATE RESEARCH}

DENBO, D. W., and SKYLLINGSTAD, E. D.

\section{BATTELLE MARINE SCIENCES LABORATORY}

$$
\begin{array}{cc}
\text { FY 1990 } & 262 \\
\text { FY 1989 } & 0 \\
\text { FY 1988 } & 0 \\
& \\
03 / 01 / 20-09 / 30 / 90
\end{array}
$$

Objective: To design and test a numerica! model of open-water deep convection in the ocean and is appily the nuoviè tu the develópmeni of in- 
proved parameterizations in iuture ocean models used for climate studies.

Product: An analysis of convective overturning in the WOCE Community Modeling Effort North Atlantic Ocean circulation model (WOCE/CME), Labrador Sea subdomain, and a working $2-D$ convection model including salinity and thermobaric effects.

Approach: An analysis of the WOCE/CME model simulation for the Labrador Sea subdomain will be completed with a paper discussing the effects of simple convective paras neterizations on large-scale ocean models. The analysis of the CME results will focus on three core areas. First, basin-scale balances of heat, momentum, and salt will be calculated to verify conservation of these quantities. Second, a systematic comparison will be made between (1) general circulation and hydrography in the model subdomain including the Labrador Sea and the adjacent region of the North Atlantic and (2) available observations made since World War II to determine if the model simulates major features. The comparison will also use box models of the Labrador Sea to partition transports among major current systems and to examine water-mass production rates in the CME model. Finally, we will compare the spatial patterns, time variance, and seasonal cycle of layer overturn in the CME model down to $1500 \mathrm{~m}$ with available time-series and synoptic hydrographic observations to determine how well the model performs. By examining the CME results in this broad physical context, we hope to develop a better understanding of dynamic and hydrographic scenarios leading to the transition between stratified and convecting oceanic systems.

Development of a 2-D nonhydrostatic ocean model will begin with code derived from an existing atmospheric-boundary-layer model. This model will be altered to include salinity, an oceanic equation of state, a sub-grid-scale turbulence-closure scheme, and the coriolis effect for initial examination of the convection problem. The grid spacing of this model will be of order $100 \mathrm{~m}$ to resolve eddies with equal horizontal and vertical dimensions. Heat flux at the model top will be prescribed with values similar to those observed in polar regions.

Of main interest in the early phase of model development is an accurately coded computer program. Therefore, testing will emphasize proper quality control to ensure numerical accuracy. Comparisons to actual convective events will then be performed along with conversion to a 3-D model.

Results to Date: The initial work with the WOCE/CME model simulation has shown that simple, modeled overturning is inadequate for representing deep convection. The model produces areas of convection over the entire Labrador Sea area instead of in limited regions as observed. The convection process appears partially linked to unobserved warm-water transport into the Labrador Sea from the southeast.

\section{CERTIFIED REFERENCE MATERIALS FOR CARBON DIOXIDE MEASUREMENTS IN SEAWATER}

$$
\text { DICKSON, ANDREW G. }
$$

\section{SCRIPPS INSTITUTION OF OCEANOGRAPHY}

$$
\begin{array}{lr}
\text { FY 1990 } & 95 \\
\text { FY 1989 } & 0 \\
\text { FY 1988 } & 0 \\
08 / 01 / 90-07 / 31 / 91
\end{array}
$$

Objective: To ensure consistency among $\mathrm{CO}_{2}$ measurements made by several teams, working independently aboard U.S. and international research vessels and to provide continuous intercalibration of instrumentation during the 7-year Global Survey of Carbon Dioxide in the Ocean during the World Circulation Experiment Hydrography Program one-time survey; specifically, to produce, certify, and distribute seawater reference materials (CRMs) to monitor the 
performance of coulomeiers used to measure dissolved inorganic carbon (DIC) in seawater samples.

Product: Certified reference materials and documentation of the methods for their production, certification, and distribution.

Approach: Two batches of low-nutrient seawater collected off the coast of California will be filtered and sterilized and adjusted to low (1800) to $19 \mathrm{Co}$ micromole $/ \mathrm{kg}$ ) and high (2250 to 2400 micromole $/ \mathrm{kg}$ ) DIC concentrations by gaseous $\mathrm{CO}_{2}$ injection. In addition, two batches of aqueous sodium bicarbonate solution with $\mathrm{pH}$ and ionic strength equivalent to 34 to 35 parts per thousand salinity will be prepared and adjusted to low (1800 to 1900 micromole $/ \mathrm{kg}$ ) and high (2250 to 2400 micromole $/ \mathrm{kg}$ ) DIC concentrations. These materials will be analyzed by standard methods to certify salinity, total alkalinity, and DIC, and then they will be preserved in 0.5 - $\mathrm{L}$ glass bottles suitable for long-tern storage.

The bottled CRMs will be distributed to scientists participating in the DOE, JGOFS, and NOAA ocean-carbon-chemistry observation programs. A system will be designed and implemented to monitor the chemical stability and effective use of these materials during the global carbon dioxide survey.

\section{CARBON DIOXIDE OCEAN RESEARCH}

DOWNING, JOHN P.

\section{BATTELLE MARINE SCIENCES LABORATORY}

$\begin{array}{ccc}\text { FY } & 1990 & 287 \\ \text { FY } & 1989 & 180 \\ \text { FY } 1988 & 165 \\ & \\ \text { 10/01/89-09/30/90 }\end{array}$

Objective: To implement Phase ' ${ }^{\text {I }}$ of the Ocean Research Plan completed in August 1989, to begin the global survey of carbon dioxide in the ocean (SRGP 89-7A), and to establish the Science Team for the program.

Product: A framework with which to analyze the data streams resulting from the large multiagency ocean observations to be conducted in the nineties, a working prototype AXCTD with ARGOS-satellite data-telemetry link, and numerous technical reports to assist the ACRD with CES and interagency coordination of ocean research.

Approach: Phase I of the Ocean Research Plan will include process studies, data analysis, and ocean-model development designed to improve existing ocean simulation and prediction capabilities. These activities will be conducted in anticipation of large multiagency ocean observations to be conducted in the nineties, such as the World Ocean Circulation Experiment (WOCE) and the Joint Global Ocean Flux Study (JGOFS). The results will provide a better framework with which to analyze the large data streams expected during the 5 to 10 years of these programs.

Results to Date: Phase-I $r$.jearch initiated or continued this year includes (1) laboratory experiments to determine the effects of whitecaps on the air-sea exchange of $\mathrm{CO}_{2} ;(2)$ development of a model with a simple ecosystem paradigm for interpreting time-series of carbon chemistry, thermal structure, nutrients, and ${ }^{14} \mathrm{C}$ primary production in the ocean mixed layer; (3) large-eddy simulations of surface ocean mixing and convection processes; and (4) a global survey of $\mathrm{CO}_{2}$ in the ocean coordinated with the WOCE Hydrographic Program one-time survey, which is guided by a Science Team coordinated by this project.

In addition to the Phase-I research initiated this year, coordination and technical oversight of the SBIR topic on sensors for ocean measurcments continued with the startup of thi Phase-II SBIR grants. These grants will support the development of advanced, low-power in situ sensors for 
monitoring ocean optical properties and $\mathrm{pH}$ from deep-ocean moored observation systems. This project also formulated a role for DOE in a study to test the feasibility of monitoring secular changes in water temperature at oceanbasin scales. Equipment for this experiment is currently being mobilized for tests at Heard Island in the Indian Ocean.

\section{COULOMETER-INTERCOMPARISON EXPERIMENT}

DOWNING, JOHN P.

\section{BATTELLE MARINE SCIENCES LABORATORY}

$$
\begin{array}{cc}
\text { FY } 1990 & 50 \\
\text { FY } 1989 & 0 \\
\text { FY } 1988 & 0 \\
& \\
10 / 01 / 89-09 / 30 / 89
\end{array}
$$

Objective: To determine the consistency of dissolved inorganic carbon (DIC) analyses made by coulometers operated by the shipboard teams participating in the global survey of carbon dioxide in the ocean.

Product: A report and journal article de scribing the results of the intercomparison experiment.

Approach: The experiment will be conducted in three phases. The first phase will consist of a blind test with $240.5-\mathrm{L}$ bottles of sea-water reference materials. Reference materials (CRMs) will be low-nutrient seawater, collected off the coast of California, which has been filtered, sterilized, and adjusted to low-DIC (1800 to 1900 micromole/kg) and high-DIC ( 2250 to 2400 micromole $/ \mathrm{kg}$ ) concentrations by gaseous $\mathrm{CO}_{2}$ injection. They will be certified as to DIC, titration alkalinity, salinity, and $\mathrm{pH}$ by standard methods prior to distribution to participants, and will be analyzed at the rate of two bottles per day. During the second phase, a dockside test will be conducted wherein par- ticipants perform analyses on seawater samples at a remote location. This test is designed to evaluate the consistency of DIC measurements made under field conditions and will allow the teams to observe and learn from each other. The final phase of the experiment will be similar to the previous one except that the DIC measurements will be made aboard a research vessel. It is envisioned that this phased approach will effectively reveal both instrumentation and operator problems at an early stage of the global survey and provide a vehicle for their early correction.

\section{MIXED-LAYER MODEL}

$$
\text { EMERSON, STEVEN }
$$

\section{UNIVERSITY OF WASHINGTON}

$\begin{array}{lr}\text { FY } 1990 & 67 \\ \text { FY } 1989 & 0 \\ \text { FY } 1988 & 0\end{array}$

$08 / 01 / 90-07 / 31 / 91$

Objective: To understand the utility of chemical tracers for determining biological fluxes in the ocean at Station P and the JGOFS time-series station in the subtropical Pacific Ocean by using an ocean mixed-layer model incorporating chemical tracers and an ecosystern paradigm.

Product: An upper-ocean model for interpreting the time-series of temperature, salinity, nutrients, ${ }^{14} \mathrm{C}$ primary productivity, chlorophyll, dissolved organic and inorganic carbon, and particle fluxes being acquired at the JGOFS station north of Hawaii.

Approach: A mixed-layer model of the PriceWeller-Pinkle type will be used to reproduce the density field observed at Station P in the subarctic North Pacific Ocean. An ecosystem structure, including mechanisms for nutrient cycling, will be added to this model to relate mass fluxes of metabolic constituents to observable biological 
quantities. Gas-exchange rates at the air-water boundary of the model will be verified by reproducing measurements of the inert gases $\mathrm{N}_{2}, \mathrm{Ar}$, and ${ }^{222} \mathrm{Rn}$. With calculated nutrient fluxes and air-water gas-exchange rates from tho model, mixed-layer oxygen and perhaps $\mathrm{CO}_{2}$ wincentrations are a potential measure of tew tylolog. ical production. Once the model perlorms well for Station $\mathrm{P}$, it will be applied to the emerging data from the JGOFS time-series station near Hawaii.

\section{SUPPORT FOR ACTIVITIES OF THE OCEAN STUDIES BOARD}

KATSOUROS, MARY HOPE

NATIONAL ACADEMY OF SCIENCES

FY 199040

FY 19890

FY $1988 \quad 0$

$02 / 01 / 9()-07 / 31 / 91$

Objective: To provide scientific leadership and guidance to the government on important national and international issues in the ocean sciences.

Product: Guidance regarding the scientific progress and plans for investigations of the role of oceanic carbon and related biogenic elements in modifying the Earth's biogeochemical and climatic stability; identification of the major physical, chemical, biological, and geological processes that are important in understanding the role of the ocean in global change; development and ranking of the programs needed to understand these processes; an understanding of the desirability and feasibility of additional global ocean observation experiments during the late nineties; liaison between the U.S. marine research community and the international Committee on Climatic Change and the Ocean (CCCO); a report on the ocean's role in global change; and a small planning meeting to determine the desirability of studing the use of molecularbiology tools for examining global ocean processes.

Approach: The Ocean Studies Board (OSB) serves as the National Research Council focal point for the consideration of ocean issues and will identify, address, and develop studies on appropriate science and policy issues as well as respond to specific requests from federal agencies and private foundations.

The OSB is comprised of 18 regular member and four liaison members. It meets approximately three times a year to review its activities, provide a forum for presentation and discussion of irformation about federal oceanographic R\&D programs, identify issues needing scientific input, and assist in the development of U.S. positions on international ocean-science matters.

The Board is a multidisciplinary body with members from physical oceanography, marine ecology and geophysics, marine biology, marine chemistry, and social sciences. The OSB conducts much of its work through committees, working groups, and panels. Members are drawn from academic institutions, industry, and national laboratories.

OCEANIC $\mathrm{CO}_{2}$ MEASUREMENTS FOR THE WOCE HYDROYRAPHIC SURVEY

IN THE PACIFIC OCEAN, 1990-1991: SHORE-BASED ANAL,YSIS

KEELING, CHARLES D.

SCRIPPS INSTITUTYON OF OCEANOGRAPHY

$$
\begin{array}{lr}
\text { FY 1990 } & 361 \\
\text { FY 1989 } & 0 \\
\text { FY 1988 } & 0
\end{array}
$$

$(06 /(01 / 90)-05 / 31 / 91$ 
Objective: To conduct shore-based measurements of dissolved inorganic carbon (DIC) and titration alkalinity on approximately $10 \%(1400)$ of the seawater samples collected along WOCE/HP Lines P-16 and P-19 in the equatorial and southern Pacific Ocean.

Product: Data tables and plots, as well as data in a machine-readable form.

Approach: Seawater samples will be collected, many in duplicate, and prescrved aboard ship. On shore, the samples will be analyzed by the $\mathrm{CO}_{2}$ Research Group at Scripps Institution of Oceanography. Precise and rigorously calibrated measurements will be made of dissolved inorganic carbon by manometric analyses and of alkalinity by potentiometric titration. The manometric carbon analysis will be compared to results of shipboard coulometric analysis. Where possible, shore-based alkalinity measuremenis will be compared to shipboard measurements of alkalinity at the time of collection. Values of $\mathrm{CO}_{2}$ partial pressure will be calculated with measured DIC and alkalinity as well as salinity, temperature, and nutrient data. The calculated $\mathrm{CO}_{2}$ partial pressures will be compared to direct shipboard measurements of $\mathrm{CO}_{2}$ partial pressure (by equilibration/gas chromatography). The combined shore data and shipboard measurements of carbon chemistry will pro:ide the data base necessary for improving estimates of $\mathrm{CO}_{2}$ cycling in the ocean.

\section{ACOUSTIC GLOBAL WARMING FEASIBILITY EXPERIMENT}

\author{
MUNK, W., SPINDEL, R., \\ and \\ BIRDSALL, $T$.
}

\section{SCRIPPS INSTITUTION OF OCEANOGRAPHY, UNIVERSITY OF WASHINGTON, and \\ UNIVERSITY OF MICHIGAN}

$\begin{array}{lr}\text { FY 1990 } & 250 \\ \text { FY 1989 } & 0 \\ \text { FY 1988 } & 0\end{array}$

$04 / 10 / 90-04 / 15 / 91$

Objective: To test the feasibility of ensonifying a global array of underwater hydrophones with a single acoustic source to demonstrate the potential for directly measuring the rate of warming of the global ocean: more specifically, to test signaling schemes and acoustic-path reliability.

Product: A new characterization of long-range acoustic transmissions in the oceanic sound channel; determination of optimal signaling schemes; and analysis of ray path structure, travel times, and ocean temperature.

Approach: Direct atmospheric measurements of surface warming are difficult because of wide fluctuations in the ambient background air temperature. In contrast to the atmosphere, oceanic temperature fluctuations caused by mesoscale, seasonal, and decadal variations are much reduced, suggesting a robust environment for detecting long-term global temperature trends. The basis of this experiment is the idea that the travel time of acoustic energy between a source and a receiver depends on the sound speed, which in turn is determined primarily by water temperature. 
For this test, acoustic signals will be transmitted for seven days from a location near Heard Island in the south Indian Ocean to receivers off the eastern and western coasts of the United States, each a distance of about $16,000 \mathrm{~km}$, and to receivers in New Zealand, Christmas Island, and possibly Mawson station in Antarctica to determine whether received signal-to-noise levels are sufficiently high to measure arrival times to the required 10 - to $20-\mathrm{ms}$ precision.

This multi-institutional experiment will be conducted by Scripps Institution of Oceanography, the University of Michigan, and the Applied Physics Laboratory of the University of Washington. It is jointly supported by the DOE, ONR, NSF, and NOAA.

\section{OCEAN SURFACE LAYER DYNAMICS}

\author{
RICHMOND, R. C. \\ PACIFIC NORTHWEST LABORATORY \\ and BATTELLE MARINE SCIENCES \\ LABORATORY
}

$\begin{array}{cc}\text { FY 1990 } & 100 \\ \text { FY 1989 } & 0 \\ \text { FY 1988 } & 0\end{array}$

03/01/90-09/30/90

Objective: To determine, by numerical experiments on surface-layer dynamics, if a more detailed treatment of surface-layer processes will substantively change climate and atmospheric $\mathrm{CO}_{2}$ projections of simple mixed-layer models.

Product: A numerical model of the turbulent dynainics of the surface mixed layer that will integrate existing field measurements and provide insight into the role of quantities that cannot be directly measured.

Approach: The primary goal is to design and construct a numerical model capable of simulating the 3-D turbulent dynamics of the ocean surface layer. Many questions remain unresolved because of the lack of direct measurements of key quantities (e.g. buoyancy and turbulent fluxes) and because of the inherent difficulties in separating the contributions of waves, current shear, and tubulence. A numerical approach is required because of the difficulties in sampling the upper 5 to $10 \mathrm{~m}$ of the ocean. Large-eddysimulation (LES) techniques will be used to avoid the uncertainties introduced by typical turbulence-closure models. The advantage of using an LES model is that most of the turbulent energy is carried by the resolved largescale motions that are directly computed rather than modeled. The motion of the free surface will be directly computed with the marker-andcell (MAC) method. The numerics will be tested with data from laboratory experiments and openocean measurements.

The model will provide the means to siudy the complex, nonlinear interactions of organized Langmuir circulations, surface waves, and upperocean turbulence. Increased understanding of the detailed physics of these processes in the ocean mixed layer will lead to the improvement of mixed-layer models that are incorporated into ocean general circulation models.

\section{MEASUREMENTS OF $\mathrm{CO}_{2}$ IN SEAWATER DURING THE F/S METEOR (WOCE/HP LINES A21/51) EXPEDITION IN THE SOUTH ATLANTIC}

TAKAHASHI, TARO

\section{LAMONT-DOHERTY GEOLOGICAL OBSERVA:ORY}

$$
\begin{array}{lr}
\text { FY 1990 } & 207 \\
\text { FY 1989 } & 0 \\
\text { FY 1988 } & 0
\end{array}
$$$$
01 / 24 / 90-01 / 23 / 91
$$

Objective: To contribute accurate data on the carbon chemistry of seawater to a global oceanic data base for numerical modeling. 
Product: A data set of carbon-chemistry properties of South Atlantic Ocean seawater along WOCE/HP Lines A21/S1 incorporated in the expedition hydrographic report; these data will characterize the circumpolar waters flowing through the topographic constraint of the Drake Passage and improve understanding of the vertilation processes occurring in the South Atlantic Ocean.

Approach: Measurements of total $\mathrm{CO}_{2}$ and partial pressure of $\mathrm{CO}_{2}$ in water samples from 40 of the 72 hydrographic stations will be made to full depth, and partial profiles to 1000 meters will be made at the remaining stations. Total $\mathrm{CO}_{2}$ will be determined to an imprecision of $\pm 0.01 \%$ with a coulometer that is calibrated several times a day with pure gas standards and once a week with glass-encapsulated gas standards prepared by C. D. Keeling of SIO. $\mathrm{CO}_{2}$ partial pressure will be measured with an $\mathrm{e}$ quilibrator/gas-chromatograph system with an imprecision of $\pm 0.1 \%$. The system will be calibrated hourly with WMO standard reference gas mixtures. If possible, the $\mathrm{CO}_{2}$ chemistry data sets will be produced in a gridded format for numerical modeling.

Results to Date: The total carbon dioxide concentration dissolved in seawater and the partial pressures of $\mathrm{CO}_{2}$ in seawater and atmosphere have been measured during the 1990 Expedition of German Resedrch Vessel F/S Meteor (Leg 11/5), January 24 through March 8, 1990, in the southern South Atlantic Ocean and the northern Weddell Sea. Nineteen stations located across the Drake Passage between the South American and Antaictic continents constitute the WOCE section A21. During the expedition, approximately 1450 and 850 water samples were measured, respectively, for the total carbon dioxide concentration and the carbon dioxide partial pressure. These data have been merged with other associated data obtained during the expedition (temperature, salinity, and concentrations of dissolved oxygen and nutrient salts) and are being interpreted.

\section{$\mathrm{CO}_{2}$ MEASUREMENTS ALONG THE WOCE P-16 AND -19 SECTIONS IN THE SOUTH PACIFIC OCEAN: A JOINT LDGO/WHOI PROGRAM}

\author{
TAKAHASHI, TARO \\ LAMONT-DOHERTY GEOLOGICAL \\ OBSERVATORY
}

$\begin{array}{lr}\text { FY 1990 } & 70 \\ \text { FY 1989 } & 0 \\ \text { FY } 1988 & 0\end{array}$

06/01/90-05/31/91

Objective: To contribute accurate data on the carbon chemistry of seawater to a global oceanic data base for numerical modeling.

Product: Tabulated carbon-chemistry properties of South Pacific Ocean seawater and an evaluation of the compatibility of total $\mathrm{CO}_{2}$ and alkalinity measurements made by different methods.

Approach: Three carbon-chemistry properties will be measured in sefwater from the South Pacific Ocean during the WOCE P-16 and P-19 expeditions. Measurements of total $\mathrm{CO}_{2}$ and partial pressure of $\mathrm{CO}_{2}$ from at least one-third of the 440 WOCE sampling stations will yield a profile of carbon chemistry with depth in the South Pacific. At least two samples of the surface mixed layer will be analyzed at every station. Total $\mathrm{CO}_{2}$ will be determined with a coulometer aboard ship, and alkalinity analyses will be performed ashore as companion measurements for radiocarbon measurement by accelerator/mass-spectrometer at Woods Hole Oceanographic Institution. A number of ;amples will be analyzed for total $\mathrm{CO}_{2}$ by both the coulometric and manometric methods under a separate grant to resolve disagreement between the methods and to evaluate the compatibility of coulometric and manometric total- $\mathrm{CO}_{2}$ data. $\mathrm{CO}_{2}$ partial pressure will be determined aboard ship with an equilibrator/gas-chromatographsystem. Seawater 
samples will be stored for onshore alkalinity determinations by potentiometric acid titration. If possible, the $\mathrm{CO}_{2}$ chemistry data sets will be produced in a gridded format for numerical modeling. Because virtually no carbon measurements exist for either the surface or deep water of the South Pacific Ocean, the total $\mathrm{CO}_{2}, \mathrm{CO}_{2}$ partial pressure, and alkalinity measurements to be made during this project will fill an important data gap.

\section{INORGANIC CARBON MEASUREMENTS FOR THE WORLD OCEAN CIRCULATION EXPERIMENT: HYDROGRAPHIC PROGRAM}

WALLACE, D. W. R., and JOHNSON, K.

\author{
BROOKHAVEN NATIONAL \\ LABORATORY
}

$\begin{array}{lr}\text { FY 1990 } & 312 \\ \text { FY 1989 } & 0 \\ \text { FY 1988 } & 0\end{array}$

$04 / 01 / 90-(09 / 30 / 90$

Objective: To collect comprehensive, intercomparable, high-quality $\mathrm{CO}_{2}$ data on samples collected during the World Ocean Circulation Experiment Hydrographic Program(WOCE/WP) one-time survey in the Atlantic Ocean. These data are required for estimating carbe fluxes in the ocean and for understanding the lationship between $\mathrm{CO}_{2}$ and climate.

Product: Inorganic carbon and basic biomass data sets in sufficient density to allow calculation of carbon fluxes and storage by water-masstransport and ocean-circulation models.

Approar 1: Shipboard analysts on WOCE/WP cruises will analyze almost all water samples for dissolved inorganic carbon (DIC), $\mathrm{pH}$, and partial pressure of $\mathrm{CO}_{2}\left(\mathrm{pCO}_{2}\right)$. DIC will be measured by automated coulometric titration, $\mathrm{pCO}_{2}$ by headspace catalytic gas chromatography with flame-ionization detection, and $\mathrm{pH}$ by a specially designed $\mathrm{pH}$ cell interfaced to the coulometric system. These instruments are stateof-the-art methods that have been selected to yield the highest possible precision, accuracy, and processing efficiency for the greatest number of samples at sea. In addition to inorganic $\mathrm{CO}_{2}$ measurements, the basic biomass parameters chlorophyll $a$, particulate organic carbon and nitrogen, and depth of the euphotic zone will be measured during selected cruises. These field measurements will allow carbon cycling to be related to remotely sensed variables, such as chlorophyll.

\section{MEASUREMENTS OF SURFACE OCEAN CARBON DIOXIDE PARTTAL PRESSURE DURING WOCE}

\author{
WEISS, R. F. \\ SCR.IPPS INSTITUTION OF \\ OCEANOGRAPHY
}

$\begin{array}{lr}\text { FY 1990 } & 75 \\ \text { FY 1989 } & 0 \\ \text { FY 1988 } & 0\end{array}$

$06 / 01 / 90-05 / 31 / 91$

Objective: To assess the spatial and temporal roles of the oceans in the global carbon cycle with emphasis on the potential for the ocean to absorb fossil-fuel $\mathrm{CO}_{2}$.

Product: Data tables and plots, as well as data in digital form.

Approach: Shipboard measurements of $\mathrm{pCO}_{2}$ and $\mathrm{pN}_{2} \mathrm{O}$ in surface water and the atmosphere will be made along approximately three WOCE/HP lines per year. The measurements will be made by an automated high-precision 
gas-chromatographic system. The system measures $\mathrm{CO}_{2}$ by flame ionization after quantitative reaction to methane in a stream of hydrogen with a reduced nickel catalyst preceded by a palladium catalyst. Nitrous oxide is measured by a separate electron-capture detector. The system has the capability to measure $\mathrm{CO}_{2}$ and $\mathrm{N}_{2} \mathrm{O}$ in the ocean and atmosphere about twice per hour. 


\section{QUANTITATIVE LINKS}

The sense of science is that greenhouse gases can theoretically cause warming, but the state of science is one of incomplete model prediction and inconsistent observations. Scientists and politicians alike seek verification that the climate is indeed being changed and that the cause is an increase of greenhouse gases. But convincing evidence is evasive, and the lack of certitude about cause, magnitude, and timing of climate change is scientifically unsatisfying.

An urgent need exists for unequivocal detection of climate change, including greenhouse warming. Unambiguous data and scientifically valid approaches do not now exist. The Quantitative Links program secks to resolve this problem.

Research Objectives The objective of the Quantitative Links program is to establish (1) the relationships between long-term changes in global climate and changes in atmospheric composition, changes in radiative fluxes, and/or changes in local temperature and (2) the processes controlling those changes and relationships. A broad range of research on the linkages between changes in atmospheric composition and global change is to be conducted. Measurements (both field and laboratory) to quantify the relationships are the primary focus.

Improved ability to project future climate will best be achieved by the acquisition, assembly, and analysis of climate data; by the further development, analysis, and verification of climate models; and by observational studies of climatic processes. This is a central goal of the Quantitative Links program.

\section{Atmospheric-Radiation Measurement (ARM) Program}

ARM is a major component of the Quantitative Links program and is a key component of the
Department s research strategy to address global climate change. The program is a direct continuation of DOE's decade-long effort to improve GCMs and to provide reliable simulations of regional and long-term climate change in response to increasing greenhouse gases.

The ARM program is a highly focused observational and analytical research effort that will compare observations made in the field with model calculations in the interest of accelerating improvements in both observational methodology and GCMs. During the ARM program, DOE will continue to collaborate extensively with existing global-change programs at other agencies.

Research Objectives The objectives are (1) to quantitatively describe the radiation balance of the atmosphere from bottom to top and to determine the atmospheric characteristics responsible for this balance, (2) to improve the parameterization of the formation and evolution of clouds in climate models, and (3) to create an experimental testbed for testing process models used in GCMs and for the support of satellite ground-truth measurements.

Research Questions The research involves a network of ground-based remote-sensing instruments along with campaign studies with aircraft and tethered platforms. Measurements include vertical profiles of temperature, water vapor, trace gases, and aerosols, as well as solar and infrared radiation. The ARM data will provide the testbed for the process models representing the cloud-climate feedbacks in the present GCMs as well as in the future climatechange-prediction models of regional-scale resolution. ARM focuses on quantitative links between greenhouse gases and climate change and examines climate feedbaci's and energy fluxes in the coupled land-atmosphere-ocean system. In addition, the research examines atmo- 
spheric cycling and transformation of radiatively and chemically important trace species.
Program Managers

Ari Patrinos and Michael Riches

Carbon Dioxide Research Program

U.S. Department of Energy, ER-76

Washington, DC 20585

(301) 353-32ळ1

\section{MONITORING THE RESPONSE OF THE UPPER TROPOSPHERE/LOWER STRAT- OSPHERE TO A GREENHOUSE-GAS SCENARIO}

COX, STEPHEN $K$.

COLORADO STATE UNIVERSITY

\author{
FY 1990149 \\ FY $1989 \quad 0$ \\ FY $1988 \quad 0$
}

$05 / 01 / 90-04 / 30 / 91$

Objective: To develop a system capable of simultaneously monitoring the increased $\mathrm{CO}_{2}$ concentrations and signals of global warming with radiometric methods.

Product: The observations necessary for advanccing climate models and thus assist in linking the processes leading from increased greenhouse gases to global climate change.

Approach: The research will attempt to monitor three main components of a climate-change scenario. The method, which pays particular attention to the role of changing amounts of $\mathrm{CO}_{2}$, is based on field measurements of the downwelling radiation field and uses a moderateresolution interferometer. By examination of the relative changes in the zenith viewed atmospheric radiance over time and the ratios of the radiance at two observation angles, information on the concertration of $\mathrm{CO}_{2}$ and the resulting changes in $\mathrm{CO}_{2}$-emission temperatures may be extracted. A more detailed analysis of the data would provide an estimate of variation in $\mathrm{H}_{2} \mathrm{O}$ emission and cirrus cloud cover as well. By monitoring these three climatic modulators, the ability to establish the linkages of increasing $\mathrm{CO}_{2}$ concentration to climate change will be substantially enhanced.

\section{DATA-BASE SUPPORT TO ASSIST IN QUANTIFYING THE LINK BETWEEN CHANGES IN ATMOSPHERIC COMPOSITION AND CLIMATE CHANGE}

CUSHMAN, R. M., and KANCIRUK, P. OAK RIDGE NATIONAL LABORATORY

$\begin{array}{lr}\text { FY 1990 } & 442 \\ \text { FY 1989 } & 0 \\ \text { FY } 1988 & 0\end{array}$

$$
03 / 01 / 90-09 / 30 / 90
$$

Objective: To provide quality-assured data sets needed for the dutection of long-term climate trends that may be related to changes in atmospheric composition.

Product: A numeric data package based on a quality-assured long-term climate data set (including monthly-surface-air-temperature, precipitation, and atmospheric-pressure values) that is global in spatial extent; n! meric data packaces based on climate-related Jata sets that were acquired from the Soviet Union, quality-assured, and documented; and a priority list from climate 
researchers of the most important extant climate-related data sets needed for quantifying the link between radiative balance and atmospheric temperature.

Approach: Data from the World Weather Records and Monthly Climate Data for the World will be supplemented with additional data sets to increase spatial coverage; quality-assured; corrected where possible to remove erroneous data or to adjust for inhomogeneities, such as station moves; documented; and packaged for distribution as a numeric data package.

Under the auspices of existing United StatesU.S.S.R. bilateral agreements, existing climaterelated data sets residing in the Soviet Union will be identified. The most important to the quantification of the link between radiative balance and atmospheric temperature will be acquired. These data sets will be quality-assured (e.g., to remove erroneous data), documented, and packaged for distribution as a numeric data package.

Climate researchers around the world will be surveyed to identify the most important extant climate-rclated data sets for quantifying the link between radiative balance and atmospheric temperature. A workshop will be held to rank the identified data sets from the standpoint of programmatic needs and schedules.

\section{OBSERVATIONAL ANALYSIS OF CLIMATE FEEDBACKS AND TRENDS}

DEL GENIO, ANTHONY D.
Objective: To reduce the current uncertainty in global-climate sensitivity through analysis of observations of currently unconstrained feedback processes and to define useful climate parameters and regions for detecting greenhouse-gasinduced climate changes during the nineties.

Product: Techniques to constrain climate models, reủucing uncertainty in linking increasing trace gases to climate change.

Approach: The research will analyze global observations of several climate parameters that are central to the detection and understanding of long-term climate change caused by increasing concentrations of greenhouse gases. This study will focus on three important but poorly understood parameters: clouds, water vapor, and ozone. The ISCCP and SAGE I and II data sets will be the primary sources of information on these variables, supplemented by available data from SMMR. First, these data sets will be searched for evidence of correlated variations on seasonal or interannual time scales that reveal the sense of climate feedbacks, especially those produced by changes in moist convection strength or depth. By the third year of the project, each of the data sets will span almost a decade. It may then be feasible to begin to seek long-term trends and correlated patterns of change in the data as evidence of an increasing greenhouse effect. Because clouds, water vapor, and ozone all have the potential to affect uppertroposphere or lower-stratosphere temperatures, the research will assess whether any changes observed are consistent with radiosonde ev. idence of long-term trends in the vertical thermal structure of the atmosphere.

\section{GODDARD INSTITUTE FOR SPACE STUDIES}

$\begin{array}{lr}\text { FY 1990 } & 133 \\ \text { FY 1989 } & 0 \\ \text { FY 1988 } & 0\end{array}$

$05 / 01 / 90-04 / 30 / 91$ 


\section{ICRCCM PHASE II: VERIFICATION AND CALIBRATION OF RADIATION CODES IN CLIMATE MODELS}

ELLINGSON, ROBERT G.

UNIVERSITY OF MARYLAND

$\begin{array}{cr}\text { FY 1990 } & 373 \\ \text { FY 1989 } & 0 \\ \text { FY 1988 } & 0\end{array}$

$05 / 01 / 90-04 / 30 / 91$

Objective: To carry out a comprehensive program of measurement and analysis to establish an absolute standard against which to compare models.

Product: More-accurate radiation models for use in parameterizing climate models.

Approach: The ICRCCM found large differences, 30 to $70 \mathrm{Wm}^{-2}$, among fluxes predicted by sophisticated radiation models for identical atmospheres. The differences are partly caused by the lack of an accepted theory for spectralline shape and continuum absorption. But it is impossible to sort out these and other intern.. del differences because of the lack of a set of accurate atmospheric spectral-radiation data measured simultaneously with the important radiative properties of the atmosphere.

This research will carry out a comprehensive program of measurement and analysis called SPECTRE (Spectral Radiance Experiment). SPECTRE will establish an absolute standard against which to compare models and will aim to remove the "hidden variables" (unknown humidities, aerosols, etc.) that radiation modelers have invoked to excuse disagreements with observation. This removal should lead to moreaccurate radiation models for use in parameterizing climate models, which in turn play a key role in the prediction of $\mathrm{CO}_{2}$ /trace-gas greenhouse effects.
Many instruments, such as lidars, will be available at no extra cost to SPECTRE because SPECTRE is designed as a subprogram of the FIRE Cirrus II project, tentatively scheduled for November to December 1991. Small changes in cirrus are capable of exerting large positive or negative feedbacks on trace-gas greenhouse climate changes. By coordinating with FIRE, SPECTRE has a unique opportunity to contribute to the understanding and modeling not only of trace-gas greenhouse effects but also of the cirrus greenhouse effect.

The major unfinished ICRCCM goal is evaluation of the ability of radiation codes used in climate models to simulate the real atmosphere. The present work will contribute to this goal by conducting another round of model intercomparisons; however, this time the models will be intercompared with observations taken during SPECTRE as well as with each other.

\section{TEMPORARY ASSIGNMENT TO THE COMMITTEE ON EARTH SCIENCES, WASHINGTON, D.C.}

ELWOOD, J. W.

OAK RIDGE NATIONAL LABORATORY

$$
\begin{array}{lr}
\text { FY 1990 } & 120 \\
\text { FY 1989 } & 0 \\
\text { FY 1988 } & 0
\end{array}
$$

$01 / 01 / 90-09 / 30 / 90$

Objective: To provide staff support to the Committee on Earth Sciences (CES).

Product: Services in support of the activities of the CES.

Approach: Supplied staff will (1) review Federal research and development programs, including both national and international programs, in earth sciences dealing with global environmental changes; (2) assist in the interagency and inter- 
governmental planning and coordination of R\&D programs in earth sciences; (3) identify and define $R \& D$ needs related to earth sciences; (4) assist in the preparation of long-range research planning and budget planning documents for the overall federal R\&D effort in earth sciences; and (5) provide reviews, analyses, advice, and recommendations to the Federal Coordinating Council for Science, Engineering, and Technology (FCCSET) concerning federal R\&D policies and programs in earth sciences related to assessing humans' impact on the global environment.

\section{THERMOHALINE CIRCULATIONS AND GLOBAL CLIMATE CHANGE}

HANSON, HOWARD P.

UNIVERSITY OF COLORADO

$\begin{array}{lr}\text { FY 1990 } & 134 \\ \text { FY 1989 } & 0 \\ \text { FY 1988 } & 0\end{array}$

\section{$07 / 15 / 90-07 / 14 / 91$}

Objective: To investigate the sensitivity of the inermohaline circulation of the North Atlantic to changes in surface forcing that may be expected with $\mathrm{CO}_{2}$-induced global warming.

Product: Investigation of a potentially important feedback between the rate of $\mathrm{CO}_{2}$ uptake by the ocean and the production of cold water in the North Atlantic and an assessnent of the role of this feedback in the rate of global warming.

Approach: Simple sensitivity studies will be used to address the role of hydrologic forcing vs thermal forcing in the model. The role of mesoscale eddies in the annual cycle of mixed-layer deepening and retreat will then be investigated. Salinity, topography, and realistic coastlines will be explicitly included in the calculations. The feedback process will then be addressed, and the climate sensitivity to the feedback will be assessed from the model.

The numerical experiment tackles the important problem of ocean-climate interactions. It is a good complement to ongoing eddy-resolving calculations of circulation in the North Atlantic being made for the World Ocean Circulation (WOCE) and may provide new insight about high-latitude ocean circulation lacking in coarsegrid OGCMs.

This research will improve quantitative understanding of the long-term changes in glcbal temperature that may be expected to occur with increasing concentrations of $\mathrm{CO}_{2}$ in the atmosphere and will improve estimates of the ocean's ability to dissolve $\mathrm{CO}_{2}$. Because the research involves the behavior of the ocean on time scales of decades, no existing data sets are appropriate for developing this understanding, and the future data-collection efforts are unlikely to be sufficiently timely to provide the needed information. Numerical modeling is, therefore, required.

\section{CLOUD AND OCEAN EFFECTS ON GREENHOUSE WARMING}

\author{
HOFFERT, MARTIN I.
}

NEW YORK UNIVERSITY

$$
\begin{array}{cc}
\text { FY 1990 } & 212 \\
\text { FY 1989 } & 0 \\
\text { FY 1988 } & 0
\end{array}
$$

\section{$07 / 15 / 90-07 / 14 / 91$}

Objective: To investigate the effects of global cloudiness variations on global climate and their implications for cloud feedback and to continue development and application of the NYU transient climate/ocean models, with emphasis on coupled effects of greenhouse warming and feedbacks by both the clouds and oceans. 
Product: A quantitative assessment of how transient climate change may be hidden by cloud feedbacks and ocean thermal delay.

Approach: Cloud, surface-temperature, and ocean data sets as interpreted by a focused climate/ocean model will be used to develop a cloud-radiative-forcing scenario for the past 100 years and to assess the transient climate response; to narrow key uncertainties in the system; and to identify those aspects of the climate system most likely to be affected by greenhouse warming over short, medium, and long time scales. Apart from short-term transients on the decadal time scale, the research will aim at a better understanding of "latent" climatic effects (i.e., global climatic and environmental changes to which our planet may be effectively committed, but which are temporarily "hidden" as a result of thermal storage by the oceans).

The effects of cloud radiative forcing on global climate response will be assessed with an extension of the methodology previously employed to assess solar variability effects on climate. Used in this manner, the simplified model will assist in developing an understanding of the key processes before investigating with the GCMs.

\section{LINKAGE OF ANTHROPOGENIC AEROSOL TO CLOUDS AND CLIMATE}

$$
\text { HUDSON, JAMES G. }
$$

\section{DESERT RESEARCH INSTITUTE}

$$
\begin{array}{cc}
\text { FY } 1990 & 125 \\
\text { FY } 1989 & 0 \\
\text { FY } 1988 & 0 \\
07 / 15 / 90-07 / 14 / 91
\end{array}
$$

Objective: To quantitatively establish the definition of cloud-cundensation nuclei ( $\mathrm{CCN})$.

Product: A basis for separating the relative effects on cloud microphysics of natural and anthropogenic $\mathrm{CCN}$ and a definition of the nucleus supersaturation range appropriate to stratus clouds and the relative efficiency of nuclei to active cloud formation.

Approach: Clouds and cloud radiative properties are among the most important factors to be studied. The present project will establish the definition of cloud-condensation nuclei (CCN). This definition will distinguish between the overall role of natural and manmade nuclei in cloud formation. Such a distinction would allow a determination of the linkage between global air pollution and cloud microphysics that would enable realistic estimates to be made of this possible anthropogenic effect on cloud radiation balance and climate.

A measurement program for $\mathrm{CCN}$, based on proven techniques, will be carried out. Cloud formation, radiative properties, and precipitation characteristics depend on the number, size, and chemical properties of the CCN. This effort will collect data on the size and number. The $\mathrm{CCN}$ will be measured with the instantaneous $C C N$ spectrometer previously developed and proven. The device provides a detailed $\mathrm{CCN}$ spectrum over the entire range of interest to cloud physics, and the nuclei actually active in cloud formation can be subtracted out from the total aerosol.

Identification of the $\mathrm{CCN}$ can then lead to determination of the cloud-activation efficiency over a given range of size and other radiative properties of the $\mathrm{CCN}$.

Surface and aircraft measurements will be used to collect CCN/aerosol samples for analysis. Wet and dry aerosols will be separated by electrostatic means, and direct chemical as well as water-solubility properties of the materials will be deternined.

The analysis will help define the differences between the natural anc the anthropogenic CCN. 
NETWORK-BASED SOLAR AND METEOROLOGICAL CHARACTERI $7^{\wedge}$.TION OF CLOUD-RADIATION FFFECTS IN GLOBAL-CLIMATE MODELING

\author{
KLECKNER, EDWARD
}

\section{PACIFIC NORTHWEST LABORATORY}

$$
\begin{array}{lr}
\text { FY 1990 } & 100 \\
\text { FY 1989 } & 0 \\
\text { FY 1988 } & 0
\end{array}
$$

\section{$05 / 01 / 90-09 / 30 / 90$}

Objective: To investigate how clouds interact with longwave (infrared) and shortwave (solar) radiation to regulate the heating of the planet.

Product: An understanding of how the atmosphere, especially clouds, force the "top-of-theatmosphere" infrared and solar radiation to observed values; whether cirrus clouds are increasing in the non-overcast-sky condition; whether the tropospheric aerosol burden is changing with time; and how that burden affects a cloudy-sky albedo.

Approach: Clouds mask about half the earth's surface at any given time. Therefore it is important to know how clouds interact with outgoing longwave (infrared) and incoming shortwave (solar) radiation to regulate the heating of the planet. To better understand how these climatically opposed effects vary in time, with cloud type and structure, and to a limited extent with geography, a nine-station regional network will be established in the eastern United States. Each station will be equipped with standard instruments for measuring ambient temperature, total precipitation, and relative humidity. Observations of diffuse horizontal, total horizontal, and direct normal solar irradiance will be the primary solar measurements. All three solar-radiation com. ponents will be measured with the same sensor for increased stability. Upward-looking horizontal infrared and local-surface albedo will sup- plement these measurements and aid in their interpretation. Of greater utility, perhaps, than the solar observations themselves are the climate-sensitive parameters that are derived from them: cloudiness, cloud optical depth, cloud type (to some extent), and aerosol optical depth and its wavelength dependence. This approach will allow us to use our ground-based measurements in concert with the Earth Radiation Budget Experiment results to characterize cloud radiative forcing for a variety of cloud types and structures over a limited geographic area, to tiack changes in cirrus frequency and optical depth, and to track changes in aerosol optical depth and its wavelength dependence.

\section{SIGNAL AND NOISE IN GLOBAL WARMING DETECTION}

\author{
NORTH, GERALD R. \\ TEXAS A \& M UNIVERSITY \\ FY $1990 \quad 96$ \\ FY $1989 \quad 0$ \\ FY $1988 \quad 0$ \\ $07 / 15 / 90-07 / 14 / 91$
}

Objective: To estimate the length of climatological record required to identify a globalwarming signal over natural variability.

Product: An understanding of the adequacy of the historical instrument record to resolve the issue of signal and noise in the matter of global warming.

Approach: The current debate as to whether the climate has changed and, if so, what the cause might be hinges on the historical data set. If the record is not sufficient over the period of observation to resolve natural variability (i.e., to distinguish between signal and noise), then the possibility of a quantitative link is slim.

The present research will increase uncerstanding of the global trend-observing system by conduc- 
ting a statistical analysis of the variability and resolving those trends into their natural and random sampling components. Idealized mathematical models, such as noise-forced energybalance models and GCM runs of idealized planets, will be used to produce long-time-series data for analysis. This approach will provide the information needed to assess how long a data set may be required to determine natural variability. Although "real" data will not be used, the approach seeks understanding before morecomplicated climate models are applied to the task.

A formalism recently devised by North and Nakamoto will be used for sampling-error analysis. The technique can be applied to any physical field exhibiting random fluctuations over a space-time spectrum. For this research, the technique will be applied to the space-time spectrum of the surface-temperature field. The first year's effort will concentrate on anaiyzing the output of a simple energy-balance model. The second year's effort will analyze the output of a simplified version of the NCAR GCM. The third year's research will be governed by the results of the first two years' analyses.

\section{MODIFICATION OF CLOUD OPTICAL PROPERTIES BY AEROSOLS}

NOVAKOV, TIHOMIR

\section{LAWRENCE BERKELEY LABORATORY}

$\begin{array}{lr}\text { FY 1990 } & 309 \\ \text { FY 1989 } & 0 \\ \text { FY 1988 } & 0\end{array}$

03/01/90-09/30/90

Objective: To experimentally quantitate the links between the optical properties of clouds and atmospheric aerosols, such as sulfate and carbonaceous particles.
Product: A iaboratory and field data se $\mathrm{t}^{\text {to }}$ estimate the optical properties of aerosols and clouds.

Approach: How the optical properties of clouds respond to changing concentrations of anthropogenic, biogenic, and natural aerosols will be addressed with a combination of field and laboratory experiments. To assess the importance of aerosol-cloud interactions, an important prerequisite is to obtain data that will be used to derive horizontal, vertical, and seasonal variations in global concentrations. This task will rely on compilation, evaluation, and analysis of existing ambient and source-emissions data.

The radiative properties of natural clouds will be measured to determine the validity of theoretical predictions of increasing cloud albedo with increasing $\mathrm{CCN}$ (particularly sulfate and mineral dust) concentrations. The relative impacts of energy-related, crustal, and biogenic aerosols on radiative properties of clouds will be determined. The soot content of natural cloud drops will be determined so that the possible role of soot particles in decreasing cloud albedo can be assessed. Results obtained from these field studies will be used to design laboratory simulation experiments with the LBL cloud chamber to identify the physics and chemistry of dominant importance in modifying the optical properties of clouds, with special emphasis on enhanced absorption soot-associated clouds. And finally, the compilation and analysis of ambient and source-emissions data pertaining particularly to soot aerosols will help to obtain horizontal, vertical, and seasonal variations in global aerosol concentration. 


\section{THE ROLE OF AEROSOLS AND CLOUD MICROPHYSICS IN CLIMATE AND CLIMATE CHANGE}

PENNER, JOYCE E.

\section{LAWRENCE LIVERMORE NATIONAL LABORATORY}

$\begin{array}{cc}\text { FY 1990 } & : 00 \\ \text { FY 1989 } & 0 \\ \text { FY 1988 } & 0\end{array}$

\section{$05 / 01 / 90-09 / 30 / 90$}

Objective: To use data analysis together with a global model to quantify the effects of aerosols and clouds on the radiative budget of the earth and climate.

Product: Quantification of the link between aerosols, cloud microphysical properties, and climate.

Approach: Available data will be examined and compared to the predictions of a 3-D global model for aerosols and clouds. Data on individual sulfur species, aerosol concentrations, elemental carbon concentrations, and cloud microphysical properties will be used. Comparisons of the global model with long time series of data for single stations or comparisons to satellite data will be emphasized in this work, but comparison of the model with more short-term episodic data will also provide valuable insight and allow even short-term data to be folded into the analysis. In this way, the data from a single station or even an event can be extrapolated to the globe to determine the glibal impact.

\section{OCEAN-CLOUD/CLIMATE LINKAGE STUDY}

PORCH, WILLIAM M.

LOS ALAMOS NATIONAL LABORATORY

$$
\begin{array}{lr}
\text { FY 19:9 } & 260 \\
\text { FY 1989 } & 0 \\
\text { FY 1988 } & 0
\end{array}
$$

$$
03 / 01 / 90-09 / 30 / 90
$$

Objective: To improve the understanding of how marine stratocumulus clouds respond to changes in atmospheric composition and atmospheric warming and thus feed back on climate.

Product: Improved ocean-cloud parameterizations in climate models and ocean-data stratification for satellite cloud-trend studies.

Approach: The research will determine the effect of heating and aerosol nucleation on marine stratocumulus clouds by studying the effect of large ships on cloud development and albedo. Experiments will be conducted under meteorological conditions favorable to ship-trail development. Experiments will be conducted in ocean regions where clouds are particularly sensitive to anthropogenic influence. Large ships with the potential for ship-trail formation will be followed by research vessels (ships and/or aircraft) equipped to probe and sample the trails. The results will be used to test and improve dynamic and acrosol-microphysics-based numerical cloud models. The results from the experiments and mode' studies will be used to provide a matrix of sea suriace temperature and marine boundary-layer conditions occurring during highresolution-image satellite overpasses of these cloud-sensitive regions. This effort will aid in the interpretation and development of trend analysis of cloud fraction, albedo, and atmospheric composition. 


\section{CLOUD-ALBEDO PERTURBATIONS ON CLIMATE}

\author{
SCHWARTZ, STEPHEN E. \\ BROOKHAVEN NATIONAL \\ LABORATORY
}

$\begin{array}{lr}\text { FY 1990 } & 100 \\ \text { FY 1989 } & 0 \\ \text { FY 1988 } & 0\end{array}$

$05 / 01 / 90-09 / 30 / 90$

Objective: To search for evidence, principally in satellite data, for the enhancement of cloud albedo by anthropogenic $\mathrm{SO}_{2}$ emissions and to systematically evaluate the magnitude of the perturbation in cloud albedo caused by anthropogenic $\mathrm{SO}_{2}$ as a function of time and location in the context of other sources of cloud-condensation nuclei, principally biogenic sulfur compounds.

Product: A critical test of hypotheses linking responses of the earth climate to changes in radiative forcing.

Approach: A definitive assessment of enhancement of cloud albedo produced by anthropogenic sulfate aerosol and a quantitative evaluation of this enhancement will be conducted. Maps of long-time-average (e.g., annual) enhancement in planetary albedo produced by this mechanism will be compiled, and historical (100year) trends will be evaluated with historical emission patterns derived from records of fuel use and fuel-sulfur content.

In the early stages of this project, a systematic search of the ERBE data will be conducted for enhancement of albedo of low-altitude marine stratus clouds caused by anthropogenic $\mathrm{SO}_{2}$ emissions and/or biogenic DMS emissions. A spatially resolved inventory of gaseous sulfur emissions will be prepared for use in global evaluations of the anthropogenic perturbation of cloud albedo. And an initial spatially resolved assessment will be prepared of present and historical anthropogenic enhancement of cloud albedo; it will incorporate a linear or other simple assumed relationship between $\mathrm{CCN}$ concentration and modeled $\mathrm{SO}_{4}{ }^{=}$concentration into the GCM calculations.

Later, a systematic analysis of available data will be used to develop an improved relationship between sulfate aerosol concentration and $\mathrm{CCN}$ concentration. The possibility of using satellite measurements of acrosol optical density as a surrogate for modeled sulfate will be evaluated.

\section{MECHANISMS CONTROLLING THE PRODUCTION AND TRANSPORT OF METHANE, CARBON DIOXIDE, AND DISSOLVED SOLUTES WITHIN A LARGE BOREAL PEAT BASIN}

SIEGEL, DONALD I.

\section{SYRACUSE UNIVERSITY}

$\begin{array}{lr}\text { FY 1990 } & 207 \\ \text { FY 1989 } & 0 \\ \text { FY 1988 } & 0\end{array}$

$07 / 15 / 90-07 / 14 / 91$

Objective: To determine the degree to which solute and gas movement in deep organic soils is controlled by (1) local groundwater flow systems and their associated vegetation community types and (2) regional subsurface hydrogeologic settings.

Product: A definition of the potential release of $\mathrm{CO}_{2}$ and methane from boreal peat basins.

Approach: Peatlands are an important carbonstorage reservoir, but little is known about their dynamics and potential feedbacks. They are sensitive to change, and the changes have the potential to significantly alter the carbonstorage-release balance. 
An integrated modeling and field study of solute transport and groundwater-flow conditions in the Glacial Lake Agassiz Peatlands of northern Minnesota will be conduct ad to investigate the rates of carbon accumulation and loss, as well as fluxes of methane and $\mathrm{CO}_{2}$; the physical and botanical factors controlling the production of methane and $\mathrm{CO}_{2}$ within the peat profilu. ' and the role of hydrogeologic processes in conirolling fluxes of gases and solutes through the peat.

Measurements will be made of hydraulic-head gradients and solute and gas concentrations in the major vegetation communities of the peatland. The fluxes of dissolved solutes and gases from the peat in each vegetation setting will be determined from these data by mathematical modeling of the advection-dispersion equation, tested by isotopic mass balances on carbon. The results from these detailed site-specific studies will be integrated into the larger peatland setting by relating the variations in solute fluxes to the proportions of each major vegetation type in the larger peatland.

The chemical portion of this study will rely on the microsampling of gases and solutes obtained throughout the depth profile of the peat. Standard methodologies will be applied.

Isotopic analysis $\left(\Delta^{13} \mathrm{C}\right)$ will be used to provide evidence for the processes by which methane is produced and transformed within the peat.

\section{THE EFFECT OF CLOUD MICROPHYSICS ON CLIMATE SENSITIVITY}

STAMNES, KNUT

UNIVERSITY OF ALASKA

FY 1990) 74

FY $1989 \quad 0$

FY 19880

$07 / 15 / 90-07 / 14 / 91$
Objective: To develop cloud radiative parameterizations based on liquid-water content and clouddrop-size distribution for use in a radiativeconvective model to assess the impact of potential changes in cloud microphysics on cloud/radiation feedback and climate sensitivity.

Product: A more realistic treatment of clouds in climate models based on cloud microphysics.

Approach: This research will focus on the effects of potential changes in cloud microphysics caused by a greenhouse warming on the radiative energy budget of the atmosphere. The cloud liquid-water content and drop-size distribution will be used to define cloud radiative properties. Reliable and efficient parameterization of scattering and absorption/emission by cloud droplets will be developed. This work will provide a better understanding of the role of cloud microphysics in the determination of cloud radiative properties. A radiation model including these cloud parameterizations will be used for investigating seasonal and latitudinal effects of the influence of cloud microphysics and liquid-water content.

A detailed 1-D radiative-convective model will be used to study the role of cloud microphysics in the determination of cloud radiative properties. This radiative-convective model will be used to obtain first estimates of the surface-temperature response to potential changes in cloud microphysics associated with greenhouse warming. It will also be used to assess how cloud droplet size influences cloud/radiation feedback and thereby climate sensitivity. The climatic implications of changes in cloud microphysics in 1-D and multidimensional climate models will be assessed. 


\section{DETERMINING THE CHEMICAL COMPOSITION OF CLOUD- CONDENSATION NUCLEI}

WILLIAMS, ALLEN L.

ILLINOIS STATE WATER SURVEY

\author{
FY $1990 \quad 430$ \\ FY $1989 \quad 0$ \\ FY 19880
}

07/15/90-07/14/91

Objective: To develop the instrumentation and methodology needed to determine the cloudcondensation-nuclei ( $\mathrm{CCN}$ ) chemistry in ambient-air samples.

Product: The data for characterization of $\mathrm{CCN}$ and cloud microphysics in GCM models.

Approach: The underlying CCN spectrum determines, to a large extent, the cloud-droplet spectra and influences the resulting cloud radiation properties. As a result, an understanding of the $\mathrm{CCN}$ chemistry is critical to realistic analysis of the role of clouds in climate-warming scenarios.

This research will develop the appropriate instrumentation and methodology to determine the $\mathrm{CCN}$ chemistry in ambient-air samples. The experiment will continuously draw air into a flow-type thermal-diffusion cloud chamber to form droplets on the $\mathrm{CCN}$ at precisely controlled supersaturations and will immediately remove the droplets from the flow stream to minimize contamination. The droplets will then be collected on a filter for analysis. Microgram amounts of CCN material should be able to be collected. Chemical analysis will be conducted with liquid ion chromatography and atomic adsorption. Other techniques will be investigated, including $x$-ray fluorescence, neutron activation, mass spectroscopy, and electron microscopy. The ability to analyze smaller amounts of material, yet obtain a sufficiently wide range of target compounds, will be important for the routine use of the instrumentation.

\section{TECHNICAL REVIEW OF CARBON DIOXIDE RIESEARCH INITIATTVE PRCPOSALS}

\author{
WOHLPART, A. \\ OAK RIDGE ASSOCIATED \\ UNIVERSITIES
}

Objective: To provide administration of the technical review of proposals submitted in re sponse to the Carbon Dioxide Research Initiative (Special Research Grant Program Notice 89-6).

Product: Statistical data and reports that will assist DOE in making funding decisions.

Approach: Program documents will be provided to potential applicants upon request, proposals will be received and administratively screened, a proposal data base and software to manage the program will be diveloped, review meetings will be coordinated, the comments and recommendations of review panels will be documented, and other assistance will be provided as required. 


\section{STATISTICAL EXAMINATION OF CLIMATOLOGICAL DATA RELEVANT TO GLOBAL TEMPERATURE VARIATIONS}

\author{
WOODWARD, W., GRAY, H., \\ and \\ GUNST, R.
}

\section{SOUTHERN METHODIST UNIVERSITY}

$\begin{array}{lr}\text { FY 1990 } & 184 \\ \text { FY 1989 } & 0 \\ \text { FY 1988 } & 0\end{array}$

\section{$07 / 15 / 90-07 / 14 / 91$}

Objective: To construct a state-of-the-art statistical model of gloval temperatures.

Product: A better understanding of the variables and of the changes in the variables that are associated with the predicted $\mathrm{CO}_{2}$-induced climate change.

Approach: Thi research will develop a model for measures of mean global temperature with state-of-the-art statistical techniques, appropriate new methodology, and a variety of data bases consisting of relevant explanatory variables. Attention will be given to the problem of ensuring the integrity of the data. The hypothesis of a recent warming trend will be tested, and the impact on warming of changes in the explanatory variables will be investigated. The contribution of each explanatory variable to the cycles, trends, and random variations in the warming/cooling process will be ascertained. Data sources will include not only recent records but also biological and chemical data collected from archeological and geological studies.

A statistical model relating global temperature to a collection of exploratory variables will be constructed. Development and use of appropriate transfer-function models, including the possibility of long-memory processes, will be a $n_{ı}$ djor thrust of the research.

\section{USE OF A LASER-BASED MONITORING TECHNIQUE TO MEASURE TRACE-GAS FLUXES ACROSS THE AIR-SEA INTERFACE}

\author{
ZIKA, ROD G. \\ UNIVERSITY OF MIAMI

$\begin{array}{lr}\text { FY 1990 } & 145 \\ \text { FY 1989 } & 0 \\ \text { FY 1988 } & 0\end{array}$ \\ $07 / 15 / 90-07 / 14 / 91$
}

Objective: To develop a sensitive, photothermally based spectroscopic technique for measuring the in situ weak infrared absorption of atmospheric cirrbon gases and to initially assess the technique's use in two important areas of air-sea transfer.

Product: Improved measurements of the fluxes of trace and carbon gases across the air-sea interface.

Approach: For many trace gases of interest (e.g., $\mathrm{CO}_{2}, \mathrm{CO}, \mathrm{CH}_{4}$, and nonmethane hydrocarbons), the magnitude and sometimes even the sign of the air-sea concentration difference, which determines the gas tlux across the air-sea interface, is puorly known. The variability of this concentration difference on the spatial and temporal scales appropriate to oceanography has only recently begun to be addressed. As a consequence, calculation of global fluxes of these crucial atmospheric components is constrained. A large number of observations need to be made to provide reliable, globally averaged values for these terms; and analytical methods that overcome the technical difficulties of many of the measurements need to be developed.

This research will develop a sensitive, photothermally based spectroscopic technique for measuring the in situ weak infrared absorption of atmospheric carbon gases. It will also assess that method's use in measuring (1) abiotic photo- 
chemical production of atmospheric trace gases in the surface ocean and (2) photoperiod control of biologically respired trace gases in the surface ocean.

The research will develop a sensitive technique for measuring atmospheric carbon and trace gases at the atmosphere-ocean interface with photothermal deflection spectroscopy (PDS) that uses a pumped laser beam. This effort is directed at resolving disagreements between current measurements and modeling techniques. PDS has a potential of being very sensitive and providing a fast response, both of which are critical to the quantification of carbon and trace gases at the atmosphere-ocean interface.

\section{ARM Initiative}

\section{AN INTEGRATED CLOUD- OBSERVATION AND MODELING INVESTIGATION IN SUPPORT OF THE ARM PROGRAM}

ACKERMAN, THOMAS P.

\section{PENNSYLVANIA STATE UNIVERSITY}

$$
\begin{array}{lr}
\text { FY } 1990 & 637 \\
\text { FY } 1989 & 0 \\
\text { FY } 1988 & 0
\end{array}
$$

\section{$09 / 15 / 90-09 / 14 / 91$}

Objective: To use available observation systems to study cloud formation, cloud properties, and radiation transfer in the atmosphere, to develop data-assimilation models, and to use explicit simulat:ons of small-scale cloud processes for the purpose of developing suitable parameterizations for large-scale atmospheric numerical models.

Product: Information on methods of observation and data assimilation that are suitable for testbed sites of the Atmospheric-Radiation Measurement (ARM) program; parameterizations of cloud processes for large-scale atmospheric models.

Approach: Atmospheric observations will be made, analyzed, and processed. With the suite of instruments used in the Pennsylvania State University's cloud observing system (COS), data will be collected for several extended observing periods and analyzed for quantities, such as vertical velocity, cloud cover, cloud optical properties, and surface radiation budgets. With these observations, the vertical structure of the atmosphere that is equivalent to the structure simulated at an individual grid point of a mesoscale numerical model or a general-circulation model (GCM) will described. Methods for 4-D data assimilation will be developed to provide data inputs efficiently to atmospheric models.

Small-scale atmospheric processes will be simulated and parameterized for large-scale models. Methods will be developed and applied to exchange data between fields produced by a mesoscale model with modules that describe the atmospheric boundary layer (the lower $2 \mathrm{~km}$ of the atmosphere) and detailed cloud processes. Interactions of processes on small scales and the mesoscale will be examined carefully and parameterized as needed for large-scale models. As part of this work, radiative-transfer models to simulate the interactions between microphysical and radiative processes will be applied and compared to the measurements of cloud and radiation properties. As better understanding is achieved, inproved parameterizations of cloud processes will be incorporated into available mesoscale models and tested. 


\section{ADVANCED MODELS AND EXPERIMENTS FOR GLOBAL-CHANGE ESTIMATION}

BARR, SUMNER

LOS ALAMOS NATIONAL LABORATORY

FY $1990 \quad 300$

FY 19890

FY 19880

$01 / 01 / 90-09 / 30 / 90$
Research will be conducted on processes related to global-change issues that range from the microscale of cloud particles and their interaction with solar and terrestrial radiation up through the global-scale circulation of the atmosphere and ocean. A multidisciplinary approach will be applied to problems that include complex mechanisms, such as cloud-radiation feedback, that involve cloud dynamics, cloud and aerosol physics, and radiative transfer. The approach includes numerical modeling, field experiments, and laboratory experiments to gain a consistent and realistic picture of the complex processes being studicd.

\section{SCIENCE TEAM PARTICIPATION IN THE ATMOSPHERIC-RADIATION MEASUREMENT (ARM) PROGRAM}

\author{
CESS, ROBERT D. \\ STATE UNIVERSITY OF NEW YORK, \\ STONY BROOK
} parameterizations for incor
general-circulation models.

Product: Data that are essential to the ARM mission; identification and study of physical, chemical, and biospheric processes that are likely to be important to the ARM objectives; interpretation of related "pre-ARM" experiments, such as CLARET; and improved parameterizations for advanced general-circulation models.

Approach: Innovative ground-based remotesensing equipment will be operated, and the status of satellite remote-sensing data will be examined for the needs of ARM. Mechanisms will be identified that may influence the cloud and radiation fields that are explored through ongoing modeling and experimental efforts. Seminars and workshops will be hosted. Finally, through collaborations with NOAA and other agencies, modeling skills and tools will be applied to the interpretation of "pre-ARM" data sets that have been collected that will greatly assist the design of ARM field operations.

$\begin{array}{lr}\text { FY } 1990 & 50 \\ \text { FY } 1989 & 0 \\ \text { FY } 1988 & 0\end{array}$

$09 / 15 / 90-09 / 14 / 91$

Objective: To attend ARM Science Team meetings and to act as an interface between the ARM program and several related NASA projects involving satellie measurements and with a NOAA project wherein ground-based and satellite measurements are compared.

Product: An enhanced coordination between the ARM program and related NASA and NOAA projects.

Approach: ARM Science Team meetings will be attended, knowledge gained in other related programs will be shared, and ways of interfacing with these programs will be suggested. 


\section{A RESEARCH PROGRAM ON RADIATTVE-TRANSFER-MODEL. DEVELCOPMENT IN SUPPORT OF THE ARM PROGRAM}

CLOUGH, $\mathrm{S}$.

ATMOSPHERIC AND ENVIRONMENTAL RESEARCH, INC.

$\begin{array}{lr}\text { FY 1990 } & 209 \\ \text { FY 1989 } & 0 \\ \text { FY 1988 } & 0\end{array}$

$09 / 15 / 90-09 / 14 / 91$

Objective: To provide a highly accurate radiative-transport model for scattering and nonscattering atmospheres; to use calculations from this model for parameterizations required for GCM radiative-transport codes including a specific two-stream code (reported by Toon et al.); to validate this code against experimental measurements and high-accuracy model predictions for a wide range of atmospheric regimes; to provide support in the design, analysis, and interpre 4 tion of the CART measurement program; aid to facilitate the incorporation of the results into the radiative-transport models.

Product: Improved radiative-transport parameterizations for general-circulation models.

Approach: The project is divided into three topical areas: the "high-accuracy model," the "rapid model," and "measurements."

\section{High-Accuracy Model}

The necestary support will be provided to the ARM research program to implement FASCOD3 as a research-grade reference radiative-transfer model for UCM-related calculations.

Improved algorithms and interrelated data will be develored and supported for FASCOD3 to improve the accuracy of radiative-transfer cal- culations in both the short and the long wavelength regions. An improved single-layer multiple-scattering algorithm will be implemented to obtain single-layer transmitt ance and reflectance to be used in conjunction with the adding algorithm currently available in FASCOD3 for accurate multiple-scattering calculations. These results will be compared with the discrete-ordinate method being implemented for the Geophysics Laboratory (GL) in conjunction with an enhanced version of FASCOD. Specific computationally intensive sections of FASCOD will be modified to facilitate vectorization. The enhanced performance on vector machines will facilitate treatment of more-complex problems for a given computational budget. The treatment of line shape in FASCOD will be validated and modified as required, particularly as applied to water vapor and carbon dioxide. The treatment of atmospheric spectral effects of heavy molecules will be validated and modified as required. Data bases will be maintained of cross sections, including temperature dependence obtained from cross-section measurements or from lineby-line calculations.

An updated water vapor continuum model will be developed. The algorithms necessary for updating the continuum as a result of new measurements and/or modified water vapor for far-wing line shapes will be maintained.

Technical support will be provided for the maintenance of spectroscopic data bases for the ARM program by providing technical support to the ARM program for the implementation of the GL HITRAN line parameters data base as a reference ARM spectral data base, including interpretation and critical analysis of line parameters; developing and maintaining a transition spectral data base for use by ARM researchers, incorporating improved line parameters as they become available; and evaluating the status of the optical properties of clouds and aerosols and incorporating realistic scattering properties in FASCOD with an emphasis on the development of realistic phase functiors for ice clouds. 


\section{Rapid Model}

The necessary algorithms and technical support will be provided to ARM for the calculation of parameters required for the development of radiative-transfer models appropriate to $\mathrm{GCM}$ calculations. Calculation of statistical and correlated $k$ distributions, transmission functions, and high-accuracy radiative-transfer calculations for rapid radiative-transfer-model validations will be addressed.

The performance of the two-stream rapid radiative-transfer algorithm of Toon et al. will be studied and validated with particular emphasis on the spectral-overlap problem for different molecular species. The improvement attainable and the computational exnense involved in using four streams with a rapid-diagonalization procedure will be studied.

\section{Measurements}

Technical support will be provided for measurement recommendations to address requirements for radiative-transfer-model improvements for GCMs. Support will be provided for the analysis and interpretation of measurement results, and the results will be incorporated into the models and data bases, as appropriate.

Radiative-transfer calculations will be performed with the high-accuracy model in both the shortand long-wave regions for specific measurement situation. chosen by the ARM scientific team. Calculations will be performed with the rapid radiative-transfer model on extended measurement sets for validation and model improvement.

A close collaborative effort will be maintained with researchers involved in spectral radiance and transmittance measurements of the type being obtained by the University of Wisconsin HIS Program. Particular emphasis will be placed on spectral cloud properties and on molecularspectroscopic issues, including continuum and heavy-molecule effects.

\section{PARAMETERIZATION OF CONVECTIVE CLOUDS, MESOSCALE CONVECTIVE SYSTEMS, AND CONVECTIVE-GENERATED CLOUDS}

\author{
COTTON, WILLIAM B. \\ COLORADO STATE UNIVERSITY
}

$\begin{array}{lrr}\text { FY } 1990 & 271 \\ \text { FY } 1989 & 0 \\ \text { FY } & 1988 & 0\end{array}$

$09 / 15 / 90-09 / 14 / 91$

Obje tive: To use a mesoscale cloud model to develop cloud parameterizations for use in GCMs.

Product: Physical understanding and numerical techniques adequate to develop algorithms in GCMs that characterize heat-exchange (radiative, latent, and sensible) optical, and other properties of clouds accurately and with computational efficiency.

Approach: A highly capable and documented model will be used to develop cumulus param. eterization schemes that include contributions of both deep and shallow convection and mesoscale vertical velocities; identify criteria that determine if ordinary cumulonimbus or mesoscale convective complexes will dominate for a given set of conditions; examine the feasibility of simulating cirrus clouds created from the outflow of cumulus ciouds; and test the parameterization schemes with data, including ARM data. 


\section{DEVELOPMENT OF AN INTEGRATED \\ DATA-ASSIMILATION/SOUNDING SYSTEM IN SUPPORT OF THE DOE ARM PROGRAM}

\author{
DABBERDT, WALTER F.
}

NATIONAL CENTER FOR

ATMOSPHERIC RESEARCH

$\begin{array}{cc}\text { FY 1990 } & 578 \\ \text { FY 1989 } & 0 \\ \text { FY 1988 } & 0\end{array}$

$09 / 15 / 90-09 / 14 / 91$

Objective: To develop an integrated sounding system (ISS) and data-assimilation system (DAS) to couple in situ and remote-sensing instruments with a state-of-the-art mesoscale model for data assimilation to provide a time-continuous description of the 3-D atmospheric structure with a resolution of at least $20 \mathrm{~km}$ over a domain of $200 \times 200 \mathrm{~km}$ and to apply the capability to the requirement for the ARM extended site.

Product: A prototype ISS mesoscale model adapted to DAS application.

Approach: An existing suite of observational tools including in situ networks, remote-sensing systems, and mobile observation capabilities that have been recommended by all of the groups of scientists involved in the planning process for ARM field experiments will be adapted for ARM objectives. In particular, the demonstrated ability to obtain continuous vertical profiles and some 3-D patterns of wind, temperature, moisture, and important trace gases will be applied with ground-hased remote sensing (radar, lidar, or radiometry). Introduce the particularly appropriate aspect of the work, the use of a stateof-the-art mesoscale dynamical model will be introduced to assimilate and interpret data output from the measurement system.

\section{MODELING RADIATION, CLOUDS, AND} CONVECTION (MORACC)

\author{
DICKERSON, MARVIN H.
}

\section{LAWRENCE LIVERMORE NATIONAL LABORATORY}

$$
\begin{array}{cc}
\text { FY 1990 } & 400 \\
\text { FY 1989 } & 0 \\
\text { FY 1988 } & 0 \\
& \\
01 / 01 / 90-09 / 30 / 90
\end{array}
$$

Objective: To help provide an important theoretical component for the ARMt study to meet its objective of providing general-circulation models with better atmospheric radiation and cloud parameterizations.

Product: Model parameterizations verified against the ARM observational data sets.

Approach: The measurement design will be refined to meet modeling needs and to check consistency of initial ARM radiative-flux measurements against theoretical calculations. Scientific-management support will be provided to ARM by coordinating modeling studies and participating in the ARM management team. New cloud and radiation parameterizations for models of various time and space scales, consistent with the objectives and requirements of the ARM study, will be coordinated and developed.

Numerical models of microphysical and mesoscale processes will be used to help determine instrumental requirements, to design measurement programs, and to provide valuable physical insight in the interpretation of ground- and satellite-based cloudiness measurements. Numerical modeling studies and ARM data will be used to develop techniques for evaluating new GCM parameterizations and to better define the role of cumulus convection in the vertical redistribution of momentum, sensible and latent heat, moisture, and pollutants on the global scale. 
Whether improved convective parameterizations can be developed by using ARM data and interactive GCM-mesoscale simulations will be determined. And radiation codes will be used to understand the direct effect of trace gases and aerosols on the ARM measurements.

\section{A STUDY OF LONGWAVE RADIATION CODES FOR CLIMATE STUDIES: VALIDATION WTTH ARM OBSERVATIONS AND TESTS IN GENERAL-CIRCULATION MODELS}

ELLINGSON, ROBER'T G., and BAER, F.

UNIVERSITY OF MARYLAND

$\begin{array}{cc}\text { FY } 1990 & 250 \\ \text { FY 1989 } & 0 \\ \text { FY } 1988 & 0\end{array}$

$09 / 15 / 90-09 / 14 / 91$

Obiective: To develop an optimum longwave radiation model for use in general-circulation models that has been calibrated with state-ofthe-art observations; to assess the impact of the longwave radiative forcing in a GCM; to determine the sensitivity of a GCM to the radiative model implemented in the GCM; and to determine how the longwave radiative forcing contributes in comparison with shortwave radiative forcing, sensible heating, thermal advection, and expansion.

Product: An improved longwave-radiative-transport model suitable for implementation in general-circulation models and a better understanding of how longwave radiative forcing influences the equilibriv i climate of the atmosphere.

Approach: The radiation model will be developed by testing existing models in an iterative, predictive fashion. This project will supply the
Clouds and Radiation Testbed (CART) with a set of models to be compared with operationally observed data. The observed differences will lead to the development of new and improved models to be tested with new experimental data. Similarly, the GCM studies will ase existing GCMs to study the radiation sensitivity issues.

\section{DEVELOPMENT OF HIGH-SPECTRAL RESOLUTION LIDAR TECHNOLOGY FOR THE DOE ARM PROGRAM}

\author{
ELORANTA, EDWIN
}

\section{UNIVERSITY OF WISCONSIN}

$\begin{array}{cc}\text { FY 1990 } & 204 \\ \text { FY 1989 } & 0 \\ \text { FY 1988 } & 0\end{array}$

$09 / 15 / 90-09 / 14 / 91$

Objective: To develop a lidar for field application that provides high spectral resolution (HSRL) in the backscattered signal and is able to distinguish between aerosol and air backscatter by their different spectral signatures.

Product: A field-functional high-spectral-resolution lidar and interpreted measurements of ice/liquid ratios, particle size, and backscatter profiles in clouds.

Approach: A laboratory-demonstrated instrument system will be adapted to ficld operation by acquiring, insulating, and wiring a trailer; adding a beam-steering capability; shock-mounting hardware; and ruggedizing electronics.

Development modifications will be added, including a multiple-scattering capability for studyirig cloud particle size and depolarization for determining the ratio $o$ ice crystals to cloud liquid water. 


\section{EFFECT OF CLOUDINESS HETERO- GENEITY ON THE RADIATIVE BUDGET AT THE TOP OF THE ATMOSPHERE AND AT THE SURFACE: MODELING, VERIFICATION, AND ANALYSIS}

\author{
GAUTIER, CATHERINE \\ UNIVERSITY OF CALIFORNIA, \\ SANTA BARBARA
}

\author{
FY $1990 \quad 185$ \\ FY 19890 \\ FY 19880
}

$09 / 15 / 90-(99 / 14 / 91$

Objective: To develop new, more-realistic methods of modeling the structure of clouds and improved parameterizations of radiative transfer in cloudy skies.

Product: Basic insights on radiative transfer in clouds and potentially improved descriptions of the behavior of clouds and radiative transfer as simulated by GCMs to evaluate climate change.

Approach: Innovative methods will be developed to describe the structure and optical properties of cloud fields. Cloud-scaling characteristics will be determined from the analysis of data obtained with satellites. The basic multifractal parameters will be estimated. New, high-performance computer algorithms will be investigated for moreefficient extraction of the basic multifractal parameters from observations. Then, clouds with realistic scaling characteristics will be simulated with multifractal analysis and other methods. Anisotropy will be introduced to simulate vertical stratification and texture variations of clouds. Different sampling and averaging strategies will be evaluated by modeling the temporal evolution of cloud and radiation fields.

Innovative methods will be developed to describe radiative transfer in cloud fields. Mean radiances and radiation fluxes of clouds will be computed as a function of their scaling charac- teristics. Approaches will vary from simplified methods to Monte Carlo computations. Departures from plane-parallel theory (used in GCMs) as a function of cloud parameters will be evaluated. Then modeled radiances and fluxes of clouds will be evaluated by comparison to ARM testbed data, observations from satellites, and data collected by programs complementary to $\mathrm{ARM}$; the results of the investigations will be applied to improve GCM simulations of clouds and radiative transfer.

\section{TECHNICAL ASSISTANCE TO DOEMHER HEADQUARTERS}

HALES, JEREMY M.

\section{PACIFIC NORTHWEST LABORATORY}

$$
\begin{array}{cc}
\text { FY } 1990 & 90 \\
\text { FY } 1989 & 0 \\
\text { FY } 1988 & 0 \\
07 / 01 / 90-09 / 30 / 90
\end{array}
$$

Objective: To provide technical and administrative assistance, through a detailee assignment, to DOE and the Office of Health and Environmental Research.

Product: Planning, monitoring, and guidance of programs within OHER.

Approach: The detailee will interact with Headquarters staff and representatives of other government agencies and will process reports and associated planning documents related to major DOE/OHER programs and initiatives, including ARM, CHAMMP, NAPAP, the Atmospheric Chemistry Program, and the Mesoscale Meteorology initiative. 


\section{A JASON STUDY OF ENERGY \\ PROBLEMS - 1990}

HENDERSON, ROGERT G.

\section{DEFENSE ADVANCED RESEARCH PROJECTS AGENCY}

$\begin{array}{lr}\text { FY 1990 } & 75 \\ \text { FY 1989 } & 0 \\ \text { FY 1988 } & 0\end{array}$

07/15/90-07/14/91

Objective: To bring new scientific expertise, understanding, insights, and critical faculties to the problems faced by the government.

Product: Briefings to the Director of the Atmospheric and Climate Research Division, DOE, and other DOE managers on study results and methods.

Approach: JASON will review for the Director of the Atmospheric and Climate Research Division the technical progress being made on the Atmospheric-Radiation Measurement (ARM) program and the Computer Hardware, Advanced Mathematics, and Model Physics (CHAMMP) program. To provide a comprehensive review of these programs, scientists outside of JASON will be used in addition to select members of the JASON group.

\section{REMOTE SENSING OF MESOSCALE VARIABILITY}

HOSKER, R. P.

\section{ATMOSPHERIC TURBULENCE AND DIFFUSION DIVISION, NOAA}

Objective: To evaluate the use of a network of remote-sensing instruments for determining mesoscale and submesoscale meteorological variability to improve subgrid scale parameterizations of the lower atmosphere as they relate to radiative transfer.

Product: A definition of mesoscale meteorological variability in connection with improved subgrid scale parameterizations of radiative transfer.

Approach: The ERL/Wave Propagation Laboratory (WPL) will install, operate, and maintain a network of up to six portable Doppler-radar profilers equipped with. radar-acoustic-sounding systems (RASS) and a Doppler-lidar system. These systems will produce a great deal of wind data suitable for examining the temporal and spatial variability of the lower atmosphere. These systems will be operated near meteorolog ical-tower networks and other equipment placed along the front range of the Rocky Mountains near DOE's Rocky Flats facility. The ERL/ARL/ Atmospheric Turbulence and Diffusion Division (ATDD) of the National Oceanographic and Atmospheric Administration will collaborate with WPL in developing a suitable data-collection, editing, and distribution system for integrating large amounts of remote-sensing data into the already-well-established data-base protocols used for tower and tethered-balloon data. ATDD will also continue its participation in the work of the ARM site organization committee.

\section{ARM PROGRAM SUPPORT}

HULSTROM, ROLAND L.

SOLAR ENERGY RESEARCH INSTITUTE

$\begin{array}{lr}\text { FY 1990 } & 50 \\ \text { FY 1989 } & 0 \\ \text { FY 1988 } & 0\end{array}$

$04 / 01 / 90-09 / 30 / 90$ 
Objective: To initiate and conduct preliminary technical planning for the Radiation Measurement portion of the ARM program within the Instrument Team.

Product: A candidate list of radiometric instruments for deployment in the first phase of occupation of the first ARM site, including a recommendation for instruments that will be essential to meet the ARM mission, a set of options for meeting specific measurement requirements, suggested calibration protocols for each instrument, and instruments recommended to the ARM Science Team as possible candidates beyond the basic complement.

Approach: The Radiation Measurement effort will develop, deploy, and integrate radiometric instrumentation at the ARM research sites and provide a transition to the groups responsible for operation of the equipment and data systems. The project will first be developed for the Clouds and Radiation Testbed (CART), which will serve as the expcrimental framework and infrastructure in the AKivi project. CART includes fixed experimental sites, a mobile complement of instrumentation, and a series of focused campaigns aimed at particular scientific issues.

The list of candidate radiometric instruments for CART will be produced by using a group of experts to review the ARM program's requirements, experimental design, and preliminary experiment catalogue. After this review, the list of candidate radiometric instruments will be produced, containing generic names (e.g., shortwave spectral radiometer), instrument names (e.g., spectroradiometer), and variables measured (e.g., radiance and irradiance).

Support will be provided to the ARM program and Instrument Team to ensure that the ARM radiation measurements and instrumentation allow the ARM mission to be completed. This support will include initial investigations of calibration methods and analyses of total measurement uncertainty for each candidate radio- metric instrument. Recommendations will be made for instrument development in instances where available instruments are incapable (i.e., toial measurement uncertainty is too high or unknown) of meeting $\mathrm{ARM}$ requirtments.

\section{DATA-MANAGEMENT SUPPORT FOR THE DOE ARM PROGRAM}

KANCIRUK, PAUL

\section{OAK RIDGE NATIONAL LABORATORY}

$$
\begin{array}{cc}
\text { FY 1990 } & 220 \\
\text { FY 1989 } & 0 \\
\text { FY 1988 } & 0 \\
& \\
01 / 01 / 90-09 / 30 / 90
\end{array}
$$

Objective: To develop a data-management system to gather, quality assure, analyze, archive, and distribute the vast amount of information produced by the ARM program.

Product: A well-designed, smoothly functioning, research-data-management system for the ARM program.

Approach: The data-management component of the ARM project will be directed and coordinated with the ARM management, science, instrument, and operations teams. Data-management development will be overseen for ARM support.

We will work with the science and operations teams to accurately identify the volume of the data streams to be processed both at the local and remot data-management sites. The necessary processing (quality assurance, reformatting, compression, etc.) will be identified for each step in the data stream. The real-time processing needs, need for redundancy, transmission bandwidth needs, online and mass-storage needs, etc. will be identified. A hardware schedule will be developed to support both local and remote data processing and telecommunication between sii is. 
Sample data streams will be acquired from candidate field instruments and characterized as to data volume, sample intervals, special handling requirements, storage needs, and compression techniques. We will work closely with the algorithm-development team in developing a common data-storage format.

Computer-software algorithms will be developed for data compression, common data format, model interpretation of real-time data streams, and for the display of real-time data at the local computer facility. Data-access routines will be developed, and we will work closely with the documentation and quality assurance team in developing methods to quality assure the data stream and provide online metadata protection.

We will also work closely with the instrument and science teams to develop quality-assurance procedures to apply in real-time at the local site and at the remote data-management facility. Data documentation and procedures and standards will be developed as will online data catalogues for location and display of data sets.

The needs of the project will be defined in terms of developing the data-base management system. The commercial data-management package to base development on will be chosen. In this effort; we will work closely with the capacity planning team (because software needs are closely tieci to hardware requirements and data volume) and with the algorithm development and quality assurance/documentation teams.

\section{ANALYSIS OF CLOUD RADIATIVE FORCING AND FEEDBACK IN A CLIMATE GCM}

\author{
LACIS, ANDREW A. \\ GODDARD INSTITUTE FOR SPACE \\ STUDIES
}

$\begin{array}{cc}\text { FY } 1990 & 266 \\ \text { FY } 1989 & 0 \\ \text { FY } 1988 & 0\end{array}$

$09 / 15 / 90-(19 / 14 / 91$

Objective: To refine and validate the GISS GCM radiation code through model intercomparisons and comparison with ARM observations, to refine and restructure the GISS GCM diagnostics to enable more-informative comparisons to global radiation/cloud data sets, and to use ARM data to develop improved parameterizations of the radiative impact of clouds and to study the interaction of dynamics and radiation.

Product: An improved version of the GISS GCM with improved radiation codes and diagnostic codes that enable comparisons of model predictions with satellite data.

Approach: Observations and detailed models will be compared to the GISS GCM radiation code, thereby identifying differences and allowing improvement. Solar radiative codes will be improved with special emphasis being placed on the water-vapor continuum and comparison of the GISS code to ARM measurements. Longwave radiative codes will be improved by comparing line-by-line calculations to HIS aircraft measurements and then comparing the GISS GCM radiation code to the line-by-line calculations; again, emphasis will be placed on the water-vapor continuum. The multiple-scattering treatment will be improved by developing a cloud-particle-size-dependent scattering algorithm. This treatment will be verified by comparison with HIS observations to separate 
the effects of multiple-cloud layering, cloud optical thicknesses, and particle-size variations. Emphasis will be placed on improving the treatment of cirrus clouds. This effort directly supports the objective of ARM to improve radiation parameterizations in GCMs.

The GISS GCM will be revised to output more diagnostics that can be compared with ERBE, ISCCP, and other satellite data. Cloud-related quantities will be saved during the GCM run, and the importance of spatial resolution of surface albedos will be examined. An offline 1-D code will be used to examine the importance of radiative-dynamic feedback responses. This work will provide a basis to extend ARM site-specific measurements to future satellite data sets.

The treatment of clouds in the GISS GCM will be improved through a series of sensitivity experiments with the GCM in which different aspects of the cloud physics will be varied. An offline 1-D model will be developed and userl to compare the GCM cloud scheme to ARM data. This comparison will be used to improve the cloud scheme in the GCM. The modified cloud scheme, combined with the improved radiation schemes described above, will then be combined and verified against $A R M$ data.

\section{TESTBED MODEL AND DATA ASSIMILATION FOR ARM}

\section{LOUIS, JEAN-FRANCOIS}

\section{ATMOSPHERIC AND ENVIRONMENTAL RESEARCH, INC.}

$\begin{array}{lr}\text { FY 1990 } & 161 \\ \text { FY 1989 } & 0 \\ \text { FY 1988 } & 0\end{array}$

$09 / 15 / 90-09 / 14 / 91$

Objective: To develop and apply methods of data assimilation for the ARM testbed data on a scale consistent with climate models and to design and implement a model for testing parameterizations of cloud characteristics and radiative-transfer processes important in global climate change.

Product: Methods to effectively test parameterizations suitable for use in GCMs employed for studies of climate change by analysis of the large amounts of data that will be produced at ARM testbed sites and by sensitivity tests of GCM model components.

Approach: A framework model will be provided to test GCM parameterizations by further developing a 1-D model, the AER Local Forecast Adaptation (ALFA) model, and by using it to simulate conditions at ARM testbed sites in the same manner as does a GCM over a single grid cell. The 1-D model will be constructed to include the framework by which ARM researchers can test interactive modules that contain the necessary parameterizations [e.g., those on radiative transfer, cloud microphysics, and the dy namics of the atmospheric boundary layer (the lower $2 \mathrm{~km}$ of the atmosphere)].

Methods of data assimilation will be developed and applied. The ARM data, together with analysis results from the National Meteorological Center (NMC), will be assimilated with the ALFA model to produce a continuous description of the atmosphere above the ARM site. The "adjoint" method will be used to ensure that differences between observations and the evolving variables computed with ALFA are minimized.

The means to conduct sensitivity studies on parameters important in GCM modules will be developed. A form of the adjoint method will be used for this purpose. As a test case, the sensitivity of the Toon-Ackerman radiation mudel to various cloud parameters will be evaluated. 


\section{GROUND-BASED MILLIMETER-WAVE- \\ LENGTH CLOUD-PROFILING RADAR SYSTEM (CPRS)}

MCINTOSH, ROBERT E.

UNIVERSITY OF MASSACHUSETTS

\author{
FY $1990 \quad 315$ \\ FY $1989 \quad 0$ \\ FY $1988 \quad 0$
}

$09 / 15 / 90-09 / 14 / 91$

Objective: To develop a millimeter-wavelength radar to fill the recognized need for cloud-fieló mapping.

Product: A remote-sensing system that fills a gap in the penetration-backscatter-strength tradeoff and can yield information on the water-to-ice ratios of clouds, profiles of cloud water amount, backscatter/absorption ratios, and vertical velocities in clouds.

Approach: Instrumentation will be developed to provide a millimeter-wavelength radar to fill the recognized need for cloud-field mapping. It will use two well-selected wavelengths that are intended to help the researchers to distinguish between scattering and absorption processes. Measurements of the polarization of the return signal will assist the interpretation of water-toice ratios, and the Doppler shift in the return will indicate vertical velocity, a crucial quantity for cloud formation. Existing prototype and operational airborne millimeter-wavelength designs will be used as a basis for this highpower ground-based mobile facility.

\section{DEVELOPMENT OF ROTATING SHADOWBAND SPECTRAL RADIOMETERS AND JCM- RADIATION-CODE-TEST DATA SETS IN SUPPORT OF ARM}

\author{
MICHALSKY, J., and HARRISON, L. \\ STATE UNIVERSITY OF NEW YORK, \\ ALBANY
}

$\begin{array}{cr}\text { FY 1990 } & 257 \\ \text { FY 1989 } & 0 \\ \text { FY 1988 } & 0\end{array}$

$09 / 15 / 90-09 / 14 / 91$

Objective: To develop a high-quality data set of cloud/aerosol-modified direct and diffuse solar irradiances that would enable development of improved GCM parameterizations; to develop a filter-based rotating shadowband radiometer (RSR) suitable for use at CART extended sites; and to develop a CCD-array-based RSR suitable for use at a CART central site.

Product: (1) Ground and satellite data related to direct and diffuse solar irradiances assembled in a common data base and (2) prototype RSR instrumentation to be delivered to and evaluated at the first CART site.

Approach: Existing ground-based radiation and meteorological data sets of high quality that can be used in conjunction with existing satellite data to provide modelers with a basic data set for refining the cloud/radiation models in current GCM codes will be assembled.

The data quality and comprehensiveness of existing ground-based data will likely fall short of what will modelers need. To provide modelers with improved data until the CART sites produce data, an observational program will be conducted to add key parameters measured at a single site in upstate New York. 
Two variants of the rotating shadowband radiometer (RSR) that will measure the spectrally resolved direct and diffuse irradiances will be developed, carefully tested, and deployed. One of these instruments will measure the irradiance in seven discrete spectral intervals of 10-nm (or greater) half-width selected within the range of 380 to $2500 \mathrm{~nm}$; the other will measure the irradiance in 256 wavelength intervals nonlinearly distributed over the range of 350 to $1050 \mathrm{~nm}$, providing a spectral resolution of $0.6 \mathrm{~nm}$ at the blue end of this spectrum and $10 \mathrm{~nm}$ at the infrared end. The first instrument will fill the needs of the Extended Observing Network of each CART, and the second those of the central site.

The entire effort is directed at improving radiation-transport models through improved measurements of shortwave fluxes and a better understanding of the optical effects of clouds and aerosols. The scientific approach is to assemble available data, acquire experimental data as necessary, and to develop parametric descriptions of the radiometric effects of clouds and aerosols for incorporation into radiation transport modules of GCMs.

\section{HIGH-SPECTRAL-RESOLUTION RADIANCE MEASUREMENTS FOR THE ARM PROGRAM}

REVERCOMB, H.

\section{UNIVERSITY OF WISCUNSIN}

$$
\begin{array}{cr}
\text { FY 1990 } & 358 \\
\text { FY 1989 } & 0 \\
\text { FY 1988 } & 0
\end{array}
$$

$$
09 / 15 / 90-09 / 14 / 91
$$

Objective: To design and deliver three instruments to a CART site to provide the highly accurate observations needed for detailed comparisons with line-by-line calculations (such as FASCOD3) and for determining the radiative characteristics of clouds, aerosols, and trace gases.

Product: Fourier-transform infrared-spectroscopic expertise and instrumentation to support the improvement of high-resolution line-by-line radiative-transport codes and to improve the physical understanding of longwave radiation transport in the atmosphere.

Approach: State-of-the-art Fourier transform infrared (FTIR) radiometric instrumentation will be developed to acquire higi-quality, high-spectral-resolution infrared atmospheric-radiance data and atmospheric-molecular-absorption data, especially in the water-vapor-continuum region. The data acquired with this instrumentation will be compared with the predictions of infraredradiation-transport models, such as FASCOD3, to identify candidate areas for code improvements (e.g., by implementing improved or alternative spectral-line parameters).

Three instrument types will provide the highly accurate observations. Two (AERI and AERIX) will measure the radiation emitted by the atmosphere, and the third (SORTI) will measure the atmospheric transmission with observations of the sun at different air masses. All of the instruments are based on existing research systems at UW/UD and use commercial interferometers to enhance reliability and to limit procurement and maintenance costs.

The AERI (Atmospheric Emitted Radiance Interferometer) instrument will operate over the spectral range from 4 to 20 microns ( 2500 to 500 wavenumbers) at a resolution of 1 wavenumber. It will be sufficiently inexpensive to be deployed throughout the ARM networks, and will provide the link of point measurements to the larger scale. A system of AERI instruments will also provide important three-dimensional measurements of meteorological parameters in the lower atmosphere.

The AERI-X will provide improved spectral resolution ( 0.1 wavenumber) over the same 
wavelength range. It will provide the higher spectral resolution that will be needed at a limited number of locations to acquire the best available emission observations for comparison with line-by-line calculations.

With a resolution of 0.002 wavenumber, the Solar Radiance Transmission Interferometer (SORTI) measurements will yield the atmospheric transmission at essentially full resolution. It will reveal deficiencies in the way model calculations handle absorption line shapes and line interactions. Prototypes of all instruments will be delivered for testing at the first CART site in 1992.

\section{CLOUD AND AEROSOL CHARACTERIZATION FOR THE ARM CENTRAL FACILITY: MULTIPLE- REMOTE-SENSOR-TECHNIQUJES DEVELOPMENT}

\author{
SASSEN, KENNETH
}

UNIVERSITY OF UTAH

$$
\begin{array}{lr}
\text { FY 1990 } & 344 \\
\text { FY 1989 } & 0 \\
\text { FY 1988 } & 0
\end{array}
$$

\section{$09 / 15 / 90-09 / 14 / 91$}

Objective: To develop and deploy a combination of active remote-sensing systems to observe features of clouds that are crucial to ARM, including cloud water-to-ice ratios, crystal shape and orientation, and cloud optical properties.

Product: Enhanced measurements and interpretation of cloud distribution and type, cloud structure, cloud ice-to-water ratio, crystal shape and orientation, and cloud optical properties with a combination of instruments including polarization-diversity lidar, 8-inm radar, infrared Doppler lidar, infrared and microwave raciometers, and an all-sky video imager.
Approach: The University of Utah will build on its polarization-lidar capability and develop a polarization-diversity lidar (PDL) that will use two wavelengths with parallel and orthogonal polarization components to enhance observation of cloud distribution and type, cloud structure, cloud ice/water ratio, crystal shape and orientation, and cloud optical properties. The system plus two supporting passive remote-sensing systems (an infrared radiometer and an all-sky video imaging system) will be deployed in conjunction with NOAA equipment in two field experiments to compare multiple sensing systems. Two applications will be to participate in FIRE II in the autumn of 1991 and CLARET II in the spring of 1991. The NOAA Wave Propagation Laboratory will deploy a radar, doppler lidar, passive radiometers, and cloud imaging systems. In a manner similar to the first CLARET experiment, interpretation of the data will be conducted in collaboration with the broader ARM research community to design future needs for ARM's continuous cloud and radiation testbed (CART) operations.

\section{ATMOSPHERIC-RADIATION MEASUREMENT (ARM): SITE SELECTION, CAMPAIGNS, AND DATA AUGMENTATION}

$$
\text { SCHWARTZ, STEPHEN E. }
$$

\section{BROOKHAVEN NATIONAL LABORATORY}

$$
\begin{array}{cc}
\text { FY } 1990 & 500 \\
\text { FY } 1989 & 0 \\
\text { FY } 1988 & 0 \\
01 / 01 / 90-(09 / 30 / 90
\end{array}
$$

Objective: To identify sites for conducting measurements of atmospheric radiation and controlling properties and processes suitable to meet objectives of the DOE Atmospheric-Radiation Measurement (ARM) program, to identify sites and situations suitable for conduct of specialized 
measurement campaigns, and to develop procedures for obtaining data needed to meet ARM objectives from other programs and agencies.

Product: Specification of requisite attributes of ARM sites and site-selection procedure, identification of candidate sites and situations suitable for specialized ARM field measurement campaigns, and identification of external data necessary to meet ARM program objectives and of approaches to acquire these data.

Approach: BNL will canvass leading scientists in the field of atmospheric-radiation measurements and controlling processes, including persons from the modeling community and those engaged and experienced in operation of land-based field measurements. The site-selection team will prepare lists of candidate sites potentially suitable as the base sites of the ARM program. These lists will be based on scientific and logistical considerations, including coordination with activities of other agencies. The lists will represent incremental additions of up to six sites.

The site-selection team will also contact atmospheric-radiation-measurement and oceanographic researchers and formulate a list of options for ocean ARM sites. Those consulted will include leading academic scientists and investigators and administrators at other national iaboratories, other Federai agencies, and universities. The site-selection team will, based on external technical advise, provide DOE information related to the feasibility of establishing and maintaining an ocean ARM site, the instruments that may be supported continuously from various platforms, and a cost estimate for an ocean site and campaign support.

The modeling community will be consulted to determine the quantities to be measured, conditions under which measurements should be made, and accuracy and precision requirements for the data. The remote-sensing community will be consulted to determine the needs for in situ measurements to evaluate and supplement remote-sensing measurements. Other agencies and programs will be consulted to identify sites and projects suitable for coordinated efforts.

As a consensus develops on the data requirements of the various communities, an evaluation of measurement facilities will be conducted.

The operation plan, which will be the principal output of this activity, will include (1) a statement of the objectives of the program, including a rationale for the measurements that will be conducted and a statement of the expected output of the program; (2) a description of the instruments and facilities that will be used in the program; (3) flight plans; (4) a data-management plan; and (5) a quality-assurance plan.

Data needs will be identified, external sources of these data and means of acquiring them will be identified; and a procedure for the effective, timely, and cost-efficient acquisition and dissemination within the ARM projuct of needed data will be designed, including facilities for archiving data as necessary.

\section{DIAGNOSTIC MODELING OF THE ARM EXPERIMENTAL CONFIGURATION}

$$
\begin{aligned}
& \text { SOMERVILLE, RICHARD C. J. } \\
& \text { SCRIPPS INSTITUTION OF } \\
& \text { OCEANOGRAPHY }
\end{aligned}
$$

$$
\begin{array}{cc}
\text { FY } 1990 & 110 \\
\text { FY } 1989 & 0 \\
\text { FY } 1988 & 0 \\
09 / 15 / 90-09 / 14 / 91
\end{array}
$$

Objective: To test parameterizations of cloud formation that are currently in use in generalcirculation models with data gathered by ARM.

Product: $A$ better understanding of the validity of various parameterizations in use in GCMs.

Approach: The research will use a 1-D diagnostic model of a single GCM grid and combine 
measurements of initial conditions and horizontal transports made at the ARM site with the model to predict cloud formation and characterization. The prediction of clouds by the model will use the parameterizations in use in generalcirculation models. The resulting predictions will be compared to the ARM measurements to test the accuracy of the cloud parameterizations. The relative merits of a variety of competing parameterizations will be studied. As a result, improvements and alterations will be made to the existing 1-D diagnostic model, modeling will be diagnosed by the comparison of ARM data and the predictions of various parameterization schemes, and this new knowledge will be provided to GCM modelers so they can improve the cloud-modeling aspects of the GCM.

\section{A STOCHASTIC FORMULATION OF RADIATIVE TRANSFER IN CLOUDS}

STEPHENS, G. L., and GABRIEL, P.

\section{COLORADO STATE UNIVERSITY}

$$
\begin{array}{lr}
\text { FY } 1990 & 69 \\
\text { FY } 1989 & 0 \\
\text { FY 1988 } & 0
\end{array}
$$

$09 / 15 / 90-09 / 14 / 91$

Objective: To develop new theoretical methods for describing radiative transfer in inhomogeneous clouds and cloud fields in the atmosphere and for analyzing cloud and radiation data.

Product: Basic insights on radiative transfer in clouds and potentially some of the methods to achieve the parameterizations required in largescale atmospheric numerical models to describe the radiation balance irnportant in the study of global climate change.

Approach: The theory of the influence of clouds on atmospheric radiative transfer will be advanced. Simple mathematical relationships will be developed between the statistical moments of the radiation field and statistical moments of the optical properties of clouds, mainly on the basis of results obtained with a two-stream radiation model applied in a plane-parallel medium. Cloud optical depth would be the primary independent variable. More-sophisticated mathematical relationships will be derived that describe the influence of the statistics of the horizontal structure of clouds on the radiative transfer through them. Data obtained from satellites and aircraft as well as from ground stations would be used to develop a measure of the statistics of horizontal variability of cloud properties. Histograms of the reflectance and transmission properties will be produced with the Ricatti equation, whose solutions will be constructed and manipulated with advanced mathematical techniques.

Simple relationships will be constructed suitable for parameterizing cloud-radiation interactions in GCMs, particularly on the transmission, absorption, and reflection of radiation as a function of cloud parameters that can be produced in GCMs.

\section{ATMOSPHERIC-RADIATION MEASUREMENT' PROGRAM (ARM)}

STOKES, GERALD M.

\section{PACIFIC NOR'THWEST LABORATORY}

$\begin{array}{cc}\text { FY 1990 } & 4000 \\ \text { FY 1989 } & 0 \\ \text { FY 1988 } & 0\end{array}$

$01 / 01 / 90-09 / 30 / 90$

Objective: To improve the performance of general-circulation models of the atmosphere for the purpose of global and regional climate prediction. ARM will focus specifically on two aspects of that improvement: the treatment of radiative-transfer models in GCMs under clearsky, general-overcast, and broken-cloud conditions; and the parameterization of cloud prop- 
erties, cloud formation, and cloud maintenance in GCMs.

Task I. ARM Management (Gerald M. Stokes, Pacific Northwest Laboratory)

Product: The management of the AtmosphericRadiation Measurement program and the development of the experimental infrastructure of that program, known as the Clouds and Radiation Testbed (CART). The ARM experimental framework provides a basis for the detailed testing and verification of the modeling of subgrid processes in general-circulation models, the ability to rapidly deploy experiments to the field, and a strong coupling to the scientific goals of the program. Another product is the management of the Data System Tearn and the design of the data system within the ARM infrastructure based on the requirements of the Science Team as manifested in approved ARM experiments.

Approach: The ARM program will be managed from the ARM Project Office, currently located at the Pacific Northwest Laboratory, and will consist of three other distinct entities: the Science Team, the Instrument De lopment program, and the Clouds and Radiation Testbed.

The Project Office will provide central planning and management for the ARM program, support of the DOE/OHER Atmospheric and Climate Research Division's activities, and coordination of the ARM program activities with related technical activities in other agencies and countries.

The Science Team will conduct approved research projects; provide basic guidance for the selection of sites, common modeling activities, and instrument selection; and set the scientific direction of the ARM program.

The Instrument Development program will provide a program for the long-term, high-risk development of critical technologies that will be of long-term interest to ARM, and it will pro- vide a directed instrument-development activity when an instrument must be developed to meet a need within ARM that cannot be met by other means.

The Clouds and Radiation Testbed (CART) is the basic experimental infrastructure for the ARM program. The CART itself consists of several permanent observing stations; the ability to provide some mobile measurement capability; an ability to support intensive campaign activities either at a fixed ARM site or in collaboration with related programs; and a data system that supports the above activities, the acquisition of other related data, and the analysis of these data by the Science Team.

The CART is under development by several interlaboratory teams related to the data system, modeling, instruments, site selection, and site operations. Each team is headed by a principal investigator from one of the DOE's national laboratories.

Results to Date: The ARM program developed a program plan (DOE/ER-0041) that was peer reviewed with the result that $A R M$ was incorporated in the U.S. Global Change Research Progran for IFY 1991. A detailed project plan was then developed early in 1990, and a series of scientific workshops was held to further refine the scientific objectives and approach for the program. Through this planning process, the basic management teams were formed and their work initiated.

The ARM management also supported the formation of the ARM Science Team. The nonDOE-laboratory investigators were selected in July, and the DOE-laboratory investigators in September. The ARM program was reviewed by the JASON group in August, and regular meetings have been held with the ARM interagency working group.

In May, the Data System Team developed the first elements of the ARM-data-system-requirements definition and analysis. The resulting 
document was issued as an informational document to the ARM Management Team. The results from this design session were presented to the Interagency Working Group in June and have been used to support elements of the Site Operations Team's activities.

Task II. Site Operations Team (Sumner Barr, Los Alamos National Laboratory)

Product: Management of the site-operations activities within the infrastructure of ARM and overseeing of the operation of individual sites by site-operations contractors.

Approach: The Site Operations Team will serve as a bridge between activities that lead to the development of CART and the contractor responsible for the eventual operation of individual ARM sites. They will develop the initial site-operation plan for each individual site to incorporate constraints; they will generate the statement of work for the solicitation of siteoperations contractors and the selection criteria to evaluate responses; and they will train operations contractors during the site-deployment period, finally transferring the site, its associated equipment, and the maintenance of the siteoperations plan to the contractor.

Results to Date: The Site Operations Team, formed in April, has emphasized the development of the initial generic site-operations plan and has supported tise identification and training of the first site contractor. A detailed design of the site-operations system was developed in August and September, and a version of the siteoperations plan will be ready for review by the Science Team in early FY 1991.

Task III. Modeling Team (Marvin H. Dickerson, Lawrence Livermore National Laboratory)

Product: Management of the modeling activities within the infrastructure of ARM and the development of a system that supports the testing of models within the ARM data system.
Approach: LLNL will sperify the support required by modelers from the ARM Data System for experimental models, for a suite of operational models, and for the CART community models that are maintained for the general ARM research community. They will identify possible community models for consideration by the Science Team and will conduct sensitivity studies in support of the identification of observational precision and accuracy requirements. Finally, the Modeling Team will develop a method for comparing model performarice and a method for the integration of ARM results with other modeling activities, most notably the Program for Climate Model Diagnostics at Lawrence Livermore National Laboratory.

Results to Date: The initial meeting of the Modeling Team occurred in April and centered on a review of DOE modeling capability, the Program for Climate Model Diagnosis and Intercomparison (PCMDI), and the identification of models for use in the design of three experiments described at the March science workshop. In the remaining months, the emphasis of the Modeling Team work was on further model identification, development of the model cat $=\log$, the definition of community models for the ARM Science Team, and the design of a modeling intercomparison framework. Most of this work has taken place in the context of using radiometric models as a representative class of models. For the remainder of the year the emphasis has moved toward cloud formation and parameterization.

Task IV. Site Selection Team (Stephen E. Schwartz, Brookhaven National Laboratory)

Product: Management of the site-selection activities within the infrastructure of ARM and identification of potential relationships between ARM and other experimental programs.

Approach: BNL will guide and support the process of site selection in ARM. While the Science Team will set the requirements for site selection, the S: $:$ Selection Team will translate 
the experimental requirements that come from the design process into candidate site-selection criteria. Once the criteria are approved by the Science Team, the Site Selection Team will translate these criteria into bid specifications for placing the site-operations contract.

In support of the Science Team, the Site Selection Team will conduct a variety of activities aimed at the development of the site-selection criteria. Among these are the relationships between ARM and other related experimental programs that could be enhanced by collocating experimental facilities or by strategically placing an ARM site in an area that may have been or will be the site of major experimental campaigns with compatible scientific objectives.

Finally, the Site Selection Team will interpret each specific site selection into a framework that lets the Science Team understand the extent to which the site allows ARM to explore the range of meteorological conditions of interest to an individual ARM investigator.

Results to Date: The site-selection process emphasized collection of basic information concernirg possible sites, definition of the form and content of the site catalog, and the development of guides for "climatic evaluations." The latter work created a basic framework for the comparison of different sites for scientific suitability.

Following this preliminary work, it was decided to focus on a prioritization scheme that emphasized broad geugraphical and climatological "locales" rather than specific sites. A process for the development of the prioritization was developed, and it will culminate by the end of the year in a set of recommendations for reviev by the full Science Team.

As part of the development of both siting candidates and possible campaign activities for ARM, a systematic effort to contact representatives for major programs being coordinated by other federal and international agencies is in progress.

Task V. Instrument Team (Marvin L. Wesley, Argonne National Laboratory)

Product: Management of the instrumentation activities within the infrastructure of ARM and the identification of observational approaches to meet the requirements for data input to models being tested in the ARM program.

Approach: ANL will identify and test technologies for possible incorporation in the CART observational infrastructure, will support the deliberations of the Science Team in considering its recommendation for the ARM instrument complement, will support the acquisition of instruments for ARM sites or the ARM mobile system, and will develop the initial operational and calibration protocols for each item of experimental equipment before transferring it to individual ARM site operations teams for operation.

Results to Date: The Instrument Team was formed in April and includes leadership for working groups on particular classes of instrumentation and interfaces to other teams. The Instrumentation Team met at SERI in April with a larger group to begin the process of defining the instrument catalog, a central data base containing the descriptions and operational characteristics of candidate instruments. In the latter part of the year, the initiation of sensitivity studies for radiometric instrumentation, the development of computer models of critical instrument systems, the development of plans for pilot observational programs, and the analysis of data from the CLARET experiment and the Wave Propagation Laboratory have been emphasized. 


\section{MODELING CLOUDS IIND RADIATION FOR DEVELOPING \\ PARAMETERIZATIONS FOR GENERAL CIRCULATION MODELS}

TOON, O. B., and WESTPHAL, D.

NASA AMES RESEARCH CENTER

$\begin{array}{cc}\text { FY 1990 } & 120 \\ \text { FY 1989 } & 0 \\ \text { FY 1988 } & 0\end{array}$

$09 / 15 / 90-09 / 14 / 91$

Objective: To develop practical parameterizations for treating cirrus and stratus clouds for use in global-scale models and to develop new, accurate treatments of radiative transfer.

Product: A new parameterization for treating cirrus and stratus clouds in a GCM and moreaccurate treatment for radiative transfer.

Approach: A hierarchy of models will be developed and tested so that the accuracy of both the radiation model and the cloud model can be determined.

A 4-D data-assimilation analysis package will be developed to allow the mesoscale model to more correctly match observed variables at the ARM sites. The mesoscale model and 4-D data-assimilation scherne will be used to investigate intensive observational studies at ARM sites and to test the ability of dynamical models to properly reproduce moisture fields. The mesoscale model will be used with different cloud microphysics parameterizations and compared with observations at the ARM sites to test the cloud parameterizations.

Radiative-trarısfer schemes will be improved. Absorption coefficients will be developed with the exponential-sum approach. This approach will be extended to treat overlap regions of different gases and inhorngeneous atmospheres. The choice of coefficienis will be tested with line-by-line techniques. Other fast radiationtransfer techniques will be developed and tested to see if they are more accurate than the twostream approach. Also, techniques for treating the spherical nature of the atmosphere in a simple manner will be adopted. The radiation models will be tested against ARM data, and new absorption coefficients will be derived as needed. Develop Radiation codes will be developed to compare the mesoscale-model output with intensity observations. And radiation codes that consider the effects of broken cloud fields at the scale of both the mesoscale model and the GCM grid scale will be developed and tested.

Cloud microphysical parameterizations for cirrus and stratus clouds that are appropriate for use in GCMs will be developed. The marine-stratus model will be used to investigate how the albedos and latent-heat releases of marine strata vary in response to changing environmental conditions. Parameterization schemes will be developed for marine stratus in GCMs. The 1-D cirrus/aerosol model will be applied to study tropospheric cirrus clouds and the development of vertical variations in the size distribution of ice crystals. Parameterizations of ice employing bulk fall speeds will be evaluated.The effects of optical and microphysical properties of ice crystals on the generation of cirrus will be studied. The sensitivity of cirrus radiative properties to the large-scale dynamical properties in the atmosphere will be determined. The minimum resolution of the size distribution needed to match observations and retain an adequate representation of the original model at full resolution will be determined to develop a simplified nodel that is suitable for inclusion in the mesoscale model. And cloud microphysical parameterizations in the mesoscale model will be tested by comparing the model results to measurements at ARM sites. 


\section{THREE-DIMENSIONAL CHARACTERIZATION OF CLOUDS AND REILTED PARAMETERS}

VITKO, JOHN, JR.

SANDIA NATIONAL LABORATORIES

$$
\begin{array}{lr}
\text { FY 1990 } & 250 \\
\text { FY 1989 } & 0 \\
\text { FY 1988 } & 0
\end{array}
$$

$$
01 / 01 / 90-09 / 30 / 90
$$

Objective: To provide the Atmospheric-Radiation Measurement (ARM) program with an assessment of 3-D "cloud-mapping" capabilities and issues and to develop a method for evaluating proposed concepts.

Product: A systematic decision-making framework to evaluate proposed instrument systems for ARM that will characterize the cloud field and other 3-D measirements related to atmospheric cloud-radiation interaction.

Approach: To develop these decision criteria, the ARM requirements for cloud studies will be reviewed and refined, existing and near-term technologies for making these measurements will be assessed, and criteria for arriving at hierarchies of desired ARM measurements will be developed and applied. The assessment of measurement capabilities will include data reduction and requirements for ancillary data, as well as the basic instrumentation, to accurately reflect the overall measurement accuracy, and these capabilities will then be compared against the ARM measurement requirements. The use of the decision framework methodology will then be illustrated by application to examples of possible ARM instrumentation suites.

\section{LOCAL DATA MANAGEMENT FOR THE ATMOSPHERIC-RADIATION- MEASUREMENT INITIATIVE}

VITKO, JOHN, JR.

\section{SANDIA NATIONAL LABORATORIES}

$\begin{array}{lr}\text { FY 1990 } & 50 \\ \text { FY 1989 } & 0 \\ \text { FY 1988 } & 0\end{array}$

$01 / 01 / 90-09 / 30 / 90$

Objective: To develop guidelines and decision criteria for evaluating ARM onsite data-management systeras.

Product: A report describing the local datamanagement needs, options, and issues and a decision framework for use in evaluating proposed data-management concepts.

Approach: To develop the decision criteria for such a system, we will (1) develop a detailed set of system requirements; (2) assess existing and near-term technologies in the related areas of computing hardware and software, data communications, and methods for data fusion and quality control; and (3) develop and apply criteria and methods for evaluating proposed datamanagement architectures.

\section{TREATMENT OF CLOUD RADIATTVE EFFECTS IN GENERAL-CIRCULATION MODELS}

$$
\text { WANG, WEI-CHYUNG }
$$

\section{STATE UNIVERSITY OF NEW YORK, ALBANY}

$$
\begin{array}{cc}
\text { FY 1990 } & 328 \\
\text { FY 1989 } & 0 \\
\text { FY 1988 } & 0
\end{array}
$$

$09 / 15 / 90-09 / 14 / 91$ 
Objective: To improve in current GCMs the parameterizations of the radiative effects of clouds at different heights overlapping horizontally, to incorporate cloud optical properties into radiation codes, and to evaluate effects on climate simulations.

Product: Improved large-scale atmospheric models, evaluation of parameterizations of clouds and radiative-transfer processes, and specification of measurements and parameterizations that might substantially improve their performance.

Approach: The treatment of clouds in current large-scale atmospheric models will be evaluated and further developed. The effects of clouds horizontally overlapping at different heights and variations in their optical properties will be investigated wich the use of ground- and satellite-based measurements. The adequacy of random cloud overlapping, currently assumed in all GCMs, will be evaluated by comparison of results to those from alternative overlapping schemes that might be more realistic. The cloud optical parameters of single-scattering albedo, the asymmetry factor, and extinction coefficient as a function of radiation wavelength will be precalculated by cloud-particle models for use in GCMs or will be derived from observations from satellites. Radiation codes in large-scale models will then be modified to use these cloud optical parameters.

The effects of the new treatments of clouds on climate simulations will be evaluated. These simulations will be carried out with a $1-\mathrm{D}$ radiative-convective model and a $2-D$ radiative-dynamical model to evaluate the greenhouse effect caused on the present climate by increasing $\mathrm{CO}_{2}$, $\mathrm{CH}_{4}, \mathrm{~N}_{2} \mathrm{O}$, and CFCs. Simulations with the CCM1 (the Community Climate Model, One) will be carried out in a similar manner. In addition, the CCM1 will simulate energy balances at ARM testbed sites and in regions expected to have atmospheric radiative balances quite different from those at the ARM sites.
ARM Science Team activities will be participated in to provide information on the findings of this work that will be relevant to measurements and experiments carried out at ARM testbed sites.

\section{ATMOSPHERIC-RADIATION MEASUREMENT (ARM): EXPERIMENTS AND MODELING}

\author{
WESELY, MARVIN L.
}

\section{ARGONNE NATIONAL LABORATORY}

$$
\begin{array}{lr}
\text { FY 1990 } & 450 \\
\text { FY 1989 } & 0 \\
\text { FY 1988 } & 0
\end{array}
$$

$$
01 / 01 / 90-09 / 30 / 90
$$

Objective: To improve GCM simulations' treatment of atmospheric radiative transfer in clearsky, general-overcast, and broken-cloud conditions and their parameterization of processes of cloud formation, maintenance, and dissipation and the associated cioud characteristics important in the global radiation balance.

Product: Coordination of ARM infrastructure activities concerning instrumentation and the identification of observational approaches necessary to meet the data requirements for testing numerical-model components being developed for use in GCMs.

Approach: Technologies will be identified and evaluated for possible incorporation in CART observation systems; information and responses concerning instrumientation will be provided to the Science Team during its deliberations on ARM experiments; technical information will be provided to support the acquisition of instruments for ARM sites and the ARM mobile system; and the initial operational and calibration protocols for each item of experimental equipment will be developed before it is transferred to individual ARM site operators. 


\section{THEORETICAL CLOUD-RADIATION STUDIES IN SUPPORT OF THE ATMOSPHERIC-RADIATTON MEASUREMENT (ARM) PROGRAM}

\author{
WISCOMBE, WARREN J. \\ NASA GODDARD SPACEFLIGHT \\ CENTER
}

$\begin{array}{lr}\text { FY 1990 } & 44 \\ \text { FY 1989 } & 0 \\ \text { FY 1988 } & 0\end{array}$

$09 / 15 / 90-09 / 14 / 91$

Objective: To develop a 3-D radiation-transfer model and make it available to ARM as a "community model," learning, in the process, a great deal about the statistical nature of clouds and how to represent them in models.

Product: A 3-D radiation-transfer model.

Approach: Models based on the fractal nature of clouds will be developed for the spatial distribution of cloud optical depths. These models will be constrained by data from FIRE and Landsat and by principles from turbulence theory and cloud physics. As a test of their applicability, they will be applied to cloud types that are not used in the development phase. Thus, while the properties of stratocumulus clouds may be used to develop these models, their statistical accuracy will be tested by comparison with cirrus clouds.

The Goddard 1-D Monte Carlo radiation model will be further developed by both an attempt to reduce the computer time requirements for this model (by a variety of approaches) and the extension of this model to handle a 2-D checkerboard grid of cloud optical depths in space. With a 2-D field of optical depths, the model will be a 3 -D radiative-transfer model that can treat cloud fields that are inhomogeneous in two dimensions.

A three-dimensional Fourier-transform radiation model will be further developed as an alternative to the Monte Carlo model.

The 3-D radiation model together with the cloud-optical-depth model discussed above will be used to study the sensitivity of the bulk-cloud optical properties (i.e. transmission and reflection) to the optical-depth distribution. These studies will be used to evaluate the adequacy of current assumptions that $1-D$ radiative-transfer models can be used to treat the 3-D cloud field within each "pixel" (or grid box in a generalcirculation model).

Both 3-D radiative-transfer models referred to above will be documented and generalized so they are appropriate community models for ARM and CART.

The models and the ARM data will be used to test the extent to which averages of time-series data at a single point can be used to represent spatial averages.

Stochastic radiative transfer will be studied as a shortcut to using a brute-force method (wherein many realizations of different cloud geometries must be calculated) to gather reasonable statistics on cloud radiative properties. 


\section{APPENDIX A \\ ADDRESSES OF PRINCIPAL INVESTIGATORS}

Abbott, Sherborne

National Academy of Sciences

2100 Constitution Ave., NW

Washington, DC 20418

202-334-3487

Ackerman, Thomas P.

Pennsylvania State University

516 Walker Bldg.

University Park, PA 16802

814-865-2915

Acock, Basil

USDA-ARS Agricultural Systems Research Institute

Bldg. 007, Rm. 56, BARC-West

Beltsville, MD 20750

601-323-2230 ext. 62

Allen, L. H.

USDA-ARS Plant Science Research Lab.

University of Florida, Agronomy Dept.

Gainesville, FL 32611

904-392-6180

Anderson, Patricia A.

National Science Foundation

18th And G St, NW

Washington, DC 20550

301-357-7357

Ascher, William

Battelle Marine Sciences Laboratory

439 West Sequim Bay Road

Sequim, WA 98232

206-683-4151

Bader, David C.

Pacific Northwest Laboratory

P.O. Box 999

Richland, WA 99352

FTS 444-4811

Baer, F.

University of Maryland

Cooperative Institute for Climate Studies

College Park, MD 20742

301-405-5387

Barr, Sumner

Los Alamos National Laboratory

P.O. Box 1663

Los Alamos, NM 87545

FIS $855-2868$
Bazzaz, F. A.

Harvard University

Dept. of Organismic and Evolutionary Biology

Cambridge, MA 02138

617-495-2305

Birdsall, Theodore

Electrical Engineering and Computer Science

1301 Beal

University of Michigan

Ann Arbor, MI 48109-2122

313-936-0267

Biswas, P. K.

Tuskegee Institute, P.O. Box 704

Dept. of Agricultural Sciences

Tuskegee, AL 36088

205-727-8452

Bradley, Raymond S.

University of Massachusetts

Dept. of Geology and Geography

Amherst, MA 01003

413-545-2794

Brewer, Peter G.

Woods Hole Oceanographic Institute

Department of Chemistry

Woods Hole, MA 02543

617-548-1400, 2896

Brown, Sandra

University of Illinois

Department of Forestry

Urbana, IL 61801

217-333-1643

Carter, G. C.

National Academy of Sciences

2101 Constitution Ave.

Washington, DC 20418

202-334-2755

Cess, Robert D.

State Univ. of New York at Stony Brook Laboratory for Planetary Aimospheres Research

Long Island, NY 11794

$516-246-6764$

Chen, T. C.

Ames Laboratory

Iowa State University

Ames, IA 50011

515-294-9874 
Cheng, Hsing C.

Brookhaven National Laboratory

Dept. of Applied Science

Upton, NY 11973

FIS 666-2958

Cline, Raymond E., Jr.

Sandia National Laboratories

P.O. Box 5800

Albuquerque, NM 87185

FTS 294-1395

Clough, Shepard A.

Atmospheric and Environmental Research, Inc.

840 Memorial Drive

Cambridge, MA 02139

617-547-6207

Cotton, William R.

Colorado State University

Dept. of Atmospheric Sciences

Fort Collins, CO 80523

303-491-8593

Cox, Stephen $\mathrm{K}$.

Colorado State University

Department of Atmosheric Sciences

Fort Collins, CO 80523

303-491-8594

Cure, Jennifer D.

Duke University

Department of Botany

Durham, NC 27706

919-684-6532

Cushman, Robert $M$.

Oak Ridge National Laboratory

CDIAC, P.O. Box 2008

Oak Ridge, TN 37831

615-574-0390

Dabberdt, Walter F.

National Center for Atmospheric Kesearch

Atmospheric Technology Division, P.O. Box 3000

Boulder, CO 80307-3000

303-497-8819

Dannevik, William P.

Lawrence Livermore National Laboratory

P.O. Box 808

Liveimore, CA 94550

FrS-53?-3132

Del Genio, Anthony D.

Goddard Institute for Space Studies

2880 Broadway

New York, NY 10025

$212-678.5500$
Denbo, D. W.

Battelle Marine Sciences Laboratory

439 West Sequim Bay Road

Sequim, WA 98232

206-683-3616

Dickerson, Marvin $\mathrm{H}$.

Lawrence Livermore National Laboratory

P.O. Box 808

Livermore, CA 94550

FIS 532-1806

Dickson, Andrew G.

Scripps Institution of Oceanography

A -024

La Jolla, CA 92093

619-534-2582

Downing, John P.

Marine Sciences Laboratory

439 West Sequim Bay Road

Sequim, WA 98232

206-683-4151

Drake, Bert G.

Smithsonian Institution

A\&I Builaing, Room 2203

Washington, DC 20560

301-443-2343

Eddy, Juhn A.

University Corporation for Atmospheric Rescarch

Office for Interdisciplinary Earth Studies

P.O. Box 3000

Boulder, CO $80307-3000$

303-497-1607

Edmonds, James A

Battelle Pacific Northwest Iaboratory

Suite 900

370 L'Enfant Promenade

901 D St., S.W.

Washington, DC 20(124-2115

202-646-5243

Ellingson, Rogert $G$.

University of Maryland

Cooperative Institute for Climate Studies

College Park, MD 20742

301-405-5386

Eloranta, Edwin

University of Wisconsin

Space Science and Engineering Center

Madison, WI 53707

608.263 .7327 
Elwood, J. W.

Oak Ridge National Lahoratory

P.O. Box 2008

Oak Ridge, TN 37831

FTS $524-7370$

Emerson, Steven

University of Washington

School of Oceanography, WB-10

Seattle, WA 98195

206-543-0428

Farrell, Michael P.

Oak Ridge National Laboratory

Carbon Dioxide Information Analysis Center

Oak Ridge, TN 37831

FIS 624-0390

Fasham, Michael J. R.

Institute of Oceanographic Sciences, NERC

Deacon Lab, Brooks Rd., Wormley, Godalming

Surrey GU8 5UB

U.K.

Foster, I. T.

Argonne National Laboratory

9700 S. Cass Ave.

Argonne, IL 60439

FIS $972-4619$

708-972-4619

Fung, Inez Y.-S.

Gcddard Institute for Space Studies

2880 Broadway

New York, NY 10025

FTS $664-5590$

Gabriel, P.

Colorado State University

Dept. of Atmospheric Sciences

Fort Collins, CO 80523

$303-491-8366$

Gates, W. Lawrence

Lawrence Livermore National Laboratory

P.O. Box 808

Livermore, CA 94550

FTS $532-1806$

Gautier, Catherine

Geography Dept.

University of California, Santa Barbara

Santa Barbara, CA 93106

805-893-3663

Gornitz, Vivien M.

Lamont-Doherty Geological Observatory

Columbia University

Palisades, NY 10964

914-359-2900
Gray, H.

Southern Methodist University

Dept. of Statistical Sciences

Dallas, TX 75275

214-692-3212

Gunst, R.

Southern Methodist University

Dept. of Statistical Sciences

Dallas, TX 75275

214-692-2466

Gustafson, John

Ames Laboratory

Iowa State University

Ames, IA 50011

515-294-9294

Gutowski, William J.

Atmospheric and Environmental Research, Inc.

840 Memnrial Drive

Cambridge, MA 02139

617-547-6207

Hales, Jake

Pacific Northwest Laboratory

P.O. Box 999

Richland, WA 99352

FTS 444-8447

Hall, Charles A. S.

State University of New York

459 Illick Hall, Room 350

Syracuse, NY 13210

$315-470-6870$

Hameed, S.

State Univ. of New York at Stony Brook

Laboratory for Planetary Atmospheres Research

Long Island, NY 11794

516-246-8319

Hanson, Howard P.

University of Crslorado at Boulder

CIRES, Center for the Study of Global Change, CB 2

Boulder, CO 80309-0216

303-492-1227

Harrison, L.

State University of New York, Albany

Atmospheric Sciences Research Center

Albany, NY 12222

518-442-3811

Henderson, Robert $G$.

Defense Advanced Rescarch Projects Agency

1400 Wilson Blvd.

Arlington, VA $22200^{\circ}$ 
Hendrey, George

Brookhaven National Laboratory

Dept. of Applied Science

Upton, NY 11973

F1S 666-3262

516-282-3262

Hoffert, Martin I.

New York University

Washington Square

New York, NY 10003

212-998-8995

Hosker, R. P.

Atmospheric Turbulence and Diffusion Division/NOAA

456 South Illinois Ave., P.O. Box 2456

Oak Ridge, TN 37831-2456

FTS $626-1248$

615-576-1248

Houghtnn. R. A.

Woods Hole Research Center

P.O. Rox 296

Woods Hole, MA 02543

617-540-9900

Hudson, James G.

Desert Research Institute

Atmospheric Sciences Center, P.O. Box 60222

Reno, NV 60220

702-677-3119

Hulstrom, Roland $\mathrm{L}$.

Solar Energy Research Institute

1617 Cole Blvd.

Golden, CO 80401

FTS 327-1220

Illangasekare, T. H.

INSTAAR

University of Colorado

Campus Box 450

Boulder, CO 80309

303-492-6388

Johnson, $\mathrm{K}$

Brookhaven National Laboratory

Oceanographic Sciences Division

Upton, NY 11973

FTS $666-5668$

516-282-5668

Jones, P. D.

University of East Anglia

School of Environmental Sciences

Norwich, NR4 7TJ

U.K.
Kanciruk, Paul

Oak Ridge National Laboratory

CDIAC, P.O. Box 2008

Oak Ridge, TN $37831-6050$

FTS 624-0390

615-574-0390

Karl, Thomas R.

National Climatic Data Center/NOAA

Federal Building

Asheville, NC 28801

FTS $672-0450$

Katsouros, Mary Hope

National Academy of Sciences

2101 Constitution Ave., NW

Washington, DC 20418

202-334-2714

Keeling, Charles D.

Scripps Institution of Oceanography

A-020, 2314 Ritter Hall

La Jolla, CA 92093

619.534-4230

Kimball, Bruce

USDA-ARS Water Conservation Lab.

4331 E. Broadway

Phoenix, AZ 85040

602-261-4356

Kirkham, M. B.

Kansas State University

Department of Agronomy

Manhattan, KS 66506

913-532-6101

Kleckner, Edward

Pacific Northwest Laboratory MS K6-84

P.O. Box 999

Richland, WA 99352

FTS 444-8416

Knox, Joseph

National Institute for Global Environmental Change

1477 Drew Avenue

Davis, CA 95616

916-756-6494

Kukla, George

Lamont-Doherty Geological Observatory

Columbia University

Palisades, NY 10964

914-359-2900

Lacis, Andrew A.

NASA Goddard Institute for Space Studies

2880 Broadway

New York, NY 10025

212-678-5595 
Lincoln, David E.

University of South Carolina

Department of Biology

Columbia, SC 29208

803-777-7306

Louis, Jean-Francois

Atmospheric and Environmental Research, Inc. 840 Memorial Dr.

Cambridge, MA 02139

617-547-6207

Luxmoore, Robert J.

Environmental Sciences Division

Oak Ridge National Laboratory

P.O. Box 2008

Oak Ridge, TN 37831-6038

FTS 624-7357

615-574-7357

MacCracken, Michael C.

Lawrence Livermore National Laboratory

P.O. Box 80 \&

Livermore, CA 94550

FTS 532-1826

Mauney, Jack

USDA, ARS

Western Cotton Research Laboratory

4135 East Broadway

Phoenix, AZ 85040

602-261-3524

Mcintosh, Robert E.

University of Massachusetts

Dept. of Electrical \& Computer Engineering

Amherst, MA 01003

413-545-4858

Meehl, Gerald A.

National Center for Atmospheric Research

P.O. Box 3000

Boulder, CO 80307

FTS 320-1331

303-497-1331

Meier, Mark F.

INSTAAR, University of Colorado

Campus Box 450

Boulder, CO 80309

303-492-7909

Michael, P. A.

Brookhaven National I aboratory

Dept. of Applied Science

Upton, NY 11973

FTS 666-2264

516-282-2264
Michalsky, Joseph

State University of New York, Albany

Atmospheric Sciences Research Center

Albany, NY 12222

$518-442-3809$

Moore, Barrier, III

University of New Hampshire

Complex Systenıs Research Center

Durham, NH 03824

603-862-1792

Munk, Walter H.

Scripps Institution of Oceanography

A-020

La Jolla, CA 92093

619-534-2877

Norby, Richard J.

Environmental Sciences Division

Oak Ridge National Laboratory

P.O. Box 2008

Oak Ridge, TN 37831

FTS 624-7301

615-574-7301

North, Gerald R.

Texas A \& M University

Department of Meteorology

College Station, TX 77843

409-845-8083

Novakov, Tihomir

Lawrence Berkelcy Laboratory

1 Cyclotron Road

Berkeley, CA 94720

FTS $451-5319$

Oechel, Walter C.

San Diego State University

Dept. of Biology, College of Science

San Diego, CA 92182

714-265-6767

O'Neill, E. G.

Environmental Sciences Division

Oak Ridge National Latoratory

P.O. Box 2008

Oak Ridge, TN 37831-6038

FTS 624-7850

615-574-7850

Owensby, C.

Kansas State University

Department of Agronomy

Manhattan, KS 66506

913-532-5731 
Patrinos, A.

Atmospheric and Climate Research Division Office of Health and Environmental Research U.S. Department of Energy, ER-76

Washington, DC 20585

301-353-3281

Peierls, Ronald F.

Brookhaven National Laboratory

Dept. of Applied Science

Upton, NY 11973

FIS $666-4104$

Penner, Joyce E.

Lawrence Livermore National Laboratory

P.O. Box 808

Livermore, CA 94550

FIS $532-4140$

Porch, William B.

Los Alamos National Laboratory

P.O. Box 1663

Los Alamos, NM 87545

FIS 843-0971

Randall, David A.

Colorado State University

Department of Atmospheric Sciences

Fort Collins, CO 80523

303-491-8474

Rasmussen, R. A.

Oregon Graduate Center

19600 N.W. Walker Rd.

Beaverton, OR 97006

$503-645-1121$

Revercomb, Henry $\mathrm{E}$.

University of Wisconsin

Space Science and Engincering Center

Madison, WI 53706

608-263-6758

Reynolds, James F.

San Diego State University

Dept. of Mathematical Sciences and Biology

San Diego, CA 92182

$619.265-6613$

Richards, John F.

Duke University

Department of History

Durham, NC 27706

919-684-3626

Richmond, M. C.

Marine Sciences I aboratory

439 West Sequim Bay Road

Sequim, WA 98232

$206-681-3618$
Robock, Alan

University of Maryland

Dept. of Niteorology

College stirk, MD 20742

301-454-5089

Sarmiento, Jorge L.

Princeton University

Geophysical Fluid Dynamics Program

Princeton, NJ 08540

609-452-6585

Sassen, Kenneth

University of Utah

$819 \mathrm{Wm}$. Browning Bldg.

Salt Lake City, UT 84122

801-581-6136

Schlesinger, Michael E.

University of Illinois

Dept. of Atmos. Sci., 105 S. Gregory Ave.

Urbana, IL 61801

217-333-2192

Scott, Michael

Battelle Pacific Northwest Laboratory

P.O. Box 999

Richland, WA 99352

509-376-2458

Schwartz, Stephen E.

Brookhaven National Laboratory

Applied Sciences Division

Upton, NY 11973

FIS 666-3100

Seigel, Donald E.

Syracuse University

204 Heroy Geology Laboratory

Syracuse, NY 13244-1070

315-443-3707/2672

Siegenthaler, U.

University of Bern, Physikalisches Institut

Sidlerstrasse 5, CH3012

Bern, Switzerland

$011-41-31-658611$

Skole, D. L.

University of New Hampshire

Complex Systems Research Center

Durham, NH 03824

603-862-1792

Skyllingstad, E. D.

Battelle Pacific Northwest Laboratory

P.O. Box 909

Richland, WA 99352

509-376-6098 
Somerville, Richard C. J.

Scripps Institution of Oceanography

Climate Research group

La Jolla, CA 92093

619-534-4644

Spindel, R. C.

Applied Physics Laboratory

University of Washington, $\mathrm{HN}-10$

Seattle, WA 98195

206-543-1310

Stamnes, Knut

University of Alaska, Fairbanks

Geophysical Institute

Fairbanks, AK 99775-0800

907-474-7368

Steinberg, Meyer

Brookhaven National Laboratory

Building 526

Upton, NY 11973

FTS 666-3036

516-282-3036

Stephens, Graeme L.

Colorado State Untversity

Dept. of Atmospheric Sciences

Fort Collins, CO 80523

303-491-8541

Stokes, Gerald M.

Pacific Northwest Laboratory

P.O. Box 999

Richland, WA 99352

509-375-3186

Strain, Boyd R.

Duke University

Department of Botany

Durham, NC 27706

919-684-6523

Takahashi, Taro

Lamont-Doherty Geological Observatory

Columbia University

Palisades, NY 10964

914-359-2900, 537

Takle, Eugene

Ames Laboratory

Iowa State University

Ames, IA 50011

515-294-9871
Toon, Owen Brian

NASA Ames Research Center

Earth System Science Division, MS 24,5-3

Moffett Field, CA 94035-1000

FTS 464-5971

415-604-5971

Trease, Harold

Los Alamos National Laboratory

P.O. Box 1663

Los Alamos, NM 87545

FTS 843-5000

Veigel, J. M.

Oak Ridge Associated Universities

P.O. Box 117

Oak Ridge, TN 37831-0117

615-576-3300

Vitko, John, Jr.

8300-A

7011 East Ave.

Sandia National Laboratories

P.O. Box 969

Livermore, CA 94550-0969

FTS 234-2820

415-294-2820

Wallace, Douglas W. R.

Brookhaven National Laboratory

Oceanographic Sciences Division

Upton, NY 11973

FTS 666-2945

516-282-2945

Wang, Wei-Chyung

State University of New York, Albany

Atmospheric Sciences Research Center

Albany, NY 12222

518-442-3357

Ward, Robert C.

Oak Ridge National Laboratory

P.O. Box 2008, Engineering Physics and Math Div.

Oak Ridge, TN 37831

FTS 624-3125

615-574-3125

Washington, Warren $\mathrm{M}$.

National Center for Atmospheric Research

P.O. Box 3000

Boulder, CO 80307

303-497-1321

Webb, Thompson, III

Brown University

Dept. of Geological Sciences

Providence, RI 02912

401-863-3334 
Weiss, R. F.

Scripps Institution of Oceanography A-020

La Jolla, CA 92093

619-534-2598

Weller, Gunter

Geophysical Institute

University of Alaska

Fairbanks, AK 99775-0800

907-474-7371

Wesely, Marvin L. Argonne Nationa! I aboratory 9700 S. Cass Avenue

Argonne, IL 60439

FTS $972-5827$

Westphal, D.

NASA Ames Research Center

Earth System Science Division, MS 245-3

Moffett Field, CA 94035-1000

FTS 464-3522

415-604-3522

Wigley, T. M. L.

University of East Anglia

School of Environmental Sciences

Norwich, NR4 TTJ

U.K.

44-603-56161

Williams, Allen L.

Illir uls State Water Survey

2204 Griffith Dr.

Champaign, IL 61820

217-244-0373
Wiscombe, Warren J.

NASA Goddard Space Flight Center

Code 613

Greenbelt, MD 20771

301-286-8499

Wohlpart, A.

Oak Ridge Associated Universities

P.O. Box 117

Oak Ridge, TN 37831-0117

FTS 626-3421

615-576-3421

Woodward, Wayne A.

Southern Methodist University

Dept. of Statistical Sciences

Dallas, TX 75275

214-692-2457

Wuebbles, Donald J.

Lawrence Livermore National Laboratory

P.O. Box 808

Livermore, CA 94550

FTS 532-1845

Zika, Rod G.

University of Miami, RSMAS, MAC

4600 Richenbacker Causeway

Miami, FL 33149-1098

305-361-4715 


\section{SUBJECT INDEX}

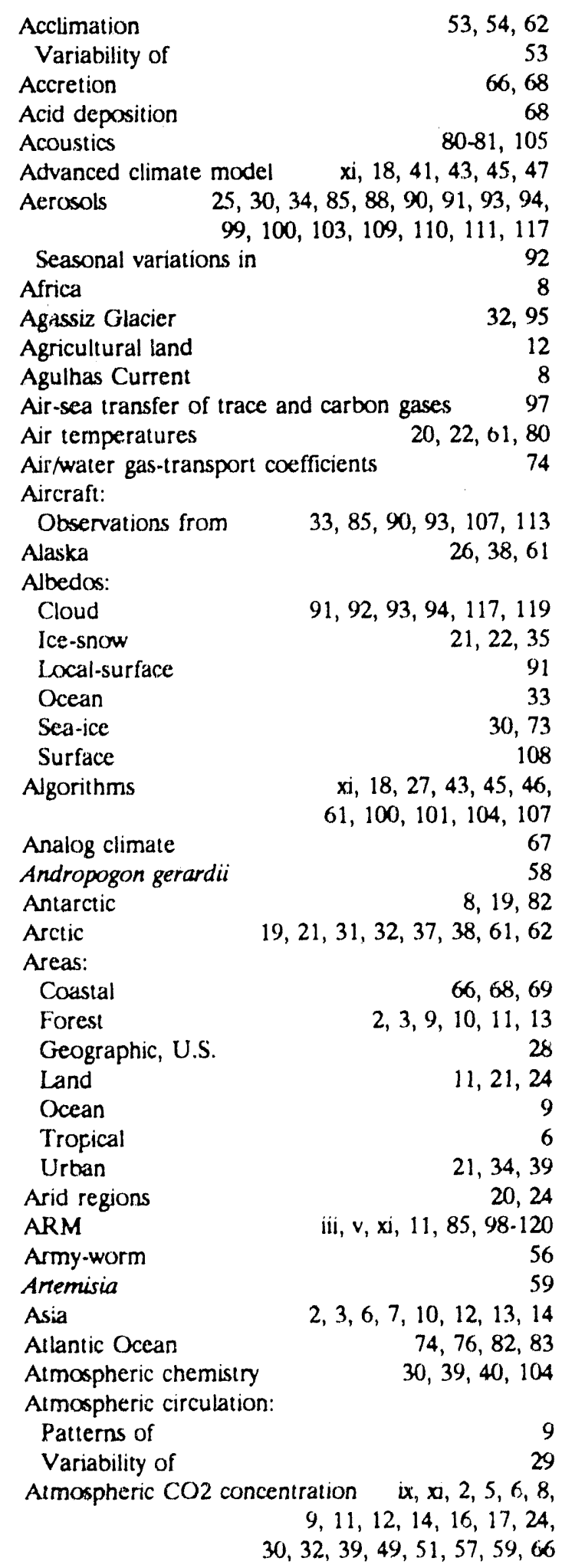

$\begin{array}{lr}\begin{array}{lr}\text { Atmospheric CO2 concentration (Cont.) } \\ \text { Projections of }\end{array} & 1,81 \\ \text { Atmospheric-pressure values } & 86 \\ \text { Atmospheric processes } & 98 \\ \text { Atmospheric-Radiation Measurement } & \mathrm{iii}, \mathrm{v}, \mathrm{xi}, \\ & 11,85,98-120 \\ \text { Atmospheric thermal storage } & 24 \\ \text { Australia } & 22,39 \\ \text { Balloon launches } & 27 \\ \text { Bangladesh } & 14 \\ \text { Barrier coasts } & 69 \\ \text { Big bluestem } & 58 \\ \text { Biogas } & 33,34 \\ \text { Biological fluxes } & 78\end{array}$

Biomass

$2,3,4,5,9,10,11,12,13,14$, $54,57,58,60,61,62,64,83$

Biomass partitioning

Bolivia

Boltworm

Boreal peat basins

Brazil

Bromus tectorum

Bubble plumes

Buoyancy

Burma

C3 plants

C4 plants

Canada

Canopy

Carbohydrates

Carbon, sequestering of

Carbon-12

Carbon-13

Carbon-14

Carbon budget

Carbon-chemistry properties

Carbon cycle

Globeil

Carbon Dioxide Information

Analysis Center

Carbon dynamics

Carbon exchange

Carbon fixation

Carbon fluxes

Carbon release, historical

Carbon reservoirs

Carbon storage

Carbon uptake

CARDS

CCN

CDIAC 


\begin{tabular}{|c|c|}
\hline \multicolumn{2}{|c|}{$4,5,19,20,77,88$} \\
\hline \multirow{2}{*}{\multicolumn{2}{|c|}{$v, x i, 18,31,40-47,104,105$}} \\
\hline Chesapeake Bay & \\
\hline $5,22,24,25$ & $5,22,24,25,26,27,33,34,39$ \\
\hline Chlorocarbons & \\
\hline \multicolumn{2}{|l|}{ Chlorofluorocarbons } \\
\hline Chlorophyll & $53,63,78,83$ \\
\hline \multicolumn{2}{|l|}{ Christmas Island } \\
\hline \multicolumn{2}{|l|}{ Circulation: } \\
\hline Atmospheric & $9,12,29,46$ \\
\hline Glotal atmosphere/ocean & 99 \\
\hline Langmuir & 81 \\
\hline Low-level atmospheric & 41 \\
\hline Ocean & $8,15,38,73$ \\
\hline Thermohaline & $16,73,89$ \\
\hline Circumpolar waters & 8,82 \\
\hline Citrus aurantium & 56 \\
\hline CLARET experiment & $99,111,116$ \\
\hline Clearing of forests & 6,7 \\
\hline \multicolumn{2}{|l|}{ Climate: } \\
\hline $\begin{array}{l}\text { Natural variability of } \\
\text { Regional variability of } \\
\text { Sensitivity of }\end{array}$ & $\begin{array}{r}34,38,39,91-92 \\
25,37,105 \\
v, 9,87,89,95\end{array}$ \\
\hline \multicolumn{2}{|c|}{ 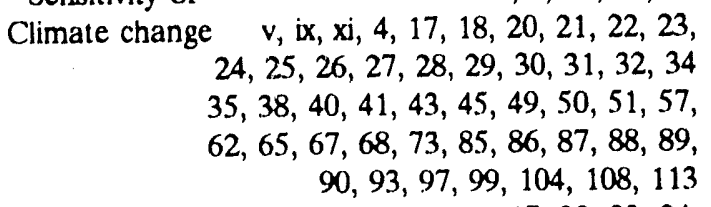 } \\
\hline Carbon dioxide-induced & $\begin{array}{l}17,20,23,24 \\
25,29,35,97\end{array}$ \\
\hline Detection of & $\begin{array}{l}25,26,29,35,38 \\
39,85,86,87,91\end{array}$ \\
\hline Patterns of & $21,31,39,87$ \\
\hline Projections of & $21,29,30,81$ \\
\hline Uncertainty in & $31,67,87$ \\
\hline $\begin{array}{r}\text { Regional } \quad v, i x, x i, 8 \\
23,24 \\
3\end{array}$ & $\begin{array}{l}17,18,20,21,22 \\
25,26,27,28,29 \\
36,41,43,44,85\end{array}$ \\
\hline Climate data, historical & $\begin{array}{l}\text { ix } 22,24,27 \\
30,67,91,94\end{array}$ \\
\hline Climate prediction, regional & 113 \\
\hline Climate sensitivity & $v, i x, 87,89,95$ \\
\hline Climatological Aerological & \\
\hline Reference Data Set & 27 \\
\hline Climatological Prediction by & \\
\hline Model Statistics & 27 \\
\hline Cloud-condensation nuclei & $90,92,94,96$ \\
\hline Cloud-droplet spectra & 96 \\
\hline Cloud feedback & $17,21,73,89$ \\
\hline Cloud-fieid mapping & 109 \\
\hline Cloud mapping & 118 \\
\hline Cloud microphysical properties & 93 \\
\hline Cloud optical depth & 91,113 \\
\hline Cloud overlapping & 119 \\
\hline Cloud-radiation effects & 91 \\
\hline Cloud type & 91 \\
\hline
\end{tabular}

Cloudiness

$17,26,29,32,33$,

Clouds

Cirrus

Stratocumulus

Stratus

$89,91,102,104$

v, ix, xi, 17, 21, 22, 23, 24, 26, $27,30,31,32,33,35,36,73$, $85,86,87,89,90,91,92,93$, $94,95,96,98,99,100,101$, $102,103,104,106,107,108$, $109,110,111,112,113,114$, $115,117,118,119,120$ $86,88,91,101,108,117,120$ 93, 120 $90,94,117$

Coal

Coastal Hazards Data Base

60,68

Coastal resources

Coastal-Vulnerability Index

CODATA

Committee on Earth Sciences

Committee on Global Change

Communication

Competition among plants

Computer Hardware, Advanced

Mathematics, and Model Physics

$v, x j, 18,31$, $40-47,104,105$

Convection $75,76,77,87,101,102$

Corn

Cotton $53,55,56,57,64,101$

Coulometers

Coulometric analysis

CPMS

Cray computers

Critical technologies

Crop responses to carbon dioxide

Crystals, ice

Currents, oceanic

$75,78,82$

Cyciones

Dams

$4,5,19,20,77,88$

Data-assimilation systems

Data-management systems

Data products

Decomposition

Deep water

Defoliation

Deforestation

Degradation, biomass

Desertification

Diagnosis of climate models

DIC

Dissolved inorganic carbon

Dissolved matter, mixing of

Dissolved organic matter

Diurnal-cycle changes:

Carbon dioxide-induced

Drake Passage

Drought
71,72 52,63
$18,23,42,43,44,45,46,50$ 114

$50,51,55$

$103,111,117$ $8,76,81$ 41 21 102 $72,86,106,118$

$54,60,61$ $8,16,73,75,76,78,83$

$9,10,12,13$ $2,3,9,10,11,12,13,14$

$9,21,22,23,30$ $35,36,107,108,115$ $77,78,80,83$ $77,78,80,83$ $15,73,78$ 35 22,60

82 


\begin{tabular}{|c|c|}
\hline Drying, carbon dioxide-induced & Fuxes (Cont.) \\
\hline Dust & Waier \\
\hline Dynamical feedback processes & Forest inventories \\
\hline Economics, regional & Arrest succession \\
\hline Ecosystems: & $2,3,6,7,9,10,11,12,13$ \\
\hline Grassland & $14,49,59,60,61,65,67$ \\
\hline Tundra & Clearing of \\
\hline Unmanaged & FORET \\
\hline Eddies, mesoscale & $1,3,5,6,7,8,10,83$ \\
\hline Eddy diffusivity & Savings of \\
\hline El Nino & France \\
\hline Eleusine indico & Free-air carbon dioxide \\
\hline Emissions: & experiment (FACE) \\
\hline $\begin{array}{r}1,3,4,5,6,7,8,16,39,40 \\
72,73,86,92,94,95,111\end{array}$ & $\begin{array}{l}\text { Gas-exchange: } \\
\text { Leaf }\end{array}$ \\
\hline Projections of & Oceanic \\
\hline Methane & Pest \\
\hline Uncertainty in & Geographic information systems \\
\hline End-use patterns, energy & $13,66,68,72$ \\
\hline Energy efficiency & GEOSECS \\
\hline ENSO & Germany \\
\hline Equilibrator/gas-chromatograph system & Glaciers \\
\hline Erosion & ix, $6,7,12,15,16,83$ \\
\hline Estuaries & Global Ocean Fiux Study 8,73 \\
\hline $\begin{array}{r}2,7,9,10,11,12,13 \\
15,47,61,74,77,79\end{array}$ & $\begin{array}{l}\text { Global warming } \quad v, 25,26,27,40,80,86,89,91 \\
\text { GOFS } \\
8,73\end{array}$ \\
\hline Explansion factors, forest & Gossypium hirsutum \\
\hline $53,55,56,57$ & Grasshoppers \\
\hline Farquhar equation & Grasslands \\
\hline FASCOD3 & $v, i x, x i, 15,17,18,35$ \\
\hline FASCODE & $40,44,73,85,86,87$ \\
\hline Feedback inhibition & Sensitivity to \\
\hline Feedbacks: & Grid-point numeric formulations \\
\hline$v, x i, 26,62,73,87$ & Ground-truth measurements $\quad 85$ \\
\hline $\begin{array}{r}17,21,23,26,31,32,35 \\
73,85,89,90,95,99,107\end{array}$ & $\begin{array}{rr}\text { Growth, plant } \quad 7,49,50,51,52,53,54,55,56, \\
& 57,58,59,60,61,62,63,64\end{array}$ \\
\hline 25,108 & Guatemala \\
\hline Heat-transport & Guyana \\
\hline Ocean & Harvest index \\
\hline Sea-ice-albedo & Health, human \\
\hline Snow-albedo & Heard Island \\
\hline Water-vapor & Heat fluxes \\
\hline Fertilization & Heat storage \\
\hline Finite-difference method & Heat transport \\
\hline Finite-element methods & Herbivores \\
\hline $88,111,120$ & HILDA \\
\hline 32 & Historical climate data \\
\hline Fixation & $30,67,91,94$ \\
\hline Flux estimates, uncertainty in & $27,29,30,57,61,91$ \\
\hline Fluxes: & Hydrological variability \\
\hline Biological & Hydrophones \\
\hline $1,7,10,47,61,74,83,95,97$ & $20,21,23,30,32,33,35$ \\
\hline $24,32,85$ & $36,37,45,73,100,109$ \\
\hline Moisture & 16,34 \\
\hline Nutrient & $103,111,117$ \\
\hline $32,33,85,104,110$ & ICRCCM \\
\hline
\end{tabular}


ICSU

Indexes:

Coastal Vulnerability

Harvest

Lamb Dust Veil

Normalized Difference Vegetation

India

Indian Ocean

Inciustrial productivity

Irifiltration of water

issects

Instrument data

Instruments, uncertainty in

Intergovernmental Panel on

Climate Change

International Council of

Scientific Unions

International Geosphere-

Biosphere Program

Iowa

IPCC

Irrigation

ISCCP data set

Isotopic analysis

Japan

JGOFS

Joint Global Ocean Flux Study

Kansas

Ketvin effect

Labrador Sea

Lagoons

Lake-level data

Lamb Dust Veil Index

Land-cover detection

Land sinks and sources

Land use

Land-use change

Land-use data, historical

Laser-based monitoring

Latent climatic effects

Latin America

Lidars

Life zones

Linda

Liquid water

Liriodendrum

Litter

Livestock

Loblolly pine

Long-memory processes

Longwave radiation

Manometric methods

Mauna Loa

Mawson Station

Melanoplus

Melting
$19,20,71$

$19,20,7$

69
5
egetation $\quad 2,10$
14

$38,78,81$

65

31-32

$56,57,59$

20

106

$4,31,50$

$19,20,71$

19

66,67

$4,5,37$

57,68

87,108

95

$4,5,22$

$9,77,78,79$

$9,77,78,79$

$57,66,67$

75

76

69

38

34

13

10

$2,7,9,10,11,13,14,65$

$2,6,7,11,12,14$

$7,13,14$

97

90

12

$88,102,103,105,111$

3
41
36,103
60
60
14,68
63
97
$26,33,91,103,110$
75,82
12
81
59

$27,32,37$
Mer de Glace Agassiz

32,95

Mesoscale eddies

36,89

Meteorology

Mesoscale

Methane

Mexico

MIMD computers

Ming Dynasty

Missouri

104,105

$4,5,33,34,61,84,94,95$

Mixing, oceanic

Mixing and convection processes

Models

$v, 1,2,14,20,44,49,59$, $60,61,62,66,72,73,74,77$, $79,105,109,111,114,116$

$1-\mathrm{D}$

2-D

$9,39,40,42,95,108$,

$112,113,117,119,120$

$26,30,32,39,40,42$,

$50,76,119,120$

3-D $8,9,10,12,15,16,30,42,45,46$, $56,76,81,93,102,110,118,120$

98,117

4-D

$x i, 18,41,43,45,47$

AIFA

Atmospheric-chemistry-transport

108

Atmospheric-circulation

Atmospheric-transport

39

Biophysical

Box

Box-diffusion

CCM 1

CCM2

Community climate

13,54

$6,16,76,120$

$24,25,26,37,119$

$43,46,47$

$24,25,26,37$,

$43,46,47,119$

COTCO2

$53,55,56,57$

Coupled

Crop

Deep-convection

Diagnosis of

Diagnostic

Erdmonds-Reilly

European Centre for Medium

Range Weather Forecasts

$x i, 9,22,32,33,35,36,37$,

$43,45,47,50,63,85,89$

$50,51,52-53,67$

$9,21,22,23,30,35$, $36,107,108,115$

112-113

4,5

General-circulation (GCMs)

$31,22,23,24,25,26,27,29$
$30,31,32,33,34,35,36,37$

$38,39,41,42,43,45,76,81$,

$85,90,92,94,96,98,100,101$,

$102,103,104,107,108,109$,

$110,112,113,114,117,119$

GFDI

15,22

GISS

$10,107,108$

GLOBC8

GLYCIM 
Models (Cont.)

Intercomparisons of

ix, 21, 22, 23,

$31,32,33,37,78,115$

Mesoscale

$24,41,98,101,102,103,117$

Mixed-layer

NCAR $24,25,26,29,36,37,41,43,46,92$

Ocean-circulation $\quad 8,15-16,42,45,76,81,83$

Plant-community

19,63

Plant-competition

52

Plant-growth

Plant-productivity

56

67

PRECO

64

Princeton

9, 15

Q-flux

Radiative-transfer

Radiative-transport

Sea-ice

Semtner-Chervin

Sensitivity of

\section{SERECO}

SOILSIM

Statospheric-photochemical

$25,35,40,98,99,100$, $101,104,105,113,120$ $40,100,103$

37

36

$2,9,10,11,13,14,23,30$, $35,36,39,42,50,103,108$

Transfer-function

Uncertainty in

Validation of

$9,12,22,23,24,29,32,3$

$38,39,47,49,50,51,53$

$57,62,73,100,101,103,107$

Moisture

$17,23,24,26,52,57$, $58,61,62,73,102,117$

Moistuie fluxes

Monsoons

Variability of

24,38

Montreal Protocol

Multifractal analysis

National Institute for

Global Environmental Change

NDVI

Nebraska

Net primary productivity

New Zealand

Nicaragua

NIGEC

Night respiration

Normalized Difference Vegetation Index

Numerical Data Advisory Board

Nutrient fluxes

Nutrients

$15,51,52,53,55,57,58$

$\mathrm{xi}, \mathrm{xii}, 28$

2,10

66,67

$2,55,78$

81

xi, xii, 28

64

2,10

71

79

$59,60,63,77,78,79,80,82$

Observation, methods of $\quad 85,98,102,119$

Observations, satellite

Oceanic carbon uptake, regional 8

Oceans

$73-84$

Carbon dioxide in

Carbon dynamics of
Oceans (Conit.)

Currents in

Mesoscale temperature variations in

Mixing of the

$8,76,81$

Role of in carbon cycle

Thermal storage by the

Ventilation processes of

Oryza sativa

Ozone

Pacific Ocean

Paieoclimatic data

$x i, 8$

$15,16,83$

xi, 17, 39, 73, 90

82

40,87

Panama

$75,78,79,80,82,83$

$37-38$

Parallel computing xi, 18, 41, 42, 43, 44, 45, 46, 47

Parameterizations

$25,30,32,33,35,36,74$,

$76,85,93,95,98,99,100,101$,

$102,103,104,105,107,108$,

$109,112,113,115,117,119$

Partial pressure, carbon dioxide $75,80,82,83$

$\mathrm{pCO}_{2}$ $75,80,82,83$

Peatlands

94,95

Peninsular Malaysia

Peru

Phosphorus uptake

Photochemical production of gases $\quad 97-98$

Photoperiods

Photosynthesis

ix, $7,49,51,52,53,54$

Feedback inhibition of $55,56,57,58,60,62,64$

Photothermal deflection spectroscopy

PICL $\quad 41,46$

Plant communities $\quad 52,54-55,63,94$

Plants

ix, $6,7,49,50,51,52,53$,

$54,55,56,57,58,59,60$,

$62,63,64,67$

Changes in, carbon dioxide-induced 59

Competition among $\quad 52,63$

PNET

Polar Research Board

51

Policy issues v, xii, 20, 28, 71, 72, 79

Pollen data 38

Population dynamics $\quad 56$

Populations:

Biological 9

Human 14, 65

Insect $\quad 56,59$

Microbial 60

Plant 62-63.3

Postdoctoral research programs $\quad 69$

Potentiometric titration

Precipitation

$17,20,21,22,24,26,27$,

PRISM

$29,32,36,38,41,90,91$

Productivity of ecusystems

Productivity of plants

$2,7,49,51,52$

Proposals, review of

$55,65,67,78$

$40,67,96$ 


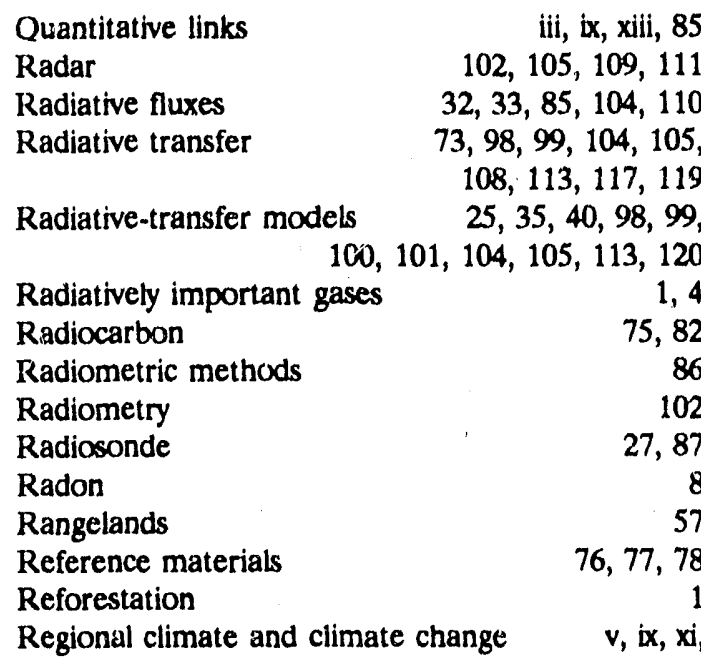

$8,17,18,20,21,22$,

$23,24,25,26,27,28$, $29,31,36,41,43,44,85$

Releases:

Carbon

Carbon dicoxide

Chlorocarbon

Methane

Nitrogen

Reliable simulations

Remote sensing

Respiration

RHIZOS

Rice

Rising sea level

$6,7,11,12,14,61$

$1,6,10,14,55,94$

$4,5,33,61,94$

$13,74,85,99$

$102,105,109,111,112$

$7,53,55,62,64$

$33,34,51,52$

65,66

Roots $54,55,60$

Rotating shadowband spectral radiometers 109

RuBisCo $53,54,63$

RuBP

Runoff

31,32

SAGE

Salinity

Salt marshes

Satellite observations

Sea-ice

Distribution of

Parameterization of

Sea-ice-albedo feedback

Sea level

Rising

Seawater

Sediments

Sensitivity analysis

Sequestering of carbon

Sheep

Shifting cultivation

\begin{tabular}{|c|c|}
\hline Quantitative links & iii, ix, xili, 85 \\
\hline Radar & $102,105,109,111$ \\
\hline Radiative fluxes & $32,33,85,104,110$ \\
\hline Radiative transfer & $\begin{array}{r}73,98,99,104,105 \\
108,113,117,119\end{array}$ \\
\hline Radiative-transfer model & $\begin{array}{r}25,35,40,98,99 \\
0,101,104,105,113,120\end{array}$ \\
\hline Radiatively important gas & es $\quad 1,4$ \\
\hline Radiocarbon & 75,82 \\
\hline Radiometric methods & 86 \\
\hline Radiomet & 102 \\
\hline Radioso & 27,87 \\
\hline Radon & \\
\hline Rangelands & 57 \\
\hline materials & $76,77,78$ \\
\hline Refore & \\
\hline Regional climate and clin & $\begin{array}{r}\text { ate change } v \text {, ix, xi, } \\
8,17,18,20,21,22, \\
23,24,25,26,27,28, \\
29,31,36,41,43,44,85\end{array}$ \\
\hline Releases: & \\
\hline Carb & $6,7,11,12,14,61$ \\
\hline dicoxide & $1,6,10,14,55,94$ \\
\hline Chlor & 34 \\
\hline Meth & $4,5,33,61,94$ \\
\hline Nitro & 60 \\
\hline mulations & 85 \\
\hline Remote sensing & $\begin{array}{r}13,74,85,99 \\
102,105,109,111,112\end{array}$ \\
\hline Respira & $7,53,55,62,64$ \\
\hline RHIZC & 50 \\
\hline Ric & $33,34,51,52$ \\
\hline Rising $s$ & 65,66 \\
\hline Roots & $54,55,60$ \\
\hline Rotating shadowband sp & ctral radiometers $\quad 109$ \\
\hline RuBisC & $53,54,63$ \\
\hline & 53 \\
\hline & 31,32 \\
\hline SAGE & 87 \\
\hline Sali & $57,76,77,78,80,82,89$ \\
\hline Salt & 54 \\
\hline Satellite observations & $\begin{array}{r}x i, 9,13,23,25,33,74 \\
77,85,93,94,99,102 \\
107,108,109,119\end{array}$ \\
\hline Sea-ice & 36 \\
\hline Distribu & 23 \\
\hline Parar & 33 \\
\hline albedo feedback & 30,73 \\
\hline Sea level & 31,68 \\
\hline & 65,66 \\
\hline Seawater & $75,76,77,78,80,81,82$ \\
\hline Sed & $38,68,69$ \\
\hline & 50 \\
\hline Sequestering of carbon & ix $, 16,62$ \\
\hline & $57,58,59$ \\
\hline Shifting cult & \\
\hline
\end{tabular}

\section{2} 2 (1) 政

Shortwave radiation $\quad 91,103,106,110$

SIMD computers 46

Simulations, reliable $\quad 85$

Sinks, land 10

Site selection 111, 114, 115, 116

Small-scale atmospheric processes $\quad 98$

SMMR data $\quad 87$

Snow $21,22,26,27,31,32$

Snowmelt 27, 37

Soil solutes $\quad 50,94-95$

Soils $\quad 2,6,9,10,11,13,14,17,33,34$,

$35,50,53,57,58,59,60,61,94$

Solar flux $\quad 32,35$

Solar forcing 22, 39

Solar radiation $24,27,34,38,73,85,91,99,109$

Solar variability 21,90

Solutes, dissolved in soil $\quad 50,94-95$

Sounding systems 102

Source-sink mechanisms 1

Sources, land 10

Soybeans $\quad 50,67$

Spectral cloud properties $\quad 101$

Spectral data bases $\quad 100$

Spectral effects of molecules $\quad 100$

Spectral formulations $\quad 24$

Spectral methods $\quad 42,46$

Spectral radiation $\quad 88,110$

Spectral signatures $\quad 103$

SPECTRE 88

SPS 53,64

Statistical analysis of

variability

Stochastic formulaticns $\quad 113$

Stomata $\quad 54,57,58,62$

Stratosphere $\quad 39,86,87$

Stress:

Nitrogen 63

Nutrient $\quad 51,52,53$

Temperature $\quad 51,63$

Water $51,52,53,56,62,63$

Wind 36

Sucrose phosphate synthase activity 64

Sunshine 22,27

Surface-layer dynamics $\quad 81$

Surinam

Temperature data $20,21,27,29,32,39$

Temperatures:

Air

$20,22,61,80$

Atmospheric

Global

ix, 21, 27, 87

Ocean

Sea-surface

$17,26,80,89,97$

78,80

Soil

$21,22,23,29,30,31,36$,

$37,41,73,74,93$

Stratospheric

Surface

26,87

$26,30,34,36,73,90,92,95$ 
Temperatures (Cont.)

Variability of

29

Testbed data

104,108

Thermal expansion

Thermal storage by the oceans

Thermobaric effects

90

Thermohaline circulation

Sensitivity of

Thunderstorms

Tidal regimes

Toolik Lake, Alaska

Trace gases

$25,26,30,34,39,40,72,85,86$

$87,88,97,98,102,103,110$

$8,15,16,35,78$

Tracers

Transition spectral data base

100

Translocation

Transpiration

Trees

Tree-ring chronologies

Trends 90

Tritium

Tropics

Troposphere

Tulip poplar

Tundra

Turbulent fluxes

Turnover

U.K.

U.N.

Uncertainty analysis

United Kingdom

United Nations

Unmanaged ecosystems

ix $7,49,53,57,58,60,62$

2, 56,57

59,60

72

$8,35,36$

$7,9,13,33,37$

$26,33,39,73,86,87$

60

81

$6,7,8$

$20,22,37$

50

$20,22,37$
Upwelling 33

Urban heat island 27

Urban warming

$20,25,39$

U.S.S.R.

$22,39,40,87$

Validation, model $\quad 9,12,22,23,24,29,32,37$, $38,39,47,49,50,51,53,55,56$ $57,62,73,100,101,103,107$

Variability:

Statistical analysis of $\quad 31,35,92,97,113$

Vegetation iii, v, ix, xiii, 2, 7, 10, 13, 14 $47,49,56,58,61,65,94,95$

Venezuela

Ventilation of oceans

Video imager, all-sky

Volcanic activity

$30,34,38$

Warming, carbon dioxide-induced $\quad 33,35,89$

Water, infiltration of 31-32

61,62

3,6

3,6

63
Water fluxes

Water use

Water-use efficiency

Water vapor

Water-vapor continuum

Waves

Weather records

Wetlands

Wheat

White oak

Whitecaps

Wind

WOCE

World Ocean Circulation Experiment

$73,75,76,77,79,80,81,82,83,89$

$27,85,87,100$

$25,26,107$

74,81

$14,34,54$

51,67

60

74,75

$16,26,27,36,55,102,105$

Yellow poplar

60
$51,52,53,57,58,60$ 


\section{PRINCIPAL INVESTIGATOR INDEX}

\begin{tabular}{|c|c|}
\hline Abbott, Sherborne & 19 \\
\hline Ackerman, Thomas P. & 98 \\
\hline Acock, Basil & 50 \\
\hline Allen, L. H. & 51 \\
\hline Anderson, Patricia A. & 19 \\
\hline Ascher, W. E. & 74 \\
\hline Bader, David C. & 40 \\
\hline Baer, F. & 103 \\
\hline Barr, Sumner & 99,115 \\
\hline Bazzaz, F. A. & 52 \\
\hline Birdsall, T. & 80 \\
\hline Biswas, P. K. & 52 \\
\hline Bradley, Raymond S. & 20 \\
\hline Brewer, Peter G. & 75 \\
\hline Brown, Sandra & 2 \\
\hline Carter, G. C. & 71 \\
\hline Cess, Robert D. & 21,99 \\
\hline Chen, Tsing-Chang & 41 \\
\hline Cheng, H. C. & 3 \\
\hline Cline, Raymond E., Jr. & 41 \\
\hline Clough, S. & 100 \\
\hline Cotton, William B. & 101 \\
\hline Cox, Stephen K. & 86 \\
\hline Cure, Jennifer D. & 53 \\
\hline Cushman, Robert & $66,72,86$ \\
\hline Dabberdt, Walter F. & 102 \\
\hline Dale, V. H. & 6 \\
\hline Dannevik, William P. & 42 \\
\hline del Genio, Anthorly D. & 87 \\
\hline Denbo, D. W. & 75 \\
\hline Dickerson, Marvin $\mathrm{H}$. & 102,115 \\
\hline Dickson, Andrew G. & 76 \\
\hline Downing, John P. & 77,78 \\
\hline Drake, Bert G. & 54 \\
\hline Eddy, John A. & 22 \\
\hline Edmonds, James A. & $4,66,68$ \\
\hline Ellingson, Robert G. & 88,103 \\
\hline Eloranta, Edwin & 103 \\
\hline Elwood, J. W. & 88 \\
\hline Emanuel, W. R. & 5 \\
\hline Emerson, Steven & 78 \\
\hline Farrell, Michael P. & 5 \\
\hline Fasham, Michael J. R. & 8 \\
\hline Foster, I. 'T. & 43 \\
\hline Fung, 1. Y.-S. & 9 \\
\hline Gabriel, P. & 113 \\
\hline Gates, W. Lawrence & 23,43 \\
\hline Gautier, Catherine & 104 \\
\hline Gornitz, Vivien M. & 68 \\
\hline Gray, $\mathrm{H}$ & 97 \\
\hline Gunst, $R$. & 97 \\
\hline Gustafson, John & 41 \\
\hline Gutowski, William J. & 24,25 \\
\hline
\end{tabular}

Hales, Jeremy M. 104

Hall, Charles A. S.

Hameed, S. 21

Hanson, Howard P. 89

Harrison, L. $\quad 109$

Henderson, Rogert $G$. $\quad 105$

Hendrey, George $\quad 55$

Hoffert, Martin I. 89

Hosker, R. P. 105

Houghton, R. A. 11

Hudson, James G. $\quad 90$

Hulstrom, Roland L. 105

Illangasekare, T. H. 31

Johnson, $\mathrm{K}$. $\quad 83$

Jones, P. D. $\quad 38$

Kanciruk, Paul $\quad 72,86,106$

Karl, Thomas R. 26, 27

Katsouros, Mary Hope $\quad 79$

Keeling, Charles D. $\quad 12,79$

Kimball, B.

King, A. W. 5

Kirkham, M. B. $\quad 57$

Kleckncr, Edward 91

Knox, Joseph 28

Kukla, George 29

Lacis, Andrew A. $\quad 107$

Lincoln, David E. $\quad 59$

Louis, Jean-Francois 108

Luxmoore, R. J. 59

MacCracken, Michael C. $\quad 30,31,44$

Mauney, J. $\quad 56$

Mcintosh, Robert E. $\quad 109$

Meehl, G. $\quad 36$

Meier, M. F. 31

Michael, P. A.

Michalsky, J. $\quad 109$

Moore, B., III 13

Munk, W. $\quad 80$

Norby, R. J.

North, Gerald R. $\quad 91$

Novakov, Tihomir $\quad 92$

O'Neill, E. G. $\quad 59$

Oechel, Walter C. 61

Owensby, C. $\quad 57$

Patrinos, A. $\quad 43$

Peierls, R. F. $\quad 45$

Peng, T.-H. 8

Penner, Joyce E. $\quad 93$

Porch, William M. 93

Post, W. M. 6

Potter, G. $\quad 31$

Randall, David A. 32

Rasmussen, R. A. 33 
Revercomb, H. 110

Reynolds, J. $\quad 62$

Richards, John F. 13

Richmond, R. C. $\quad 81$

Robock, Alan $\quad 34$

Sarmiento, Jorge L. $\quad 15$

Sassen, Kenneth 111

Schlesinger, Michael E. $\quad 34$

Schwartz, Stephen E. 94, 111, 115

Scott, Michael

Siegel, Donald I.

Siegenthaler, U.

Skole, D. L.

Skyllingstad, E. D.

Somerville, Richard C.J.

Spindel, R.

Stamnes, Knut

Steinberg, M.

Stephens, G. L.

Stokes, Gerald M.

Strain, Boyd R.

Takahashi, 'Iaro
Takle, Eugene

Taylor, K. E.

Toon, O. B. $\quad 117$

Trease, Harold 45

Vitko, John, Jr. $\quad 118$

Wallace, D. W. R. $\quad 83$

Wang, Wei-Chyung 118

Ward, Robert C. $\quad 46$

Washington, W. M.

Webb, Thompson, III $\quad 37$

Weiss, R. F. $\quad 83$

Weller, Gunter 38

Wesety, Marvin L. $\quad 116,119$

Westphal, D. 117

Wigley, T. M. L. $\quad 38$

Williams, Allen L. $\quad 96$

Wiscombe, Warren J. $\quad 120$

Wohlpart, A. $\quad 69,96$

Woodward, W. $\quad 97$

Wuebbles, Donald J. $\quad 39,47$

Zika, Rod G. 


\section{INSTITUTION INDEX}

Ames Laboratory

Argonne National Laboratory

Atmospheric and Environmental

Research, Inc.

Atmospheric Turbulence and Diffusion

Division, NOAA

Battelle Marine Sciences

Laboratory

Brookhaven National

Laboratory

Brown University

$3,45,55,83,94,111,115$

Colorado State University

Defense Advanced Research

Projects Agency

Desert Research Institute

$43,115,119$

41
119

$24,25,100,108$

Duke University

Goddard Institute for Space Studies

37

$32,86,101,113$

105

90

$13,53,63$

Harvard University

$9,87,107$

Illinois State Water Survey

Institute of Arctic and Alpine Research

Institute of Oceanographic Sciences

Kansas State Universily

Lamont-Doherty Geological

Observatory

Lawrence Berkeley

Laboratory

$29,68,81,82$

Lawrence Livermore National

Laboratory 23, 30, 39, 42, 43, 44, 47, 93, 102, 115

Los Alamos National I aboratory $45,93,99,115$

NASA Ames Research Center

117

NASA Goddard Spaceflight Center

120

National Academy of Sciences

$19,71,79$

National Center for Atmospheric Research 36, 102

National Climatic Data Center 26, 27

New York University $\quad 89$

Oak Ridge Associated Universities $\quad 69,96$

Oak Ridge National

Laboratory $\quad 5,46,59,66,72,86,88,106$

Oregon Graduate Center

33

Pacific Northwest

Laboratory $\quad 4,40,66,68,81,91,104,113,114$
Pennsylvania State University 98

Plant Stress and Protection Research Unit 51

Princeton University $\quad 15$

San Diego State University $\quad 61,62$

Sandia National Laboratories $\quad 41,118$

Scripps Institution of

Oceanography $\quad 12,76,79,80,83,112$

Smithsonian Instilution $\quad 54$

Solar Energy Research Institute 105

Southern Methodist

University 97

State University of New York, Albany 109, 118

State University of New York,

Stony Brook

State University of New York, Syracuse

21,99

Syracuse University

Systems Research Laboratory

Texas A \& M University 91

Tuskegee Institute 52

University Corporation for

Atmospheric Research 22

University of Alaska $\quad 38,95$

University of Bern 16

University of California, Davis 28

University of California, Santa Barbara $\quad 104$

University of Colorado $\quad 89$

University of East Anglia $\quad 38$

University of Illinois 2,34

University of Maryland $\quad 34,88,103$

University of Massachuselts 20,109

University of Miami 97

University of Michigan 80

University of New Hampshire 13

University of South Carolina 59

University of Utah 111

University of Washington $\quad 78,80$

University of Wisconsin $\quad 103,110$

Water Conservation Iaboratory 56

Western Cotton Research Laboratory $\quad 56$

Woods Hole Oceanographic Institution 75

Woods Hole Research Center 11 

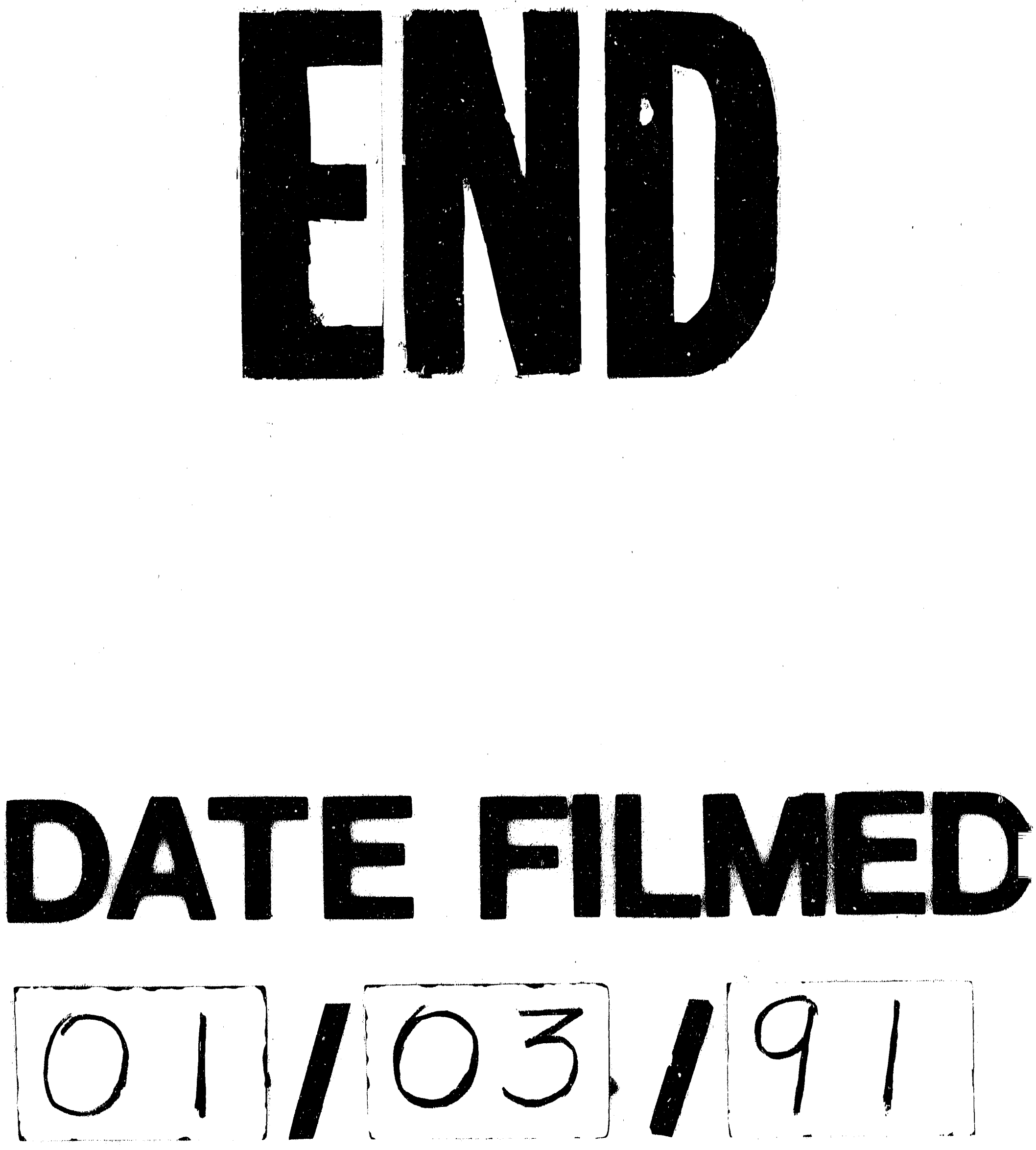
